\title{
Nuclear Data and Cross Section Testing Using ENDF/B-VIII.0
}

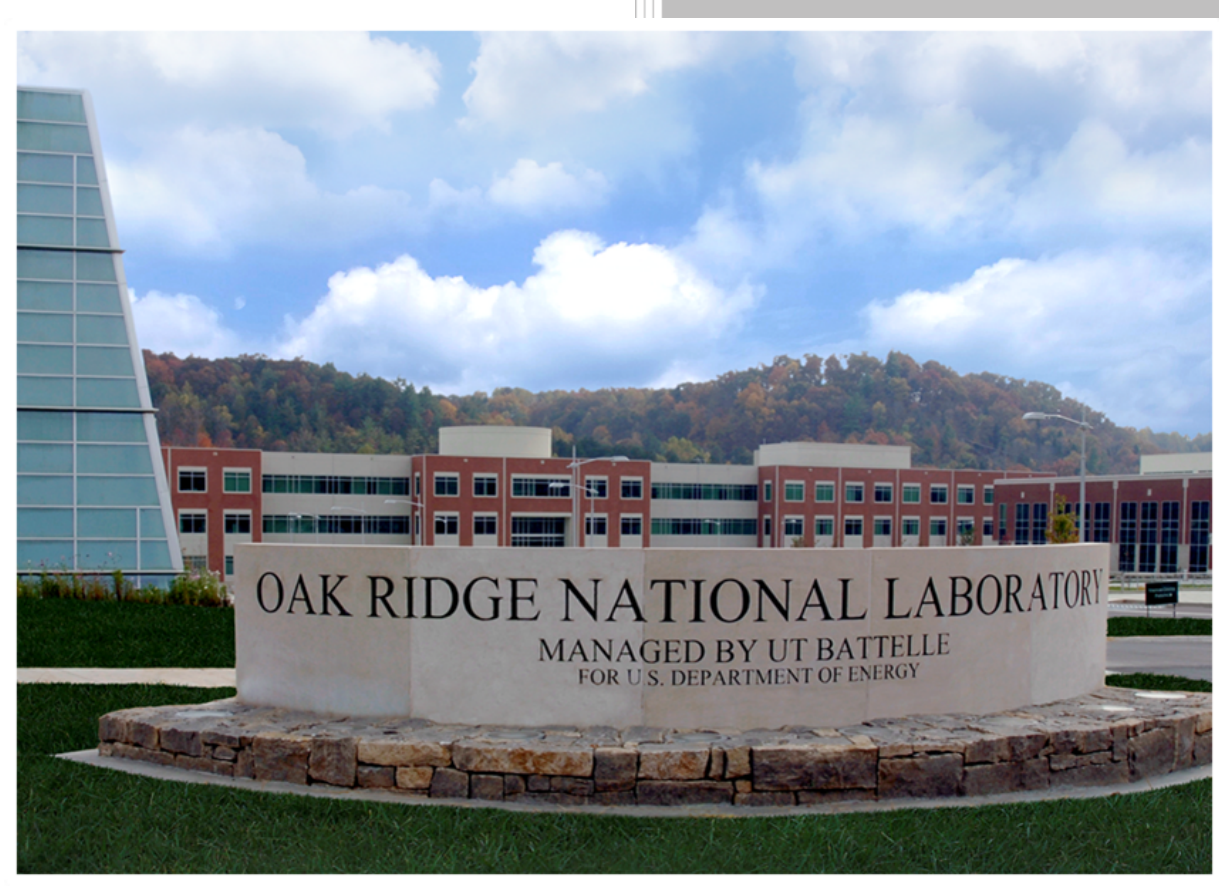

T. M. Greene

W. J. Marshall

Approved for public release. Distribution is unlimited. 


\title{
DOCUMENT AVAILABILITY
}

Reports produced after January 1, 1996, are generally available free via US Department of Energy (DOE) SciTech Connect.

Website www.osti.gov

Reports produced before January 1, 1996, may be purchased by members of the public from the following source:

\author{
National Technical Information Service \\ 5285 Port Royal Road \\ Springfield, VA 22161 \\ Telephone 703-605-6000 (1-800-553-6847) \\ TDD 703-487-4639 \\ Fax 703-605-6900 \\ E-mail info@ntis.gov \\ Website http://classic.ntis.gov/
}

Reports are available to DOE employees, DOE contractors, Energy Technology Data Exchange representatives, and International Nuclear Information System representatives from the following source:

Office of Scientific and Technical Information

PO Box 62

Oak Ridge, TN 37831

Telephone 865-576-8401

Fax 865-576-5728

E-mail reports@osti.gov

Website http://www.osti.gov/contact.html

This report was prepared as an account of work sponsored by an agency of the United States Government. Neither the United States Government nor any agency thereof, nor any of their employees, makes any warranty, express or implied, or assumes any legal liability or responsibility for the accuracy, completeness, or usefulness of any information, apparatus, product, or process disclosed, or represents that its use would not infringe privately owned rights. Reference herein to any specific commercial product, process, or service by trade name, trademark, manufacturer, or otherwise, does not necessarily constitute or imply its endorsement, recommendation, or favoring by the United States Government or any agency thereof. The views and opinions of authors expressed herein do not necessarily state or reflect those of the United States Government or any agency thereof. 
Reactor and Nuclear Systems Division

\section{Nuclear Data and Cross Section Testing Using ENDF/B-VIII.0}

T. M. Greene

W. J. Marshall

Date Published: February 2021

Prepared by OAK RIDGE NATIONAL LABORATORY

Oak Ridge, TN 37831-6283

managed by

UT-BATTELLE, LLC

for the

US DEPARTMENT OF ENERGY

under contract DE-AC05-00OR22725 



\section{CONTENTS}

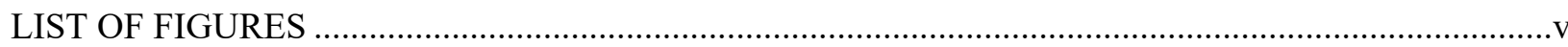

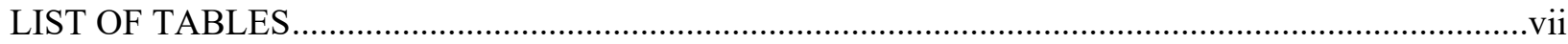

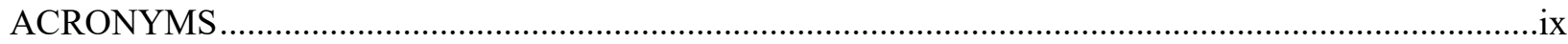

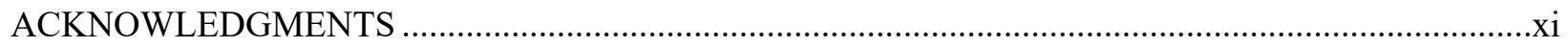

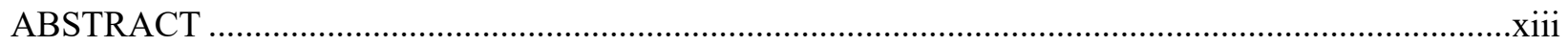

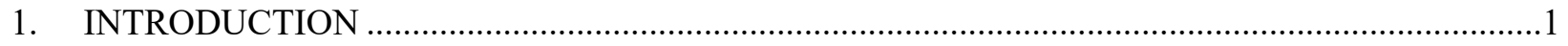

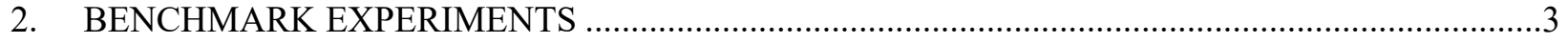

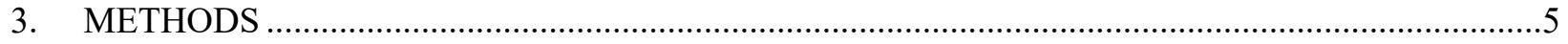

$3.1 \quad$ KENO

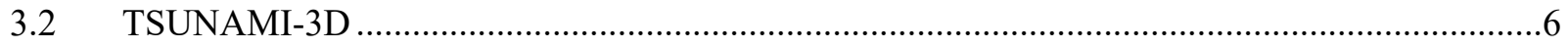

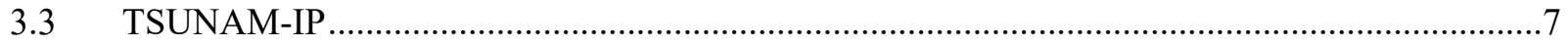

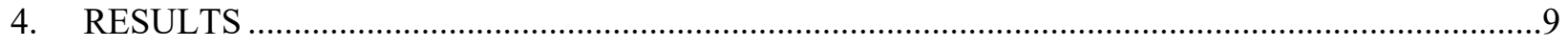

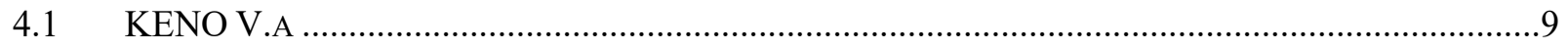

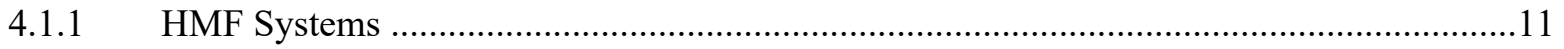

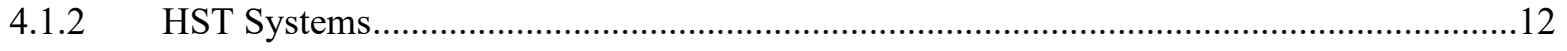

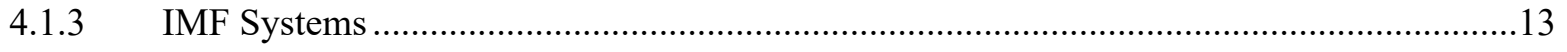

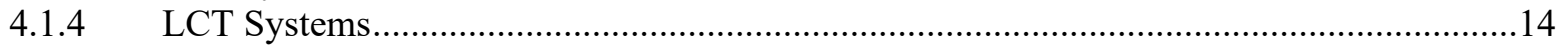

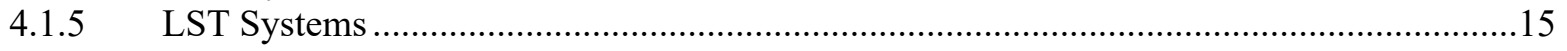

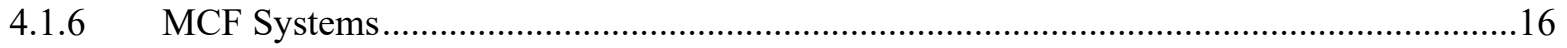

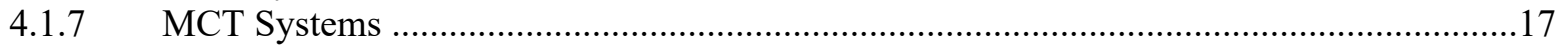

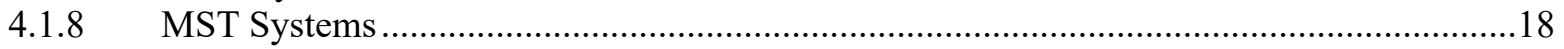

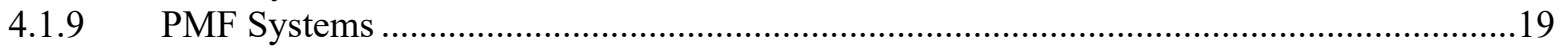

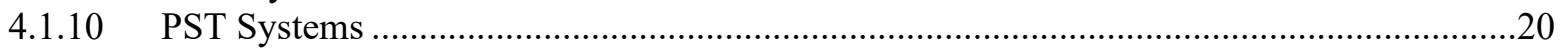

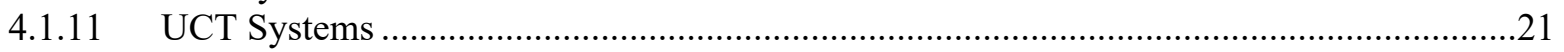

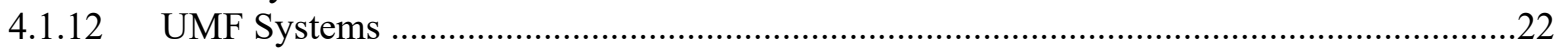

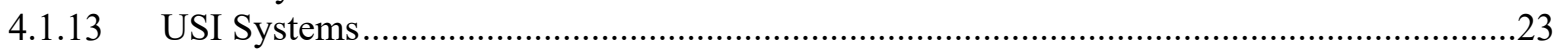

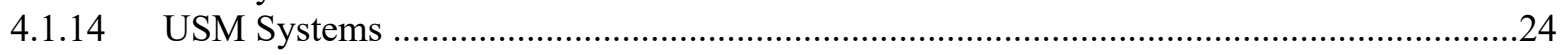

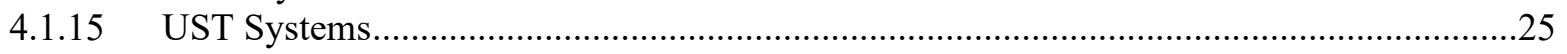

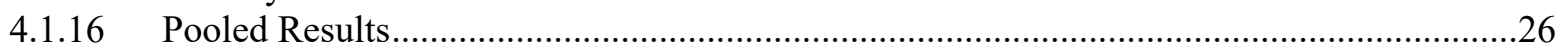

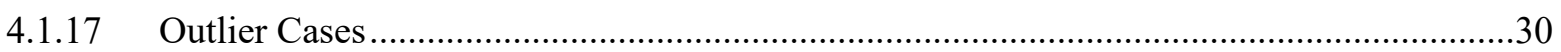

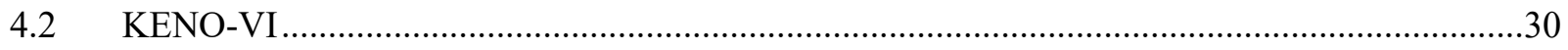

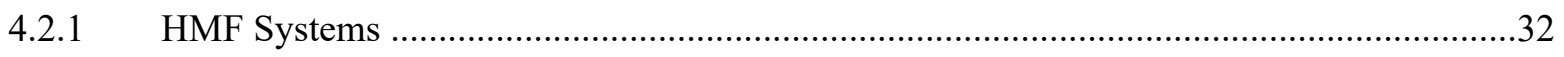

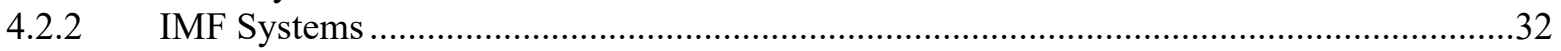

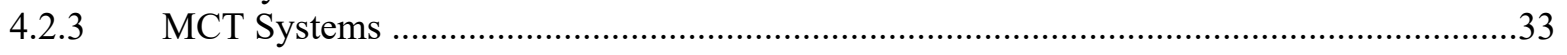

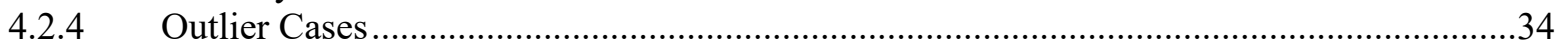

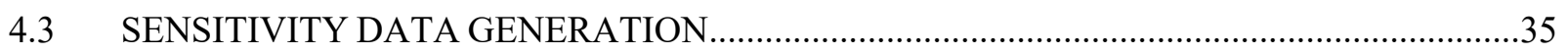

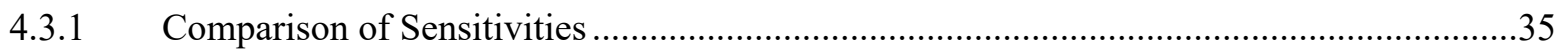

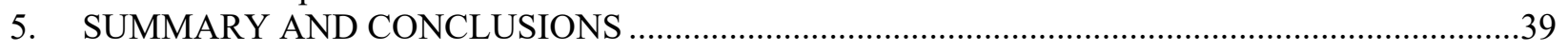

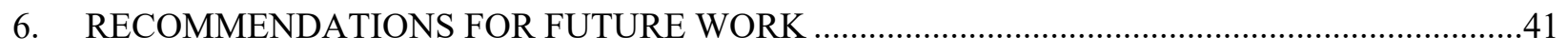

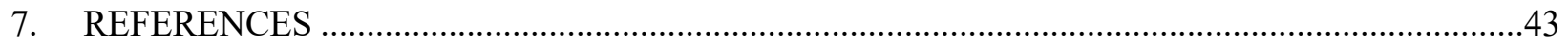





\section{LIST OF FIGURES}

Figure 1. Absolute bias for all four libraries for each of the 15 categories of experiments.......................10

Figure 2. C/E results for libraries based on ENDF/B-VII.1 and -VIII.0 for the HMF systems.................12

Figure 3. C/E results for libraries based on ENDF/B-VII.1 and -VIII.0 for the HST systems..................13

Figure 4. C/E results for libraries based on ENDF/B-VII.1 and -VIII.0 for the IMF systems. ..................14

Figure 5. C/E results for libraries based on ENDF/B-VII.1 and -VIII.0 for the LCT systems...................15

Figure 6. C/E results for libraries based on ENDF/B-VII.1 and -VIII.0 for the LST systems. ...................16

Figure 7. C/E results for libraries based on ENDF/B-VII.1 and -VIII.0 for the MCF systems...................17

Figure 8. C/E results for libraries based on ENDF/B-VII.1 and -VIII.0 for the MCT systems...................18

Figure 9. C/E results for libraries based on ENDF/B-VII.1 and -VIII.0 for the MST systems..................19

Figure 10. C/E results for libraries based on ENDF/B-VII.1 and -VIII.0 for the PMF systems. ................20

Figure 11. C/E results for libraries based on ENDF/B-VII.1 and -VIII.0 for the PST systems. ................21

Figure 12. C/E results for libraries based on ENDF/B-VII.1 and -VIII.0 for the UCT systems. ...............22

Figure 13. C/E results for libraries based on ENDF/B-VII.1 and -VIII.0 for the UMF systems................23

Figure 14. C/E results for libraries based on ENDF/B-VII.1 and -VIII.0 for the USI systems..................24

Figure 15. C/E results for libraries based on ENDF/B-VII.1 and -VIII.0 for the USM systems...............25

Figure 16. C/E results for libraries based on ENDF/B-VII.1 and -VIII.0 for the UST systems.................26

Figure 17. Absolute bias by fissile material category.........................................................................27

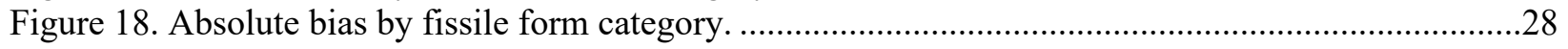

Figure 19. Absolute bias by energy spectrum category.......................................................................29

Figure 20. Absolute bias for all four libraries for each of the three categories of experiments, KENO-VI.

Figure 21. C/E results for libraries based on ENDF/B-VII.1 and -VIII.0 for the HMF systems,

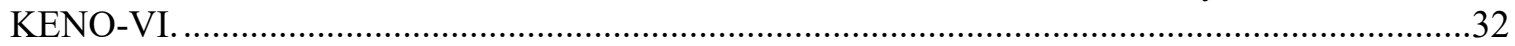

Figure 22. C/E results for libraries based on ENDF/B-VII.1 and -VIII.0 for the IMF systems,

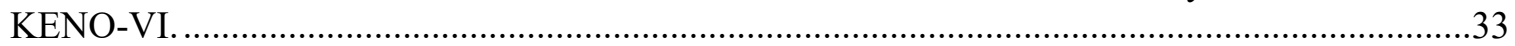

Figure 23. C/E results for libraries based on ENDF/B-VII.1 and -VIII.0 for the MCT systems,

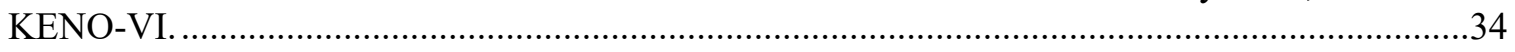

Figure 24. ${ }^{238} \mathrm{U}$ inelastic scattering profiles from the ENDF/B-VIII.0 and ENDF/B-VII.1 libraries

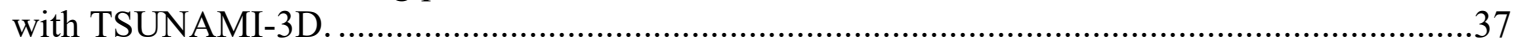

Figure 25. ${ }^{238} \mathrm{U}$ inelastic scattering profiles from the ENDF/B-VIII.0 and ENDF/B-VII.1 libraries

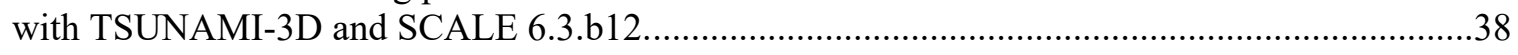





\section{LIST OF TABLES}

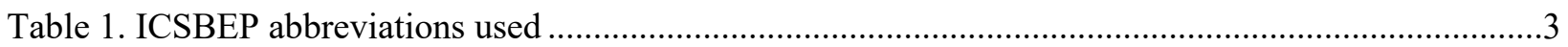

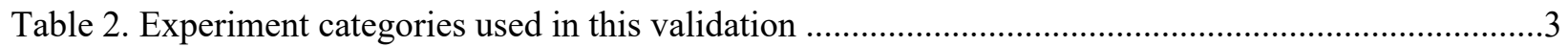

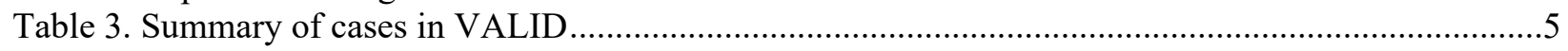

Table 4. Results by category for KENO V.a calculations with the 252-group ENDF/B-VIII.0

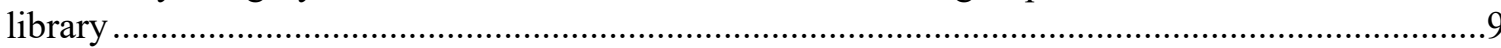

Table 5. Results by category for KENO V.a calculations with continuous energy ENDF/B-VIII.0

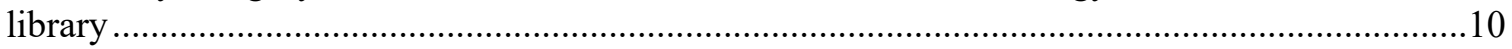

Table 6. Results by fissile material category for the 252-group ENDF/B-VIII.0 library …......................27

Table 7. Results by fissile material category for the continuous energy ENDF/B-VIII.0 library ...............27

Table 8. Results by fissile form category for the 252-group ENDF/B-VIII.0 library .............................28

Table 9. Results by fissile form category for the continuous energy ENDF/B-VIII.0 library...................28

Table 10. Results by neutron energy spectrum category for the 252-group ENDF/B-VIII.0 library ..........29

Table 11. Results by neutron energy spectrum category for the continuous energy ENDF/B-VIII.0

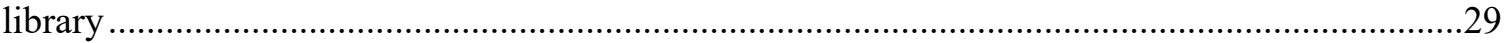

Table 12. Maximum individual case absolute differences for KENO V.a for all libraries........................30

Table 13. Results by category for KENO-VI calculations with 252-group ENDF/B-VIII.0 library...........31

Table 14. Results by category for KENO-VI calculations with continuous energy ENDF/B-VIII.0

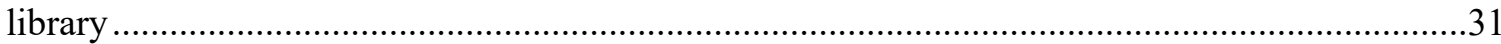

Table 15. Maximum individual case absolute differences for KENO-VI for all libraries..........................34

Table 16. Selected cases used for TSUNAMI-3D sensitivity data file generation....................................35

Table 17. Integral parameters comparing ENDF/B-VIII.0 and ENDF/B-VII.1 TSUNAMI-3D, KENO V.a .36

Table 18. Integral parameters comparing ENDF/B-VIII.0 and ENDF/B-VII.1 TSUNAMI-3D, KENO-VI . .36

Table A-1. Detailed ENDF/B-VIII.0 252-group results for KENO V.a HMF systems ..........................A-3

Table A-2. Detailed ENDF/B-VII.1 252-group results for KENO V.a HMF systems...............................-3

Table A-3. Detailed ENDF/B-VIII.0 CE results for KENO V.a HMF systems ......................................-4

Table A-4. Detailed ENDF/B-VII.1 CE results for KENO V.a HMF systems .....................................A-4

Table A-5. Detailed ENDF/B-VIII.0 252-group results for KENO V.a HST systems ............................

Table A-6. Detailed ENDF/B-VII.1 252-group results for KENO V.a HST systems...............................6

Table A-7. Detailed ENDF/B-VIII.0 CE results for KENO V.a HST systems ........................................7

Table A-8. Detailed ENDF/B-VII.1 CE results for KENO V.a HST systems ........................................8

Table A-9. Detailed ENDF/B-VIII.0 252-group results for KENO V.a IMF systems ............................A-9

Table A-10. Detailed ENDF/B-VII.1 252-group results for KENO V.a IMF systems ...........................A-9

Table A-11. Detailed ENDF/B-VIII.0 CE results for KENO V.a IMF systems ....................................9

Table A-12. Detailed ENDF/B-VII.1 CE results for KENO V.a IMF systems ......................................10

Table A-13. Detailed ENDF/B-VIII.0 252-group results for KENO V.a LCT systems ..........................10

Table A-14. Detailed ENDF/B-VII.1 252-group results for KENO V.a LCT systems............................13

Table A-15. Detailed ENDF/B-VIII.0 CE results for KENO V.a LCT systems ....................................16

Table A-16. Detailed ENDF/B-VII.1 CE results for KENO V.a LCT systems .....................................19

Table A-17. Detailed ENDF/B-VIII.0 252-group results for KENO V.a LST systems .........................A-21

Table A-18. Detailed ENDF/B-VII.1 252-group results for KENO V.a LST systems ...........................22

Table A-19. Detailed ENDF/B-VIII.0 CE results for KENO V.a LST systems ..................................A-22

Table A-20. Detailed ENDF/B-VII.1 CE results for KENO V.a LST systems.......................................23

Table A-21. Detailed ENDF/B-VIII.0 252-group results for KENO V.a MCF systems ........................23

Table A-22. Detailed ENDF/B-VII.1 252-group results for KENO V.a MCF systems ...........................23

Table A-23. Detailed ENDF/B-VIII.0 CE results for KENO V.a MCF systems ....................................23

Table A-24. Detailed ENDF/B-VII.1 CE results for KENO V.a MCF systems .....................................23 
Table A-25. Detailed ENDF/B-VIII.0 252-group results for KENO V.a MCT systems ........................A-24

Table A-26. Detailed ENDF/B-VII.1 252-group results for KENO V.a MCT systems...........................24

Table A-27. Detailed ENDF/B-VIII.0 CE results for KENO V.a MCT systems ...................................25

Table A-28. Detailed ENDF/B-VII.1 CE results for KENO V.a MCT systems .....................................25

Table A-29. Detailed ENDF/B-VIII.0 252-group results for KENO V.a MST systems.........................26

Table A-30. Detailed ENDF/B-VII.1 252-group results for KENO V.a MST systems ...........................26

Table A-31. Detailed ENDF/B-VIII.0 CE results for KENO V.a MST systems ...................................26

Table A-32. Detailed ENDF/B-VII.1 CE results for KENO V.a MST systems.....................................26

Table A-33. Detailed ENDF/B-VIII.0 252-group results for KENO V.a PMF systems ........................A-27

Table A-34. Detailed ENDF/B-VII.1 252-group results for KENO V.a PMF systems ..........................A-27

Table A-35. Detailed ENDF/B-VIII.0 CE results for KENO V.a PMF systems ................................... 27

Table A-36. Detailed ENDF/B-VII.1 CE results for KENO V.a PMF systems ......................................28

Table A-37. Detailed ENDF/B-VIII.0 252-group results for KENO V.a PST systems .........................A-28

Table A-38. Detailed ENDF/B-VII.1 252-group results for KENO V.a PST systems ...........................29

Table A-39. Detailed ENDF/B-VIII.0 CE results for KENO V.a PST systems......................................32

Table A-40. Detailed ENDF/B-VII.1 CE results for KENO V.a PST systems .......................................33

Table A-41. Detailed ENDF/B-VIII.0 252-group results for KENO V.a UCT systems ..........................35

Table A-42. Detailed ENDF/B-VII.1 252-group results for KENO V.a UCT systems ...........................35

Table A-43. Detailed ENDF/B-VIII.0 252-group results for KENO V.a UCT systems ..........................35

Table A-44. Detailed ENDF/B-VII.1 252-group results for KENO V.a UCT systems ............................35

Table A-45. Detailed ENDF/B-VIII.0 252-group results for KENO V.a UMF systems .......................A-35

Table A-46. Detailed ENDF/B-VII.1 252-group results for KENO V.a UMF systems...........................35

Table A-47. Detailed ENDF/B-VIII.0 CE results for KENO V.a UMF systems.....................................36

Table A-48. Detailed ENDF/B-VII.1 CE results for KENO V.a UMF systems .................................A-36

Table A-49. Detailed ENDF/B-VIII.0 252-group results for KENO V.a USI systems ........................A-36

Table A-50. Detailed ENDF/B-VII.1 252-group results for KENO V.a USI systems ..........................A-37

Table A-51. Detailed ENDF/B-VIII.0 CE results for KENO V.a USI systems .....................................-38

Table A-52. Detailed ENDF/B-VII.1 CE results for KENO V.a USI systems ......................................

Table A-53. Detailed ENDF/B-VIII.0 252-group results for KENO V.a USM systems .......................A-39

Table A-54. Detailed ENDF/B-VII.1 252-group results for KENO V.a USM systems.........................A-39

Table A-55. Detailed ENDF/B-VIII.0 CE results for KENO V.a USM systems ......................................39

Table A-56. Detailed ENDF/B-VII.1 CE results for KENO V.a USM systems ......................................39

Table A-57. Detailed ENDF/B-VIII.0 252-group results for KENO V.a UST systems .........................40

Table A-58. Detailed ENDF/B-VII.1 252-group results for KENO V.a UST systems.........................A-42

Table A-59. Detailed ENDF/B-VIII.0 CE results for KENO V.a UST systems .....................................45

Table A-60. Detailed ENDF/B-VII.1 CE results for KENO V.a UST systems .......................................47

Table B-1. Detailed ENDF/B-VIII.0 252-group results for KENO-VI HMF systems ..............................3

Table B-2. Detailed ENDF/B-VII.1 252-group results for KENO-VI HMF systems ..............................3

Table B-3. Detailed ENDF/B-VIII.0 CE results for KENO-VI HMF systems .........................................4

Table B-4. Detailed ENDF/B-VII.1 CE results for KENO-VI HMF systems ..........................................

Table B-5. Detailed ENDF/B-VIII.0 252-group results for KENO-VI IMF systems ...............................

Table B-6. Detailed ENDF/B-VII1.1 252-group results for KENO-VI IMF systems................................5

Table B-7. Detailed ENDF/B-VIII.0 CE results for KENO-VI IMF systems ….......................................

Table B-8. Detailed ENDF/B-VII.1 CE results for KENO-VI IMF systems ….......................................

Table B-9. Detailed ENDF/B-VIII.0 252-group results for KENO-VI MCT systems ..............................

Table B-10. Detailed ENDF/B-VII.1 252-group results for KENO-VI MCT systems .............................6

Table B-11. Detailed ENDF/B-VIII.0 CE results for KENO-VI MCT systems …...................................7

Table B-12. Detailed ENDF/B-VII.1 CE results for KENO-VI MCT systems ........................................8 


\title{
ACRONYMS
}

\author{
$\mathrm{C} / \mathrm{E} \quad$ calculated-to-expected \\ $\mathrm{CE} \quad$ continuous energy \\ COMP $^{1} \quad$ compound system (e.g., lattice in water) \\ CSAS Criticality Safety Analysis Sequences \\ EALF energy of average lethargy of neutrons causing fission \\ ENDF Evaluated Nuclear Data File \\ FAST $^{1} \quad$ Fast system ( $\geq 50 \%$ of fissions above $\left.100 \mathrm{keV}\right)$ \\ $\mathrm{HEU}^{1} \quad$ high enriched uranium $\left({ }^{235} \mathrm{U} \geq 60 \mathrm{wt} \%\right)$ \\ $\mathrm{HMF}^{2}$ HEU-MET-FAST \\ HST $^{2} \quad$ HEU-SOL-THERM \\ ICSBEP International Criticality Safety Benchmark Evaluation Project \\ $\mathrm{IEU}^{1}$ \\ $\mathrm{IMF}^{2}$ \\ INTER $^{1}$ \\ $\mathrm{LCT}^{2}$ \\ LEU $^{1}$ \\ LST \\ LWR \\ $\mathrm{MCF}^{2}$ \\ MCNP \\ $\mathrm{MCT}^{2}$ \\ $\mathrm{MET}^{1}$ \\ $\mathrm{MG}$ \\ MIX $^{1}$ \\ MIXED $^{1}$ \\ $\mathrm{MST}^{2}$ \\ ORNL \\ $\mathrm{PMF}^{2}$ \\ $\mathrm{PST}^{2}$ \\ PU1 \\ SDF \\ $\mathrm{SOL}^{1}$ \\ THERM $^{1}$ \\ TSUNAMI \\ $\mathrm{U} 233^{1}$ \\ $\mathrm{UCT}^{2}$ \\ $\mathrm{UMF}^{2}$ \\ $\mathrm{USI}^{2}$ \\ $\mathrm{USM}^{2}$ \\ $\mathrm{UST}^{2}$ \\ intermediate or mixed enrichment uranium ( $60 \mathrm{wt} \%>{ }^{235} \mathrm{U}>10 \mathrm{wt} \%$ ) \\ IEU-MET-FAST \\ intermediate system $(\geq 50 \%$ of fissions from $0.625 \mathrm{eV}$ to $100 \mathrm{keV})$ \\ LEU-COMP-THERM \\ low enriched, natural, or depleted uranium $\left({ }^{235} \mathrm{U} \leq 10 \mathrm{wt} \%\right)$ \\ LEU-SOL-THERM \\ light-water reactor \\ MIX-COMP-FAST \\ Monte Carlo N-Particle Transport Code \\ MIX-COMP-THERM \\ metal \\ multigroup \\ mixed uranium and plutonium \\ mixed energy system ( $>50 \%$ of fissions do not occur in any single energy range) \\ MIX-SOL-THERM \\ Oak Ridge National Laboratory \\ PU-MET-FAST \\ PU-SOL-THERM \\ plutonium \\ sensitivity data file \\ solution \\ thermal system ( $\geq 50 \%$ of fissions below $0.625 \mathrm{eV}$ ) \\ Tools for Sensitivity and Uncertainty Analysis Methodology Implementation (SCALE) \\ ${ }^{233} \mathrm{U}$ \\ U233-COMP-THERM \\ U233-MET-FAST \\ U233-SOL-INTER \\ U233-SOL-MIXED \\ U233-SOL-THERM \\ VALID Verified, Archived Library of Inputs and Data \\ WPEC Working Party on International Nuclear Data Evaluation Co-operation \\ ${ }^{1}$ ICSBEP abbreviations used \\ ${ }^{2}$ Experiment categories used in this validation
}





\section{ACKNOWLEDGMENTS}

The authors wish to acknowledge the US Department of Energy Nuclear Criticality Safety Program for its support of this work. The careful reviews of Andrew Holcomb and Alex Shaw and the editorial assistance of Elizabeth Kirby and Tracy Cruttenden are gratefully acknowledged. 



\begin{abstract}
With the release of the Evaluated Nuclear Data File (ENDF)/B-VIII.0 library, nuclear criticality safety practitioners and engineers have access to the latest cross section sets available for their analyses. However, these cross sections must be rigorously tested and validated to ensure that the nuclear data are responsive to the needs of the individuals responsible for developing, implementing, and maintaining computational tools for criticality safety applications. Thus, the ENDF/B-VIII.0 library is tested and validated with a large collection of experiments that were vetted by the International Criticality Safety Benchmark Evaluation Project and made available in the International Handbook of Evaluated Criticality Safety Benchmark Experiments. A selection of benchmark experiments for use within the criticality safety community were prepared and reviewed within the Verified, Archived Library of Inputs and Data (VALID), which is maintained by the Nuclear Energy and Fuel Cycle Division at Oak Ridge National Laboratory. The performance of the ENDF/B-VIII.0 library is assessed by using VALID models of benchmark experiments with the beta 12 version of SCALE 6.3 KENO V.a and KENO-VI Monte Carlo codes. The performance is compared with the results obtained from with the ENDF/B-VII.1 library. This report considers multigroup (MG) and continuous energy (CE) formats of the ENDF/B-VIII.0 and -VII.1 libraries.
\end{abstract}

The benchmark experiments within VALID that validate the ENDF/B-VIII.0 library cover 15 broad system categories by using a range of fissile materials, uranium enrichments, plutonium isotopic vectors, and mixed uranium/plutonium systems. These forms are represented as metals, solutions, or various arrays of rods or plates that cover a variety of neutron energy spectra: thermal, fast, mixed, and intermediate. Over 600 cases were considered for use with the KENO V.a and KENO-VI codes with the ENDF/B-VIII.0 library.

The results of the Monte Carlo comparison of ENDF/B-VIII.0 to ENDF/B-VII.1 with both KENO V.a and KENO-VI indicate that there is a less than $0.53 \% \Delta k$ difference between the bias of calculated $k_{\text {eff }}$ from the expected values. The CE ENDF/B-VIII.0 library results in smaller magnitude biases than the ENDF/B-VII.1 data for HEU-MET-FAST, HEU-SOL-THERM, IEU-MET-FAST, LEU-SOL-THERM, PU-SOL-THERM, and U233-MET-FAST systems, while the MG results yielded smaller magnitude biases for HEU-MET-FAST, HEU-SOL-THERM, IEU-MET-FAST, LEU-COMP-THERM, LEU-SOLTHERM, MIX-COMP-FAST, and U233-MET-FAST systems. Most notable are the adjustments to the plutonium and ${ }^{233} \mathrm{U}$ cross section data, which has resulted in noticeably lower biases in the ENDF/BVIII.0 results for the mixed, plutonium, and ${ }^{233} \mathrm{U}$ systems.

Results of the sensitivity data file comparison generated from TSUNAMI-3D for selected VALID cases for the ENDF/B-VIII.0 library indicate a very high level of agreement with correlation coefficients of the effect of nuclear data uncertainty on $k_{\text {eff }}$ (the $\mathrm{c}_{\mathrm{k}}$ integral parameter) all above 0.99 . This indicates that cases with the ENDF/B-VIII.0 library would see very similar responses to any nuclear data errors or change as those with the ENDF/B-VII.1 library. 


\section{INTRODUCTION}

In February 2018, the Cross Section Evaluation Working Group (CSEWG) released the Evaluated Nuclear Data File (ENDF)/B-VIII.0 library, which uses new evaluated data from the Collaborative International Evaluation Library Organization (CIELO) project that focuses on neutron reactions of ${ }^{1} \mathrm{H}$, ${ }^{16} \mathrm{O},{ }^{56} \mathrm{Fe},{ }^{235} \mathrm{U},{ }^{238} \mathrm{U}$, and ${ }^{239} \mathrm{Pu}$ and includes improved thermal scattering data [1]. However, before this newest version of cross section data can be used in transport calculation programs, such as SCALE [2] or Monte Carlo N-Particle Transport Code (MCNP) [3], it must be processed by specific processing codes that generate cross section libraries. AMPX [4] and NJOY [11] — which are used exclusively with SCALE and MCNP, respectively - are code packages that process isotope and nuclide data into cross section libraries that can then be used for radiation transport evaluations. These generated libraries include continues energy (CE), multi-group (MG), and covariance data files.

This report focuses on the cross section libraries generated by AMPX from the ENDF/B-VIII.0 nuclear data library to be used with the SCALE code system package. The AMPX code includes several key functional processing capabilities, including the generation of temperature-dependent CE cross section data, the processing of thermal scattering law data $(S[\alpha, \beta])$, and the production of cross section covariance data files for sensitivity and uncertainty analyses, as well as others [4]. Therefore, the purpose of this report is to validate the cross section libraries generated through AMPX-processed ENDF/B-VIII.0 nuclear data through the set of critical experiments available in the Verified, Archived Library of Inputs and Data (VALID library) available through Oak Ridge National Laboratory (ORNL) [5].

VALID contains high-quality, independently reviewed, critical experiment models developed from the International Handbook of Evaluated Criticality Safety Benchmark Experiments (hereafter referred to as the ICSBEP Handbook) that can be used for analyses and validation [6]. VALID includes inputs, outputs, and other associated files, such as sensitivity data files (SDFs), which can be used for a range of applications, including criticality safety validation, cross section evaluations, and sensitivity and uncertainty analyses. The report includes rerunning all cases within the VALID system with ENDF/BVIII.0 to compare them with the results generated by ENDF/B-VII.1 [7] with CE and MG libraries. Attention was also given not only to $k_{\text {eff }}$ values but also to sensitivity data differences for specific cases to assess the similarity between the previous and newest versions of nuclear data. Thus, the project provides criticality safety practitioners with an assessment of current cross section data for analyses, supporting the mission and vision of the Nuclear Criticality Safety Program (NCSP). 



\section{BENCHMARK EXPERIMENTS}

The benchmark experiments within VALID that were used for this validation report were taken from the ICSBEP Handbook. These experiments encompass differences in neutron energy, enrichment,

composition, and fissile material. Error! Reference source not found. lists the different experiment classes, and their abbreviations are listed in Table 2. A brief description of each experiment can be found in the SCALE 6.2.2 validation report [8] or in the ICSBEP Handbook [6] and will not be included in this report.

Table 1. ICSBEP abbreviations used

\begin{tabular}{|c|c|}
\hline Abbreviation & Meaning \\
\hline \multicolumn{2}{|r|}{ Fissile material } \\
\hline HEU & High enriched uranium $\left({ }^{235} \mathrm{U} \geq 60 \mathrm{wt} \%\right)$ \\
\hline IEU & $\begin{array}{l}\text { Intermediate or mixed enrichment uranium } \\
\left(60 \mathrm{wt} \%>{ }^{235} \mathrm{U}>10 \mathrm{wt} \%\right)\end{array}$ \\
\hline LEU & $\begin{array}{l}\text { Low enriched, natural, or depleted uranium } \\
\left({ }^{235} \mathrm{U} \leq 10 \mathrm{wt} \%\right)\end{array}$ \\
\hline MIX & Mixed uranium and plutonium \\
\hline PU & Plutonium \\
\hline U233 & ${ }^{233} \mathrm{U}$ \\
\hline \multicolumn{2}{|r|}{ Physical form of fissile material } \\
\hline MET & Metal \\
\hline SOL & Solution \\
\hline COMP & Compound system (e.g., lattice in water) \\
\hline \multicolumn{2}{|r|}{ Spectrum } \\
\hline FAST & Fast system ( $\geq 50 \%$ of fissions above $100 \mathrm{keV})$ \\
\hline INTER & $\begin{array}{l}\text { Intermediate system ( } \geq 50 \% \text { of fissions from } 0.625 \mathrm{eV} \text { to } \\
100 \mathrm{keV} \text { ) }\end{array}$ \\
\hline THERM & Thermal system ( $\geq 50 \%$ of fissions below $0.625 \mathrm{eV}$ ) \\
\hline MIXED & $\begin{array}{l}\text { Mixed energy system ( }>50 \% \text { of fissions do not occur in } \\
\text { any single energy range) }\end{array}$ \\
\hline
\end{tabular}

Table 2. Experiment categories used in this validation

\begin{tabular}{ll}
\hline HMF & HEU-MET-FAST \\
HST & HEU-SOL-THERM \\
IMF & IEU-MET-FAST \\
LCT & LEU-COMP-THERM \\
LST & LEU-SOL-THERM \\
MCF & MIX-COMP-FAST \\
MCT & MIX-COMP-THERM \\
MST & MIX-SOL-THERM \\
PMF & PU-MET-FAST \\
PST & PU-SOL-THERM \\
UCT & U233-COMP-THERM \\
UMF & U233-MET-FAST \\
USI & U233-SOL-INTER \\
USM & U233-SOL-MIXED \\
UST & U233-SOL-THERM \\
\hline
\end{tabular}





\section{METHODS}

A general overview of the SCALE codes and data used in the calculations is not provided; only the calculational methods used to compare the model results from the ENDF/B-VIII.0 and -VII.1 libraries are described. Complete descriptions of the codes and data are available in the SCALE 6.2.3 manual [2].

\subsection{KENO}

As noted earlier, all benchmark experiment models used for comparison were generated and are maintained in VALID at ORNL. Table 3 summarizes the cases that were performed by using KENO V.a or KENO-VI. KENO V.a and -VI solve the $k$-effective $\left(k_{\text {eff }}\right)$ eigenvalue problem using the Monte Carlo method; however, KENO-VI can represent systems of increasingly more complex geometric configurations than KENO V.a. All calculations performed for this report utilized the CE and 252-energy MG (252-group) libraries generated by AMPX from the ENDF/B-VIII.0 nuclear data library.

Table 3. Summary of cases in VALID

\begin{tabular}{cllc}
\hline Sequence & \multicolumn{1}{c}{ Experiment class } & ICSBEP experiment numbers & $\begin{array}{c}\text { Number of } \\
\text { configurations }\end{array}$ \\
& HEU-MET-FAST & $15,16,17,18,19,20,21,25$, & $19 / 23^{a}$ \\
& HEU-SOL-THERM & $10,38,40,52,65$ & 52 \\
& IEU-MET-FAST & $1,13,14,16,28,29,30$ & $8 / 11^{a}$ \\
& LEU-COMP-THERM & $1,2,8,5,6,7,8,9,17,42,50,78,80$ & 140 \\
& LEU-SOL-THERM & $2,3,4$ & 19 \\
Criticality Safety & MIX-COMP-FAST & 5,6 & 2 \\
Analysis Sequences & MIX-COMP-THERM & $1,2^{b}, 4$ & 21 \\
5 (CSAS5)/KENO & MIX-SOL-THERM & 2,7 & 10 \\
V.a & PU-MET-FAST & $1,2,5,6,8,10,18,22,23,24$, & 12 \\
& & 25,26 & 81 \\
& PU-SOL-THERM & $1,2,3,4,5,6,7,11,20$ & 3 \\
& U233-COMP-THERM & 1 & 10 \\
& U233-MET-FAST & $1,2,3,4,5,6$ & 8 \\
& U233-SOL-INTER & 1 & 140 \\
& U233-SOL-MIXED & 1,2 & 29 \\
& U233-SOL-THERM & $1,2,3,4,5,8,9,11,12,13,15$, & \\
& & 16,17 & 2 \\
\hline & HEU-MET-FAST & $5,8,9,10,11,13,24,80,86$, & 28 \\
\hline
\end{tabular}

${ }^{a}$ The larger number includes simplified cases that are duplicate cases for which detailed models are also available in the library.

${ }^{b}$ Only simplified cases were used for models.

The performance of the ENDF/B-VIII.0 libraries with the codes is analyzed in terms of the calculated-toexpected (evaluated) (C/E) ratio. The ICSBEP evaluation provides an expected $k_{\text {eff }}$ value and its estimated uncertainty for each benchmark model configuration. The $\mathrm{C} / \mathrm{E}$ ratio and its uncertainty are calculated from the $k_{\text {eff }}$ results obtained from KENO along with the evaluation values as shown in Eqs. (1) and (2):

$$
\frac{C}{E}=\frac{k_{e f f}^{\text {calc }}}{k_{\text {eff }}^{\text {eval }}}
$$




$$
\sigma_{C / E}=\frac{C}{E}\left(\sqrt{\left(\frac{\sigma_{\text {calc }}}{k_{\text {eff }}^{\text {calc }}}\right)^{2}+\left(\frac{\sigma_{\text {eval }}}{k_{\text {eff }}^{\text {eval }}}\right)^{2}}\right),
$$

where:

$\boldsymbol{k}_{\boldsymbol{e f f}}^{\boldsymbol{c a l c}}$ is the $k_{\text {eff }}$ value calculated by KENO V.a or KENO-VI,

$\boldsymbol{k}_{\boldsymbol{e f f}}^{\boldsymbol{e v a l}}$ is the expected $k_{\text {eff }}$ value from the ICSBEP evaluation,

$\sigma_{C / E}$ is the uncertainty in the $\mathrm{C} / \mathrm{E}$ ratio,

$\sigma_{\text {calc }}$ is the calculated uncertainty in the $k_{\text {eff }}$ value from KENO V.a or KENO-VI, and

$\sigma_{\text {eval }}$ is the uncertainty value reported in the ICSBEP evaluation of the configuration.

Additionally, an average $\mathrm{C} / \mathrm{E}$ value was determined for each experiment category for each code. By using a simple unweighted arithmetic average of the individual $\mathrm{C} / \mathrm{E}$ values, these were defined as specific combinations of fissile form, fissile species, and energy spectrum, as well as within whole categories of experiments, such as HEU-MET-FAST. Depending on the case or experiment, the Monte Carlo calculations were run to achieve a small uncertainty of approximately 0.00010 or $0.00049 \Delta \boldsymbol{k}_{\text {eff }}$ as noted in the SCALE 6.2.2 validation report [8]. The uncertainty in the average $\mathrm{C} / \mathrm{E}$ value is shown in Eq. (3):

$$
\sigma_{C / E}^{A v g}=\frac{\sqrt{\sum_{i=1}^{N}\left(\sigma_{C / E}^{i}\right)^{2}}}{N}
$$

where:

$\boldsymbol{\sigma}_{\boldsymbol{C} / \boldsymbol{E}}^{\boldsymbol{A v g}}$ is the uncertainty in the average $\mathrm{C} / \mathrm{E}$ value,

$\boldsymbol{\sigma}_{\boldsymbol{C} / \boldsymbol{E}}^{\boldsymbol{i}}$ is the uncertainty in a single $\mathrm{C} / \mathrm{E}$ value, and

$N$ is the total number of configurations included for the category of experiments.

The results for each case and experiment category are reported for each library, allowing for comparisons between ENDF/B-VIII.0 and -VII.1 for CE and MG libraries, respectively. These comparisons are made through the deviations from unity in $\mathrm{C} / \mathrm{E}$ for each case and are the difference between the calculated $\mathrm{C} / \mathrm{E}$ value and 1.0 or the absolute bias. C/E values obtained from the ENDF/B-VII.1 library are thus compared against those obtained from calculations with the ENDF/B-VIII.0 library.

\subsection{TSUNAMI-3D}

The TSUNAMI-3D sequence within the SCALE code package is used to generate cross section sensitivity data for sensitivity and uncertainty analyses. The sequence calculates sensitivities based on the fluxes determined by KENO and are written in SDFs, which contain nuclide-, energy-, and reactiondependent $k_{\text {eff }}$ sensitivity coefficients. The selection of whether to use MG or CE methods to generate these SDFs was determined by the inputs from the SCALE 6.2.2 validation report. Rather than generate SDFs for the entire VALID library, only specific cases from each category were selected for the generation of SDFs for this report. These selections were based on an experiment's energy of average lethargy of neutrons causing fission (EALF) or uniqueness in the model description to provide a general representation of each category, such as reflector material, neutron poison, and so forth. More details concerning the calculation methodologies for TSUNAMI-3D are found in the SCALE 6.2.3 manual [2]. 


\subsection{TSUNAM-IP}

The TSUNAMI-IP sequence is used to evaluate the similarities of the benchmark experiments and determine the uncertainties due to cross section covariance data. Two similarity metrics are used here: the integral parameter $c_{k}$ and integral index $E$. The $c_{k}$ value is a correlation coefficient of the effect of nuclear data uncertainty on $k_{\text {eff }}$ between an experiment case and an application and is shown in Eq. (4):

$$
c_{k}=\frac{\sigma_{A p p E x p}^{2}}{\sigma_{A p p} \sigma_{E x p}}
$$

where:

$\boldsymbol{c}_{\boldsymbol{k}}$ is the similarity between an application (ENDF/B-VII.1 results) and an experiment (ENDF/B-VIII.0 results),

$\boldsymbol{\sigma}_{\text {AppExp }}^{2}$ is the covariance between the application and the experiment,

$\boldsymbol{\sigma}_{\boldsymbol{A p p}}$ is the uncertainty in the application $k_{\text {eff }}$ due to cross section covariances (uncertainties), and

$\boldsymbol{\sigma}_{\boldsymbol{E x p}}$ is the uncertainty in the experiment $k_{\text {eff }}$ due to cross section covariances (uncertainties).

A $c_{k}$ value of 1 indicates that the two systems are positively correlated, meaning that comparing the $k_{e f f}$ values for both systems would be identically affected by any nuclear data errors. The 56-group covariance data based on the ENDF/B-VIII.0 library were used to determine the uncertainty contributions or $c_{k}$.

The integral index $E$ is similar to the $c_{k}$ value, except that it does not consider the uncertainties in the nuclear data but compares only the similarities in the sensitivity data generated in the SDFs. This means that all sensitivities produced by the TSUNAMI-3D results are given equal weight and help identify important isotopes with low uncertainties. The formula used to calculate the $E$ integral index is shown in Eq. (5):

$$
E=\frac{\boldsymbol{S}_{A}^{T} \boldsymbol{S}_{E}}{\left|\boldsymbol{S}_{\boldsymbol{A}}\right|\left|\boldsymbol{S}_{E}\right|}
$$

where:

$\boldsymbol{S}_{\boldsymbol{A}}$ is the sensitivity vector for the application (ENDF/B-VII.1),

$\boldsymbol{S}_{E}$ is the sensitivity vector for the experiment (ENDF/B-VIII.0),

$\boldsymbol{S}_{A}^{T}$ is the transpose of the sensitivity vector for the application,

$\left|\boldsymbol{S}_{\boldsymbol{A}}\right|$ is the magnitude of the sensitivity vector corresponding to the L2 norm for the application (see Eq. [6]), and

$\left|\boldsymbol{S}_{E}\right|$ is the magnitude of the sensitivity vector corresponding to the L2 norm for the experiment (see Eq. [6]),

$$
\left|S_{i}\right|=\sqrt{S_{i}^{T} S_{i}}
$$

An $E$ value of 1, similar to the $c_{k}$ value, indicates that the two systems are essentially identical [2]. 



\section{RESULTS}

This section presents the results of the comparisons between ENDF/B-VIII.0 and -VII.1 through KENO V.a, KENO-VI, TSUNAMI-3D, and TSUNAMI-IP. Section 4.1 presents KENO V.a results, Section 4.2 presents results for KENO-VI, and Section 4.3 presents sensitivity results with TSUNAMI-3D and -IP. Sections 4.1 and 4.2 present the average results for each category along with more detailed discussions of the results in each category. A complete list of the calculated $k_{e f f}$ values and their uncertainties and the benchmark model $k_{\text {eff }}$ values and their uncertainties are presented in Appendix A for KENO V.a cases and in Appendix B for KENO-VI cases.

All model calculations were performed by using SCALE 6.3.b12 with the ENDF/B-VIII.0 and -VII.1 nuclear data libraries and were executed on the Apollo cluster at ORNL with each node consisting of two 12-core Intel Xeon $2.30 \mathrm{GHz}$ 5,118 CPUs and $192 \mathrm{~GB}$ of memory. Only the library names were altered from the original VALID inputs to perform calculations in KENO and TSUNAMI for this report.

\subsection{KENO V.A}

The maximum reported uncertainty for all calculations is $0.00049 \Delta k$ with more than $75 \%$ of uncertainties reduced to $0.00010 \Delta k$. The average $\mathrm{C} / \mathrm{E}$ value and its uncertainty for each category are provided in Table 4 for MG libraries (252-group) based on ENDF/B-VIII.0 and -VII.1 and in Table 5 for CE libraries. Tables 4 and 5 provide differences in the C/E values from ENDF/B-VIII.0 to -VII.1. The average C/E bias (i.e., difference from unity) is shown in Figure 1 for each of the categories for all four libraries.

Table 4. Results by category for KENO V.a calculations with the 252-group ENDF/B-VIII.0 library

\begin{tabular}{l|cc|cc|ccc}
\hline \multirow{2}{*}{ Category } & \multicolumn{2}{|c|}{ ENDF/B-VIII.0 } & \multicolumn{2}{c|}{ ENDF/B-VII.1 } & & \\
\cline { 2 - 5 } & Avg. C/E & $\begin{array}{c}\text { Avg. C/E } \\
\text { unc. }\end{array}$ & Avg. C/E & $\begin{array}{c}\text { Avg. C/E } \\
\text { unc. }\end{array}$ & Difference & Unc. & Std Dev. \\
\hline HMF & 1.00295 & 0.00039 & 1.00310 & 0.00039 & -0.00015 & 0.00055 & 0.27196 \\
HST & 0.99883 & 0.00072 & 0.99651 & 0.00072 & 0.00232 & 0.00102 & 2.27846 \\
IMF & 1.00266 & 0.00082 & 1.00572 & 0.00083 & -0.00307 & 0.00117 & 2.62268 \\
LCT & 0.99949 & 0.00018 & 0.99891 & 0.00018 & 0.00058 & 0.00026 & 2.27846 \\
LST & 0.99844 & 0.00083 & 0.99774 & 0.00083 & 0.00070 & 0.00117 & 0.59636 \\
MCF & 1.00119 & 0.00158 & 1.00350 & 0.00158 & -0.00231 & 0.00223 & 1.03381 \\
MCT & 0.99789 & 0.00087 & 0.99827 & 0.00087 & -0.00038 & 0.00123 & 0.30885 \\
MST & 0.99329 & 0.00157 & 0.99783 & 0.00158 & -0.00454 & 0.00223 & 2.03825 \\
PMF & 0.99950 & 0.00062 & 1.00003 & 0.00062 & -0.00053 & 0.00088 & 0.60446 \\
PST & 0.99752 & 0.00055 & 1.00199 & 0.00056 & -0.00447 & 0.00079 & 5.69485 \\
UCT & 0.99821 & 0.00140 & 1.00066 & 0.00141 & -0.00245 & 0.00199 & 1.23303 \\
UMF & 0.99875 & 0.00051 & 0.99868 & 0.00051 & 0.00007 & 0.00072 & 0.09705 \\
USI & 0.97931 & 0.00123 & 0.98214 & 0.00123 & -0.00283 & 0.00174 & 1.62692 \\
USM & 0.97528 & 0.00214 & 0.97830 & 0.00214 & -0.00302 & 0.00303 & 0.99788 \\
UST & 0.99669 & 0.00052 & 0.99885 & 0.00052 & -0.00216 & 0.00074 & 2.93721 \\
\hline
\end{tabular}


Table 5. Results by category for KENO V.a calculations with CE ENDF/B-VIII.0 library

\begin{tabular}{|c|c|c|c|c|c|c|c|}
\hline \multirow[b]{2}{*}{ Category } & \multicolumn{2}{|c|}{ ENDF/B-VIII.0 } & \multicolumn{2}{|c|}{ ENDF/B-VII.1 } & \multirow[b]{2}{*}{ Difference } & \multirow[b]{2}{*}{ Unc. } & \multirow[b]{2}{*}{ Std Dev } \\
\hline & Avg. C/E & $\begin{array}{l}\text { Avg. } \mathrm{C} / \mathrm{E} \\
\text { unc. }\end{array}$ & Avg. C/E & $\begin{array}{l}\text { Avg. C/E } \\
\text { unc. }\end{array}$ & & & \\
\hline HMF & 1.00179 & 0.00039 & 1.00198 & 0.00039 & -0.00019 & 0.00055 & 0.34449 \\
\hline HST & 0.99824 & 0.00074 & 0.99774 & 0.00072 & 0.00050 & 0.00103 & 0.48427 \\
\hline IMF & 1.00061 & 0.00082 & 1.00289 & 0.00083 & -0.00229 & 0.00117 & 1.95415 \\
\hline $\mathrm{LCT}$ & 0.99921 & 0.00018 & 0.99960 & 0.00018 & -0.00039 & 0.00026 & 1.53206 \\
\hline LST & 0.99845 & 0.00083 & 0.99823 & 0.00083 & 0.00022 & 0.00118 & 0.18743 \\
\hline $\mathrm{MCF}$ & 0.99797 & 0.00157 & 0.99890 & 0.00157 & -0.00093 & 0.00222 & 0.41886 \\
\hline $\mathrm{MCT}$ & 0.99811 & 0.00087 & 0.99916 & 0.00087 & -0.00105 & 0.00123 & 0.85340 \\
\hline MST & 0.99354 & 0.00157 & 0.99839 & 0.00158 & -0.00485 & 0.00223 & 2.17743 \\
\hline PMF & 0.99942 & 0.00062 & 0.99952 & 0.00062 & -0.00010 & 0.00088 & 0.11405 \\
\hline PST & 0.99772 & 0.00055 & 1.00301 & 0.00056 & -0.00529 & 0.00079 & 6.73954 \\
\hline UCT & 0.99818 & 0.00140 & 1.00080 & 0.00141 & -0.00262 & 0.00199 & 1.31858 \\
\hline UMF & 0.99860 & 0.00051 & 0.99845 & 0.00051 & 0.00015 & 0.00072 & 0.20797 \\
\hline USI & 0.97945 & 0.00123 & 0.98275 & 0.00124 & -0.00330 & 0.00174 & 1.88942 \\
\hline USM & 0.97546 & 0.00214 & 0.97901 & 0.00215 & -0.00355 & 0.00303 & 1.17027 \\
\hline UST & 0.99750 & 0.00052 & 1.00016 & 0.00052 & -0.00266 & 0.00074 & 3.61712 \\
\hline
\end{tabular}

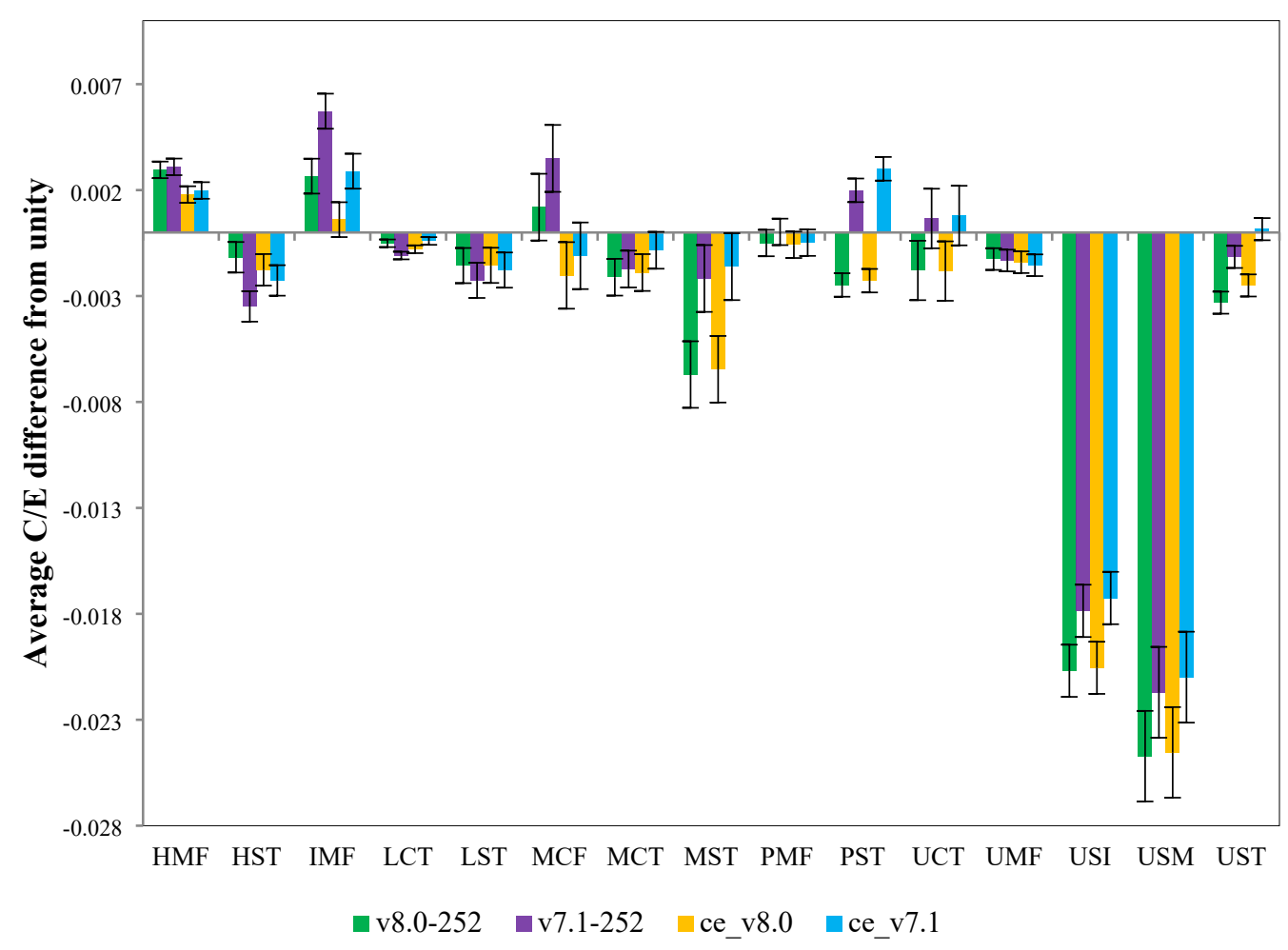

Figure 1. Absolute bias for all four libraries for each of the 15 categories of experiments.

For the 252-group ENDF/B-VIII.0 library, the largest absolute bias occurs for the USM systems and is $-2.47 \% \Delta k$. The second largest bias is for the USI systems with a bias of $-2.07 \% \Delta k$. The next largest bias is $-0.67 \% \Delta k$ for the MST systems. For the 252-group ENDF/B-VII.1 library, the largest absolute bias occurs for the USM systems and is $-2.17 \% \Delta k$. The second largest bias is for the USI systems with a bias of $-1.79 \% \Delta k$. The next largest bias is $0.57 \% \Delta k$ for the IMF systems. The largest absolute difference between the ENDF/B-VIII.0 and -VII.1 results occurs for the MST systems and is $-0.453 \% \Delta k$. The second largest difference is for the PST systems with a difference of $-0.447 \% \Delta k$. The next largest 
difference is $-0.31 \% \Delta k$ for the IMF systems. There is a decrease in the $\mathrm{C} / \mathrm{E}$ values for all 252-group comparisons between ENDF/B-VIII.0 and -VII.1, except for HST, LCT, LST, and UMF in which the C/E values have increased. Of these differences, six-HST, IMF, LCT, MST, PST, and UST-are statistically significant and have differences greater than $2 \sigma$ with the $\mathrm{C} / \mathrm{E}$ values moving closer to unity for HST, IMF, and LCT and further away for MST, PST, and UST. Three additional differences-MCF, UCT, and USI - were between 1 and $2 \sigma$ and all had C/E values moving further away from unity. The remaining six systems had differences of less than $1 \sigma$. Of those, three- HMF, LST, and UMF-had $\mathrm{C} / \mathrm{E}$ values moving closer to unity with the remaining three-MCT, PMF, and USM-moving further away. There are no cross section processing differences between ENDF/B-VIII.0 and -VII.1; the only differences are in the data.

For the CE ENDF/B-VIII.0 library, the largest absolute bias also occurs for the USM systems and is $-2.45 \% \Delta k$. The second largest bias is for the USI systems with a bias of $-2.06 \% \Delta k$. The next largest bias is $-0.65 \% \Delta k$ for the MST systems. For the CE ENDF/B-VII.1 library, the largest absolute bias also occurs for the USM systems and is $-2.10 \% \Delta k$. The second largest bias is for the USI systems with a bias of $-1.73 \% \Delta k$. The next largest bias is $0.30 \% \Delta k$ for the PST systems. The largest absolute difference between the ENDF/B-VIII.0 and -VII.1 results occurs for the PST systems and is $-0.53 \% \Delta k$. The second largest difference is for the MST systems with a difference of $-0.48 \% \Delta k$. The next largest difference is $-0.36 \% \Delta k$ for the USM systems. Again, C/E values decrease in all CE comparisons between ENDF/BVIII.0 and -VII.1, except for HST, LST, and UMF in which the C/E values have increased. Of these differences, only three-MST, PST, and UST — are statistically significant, resulting in C/E values moving further away from unity, and PST systems have the largest difference of any system for either MG or CE libraries. There are five additional differences - IMF, LCT, UCT, USI, and USM-between 1 and $2 \sigma$, and only IMF has a difference moving closer to unity. The remaining seven systems- HMF, HST, LST, MCF, MCT, PMF, and UMF - had differences less than $2 \sigma$, and only HMF, HST, LST, and $\mathrm{UMF}$ have $\mathrm{C} / \mathrm{E}$ values moving closer to unity.

Generally, there is a trend for the C/E values to decrease between ENDF/B-VII.1 to -VIII.0. This indicates that there have been several adjustments to the cross sections between libraries, which are especially noticeable in the mixed, plutonium, and ${ }^{233} \mathrm{U}$ systems. These adjustments will become more noticeable in the following subsections in which each category details the $\mathrm{C} / \mathrm{E}$ values and the benchmark $k_{\text {eff }}$ uncertainty, as reported by the ICSBEP Handbook. In the C/E figures, the reported benchmark uncertainty for each case is shown as dotted lines.

\subsubsection{HMF Systems}

The C/E data for the HMF systems are presented in Figure 2 for the ENDF/B-VIII.0 and -VII.1 libraries. All four libraries are generally in good agreement with each other, except for HMF-021and -021S, which is a steel-reflected HEU sphere. The ENDF/B-VIII.0 changes to the ${ }^{56} \mathrm{Fe}$ cross sections have resulted in a positive bias for both $\mathrm{CE}$ and $\mathrm{MG}$ calculations, causing $\mathrm{C} / \mathrm{E}$ values to move closer to unity for $\mathrm{CE}$ results and proportionally further away with the MG results. The new ENDF/B-VIII.0 evaluation indicates that several changes have occurred for ${ }^{56} \mathrm{Fe}$ cross sections in the resolved resonance region (EALF range for HMF systems ranging from 119.524 to $842.025 \mathrm{keV}$ ), including an adoption of the evaluated resonances from JENDL-4.0 [12] up to an incident energy of $850 \mathrm{keV}$, changing the $767.240 \mathrm{keV}$ resonance to $766.724 \mathrm{keV}$, and reducing the background around $800 \mathrm{keV}$ by $40 \%$ [1]. 


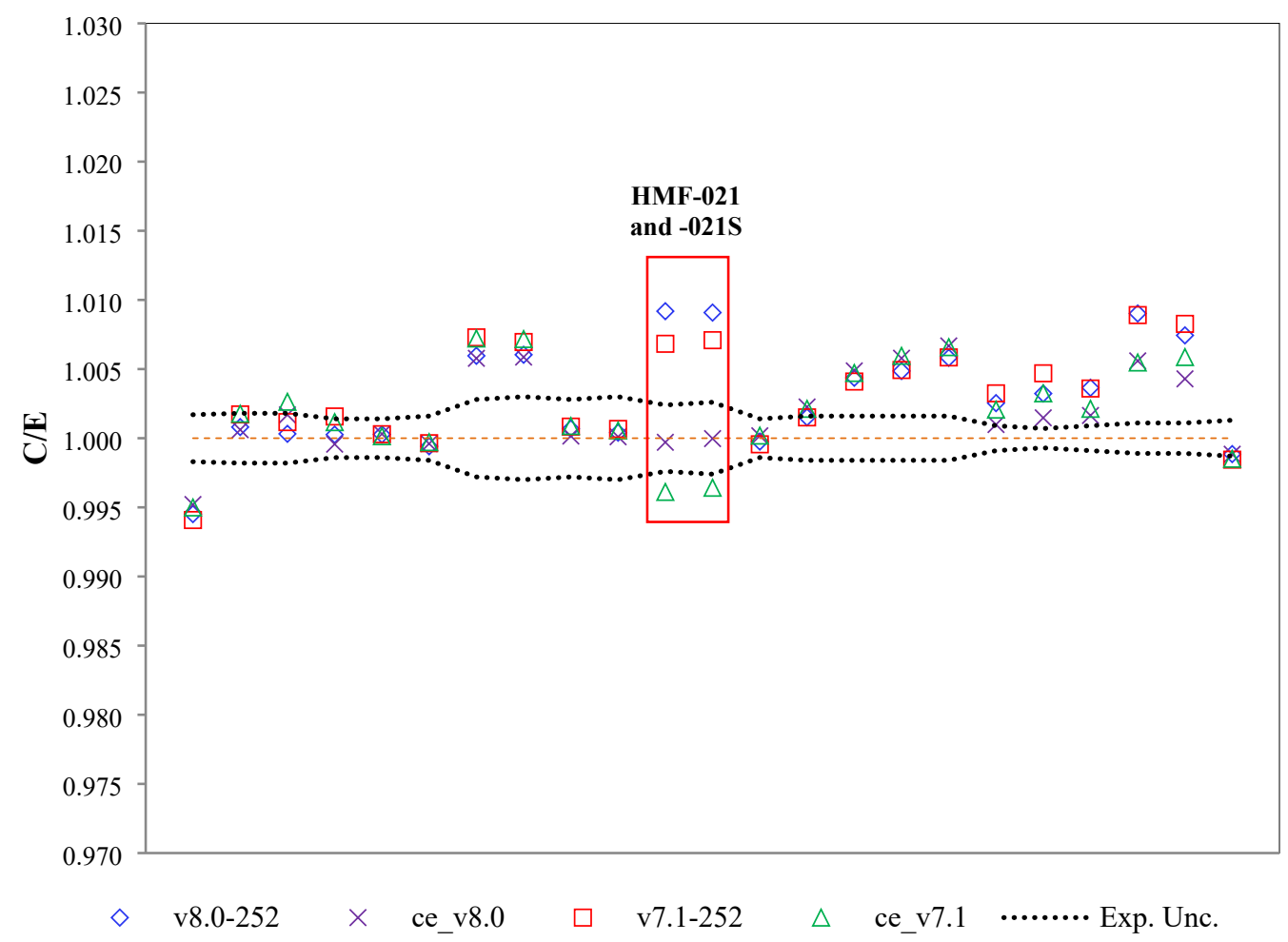

Figure 2. C/E results for libraries based on ENDF/B-VII.1 and -VIII.0 for the HMF systems.

The $\mathrm{C} / \mathrm{E}$ data are also compared against the $1 \sigma$ experimental uncertainty bands with $47.8 \%$ of the ENDF/B-VIII.0 CE library results and $30.4 \%$ of the ENDF/B-VII.1 CE library results falling within the band. These results are similar for the MG libraries in which 44 and $35 \%$ of the points are in the band for the 252-group ENDF/B-VIII.0 and -VII.1 libraries, respectively.

\subsubsection{HST Systems}

The C/E data for the HST systems are shown in Figure 3 for the ENDF/B-VIII.0 and -VII.1 libraries. Agreement between all libraries is generally good; however, as noted in Tables 4 and 5, the ENDF/BVIII.0 libraries are consistently higher than the ENDF/B-VII.1 libraries with the 252-group ENDF/BVIII.0 library values being the highest. The HST-014 and -016 cases, which contain soluble gadolinium poison, continue to be outliers for this system group and are discussed in the SCALE 6.1 and 6.2.2 validation reports $[8,9]$. 


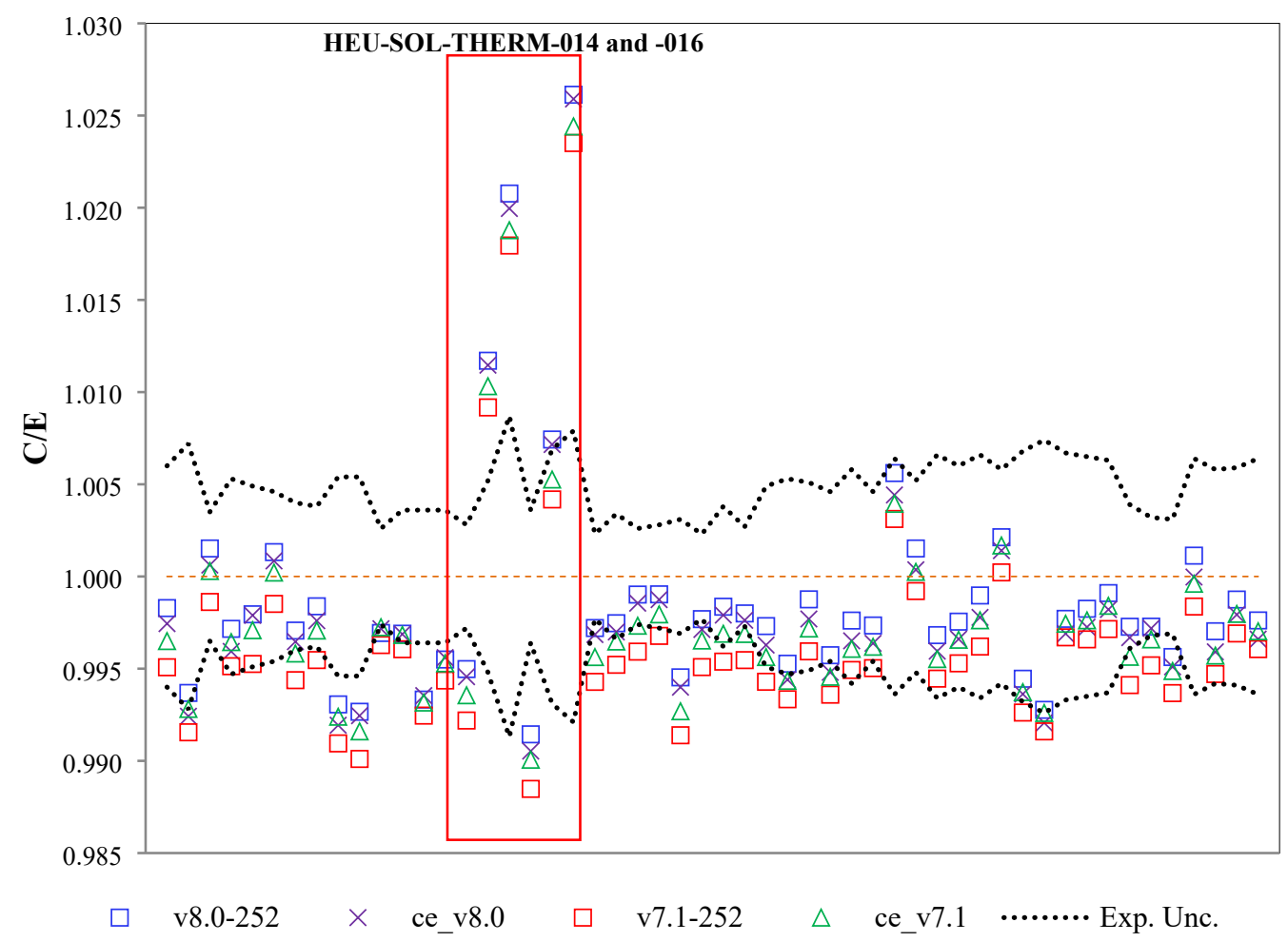

Figure 3. C/E results for libraries based on ENDF/B-VII.1 and -VIII.0 for the HST systems.

The C/E data for all HST cases are also compared against the experimental uncertainty bands with $66.0 \%$ of the ENDF/B-VIII.0 CE library results and $55.8 \%$ of the ENDF/B-VII.1 CE library results falling within the band. For the MG libraries, approximately 71 and $40 \%$ of the points are in the band for the 252-group ENDF/B-VIII.0 and -VII.1 libraries, respectively.

\subsubsection{IMF Systems}

The C/E data for the IMF systems are shown in Figure 4 for the ENDF/B-VIII.0 and -VII.1 libraries. The ENDF/B-VIII.0 values are consistently lower than the ENDF/B-VII.1 values with the largest differences for IMF-005 and -005S. This particular system has a thick steel reflector and provides similar results to those of HMF-021. 


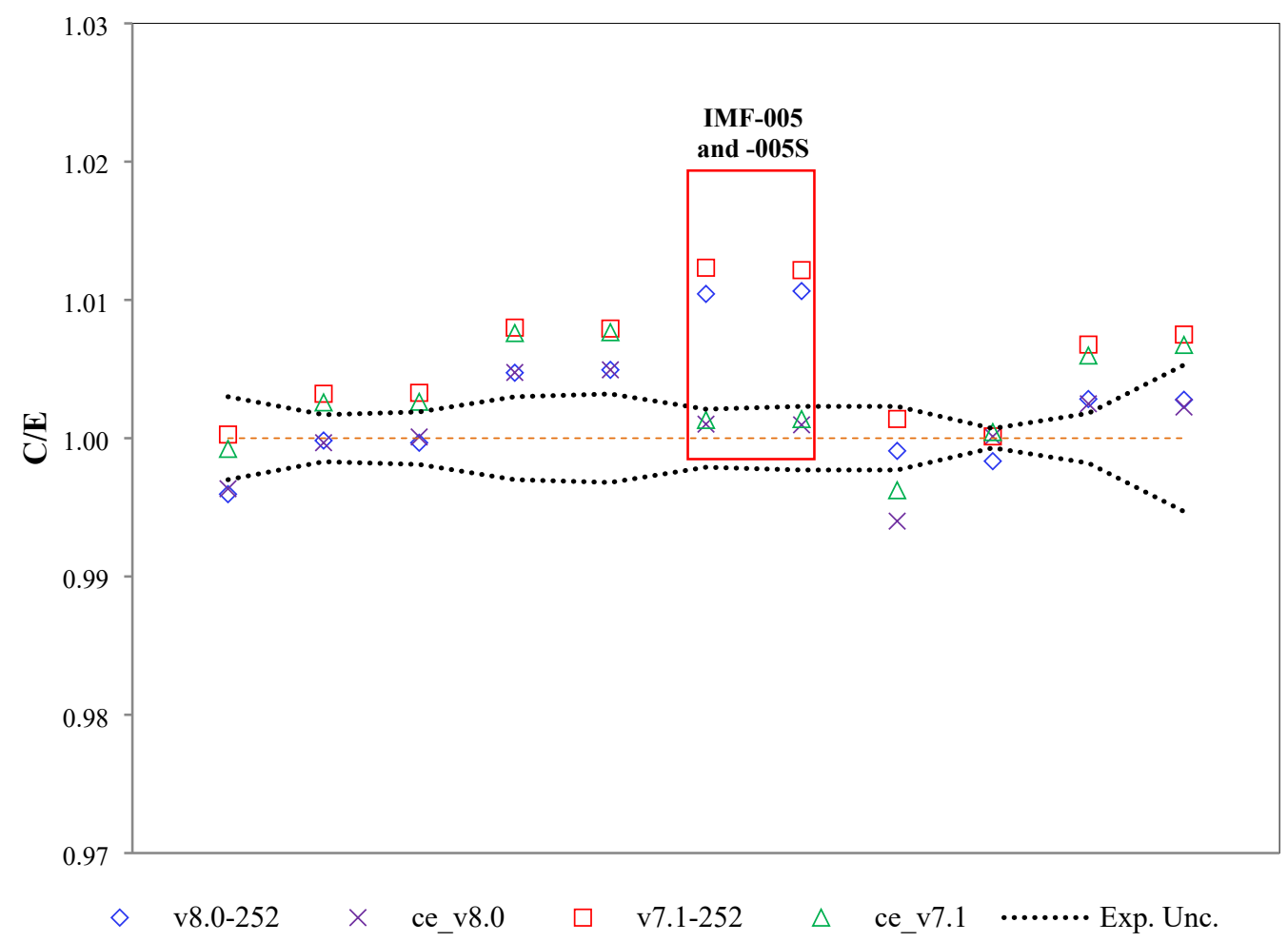

Figure 4. C/E results for libraries based on ENDF/B-VII.1 and -VIII.0 for the IMF systems.

The $\mathrm{C} / \mathrm{E}$ data for all IMF cases are also compared against the experimental uncertainty bands with 54.5\% of the ENDF/B-VIII.0 CE library results and $36.4 \%$ of the ENDF/B-VII.1 CE library results falling within the band. For the MG libraries, approximately 36 and $27 \%$ of the points are in the band for the 252-group ENDF/B-VIII.0 and -VII.1 libraries, respectively.

\subsubsection{LCT Systems}

The C/E data for the LCT systems are shown in Figure 5 for the ENDF/B-VIII.0 and -VII.1 libraries. The data generally demonstrate consistent performance between all libraries. However, as observed in Tables 4 and 5, the ENDF/B-VIII.0 CE values are generally lower than the ENDF/B-VII.1 CE values, and the ENDF/B-VIII.0 MG values are generally higher than the ENDF/B-VII.1 MG values. As noted in the SCALE 6.2.2 validation report, the cases from LCT-078 and -080 are the most consistent with all experiments completed with the same equipment at the same location [8]. There are two CE groups of experiments with largely noticeable differences between ENDF/B-VIII.0 and -VII: LCT-010-014 to -30 and LCT-078 and -080, as noted in Figure 5. Marshall notes that these differences could be attributed to a reduction of pitch between fuel rods that creates less moderation and shifts the neutron energy spectrum. This harder energy spectrum results in a more negative bias with ENDF/B-VIII.0 results as compared with -VII.1 [13]. Trkov also specifically indicates that the lower C/E values for LCT-078 and -080 could be caused by the changes in ${ }^{16} \mathrm{O}$, as introduced in ENDF/B-VIII.0 [14]. 


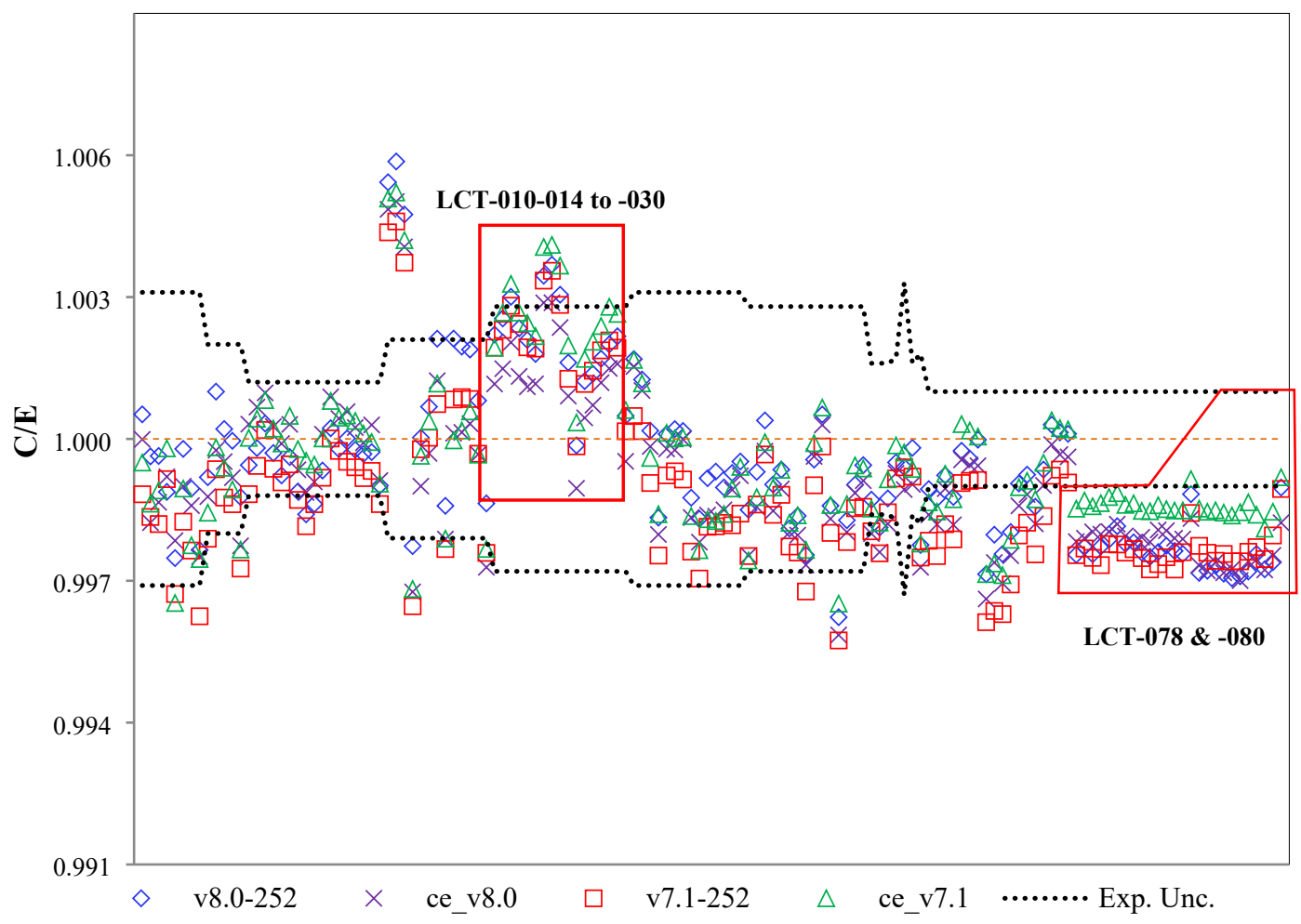

Figure 5. C/E results for libraries based on ENDF/B-VII.1 and -VIII.0 for the LCT systems.

The C/E data for all LCT cases are also compared against the experimental uncertainty bands with $65 \%$ of the ENDF/B-VIII.0 CE library results and $65.7 \%$ of the ENDF/B-VII.1 CE library results falling within the band. For the MG libraries, approximately 65 and $56 \%$ of the points are in the band for the 252-group ENDF/B-VIII.0 and -VII.1 libraries, respectively.

\subsubsection{LST Systems}

The C/E data for the LST systems are shown in Error! Reference source not found. for the ENDF/BVIII.0 and -VII.1 libraries. The data show consistent performance between all libraries, and the ENDF/BVIII.0 values tend to be higher than the ENDF/B-VII.1 values for CE and MG. 


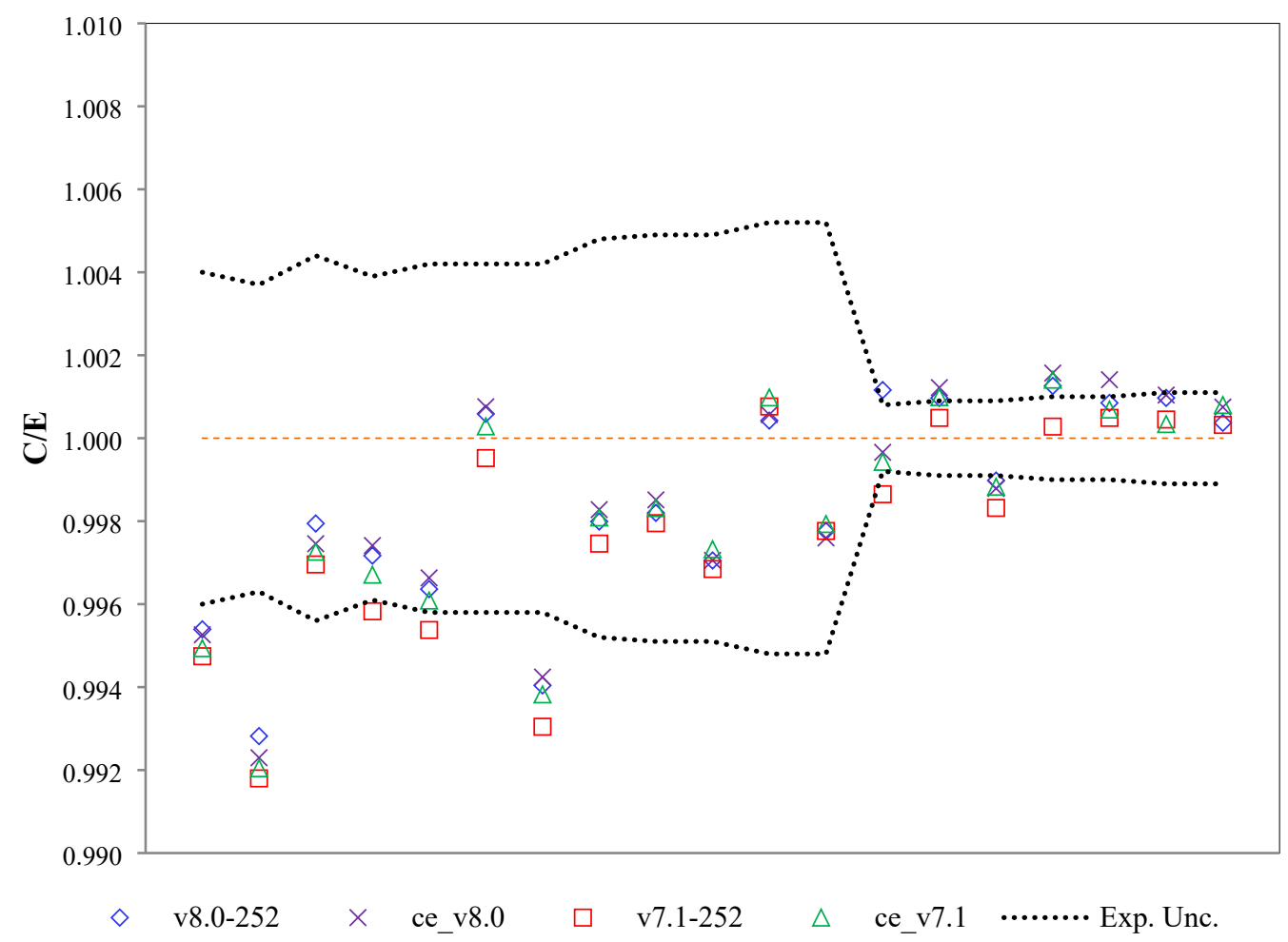

Figure 6. C/E results for libraries based on ENDF/B-VII.1 and -VIII.0 for the LST systems.

The C/E data for all LST cases are also compared against the experimental uncertainty bands with $63.2 \%$ of the ENDF/B-VIII.0 CE library results and $68.4 \%$ of the ENDF/B-VII.1 CE library results falling within the band. For the MG libraries, approximately $63 \%$ of the points are in the band for the 252-group ENDF/B-VIII.0 and -VII.1 libraries.

\subsubsection{MCF Systems}

The C/E data for the MCF systems are shown in Figure 7 for the ENDF/B-VIII.0 and -VII.1 libraries. With only two cases, generalizations on tendencies between libraries and comparisons with the experimental uncertainty data are not attempted. 


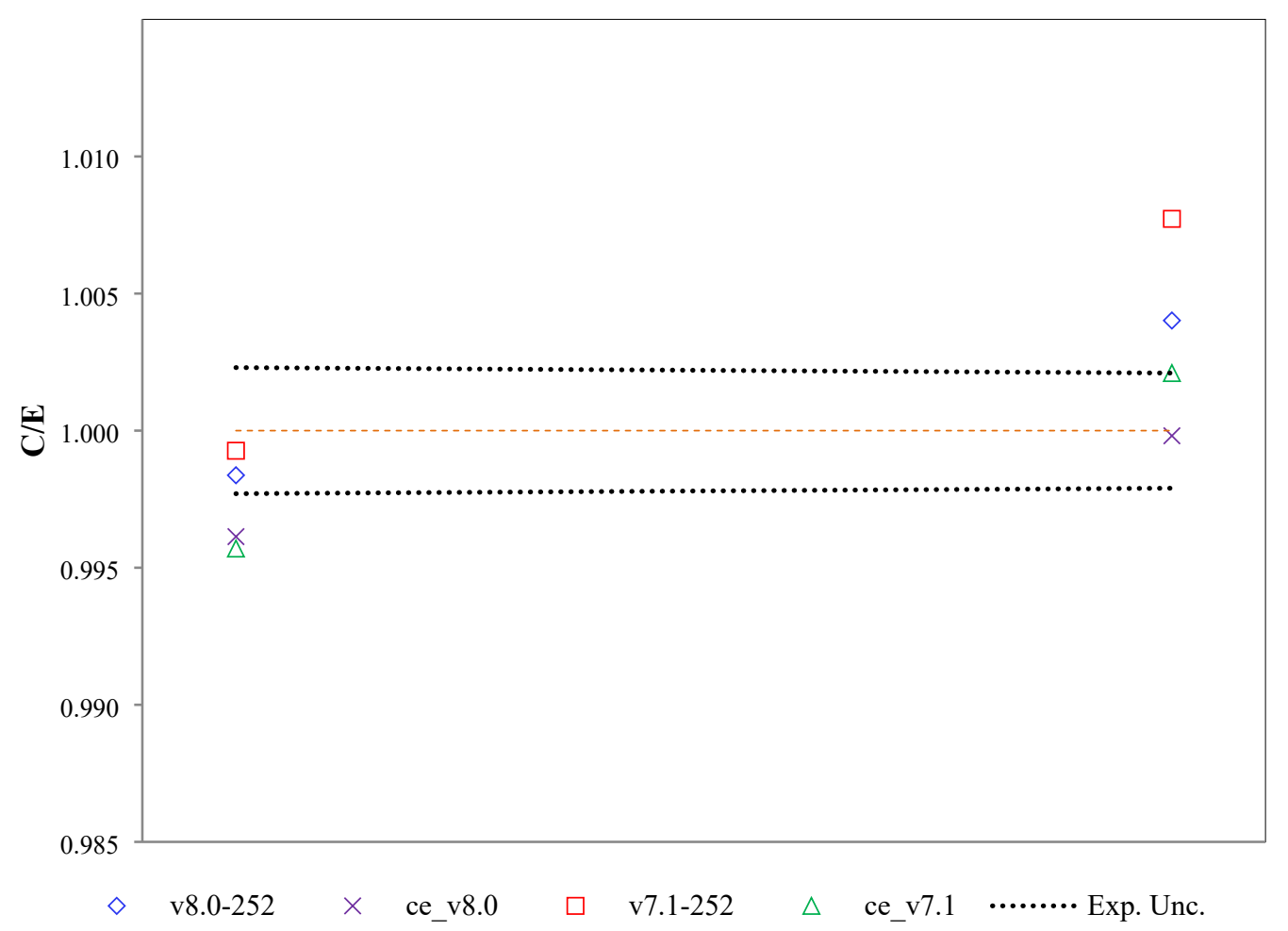

Figure 7. C/E results for libraries based on ENDF/B-VII.1 and -VIII.0 for the MCF systems.

\subsubsection{MCT Systems}

The $\mathrm{C} / \mathrm{E}$ data for the MCT systems are shown in Figure 8 for the ENDF/B-VIII.0 and -VII.1 libraries. The agreement generally varies by experiment group between the two library sets. For MCT-002, as the fuel-rod pitch increases, the ENDF/B-VIII.0 C/E values change from larger than ENDF/B-VII.1 values to smaller. Although the MCT-004 ENDF/B-VII.1 values approach unity as the fuel-rod pitch increases from case 1 to 11, the ENDF/B-VIII.0 C/E values are noticeably lower and only slightly increase in C/E towards unity. This could be a function of the pitch increases or possible changes to the plutonium cross sections present in the ENDF/B-VIII.0 library. One goal of the new ENDF/B-VIII.0 evaluation was to correct the approximately $500 \mathrm{pcm}\left(0.5 \%\right.$ in $\left.k_{\text {eff }}\right)$ overprediction of thermal plutonium solution criticality. This resulted in the adoption of previous Nuclear Energy Agency Working Party on International Nuclear Data Evaluation Co-operation (WPEC) Subgroup 34 collaboration work on resonances and prompt nubar updates, as well as influences from the ${ }^{16} \mathrm{O}$ evaluation changes and new scattering kernels recommended by WPEC/Subgroup 42 [1]. As an unintended consequence, the poor performance of these systems, such as MCT-004, may be directly attributed to these changes in cross section data. 


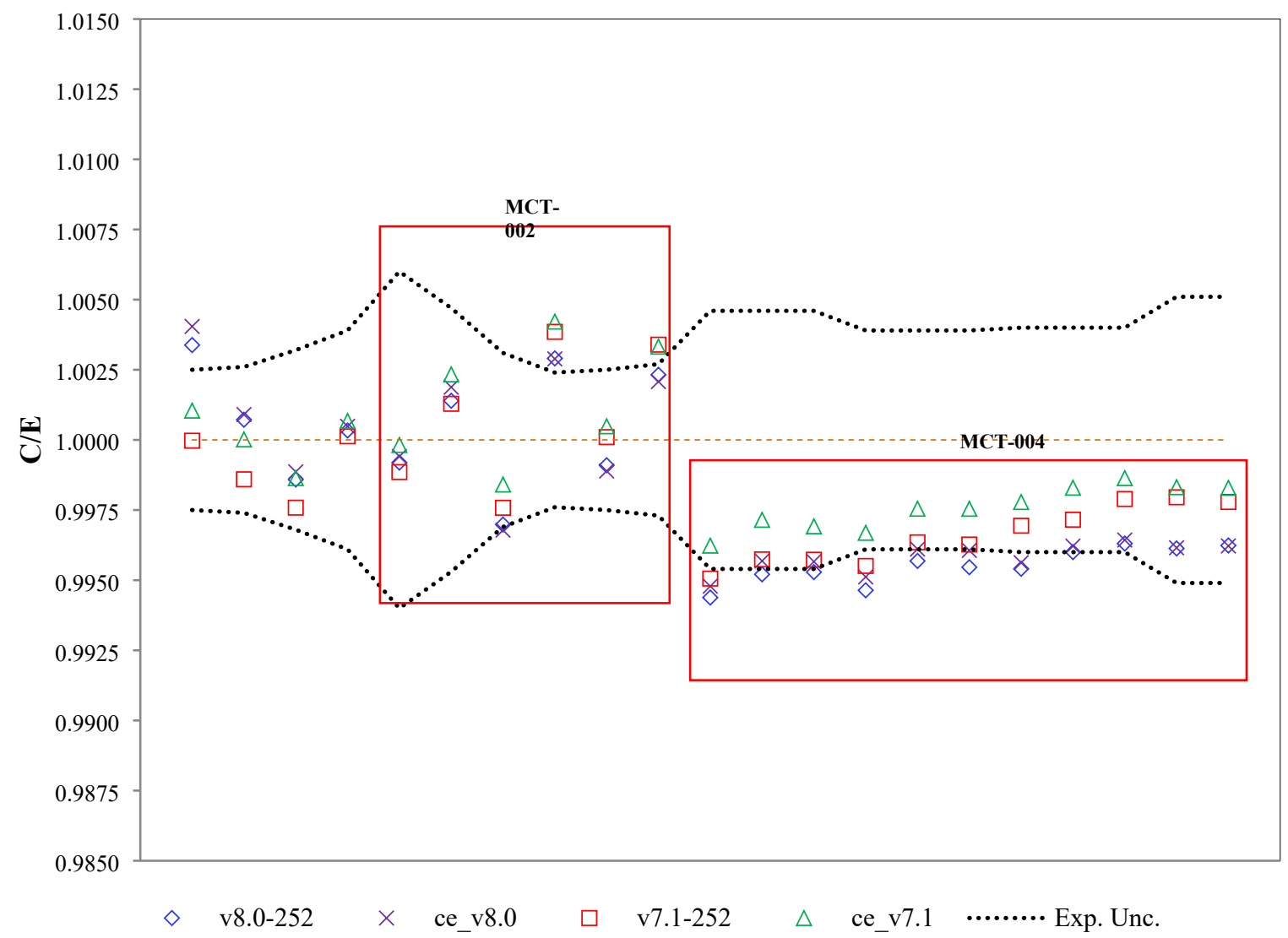

Figure 8. C/E results for libraries based on ENDF/B-VII.1 and -VIII.0 for the MCT systems.

The $\mathrm{C} / \mathrm{E}$ data for all MCT cases are also compared against the experimental uncertainty bands with $66.7 \%$ of the ENDF/B-VIII.0 CE library results and $90.5 \%$ of the ENDF/B-VII.1 CE library results falling within the band. For the MG libraries, approximately 57 and $81 \%$ of the points are in the band for the 252-group ENDF/B-VIII.0 and -VII.1 libraries, respectively. This indicates that there was a clear alteration of the plutonium cross sections based on the minimal differences of the ${ }^{235} \mathrm{U}$ cross sections, as indicated in LEU categories (Figure 1, Tables 4 and 5), which lead to fewer ENDF/B-VIII.0 values falling within the experimental uncertainty bands.

\subsubsection{MST Systems}

The C/E data for the MST systems are shown in Figure 9 for the ENDF/B-VIII.0 and -VII.1 libraries. There is a clear trend that CE and MG ENDF/B-VIII.0 C/E values are noticeably lower than the ENDF/BVII.1 C/E values. As noted subsection 4.1.7 (MCT Systems), the plutonium cross sections were adjusted to lower reactivity, and due to the high amounts of ${ }^{239} \mathrm{Pu}$ compared with ${ }^{235} \mathrm{U}$ in these systems, the lower $\mathrm{C} / \mathrm{E}$ values are quite noticeable and were somewhat expected. 


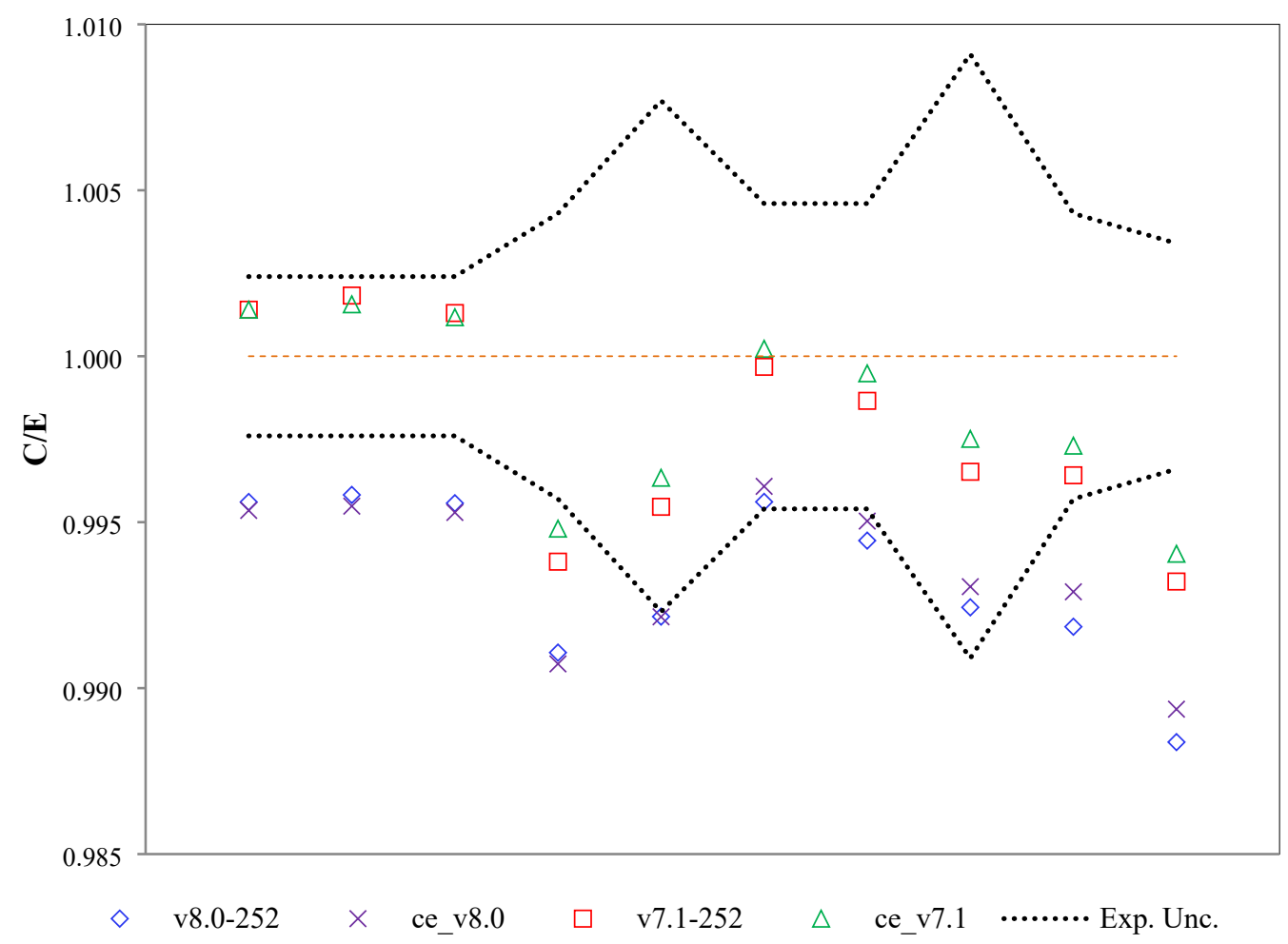

Figure 9. C/E results for libraries based on ENDF/B-VII.1 and -VIII.0 for the MST systems.

The C/E data for all MST cases are also compared against the experimental uncertainty bands with 20\% of the ENDF/B-VIII.0 CE library results and $80 \%$ of the ENDF/B-VII.1 CE library results falling within the band. For the MG libraries, approximately 20 and $80 \%$ of the points are in the band for the 252-group ENDF/B-VIII.0 and -VII.1 libraries, respectively. As noted in Figure 9, the systematic changes in the nuclear data for ${ }^{239} \mathrm{Pu}$ negatively impacted the $\mathrm{C} / \mathrm{E}$ values for these systems, which is consistent across all 10 cases.

\subsubsection{PMF Systems}

The C/E data for the PMF systems are shown in Figure 10 for the ENDF/B-VIII.0 and -VII.1 libraries. The ENDF/B-VIII.0 values are generally lower than the ENDF/B-VII.1 values for both libraries, except for PMF-002-001, -025-001, and -026-001. PMF-002-001 is a $20.1 \mathrm{wt} \%{ }^{240} \mathrm{Pu}$ system, and the fission and capture cross sections for systems of this energy spectrum (EALF of approximately $1.3 \mathrm{MeV}$ ) were replaced by the Weston evaluation from ENDF/B-VI.8 [1], which has lowered the capture cross section by about $5 \%$ with an additional $2.5 \%$ reduction in the unresolved resonance range (above $42 \mathrm{keV}$ ). PMF-025-001 has a thin iron reflector that appears to have a much smaller impact on the C/E value of the system. PMF-026-001 has a thick steel reflector and a comparable large spread in C/E values with HMF021. The trend of ENDF/B-VIII.0 plutonium cross section adjustments continues to be prevalent in these results; however, the differences are not as large as those for the mixed systems. 


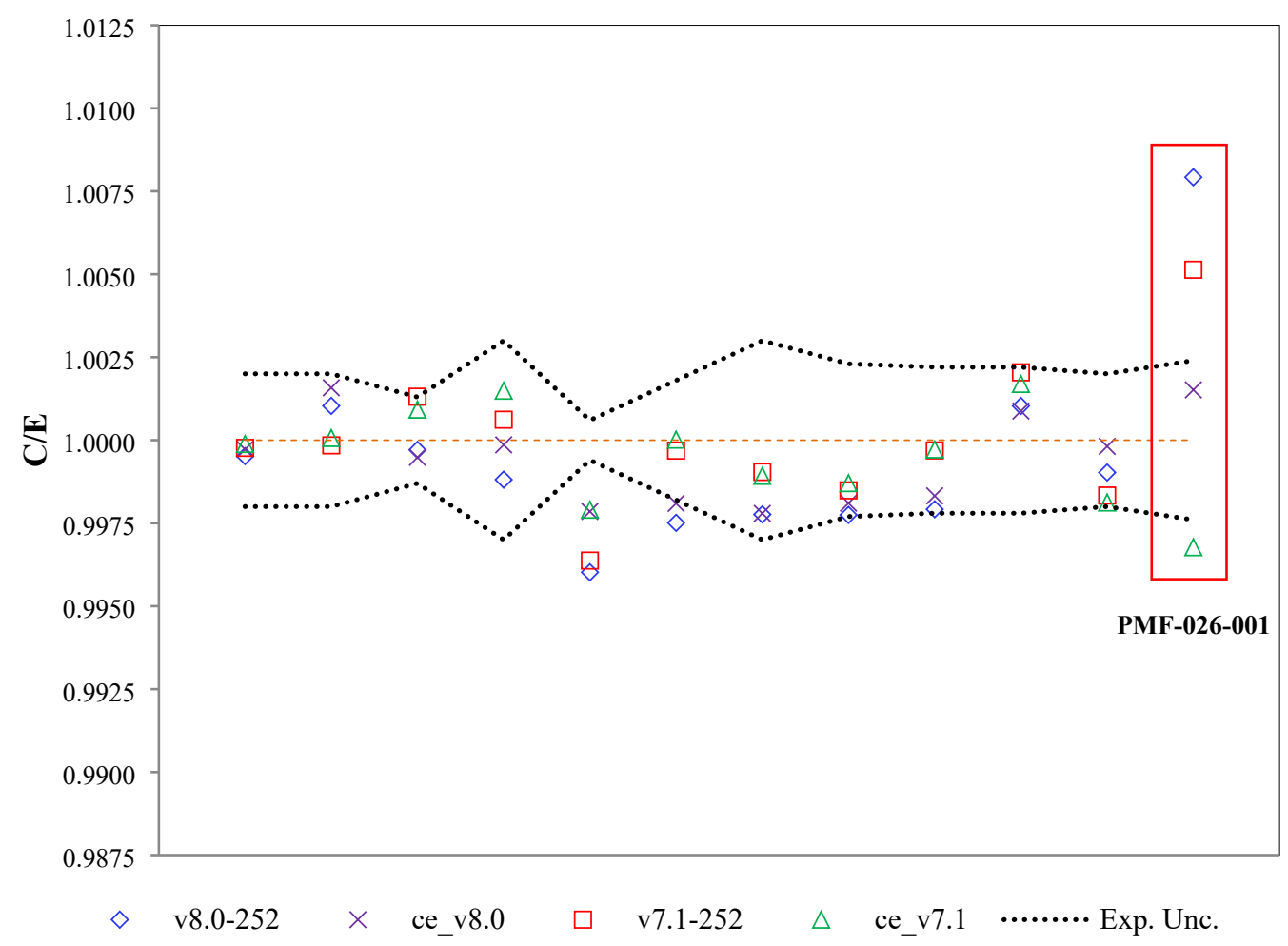

Figure 10. C/E results for libraries based on ENDF/B-VII.1 and -VIII.0 for the PMF systems.

The $\mathrm{C} / \mathrm{E}$ data for all PMF cases are also compared against the experimental uncertainty bands with $83.3 \%$ of the ENDF/B-VIII.0 and -VII.1 CE library results falling within the band. For the MG libraries, approximately $75 \%$ of the points fall in the band for both the 252-group ENDF/B-VIII.0 and -VII.1 libraries.

\subsubsection{PST Systems}

The C/E data for the PST systems are shown in Figure 11 for the ENDF/B-VIII.0 and -VII.1 libraries. The data demonstrate consistent lower values for the ENDF/B-VIII.0 libraries compared with those with ENDF/B-VII.1. The average bias difference between the CE libraries is approximately $530 \mathrm{pcm}$ and for the MG libraries is approximately $450 \mathrm{pcm}$. This is the largest bias difference between CE libraries observed in all system categories and the second largest for the MG libraries. The average bias has decreased from 301 to $228 \mathrm{pcm}$ for $\mathrm{CE}$ cross sections (average $\mathrm{C} / \mathrm{E}$ of 1.00301 for ENDF/B-VII.1 to 0.99772 for ENDF/B-VIII.0), and bias increased from 199 to $248 \mathrm{pcm}$ for the MG cross sections (average C/E of 1.00199 for ENDF/B-VII.1 to 0.99752 for ENDF/B-VIII.0). Although both cross sections manifest a similar negative bias on the resulting $\mathrm{C} / \mathrm{E}$ values, the $\mathrm{CE}$ values have moved slightly closer to unity, whereas the MG values moved further away. 


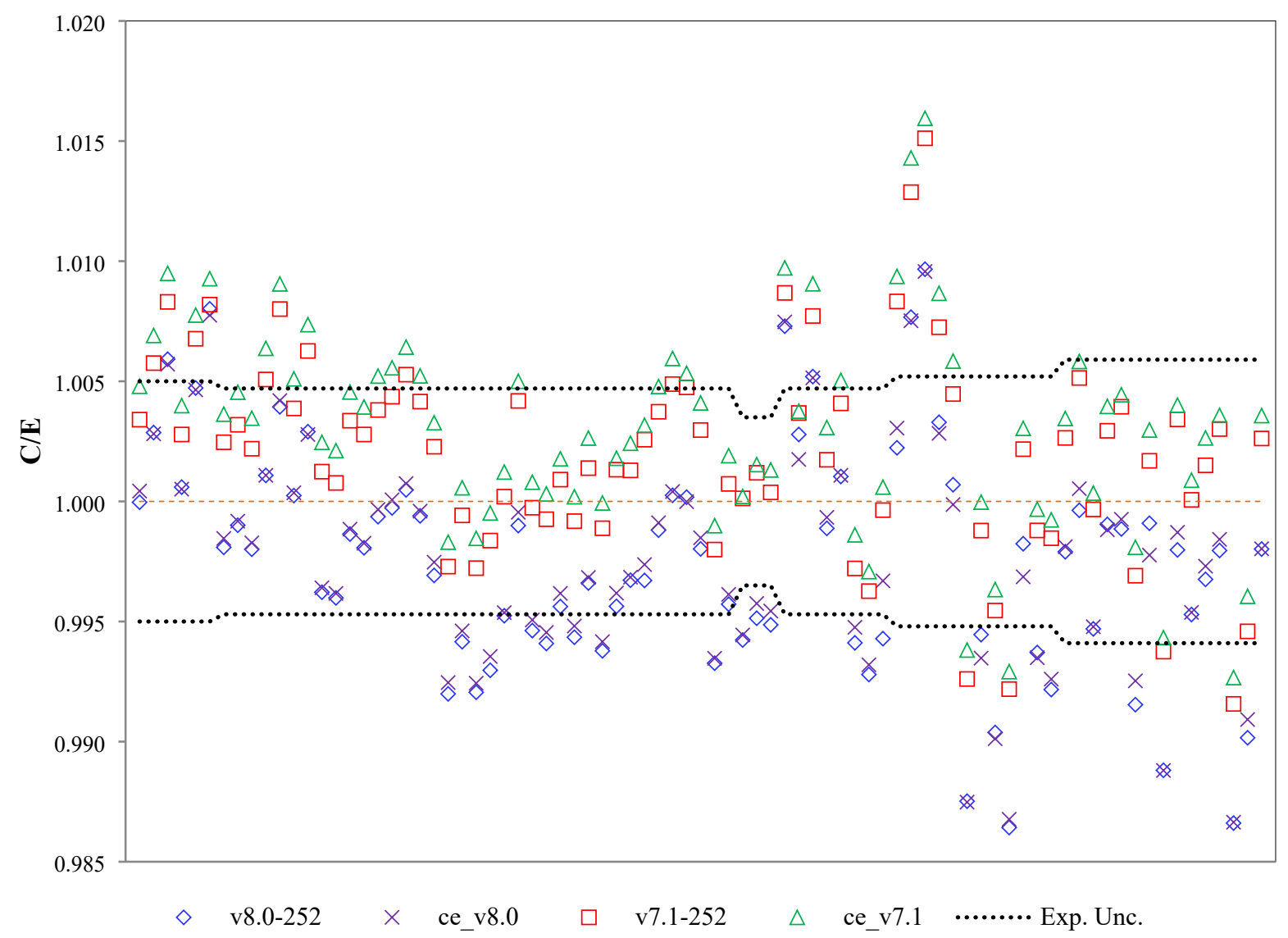

Figure 11. C/E results for libraries based on ENDF/B-VII.1 and -VIII.0 for the PST systems.

The $\mathrm{C} / \mathrm{E}$ data for all PST cases are also compared against the experimental uncertainty bands with $63.0 \%$ of the ENDF/B-VIII.0 CE library results and $66.7 \%$ of the ENDF/B-VII.1 CE library results falling within the band. For the MG libraries, approximately 61 and $75 \%$ of the points are in the band for the 252-group ENDF/B-VIII.0 and -VII.1 libraries, respectively.

\subsubsection{UCT Systems}

The C/E data for the UCT systems are shown in Figure 12 for the ENDF/B-VIII.0 and -VII.1 libraries. Although there are only three benchmark evaluations to compare, the data demonstrate consistent lower $\mathrm{C} / \mathrm{E}$ values for the ENDF/B-VIII.0 libraries compared with those with ENDF/B-VII.1. ENDF/B-VIII.0 ${ }^{233} \mathrm{U}$ cross sections were built from the JENDL-4.0 evaluation [12] with the gamma and fission widths adjusted to reproduce a thermal constant with the bound level of $-1.7565 \mathrm{eV}$ [1]. These adjustments resulted in increasing the fission cross section and lowering the inelastic and total nubar cross sections. The more negative bias shown in Figure 12 could be a result of these adjustments. 


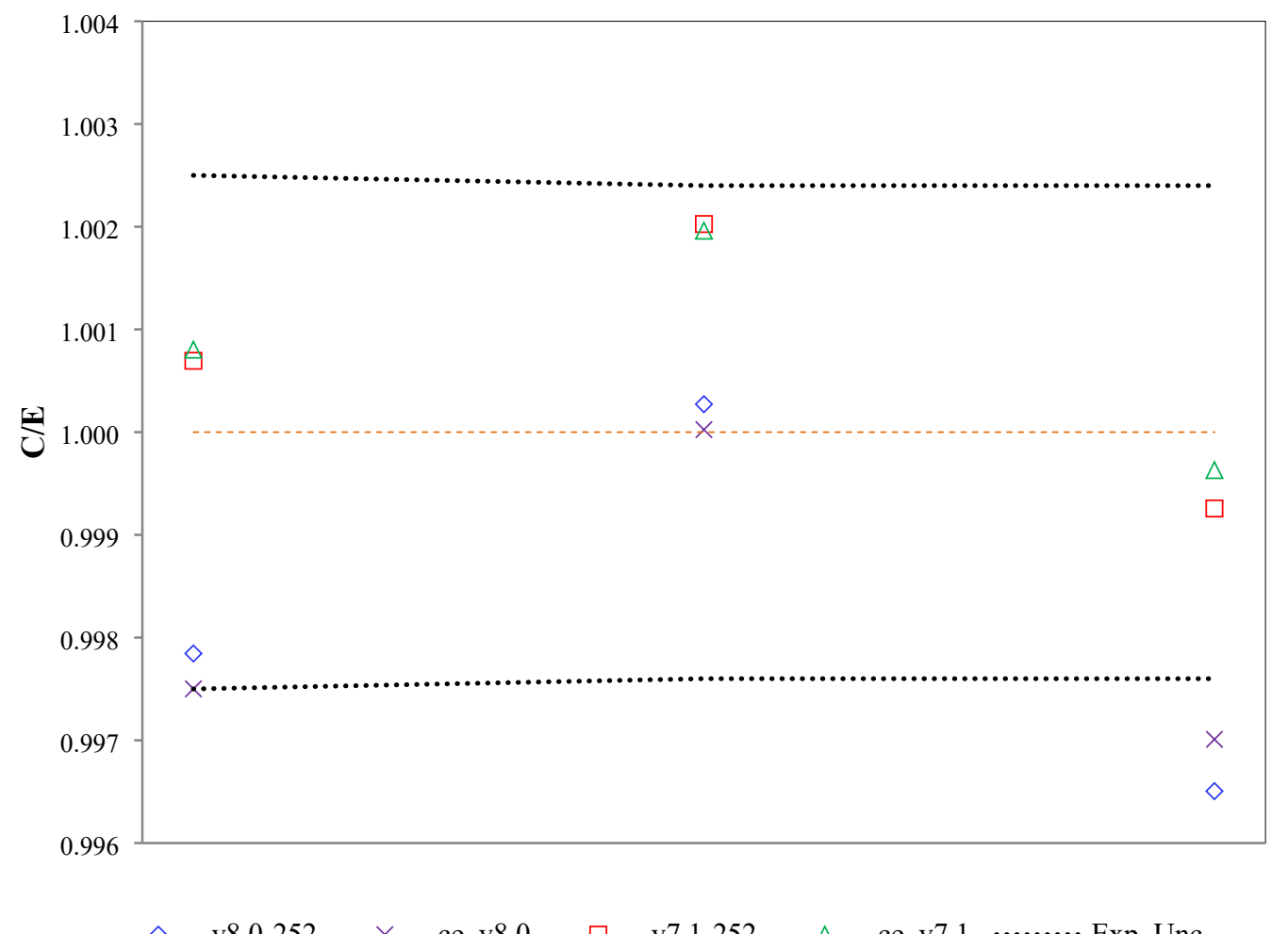

Figure 12. C/E results for libraries based on ENDF/B-VII.1 and -VIII.0 for the UCT systems.

\subsubsection{UMF Systems}

The C/E data for the UMF systems are shown in Figure 13 for the ENDF/B-VIII.0 and -VII.1 libraries. Although there is consistent behavior among all four libraries, there are no general trends as to the individual library results between the two. Four out of the 10 cases have lower ENDF/B-VIII.0 C/E values than ENDF/B-VII.1 values for CE, and four of the 10 cases have lower MG ENDF/B-VIII.0 C/E values than ENDF/B-VII.1 values. These bias differences are on the order of a $7 \mathrm{pcm}$ average for MG libraries and a $14 \mathrm{pcm}$ average for CE libraries - the smallest bias differences between all systems using KENO V.a. These fluctuations could result from various reflecting materials or other cross section adjustments present in ENDF/B-VIII.0. 


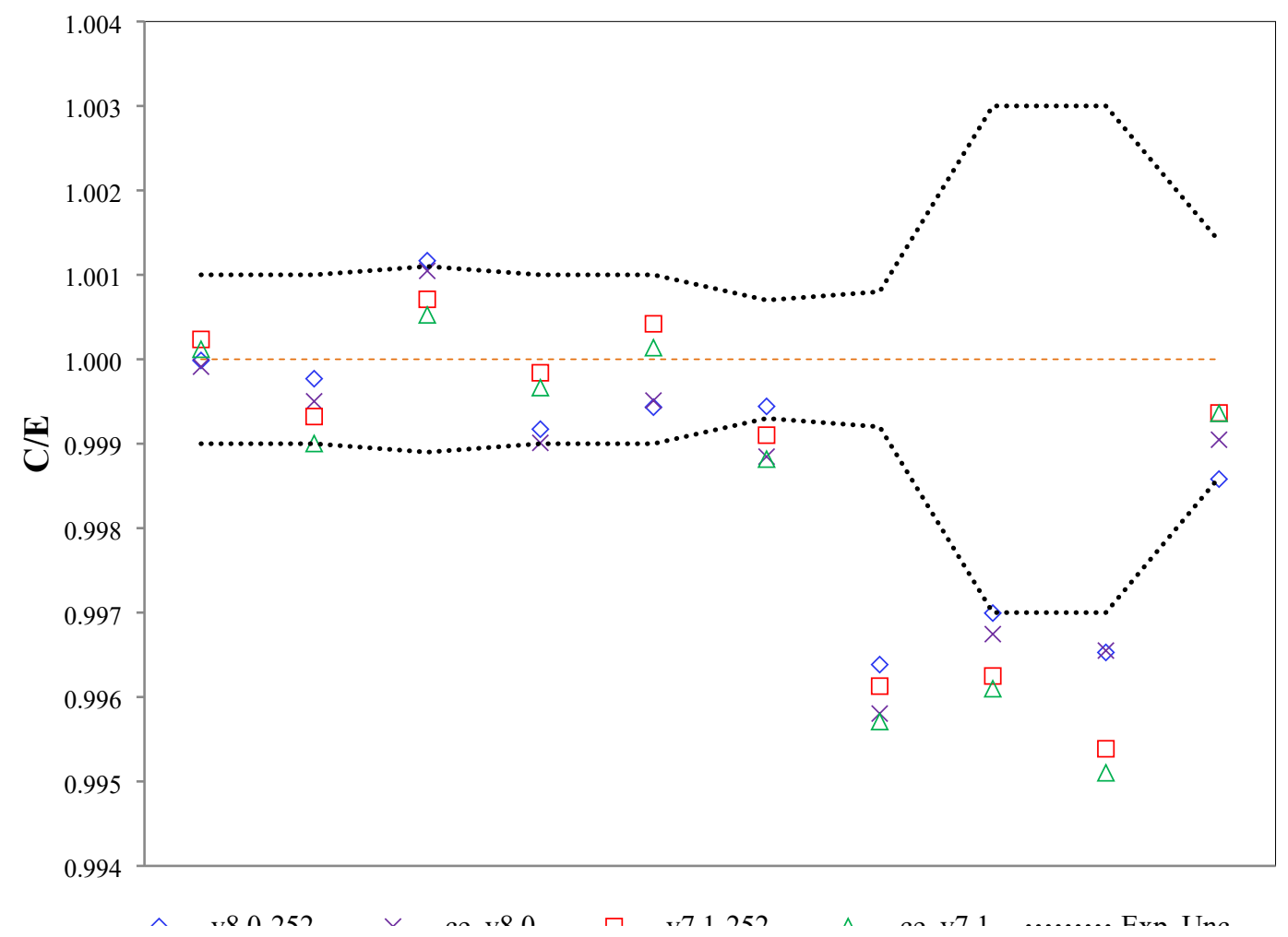

Figure 13. C/E results for libraries based on ENDF/B-VII.1 and -VIII.0 for the UMF systems.

The $\mathrm{C} / \mathrm{E}$ data for all UMF cases are also compared against the experimental uncertainty bands with $60 \%$ of the ENDF/B-VIII.0 and -VII.1 CE library results falling within the band. For the MG libraries, approximately 50 and $60 \%$ of the points are in the band for the 252-group ENDF/B-VIII.0 and -VII.1 libraries, respectively.

\subsubsection{USI Systems}

The C/E data for the USI systems are shown in Figure 14 for the ENDF/B-VIII.0 and -VII.1 libraries. Again, although there is consistent behavior among all four libraries, the data demonstrate lower values for the ENDF/B-VIII.0 libraries as compared with those with ENDF/B-VII.1. There is an average bias difference between the two MG libraries of $280 \mathrm{pcm}$ and an average of $330 \mathrm{pcm}$ between the two CE libraries. All $\mathrm{C} / \mathrm{E}$ values are less than 1.0, underpredicting $k_{\text {eff, }}$ and the differences from unity are significantly larger than most other systems. As noted in the UCT systems, the ${ }^{233} \mathrm{U}$ cross sections have undergone several adjustments that could cause the resulting negative bias. The SCALE 6.2.2 validation report also indicates that there could be inadequacies with the nuclear data for intermediate range energy systems for ENDF/B-VIII.0 and ENDF/B-VII.1 and/or the experiment descriptions for these systems [8]. 


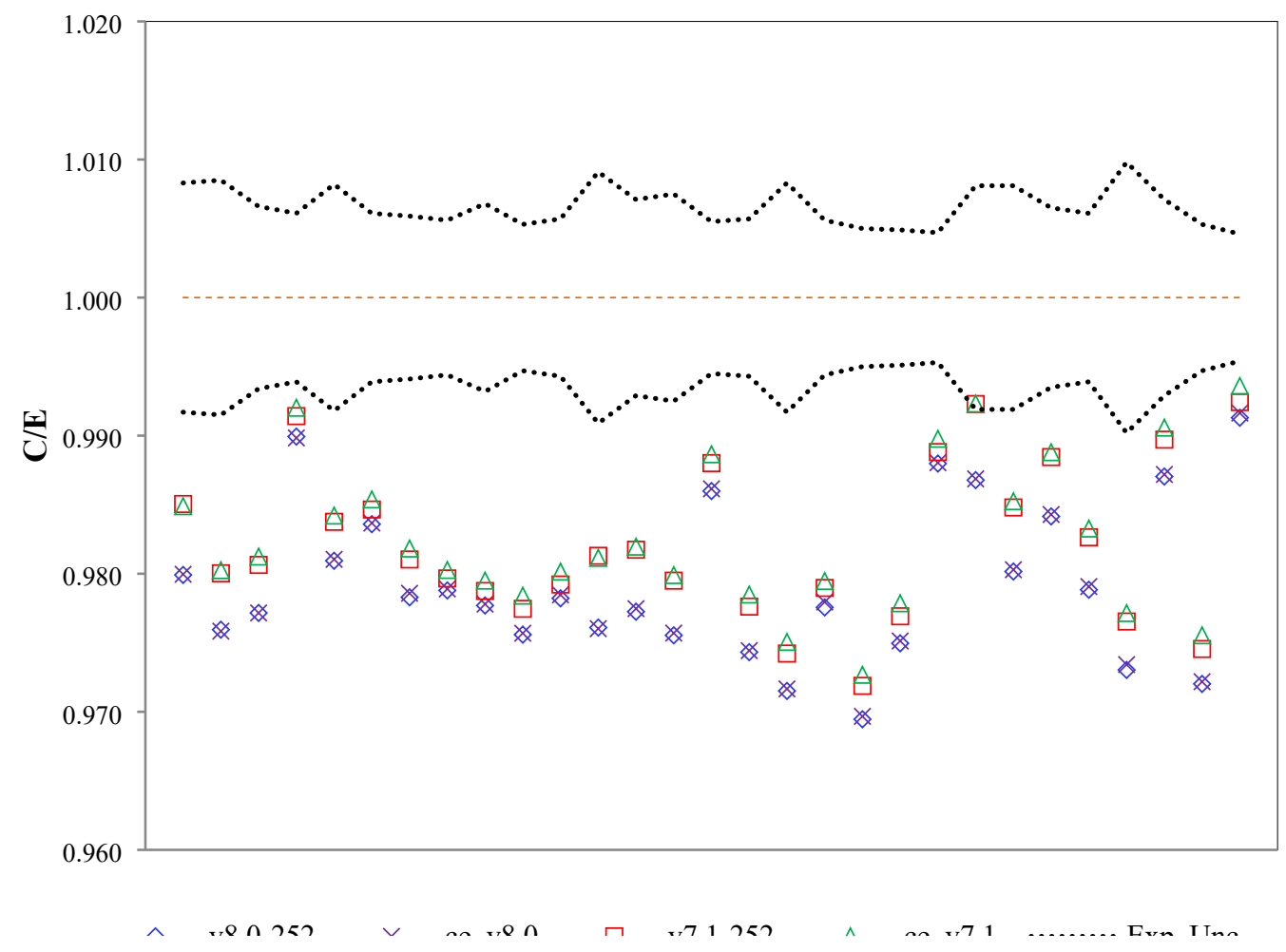

Figure 14. C/E results for libraries based on ENDF/B-VII.1 and -VIII.0 for the USI systems.

The $\mathrm{C} / \mathrm{E}$ data for all USI cases are also compared against the experimental uncertainty bands with $0 \%$ of the ENDF/B-VIII.0 CE library results and 3.4\% of the ENDF/B-VII.1 CE library results falling within the band. For the MG libraries, approximately 0 and $3 \%$ of the points are in the band for the 252-group ENDF/B-VIII.0 and -VII.1 libraries, respectively.

\subsubsection{USM Systems}

The C/E data for the USM systems are shown in Figure 15 for the ENDF/B-VII.0 and -VII.1 libraries. As with the USI data, there is consistent behavior among all four libraries; however, the data demonstrate lower values for the ENDF/B-VIII.0 libraries compared with those for ENDF/B-VII.1. There is an average bias difference between ENDF/B-VIII.0 and ENDF/B-VII.1 values for CE and MG of 360 and $300 \mathrm{pcm}$, respectively. All C/E values are less than 1.0, underpredicting $k_{\text {eff }}$, and the differences from unity are larger than most of the other systems, as was observed with the USI systems. The resulting increase in negative bias is most likely attributed to the changes in the ${ }^{233} \mathrm{U}$ cross sections, as mentioned in Section 4.1.11. The SCALE 6.2.2 report also indicates that there could be inadequacies with the nuclear data for mixed energy systems for both ENDF/B-VIII.0 and ENDF/B-VII.1 and/or the experiment descriptions for these systems. 


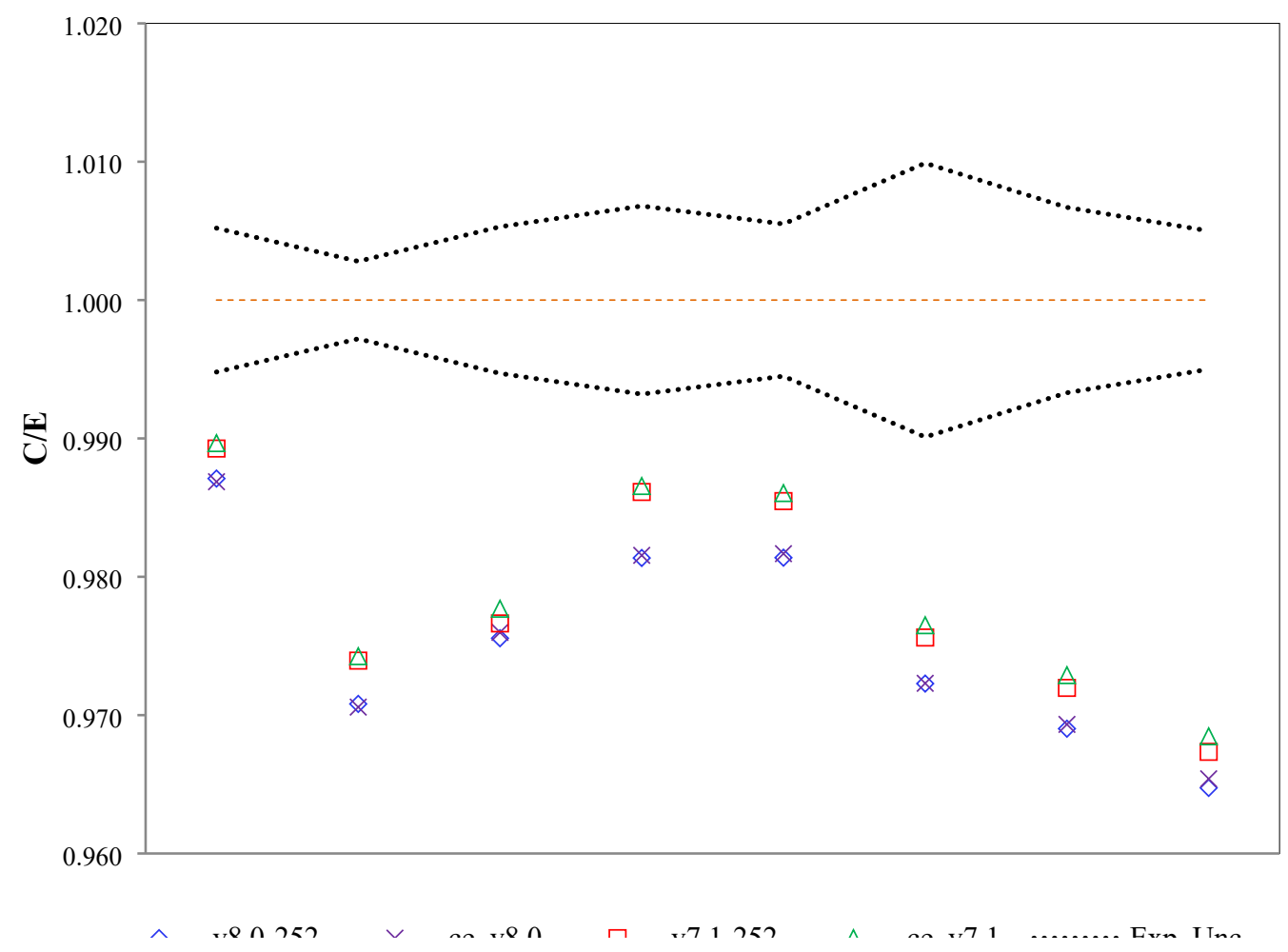

Figure 15. C/E results for libraries based on ENDF/B-VII.1 and -VIII.0 for the USM systems.

The C/E data for all USM cases are also compared against the experimental uncertainty bands, and no cases have a $\mathrm{C} / \mathrm{E}$ value for any of the four libraries that fall within these bands.

\subsubsection{UST Systems}

The C/E data for the UST systems are shown in Figure 16 for the ENDF/B-VIII.0 and -VII.1 libraries. The data generally demonstrate consistent performance between all four libraries; however, the ENDF/BVIII.0 C/E values are consistently lower than the ENDF/B-VII.1 C/E values for CE and MG. There is an average bias difference of approximately $270 \mathrm{pcm}$ between the $\mathrm{CE}$ libraries and approximately $220 \mathrm{pcm}$ between the MG libraries. These differences are in line with the other ${ }^{233} \mathrm{U}$ systems, excluding UMF, which has the smallest bias differences between ENDF/B-VIII.0 and ENDF/B-VII.1 for CE and MG libraries. As noted in the other ${ }^{233} \mathrm{U}$ systems, the changes to the cross sections as detailed in the Section 4.1.11 are most likely the cause of these significant negative bias differences. 


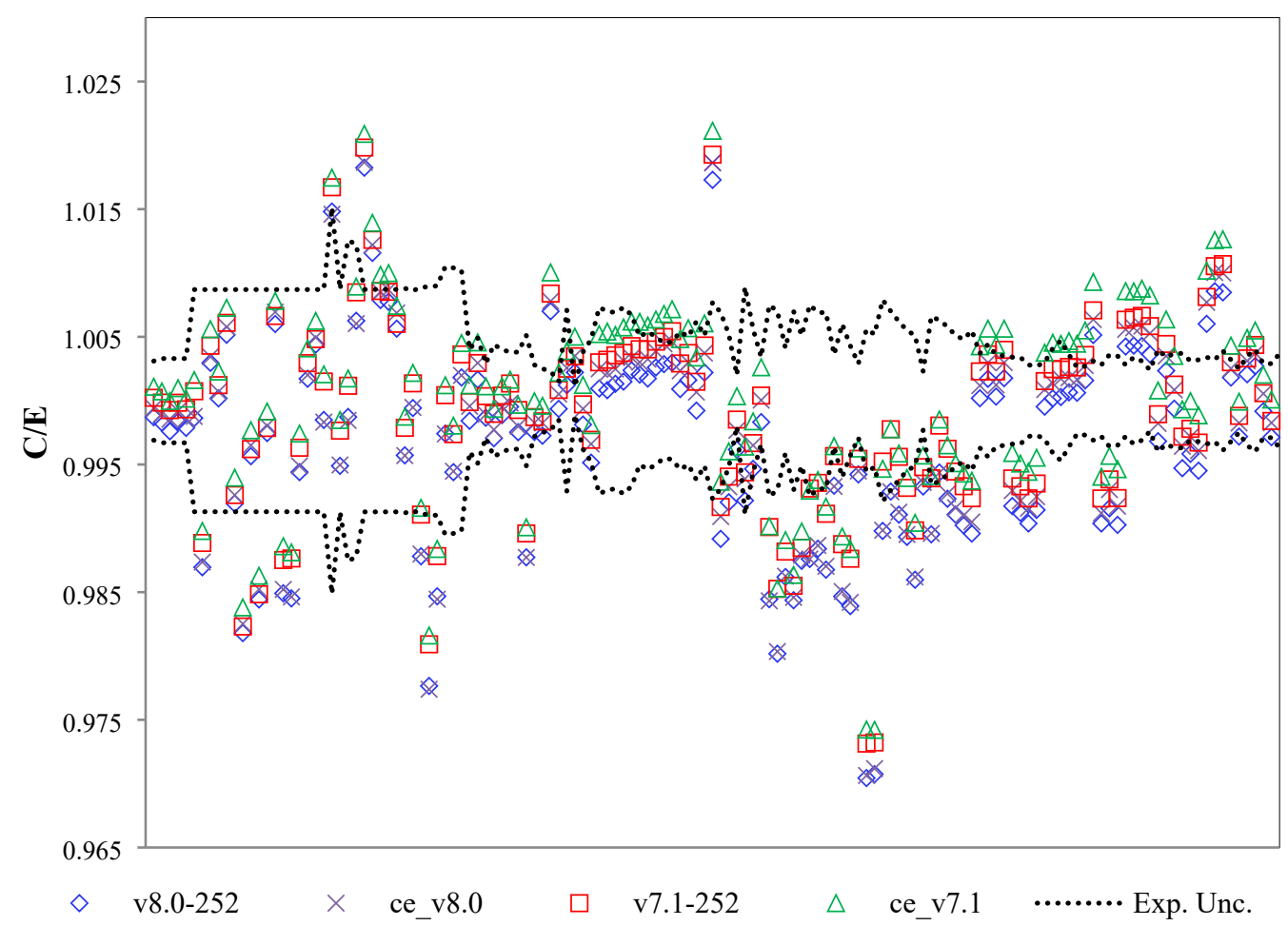

Figure 16. C/E results for libraries based on ENDF/B-VII.1 and -VIII.0 for the UST systems.

The C/E data for all UST cases are also compared against the experimental uncertainty bands with 56.4\% of the ENDF/B-VIII.0 CE library results and 51.4\% of the ENDF/B-VII.1 CE library results falling within the band. For the MG libraries, approximately $55 \%$ and $59 \%$ of the points are in the band for the 252-group ENDF/B-VIII.0 and -VII.1 libraries, respectively.

\subsubsection{Pooled Results}

The results for the different categories are pooled into similar larger groups to examine their performance over broader ranges of systems. For these comparisons, the data for each table are generated separately by combining the appropriate individual case results. The results for pooled categories of fissile material-HEU, IEU, LEU, mixed U/Pu, Pu, and U233 systems — are presented in Table 6, Table 7, and Figure 17. The IMF category is not pooled with other experiment categories because no other IEU systems are included in this report. The USI and USM results were removed from the U233* category. The results for pooled categories of fissile form - metal, solution, and compound systems - are presented in

Table 8, Table 9, and Figure 18. The USI and USM results were removed from the solution* category. The results for pooled categories of energy spectrum - fast, thermal, intermediate, and mixed spectrum systems - are presented in Table 10, Table 11, and Figure 19. The USI (i.e., intermediate energy spectrum) and USM (i.e., mixed energy spectrum) categories are only pooled with other ${ }^{233} U$-fueled solution experiments because no other intermediate or mixed energy systems are included in this report. 
Table 6. Results by fissile material category for the 252-group ENDF/B-VIII.0 library

\begin{tabular}{|c|c|c|c|c|c|c|}
\hline \multirow{2}{*}{$\begin{array}{l}\text { Fissile } \\
\text { material }\end{array}$} & \multicolumn{2}{|c|}{ ENDF/B-VIII.0 } & \multicolumn{2}{|c|}{ ENDF/B-VII.1 } & \multirow[b]{2}{*}{ Difference } & \multirow[b]{2}{*}{ Unc. } \\
\hline & Avg. C/E & $\begin{array}{l}\text { Avg. C/E } \\
\text { unc. }\end{array}$ & Avg. C/E & $\begin{array}{l}\text { Avg. C/E } \\
\text { unc. }\end{array}$ & & \\
\hline HEU & 1.00009 & 0.00051 & 0.99853 & 0.00051 & 0.00156 & 0.00073 \\
\hline IEU & 1.00266 & 0.00082 & 1.00572 & 0.00083 & -0.00307 & 0.00117 \\
\hline LEU & 0.99936 & 0.00019 & 0.99877 & 0.00019 & 0.00059 & 0.00026 \\
\hline MIXED & 0.99670 & 0.00074 & 0.99845 & 0.00074 & -0.00176 & 0.00104 \\
\hline $\mathrm{Pu}$ & 0.99778 & 0.00049 & 1.00174 & 0.00049 & -0.00396 & 0.00069 \\
\hline U233 & 0.99327 & 0.00044 & 0.99545 & 0.00044 & -0.00219 & 0.00062 \\
\hline U233* & 0.99685 & 0.00048 & 0.99887 & 0.00048 & -0.00202 & 0.00068 \\
\hline
\end{tabular}

Table 7. Results by fissile material category for the CE ENDF/B-VIII.0 library

\begin{tabular}{|c|c|c|c|c|c|c|}
\hline \multirow[b]{2}{*}{$\begin{array}{l}\text { Fissile } \\
\text { material }\end{array}$} & \multicolumn{2}{|c|}{ ENDF/B-VIII.0 } & \multicolumn{2}{|c|}{ ENDF/B-VII.1 } & \multirow[b]{2}{*}{ Difference } & \multirow[b]{2}{*}{ Unc. } \\
\hline & Avg. C/E & $\begin{array}{c}\text { Avg. C/E } \\
\text { unc. }\end{array}$ & Avg. C/E & $\begin{array}{c}\text { Avg. C/E } \\
\text { unc. }\end{array}$ & & \\
\hline HEU & 0.99927 & 0.00051 & 0.99904 & 0.00051 & 0.00023 & 0.00073 \\
\hline IEU & 1.00061 & 0.00082 & 1.00289 & 0.00083 & -0.00229 & 0.00117 \\
\hline LEU & 0.99912 & 0.00019 & 0.99943 & 0.00019 & -0.00032 & 0.00027 \\
\hline MIXED & 0.99672 & 0.00074 & 0.99891 & 0.00074 & -0.00219 & 0.00104 \\
\hline $\mathrm{Pu}$ & 0.99794 & 0.00049 & 1.00256 & 0.00049 & -0.00461 & 0.00069 \\
\hline U233 & 0.99389 & 0.00044 & 0.99653 & 0.00044 & -0.00264 & 0.00062 \\
\hline U233* & 0.99758 & 0.00048 & 1.00006 & 0.00048 & -0.00247 & 0.00068 \\
\hline
\end{tabular}

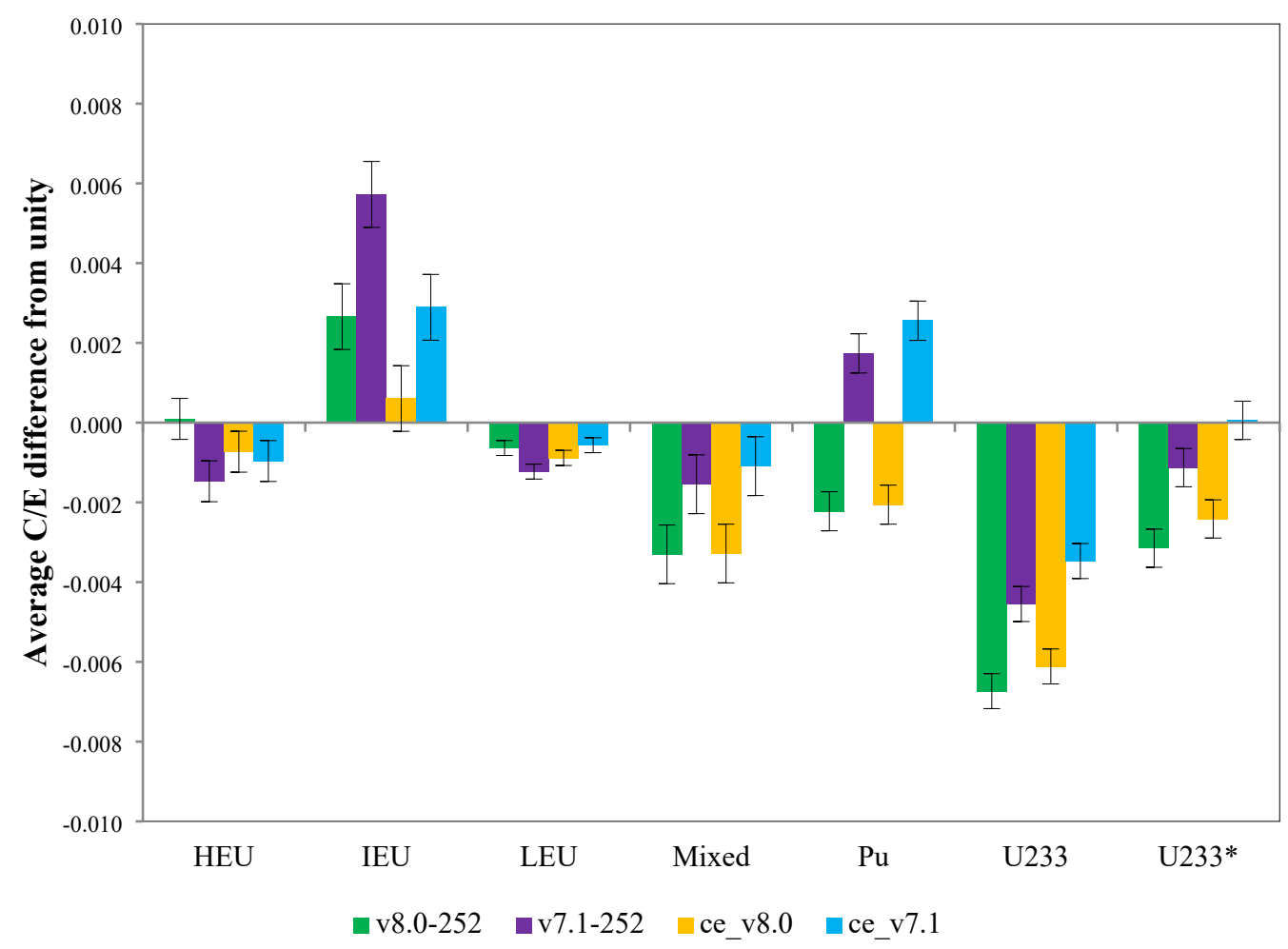

Figure 17. Absolute bias by fissile material category (USI and USM removed from U233*). 
Table 8. Results by fissile form category for the 252-group ENDF/B-VIII.0 library

\begin{tabular}{lcc|cc|cc}
\hline \multirow{2}{*}{$\begin{array}{l}\text { Fissile } \\
\text { material }\end{array}$} & \multicolumn{2}{c|}{ ENDF/B-VIII.0 } & \multicolumn{2}{c|}{ ENDF/B-VII.1 } & \multirow{2}{*}{ Difference } & Unc. \\
\cline { 2 - 5 } & Avg. C/E & $\begin{array}{c}\text { Avg. C/E } \\
\text { unc. }\end{array}$ & Avg. C/E & $\begin{array}{c}\text { Avg. C/E } \\
\text { unc. }\end{array}$ & & 0.00040 \\
Metal & 1.00141 & 0.00028 & 1.00217 & 0.00028 & -0.00076 & 0.00027 \\
Compound & 0.99928 & 0.00019 & 0.99892 & 0.00019 & 0.00037 & 0.00043 \\
Solution & 0.99522 & 0.00031 & 0.99723 & 0.00031 & -0.00201 & 0.00045 \\
Solution* & 0.99728 & 0.00032 & 0.99918 & 0.00032 & -0.00191 & \\
\hline
\end{tabular}

Table 9. Results by fissile form category for the CE ENDF/B-VIII.0 library

\begin{tabular}{|c|c|c|c|c|c|c|}
\hline \multirow{2}{*}{$\begin{array}{l}\text { Fissile } \\
\text { material }\end{array}$} & \multicolumn{2}{|c|}{ ENDF/B-VIII.0 } & \multicolumn{2}{|c|}{ ENDF/B-VII.1 } & \multirow[b]{2}{*}{ Difference } & \multirow[b]{2}{*}{ Unc. } \\
\hline & Avg. C/E & $\begin{array}{l}\text { Avg. C/E } \\
\text { unc. }\end{array}$ & Avg. C/E & $\begin{array}{l}\text { Avg. } C / E \\
\text { unc. }\end{array}$ & & \\
\hline Metal & 1.00048 & 0.00028 & 1.00100 & 0.00028 & -0.00052 & 0.00040 \\
\hline Compound & 0.99903 & 0.00019 & 0.99956 & 0.00019 & -0.00052 & 0.00027 \\
\hline Solution & 0.99552 & 0.00031 & 0.99832 & 0.00031 & -0.00279 & 0.00044 \\
\hline Solution* & 0.99761 & 0.00032 & 1.00032 & 0.00032 & -0.00271 & 0.00045 \\
\hline
\end{tabular}

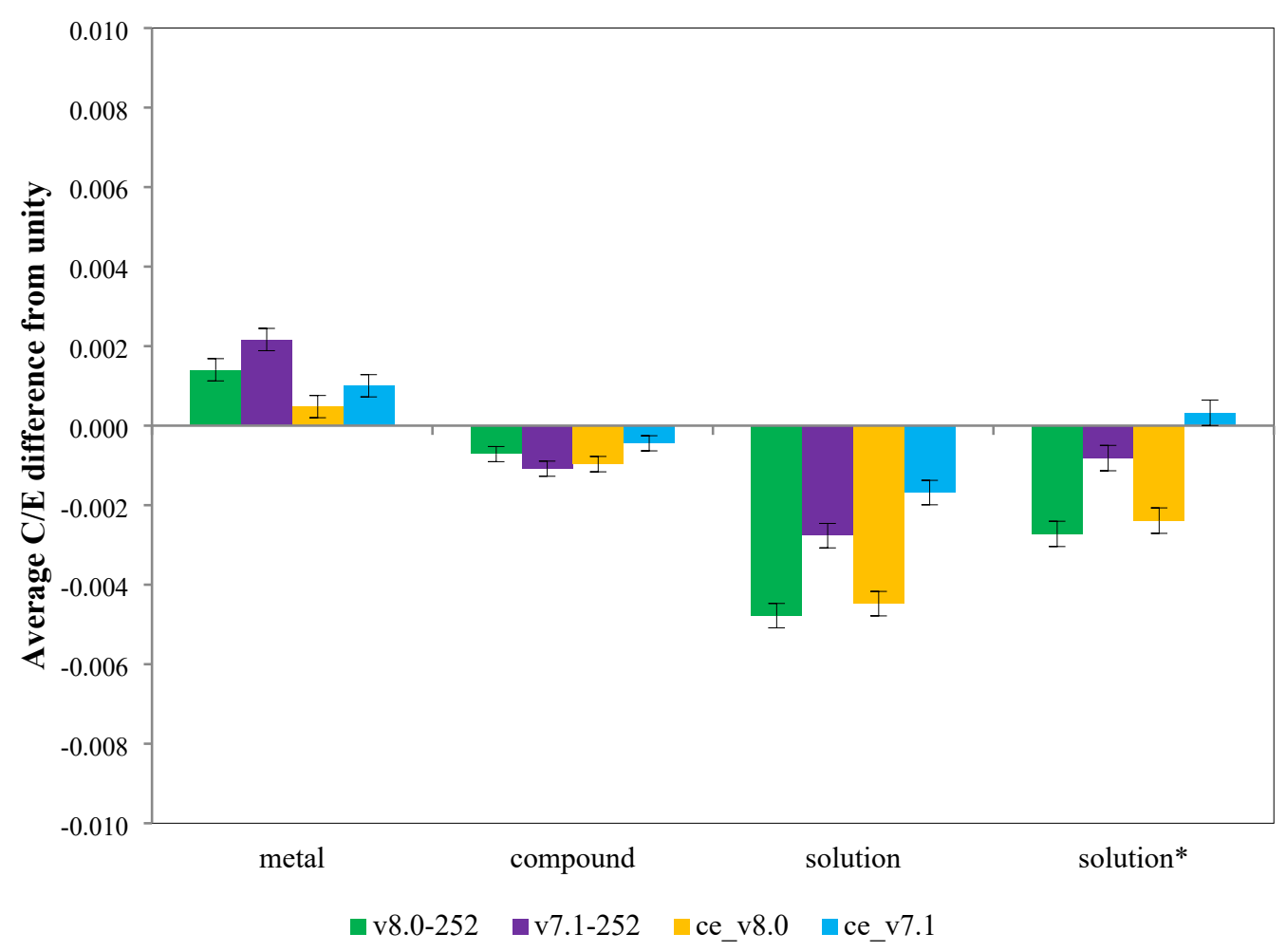

Figure 18. Absolute bias by fissile form category (USI and USM removed from solution*). 
Table 10. Results by neutron energy spectrum category for the 252-group ENDF/B-VIII.0 library

\begin{tabular}{lcc|cc|cc}
\hline \multirow{2}{*}{$\begin{array}{l}\text { Fissile } \\
\text { material }\end{array}$} & \multicolumn{2}{c|}{ ENDF/B-VIII.0 } & \multicolumn{2}{c|}{ ENDF/B-VII.1 } & \multirow{2}{*}{ Difference } & Unc. \\
\cline { 2 - 5 } & Avg. C/E & $\begin{array}{c}\text { Avg. C/E } \\
\text { unc. }\end{array}$ & Avg. C/E & $\begin{array}{c}\text { Avg. C/E } \\
\text { unc. }\end{array}$ & & 0.00039 \\
\hline Fast & 1.00140 & 0.00028 & 1.00221 & 0.00028 & -0.00081 & 0.00174 \\
Intermediate & 0.97931 & 0.00123 & 0.98214 & 0.00123 & -0.00283 & 0.00303 \\
Mixed energy & 0.97528 & 0.00214 & 0.97830 & 0.00214 & -0.00302 & 0.00031 \\
Thermal & 0.99798 & 0.00022 & 0.99907 & 0.00022 & -0.00110 & \\
\hline
\end{tabular}

Table 11. Results by neutron energy spectrum category for the CE ENDF/B-VIII.0 library

\begin{tabular}{|c|c|c|c|c|c|c|}
\hline \multirow[b]{2}{*}{$\begin{array}{l}\text { Fissile } \\
\text { material }\end{array}$} & \multicolumn{2}{|c|}{ ENDF/B-VIII.0 } & \multicolumn{2}{|c|}{ ENDF/B-VII.1 } & \multirow[b]{2}{*}{ Difference } & \multirow[b]{2}{*}{ Unc. } \\
\hline & Avg. C/E & $\begin{array}{l}\text { Avg. C/E } \\
\text { unc. }\end{array}$ & Avg. C/E & $\begin{array}{l}\text { Avg. C/E } \\
\text { unc. }\end{array}$ & & \\
\hline Fast & 1.00039 & 0.00028 & 1.00093 & 0.00028 & -0.00054 & 0.00039 \\
\hline Intermediate & 0.97945 & 0.00123 & 0.98275 & 0.00124 & -0.00330 & 0.00174 \\
\hline Mixed energy & 0.97546 & 0.00214 & 0.97901 & 0.00215 & -0.00355 & 0.00303 \\
\hline Thermal & 0.99811 & 0.00022 & 1.00006 & 0.00022 & -0.00194 & 0.00031 \\
\hline
\end{tabular}

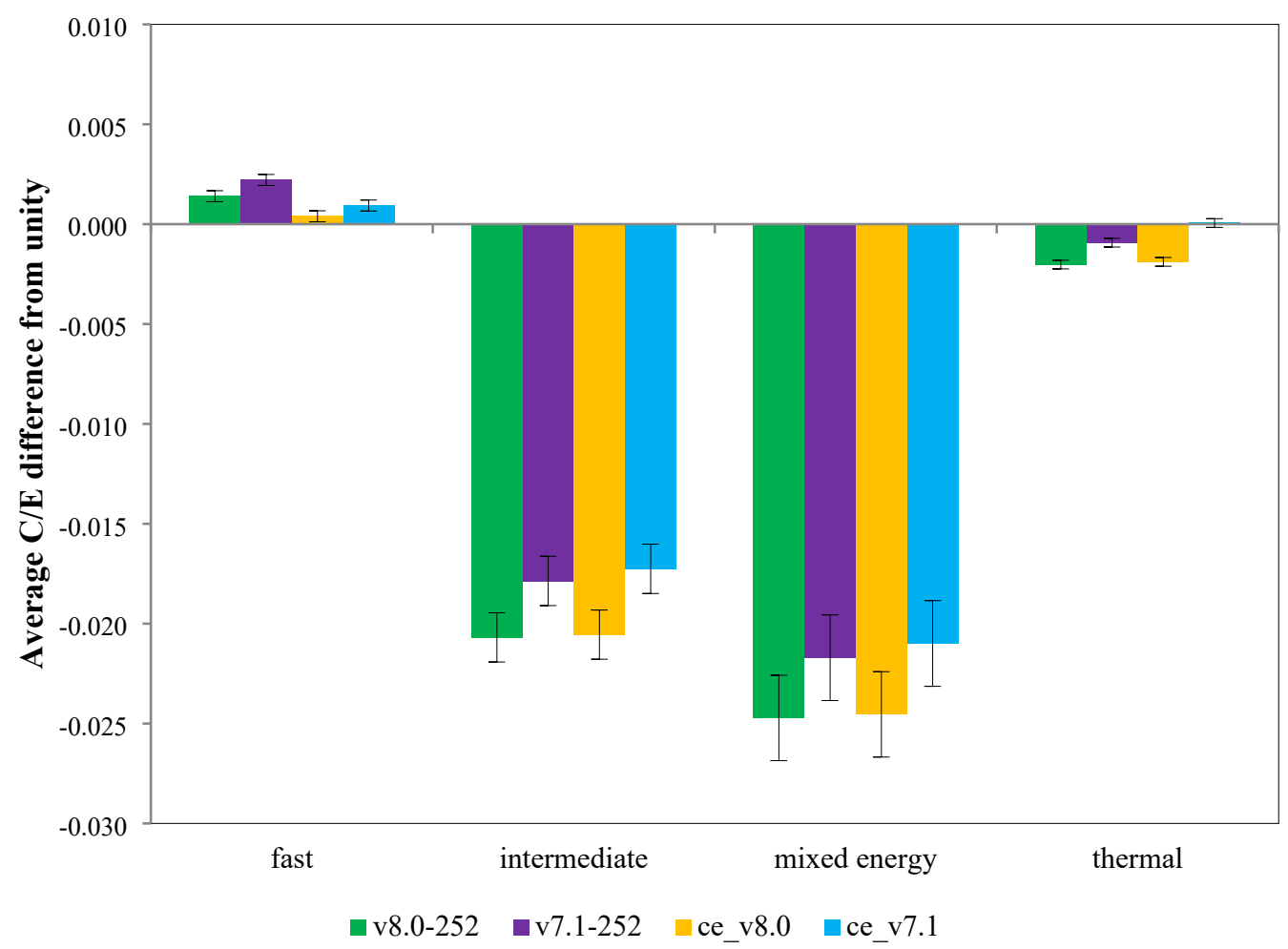

Figure 19. Absolute bias by energy spectrum category.

The results from Tables 6-7 and Figure 17 show that most HEU and LEU materials are treated accurately in KENO V.a. Between the ENDF/B-VIII.0 and ENDF/B-VII.1 MG libraries, the C/E values were reduced for all forms except HEU and LEU materials, which had small increases. As noted previously, these reductions or increases bring some material $\mathrm{C} / \mathrm{E}$ values closer to unity and others further away. The enriched uranium systems have moved closer to unity, whereas the mixed, plutonium, and ${ }^{233} \mathrm{U}$ materials have moved further away. The CE differences show reductions in $\mathrm{C} / \mathrm{E}$ values except for HEU materials, which have increased slightly from ENDF/B-VIII.0 to ENDF/B-VII.1. The HEU and IEU material systems have moved closer to unity, whereas all other material systems have moved further away. The 
largest differences for $\mathrm{CE}$ and $\mathrm{MG}$ libraries occur in the plutonium systems in which $\mathrm{C} / \mathrm{E}$ values are reduced by over $400 \mathrm{pcm}$, indicating significant changes in the ENDF/B-VIII.0 cross sections.

The results from Tables 8-9 and Figure 18 demonstrate that between the ENDF/B-VIII.0 and ENDF/BVII.1 MG and CE libraries, C/E values decreased for all fissile forms, except for MG compounds, which increased slightly. For the MG forms, metals and compounds have moved closer to unity, whereas solutions and solutions* have moved further away. For the CE libraries, only the metal forms have moved closer to unity; all others moved further away. The negative bias observed in solution* is mostly being driven by the many solutions with ${ }^{239} \mathrm{Pu}$.

The results from Tables 10-11 and Figure 19 demonstrate that between the ENDF/B-VIII.0 and ENDF/BVII.1 MG and CE libraries, $\mathrm{C} / \mathrm{E}$ values decreased for all neutron energy spectrum systems. For both $\mathrm{MG}$ and CE systems, only the fast systems have moved closer to unity, and all others have moved further away.

\subsubsection{Outlier Cases}

The results were analyzed to determine the greatest difference from a $\mathrm{C} / \mathrm{E}$ of unity for each category in each library. The case with the largest absolute bias for each category is reported in Table 12, and the bolded cases indicate that the case is different from ENDF/B-VIII.0 to ENDF/B-VII.1.

Table 12. Maximum individual case absolute differences for KENO V.a for all libraries

\begin{tabular}{|c|c|c|c|c|c|c|c|c|}
\hline \multirow[b]{2}{*}{ Category } & \multicolumn{2}{|c|}{$\begin{array}{c}\text { 252-group } \\
\text { ENDF/B-VIII.0 }\end{array}$} & \multicolumn{2}{|c|}{$\begin{array}{c}\text { 252-group } \\
\text { ENDF/B-VII.1 }\end{array}$} & \multicolumn{2}{|c|}{ CE ENDF/B-VIII.0 } & \multicolumn{2}{|c|}{ CE ENDF/B-VII.1 } \\
\hline & $\begin{array}{c}\text { Maximum } \\
\text { difference } \\
\text { (C/E from } \\
\text { unity) }\end{array}$ & Case & $\begin{array}{c}\text { Maximum } \\
\text { difference } \\
\text { (C/E from } \\
\text { unity) } \\
\end{array}$ & Case & \begin{tabular}{|c} 
Maximum \\
difference \\
(C/E from \\
unity)
\end{tabular} & Case & \begin{tabular}{|c} 
Maximum \\
difference \\
(C/E from \\
unity)
\end{tabular} & Case \\
\hline HMF & 1.00918 & 021-001 & 1.00890 & 040-001 & 1.00668 & 025-005 & 1.00721 & 019-001 \\
\hline HST & 1.02613 & 016-003 & 1.02351 & 016-003 & 1.02590 & 016-003 & 1.02441 & 016-003 \\
\hline IMF & 1.01064 & 005-001S & 1.01233 & 005-001 & 1.00495 & 004-001S & 1.00767 & 004-001S \\
\hline LCT & 1.00587 & 010-002 & 1.00460 & 010-002 & 1.00502 & 010-002 & 1.00521 & 010-002 \\
\hline LST & 0.99282 & $002-002$ & 0.99180 & 002-002 & 0.9 & 002-002 & 0.9 & 002-002 \\
\hline MCF & 1.00402 & 006-001 & 1.00772 & 006-001 & 0.99981 & 006-001 & 1.00210 & 006-001 \\
\hline MCT & 0.99438 & 004-001 & 0.99506 & 004-001 & 0.99479 & 004-001 & 1.00421 & $002-004 \mathrm{~S}$ \\
\hline MST & 0.98837 & $007-007$ & 0.99321 & 007-007 & 0.98937 & 007-007 & 0.99405 & $007-007$ \\
\hline PMF & 1.00792 & 026-001 & 1.00514 & 026-001 & 0.99779 & 018-001 & 0.99678 & 026-001 \\
\hline PST & 0.98642 & 011-009 & 1.01512 & 011-003 & 0.98665 & $020-013$ & 1.01595 & 011-003 \\
\hline UCT & 0.99651 & 001-004 & 1.00203 & 001-003 & 0.99701 & 001-004 & 1.00196 & 001-003 \\
\hline UMF & 0.99638 & 004-002 & 0.99539 & 005-002 & 0.99580 & 004-002 & 0.99510 & 005-002 \\
\hline USI & 0.96946 & 001-021 & 0.97188 & 001-021 & 0.96967 & 001-021 & 0.97268 & 001-021 \\
\hline USM & 0.96474 & 002-009 & 0.96735 & 002-009 & 0.96540 & 002-009 & 0.96847 & 002-009 \\
\hline UST & 0.97044 & $015-018$ & 0.97314 & 015-018 & 0.97064 & 015-018 & 0.97421 & 015-019 \\
\hline
\end{tabular}

\subsection{KENO-VI}

All KENO-VI cases executed for this validation were run until the Monte Carlo uncertainty was reduced to less than or equal to $0.00010 \Delta k$. The average $\mathrm{C} / \mathrm{E}$ value and its uncertainty is provided in Table 13 and Table 14 for all four libraries. The results show that the average $\mathrm{C} / \mathrm{E}$ values have decreased for both MG and CE libraries for all KENO-VI categories between ENDF/B-VIII.0 and ENDF/B-VII.1. Of these differences, none are statistically significant (i.e., greater than $2 \sigma$ ) with all three less than $1 \sigma$. However, 
these small decreases have only brought the IMF systems closer to unity, whereas the HMF and MCT systems have moved further away. The average $\mathrm{C} / \mathrm{E}$ bias (i.e., difference from unity) is shown in Figure 20 for each of the categories for all four libraries.

Table 13. Results by category for KENO-VI calculations with 252-group ENDF/B-VIII.0 library

\begin{tabular}{l|cc|cc|ccc}
\hline \multirow{2}{*}{ Category } & \multicolumn{2}{|c|}{ ENDF/B-VIII.0 } & \multicolumn{2}{c|}{ ENDF/B-VII.1 } & \multirow{2}{*}{ Difference } & Unc. & Std Dev. \\
\cline { 2 - 5 } & Avg. C/E & $\begin{array}{c}\text { Avg. C/E } \\
\text { unc. }\end{array}$ & Avg. C/E & $\begin{array}{c}\text { Avg. C/E } \\
\text { unc. }\end{array}$ & & & \\
\hline HMF & 0.99816 & 0.00044 & 0.99855 & 0.00044 & -0.00039 & 0.00062 & 0.62675 \\
IMF & 1.00300 & 0.00274 & 1.00552 & 0.00275 & -0.00252 & 0.00388 & 0.64915 \\
MCT & 0.99325 & 0.00078 & 0.99387 & 0.00078 & -0.00062 & 0.00110 & 0.56206 \\
\hline
\end{tabular}

Table 14. Results by category for KENO-VI calculations with CE ENDF/B-VIII.0 library

\begin{tabular}{|c|c|c|c|c|c|c|c|}
\hline \multirow[b]{2}{*}{ Category } & \multicolumn{2}{|c|}{ ENDF/B-VIII.0 } & \multicolumn{2}{|c|}{ ENDF/B-VII.1 } & \multirow[b]{2}{*}{ Difference } & \multirow[b]{2}{*}{ Unc. } & \multirow[b]{2}{*}{ Std Dev. } \\
\hline & Avg. C/E & $\begin{array}{l}\text { Avg. C/E } \\
\text { unc. }\end{array}$ & Avg. C/E & $\begin{array}{l}\text { Avg. C/E } \\
\text { unc. }\end{array}$ & & & \\
\hline HMF & 0.99814 & 0.00044 & 0.99872 & 0.00044 & -0.00024 & 0.00062 & 0.93210 \\
\hline IMF & 1.00407 & 0.00274 & 1.00589 & 0.00275 & -0.00165 & 0.00388 & 0.46883 \\
\hline MCT & 0.99362 & 0.00078 & 0.99417 & 0.00078 & -0.00058 & 0.00110 & 0.49860 \\
\hline
\end{tabular}

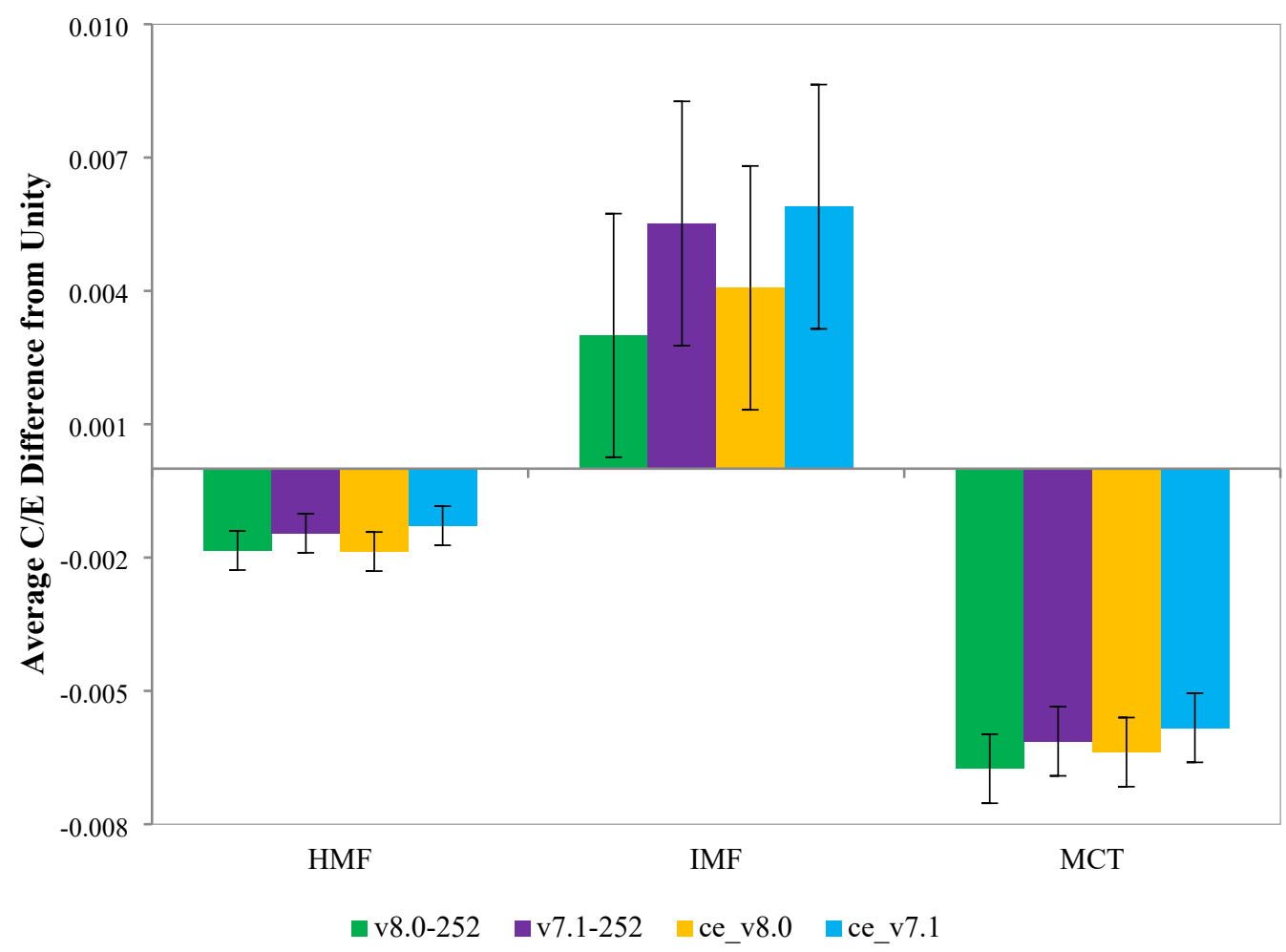

Figure 20. Absolute bias for all four libraries for each of the three categories of experiments, KENO-VI.

The largest absolute bias for the 252-group ENDF/B-VIII.0 and -VII.1 libraries occurs for the MCT systems and is approximately -0.68 and $-0.61 \% \Delta \mathrm{k}$, respectively. The largest absolute bias for the CE ENDF/B-VIII.0 and -VII. 1 libraries occurs for the MCT and IMF systems and is approximately -0.64 and $-0.59 \% \Delta \mathrm{k}$, respectively. The largest absolute difference between the 252-group and CE ENDF/B-VIII.0 and -VII.1 results occurs for the IMF systems and is -0.25 and $-0.18 \% \Delta k$, respectively. However, as 
noted previously, all the differences are statistically insignificant. The following sections detail the $\mathrm{C} / \mathrm{E}$ values and the benchmark $k_{\text {eff }}$ uncertainty, as reported in the ICSBEP Handbook.

\subsubsection{HMF Systems}

The C/E data for the HMF systems are shown in Figure 21 for the ENDF/B-VIII.0 and -VII.1 libraries. The data generally demonstrate consistent performance between all libraries. However, there is no clear pattern for the MG or CE libraries between ENDF/B-VIII.0 and ENDF/B-VII.1 because some C/E values have increased and while others have decreased.

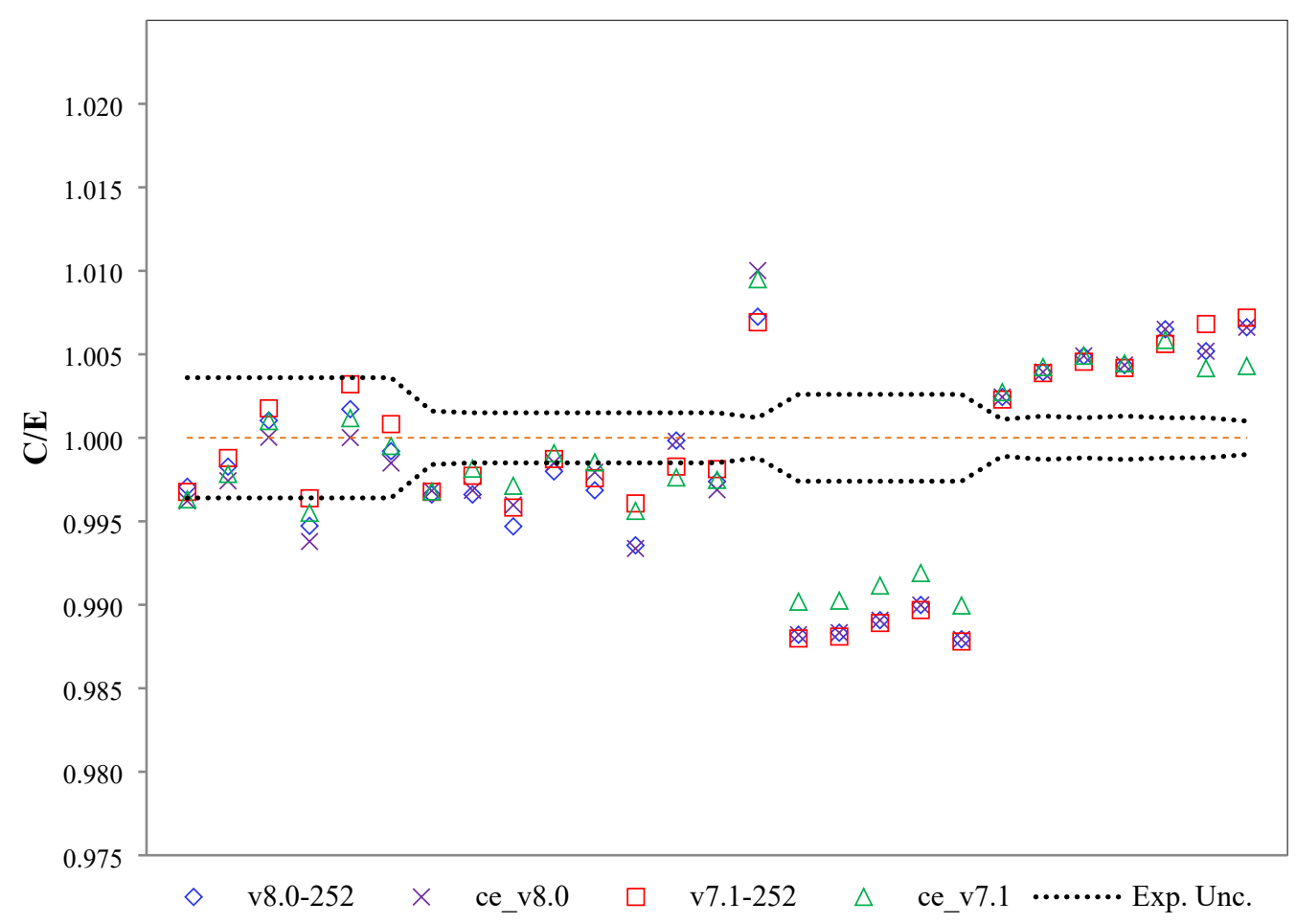

Figure 21. C/E results for libraries based on ENDF/B-VII.1 and -VIII.0 for the HMF systems, KENO-VI.

The C/E data for all HMF cases are also compared against the experimental uncertainty bands with $22.2 \%$ of the ENDF/B-VIII.0 and -VII.1 CE library results falling within the band. For the MG libraries, approximately $22 \%$ of the points are in the band for the ENDF/B-VIII.0 and -VII.1 libraries.

\subsubsection{IMF Systems}

The C/E data for the IMF systems are shown in Figure 22 for the ENDF/B-VIII.0 and -VII.1 libraries. The dataset presented here only contains two data points, making it difficult to develop generalizations about the tendencies of the different libraries. However, the MG and CE data for the ENDF/B-VIII.0 library are below their respective values from the ENDF/B-VII.1 library, moving closer to unity. 


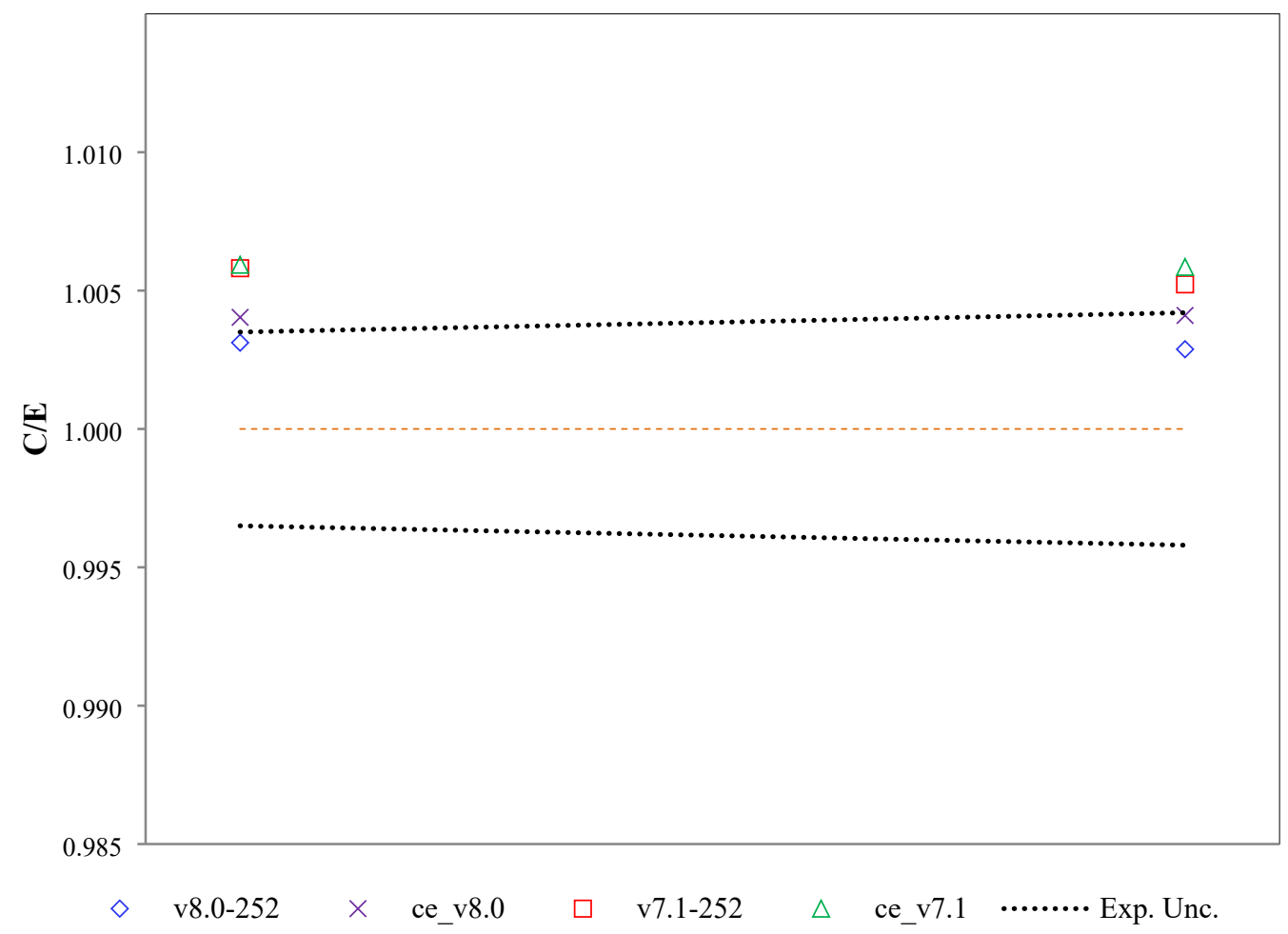

Figure 22. C/E results for libraries based on ENDF/B-VII.1 and -VIII.0 for the IMF systems, KENO-VI.

\subsubsection{MCT Systems}

The C/E data for the MCT systems are shown in Figure 23 for the ENDF/B-VIII.0 and -VII.1 libraries. The data generally demonstrate consistent performance between all libraries. However, the ENDF/BVIII.0 MG and CE libraries are generally below the comparative ENDF/B-VII.1 values, except for MCT008-001, which is higher than the ENDF/B-VII.1 values. The continued trend of mixed systems with plutonium having lower C/E values from ENDF/B-VIII.0 to ENDF/B-VII.1 is evident, further validating the updated cross section values for plutonium in ENDF/B-VIII.0. 


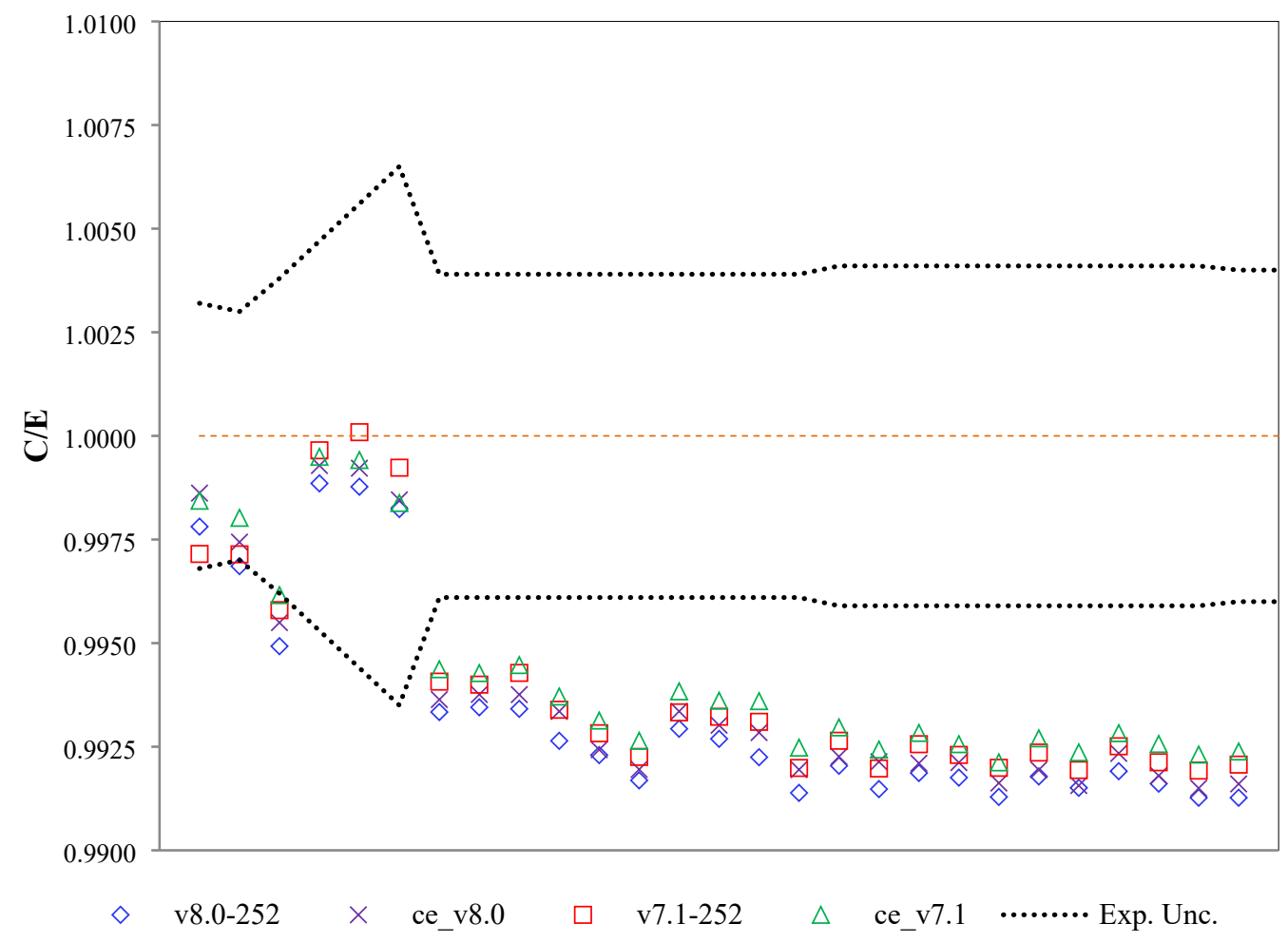

Figure 23. C/E results for libraries based on ENDF/B-VII.1 and -VIII.0 for the MCT systems, KENO-VI.

The C/E data for all MCT cases are also compared against the experimental uncertainty bands with $17.9 \%$ of the ENDF/B-VIII.0 and -VII.1 CE library results within the band. For the MG libraries, approximately 14 and $18 \%$ of the points are in the band for the 252-group ENDF/B-VIII.0 and -VII.1 libraries, respectively.

\subsubsection{Outlier Cases}

The results were analyzed to determine the greatest difference from a $\mathrm{C} / \mathrm{E}$ of unity for each category in each library. The case with the largest absolute bias for each category is reported in Table 15, and the bolded cases indicate that the case is different from ENDF/B-VIII.0 to ENDF/B-VII.1.

Table 15. Maximum individual case absolute differences for KENO-VI for all libraries

\begin{tabular}{|c|c|c|c|c|c|c|c|c|}
\hline \multirow[b]{2}{*}{ Category } & \multicolumn{2}{|c|}{$\begin{array}{c}\text { 252-group } \\
\text { ENDF/B-VIII.0 }\end{array}$} & \multicolumn{2}{|c|}{$\begin{array}{c}\text { 252-group } \\
\text { ENDF/B-VII.1 }\end{array}$} & \multicolumn{2}{|c|}{ CE ENDF/B-VIII.0 } & \multicolumn{2}{|c|}{ CE ENDF/B-VII.1 } \\
\hline & $\begin{array}{c}\text { Maximum } \\
\text { difference } \\
\text { (C/E from } \\
\text { unity) } \\
\end{array}$ & Case & $\begin{array}{c}\text { Maximum } \\
\text { difference } \\
\text { (C/E from } \\
\text { unity) }\end{array}$ & Case & \begin{tabular}{|l} 
Maximum \\
difference \\
(C/E from \\
unity)
\end{tabular} & $\begin{array}{c}\text { Maximum } \\
\text { difference } \\
\text { (C/E from } \\
\text { unity) } \\
\end{array}$ & Case & $\begin{array}{c}\text { Maximum } \\
\text { difference } \\
\text { (C/E from } \\
\text { unity) }\end{array}$ \\
\hline & & & & & $0.98793 \quad 0$ & $086-005$ & & \\
\hline IN & & & & & & & & \\
\hline MCT & 0.99127 & 008-026 & 0.99192 & $008-026$ & $0.99150 \quad 0$ & 008-026 & 0.99212 & 008-021 \\
\hline
\end{tabular}




\subsection{SENSITIVITY DATA GENERATION}

This section focuses on the generation of the sensitivity data used for comparisons between the two libraries. As noted previously, instead of using the TSUNAMI-3D sequence to generate sensitivity files for each VALID case with the ENDF/B-VIII.0 library, only SDFs from selected cases were generated. The inputs for the TSUNAMI-3D sequences were taken directly from the VALID inputs generated from the SCALE 6.1 or SCALE 6.2.2 validation with the libraries updated to the MG or CE version of ENDF/B-VIII.0. Table 16 shows the complete list of selected cases used for the sensitivity comparison.

Table 16. Selected cases used for TSUNAMI-3D SDF generation

\begin{tabular}{|c|c|c|c|c|c|c|c|}
\hline \multicolumn{6}{|c|}{ KENO V.a } & \multicolumn{2}{|c|}{ KENO-VI } \\
\hline System & Case & System & Case & System & Case & System & Case \\
\hline \multirow[t]{11}{*}{ HMF } & 015-001 & \multirow[t]{4}{*}{ LCT } & $008-010$ & $\mathrm{UCT}^{*}$ & 001-002 & \multirow[t]{15}{*}{ HMF } & 005-001 \\
\hline & 016-001 & & $017-018$ & UMF & 001-001 & & 005-002 \\
\hline & 016-002 & & 050-008 & & 002-001 & & 008-001 \\
\hline & 017-001 & & 080-007 & & 003-001 & & 009-001 \\
\hline & 019-001 & LST & $002-001$ & & 004-001 & & 009-002 \\
\hline & 020-001 & & 003-009 & & 005-002 & & 010-001 \\
\hline & 021-001 & MCF & 005-001 & USI & 001-003 & & 010-002 \\
\hline & 025-001 & & 006-001 & & 001-006 & & 011-001 \\
\hline & 030-001 & MCT & $001-001$ & & 001-010 & & 013-001 \\
\hline & 038-002 & & $002-001 \mathrm{~S}$ & & 001-019 & & 024-001 \\
\hline & 065-001 & & 004-011 & & 001-024 & & 086-005 \\
\hline \multirow[t]{6}{*}{ HST } & 001-009 & \multirow[t]{2}{*}{ MST } & 002-001 & & 001-033 & & 092-002 \\
\hline & 013-001 & & 007-007 & \multirow[t]{3}{*}{ USM } & 001-014 & & 093-001 \\
\hline & 013-004 & \multirow[t]{8}{*}{ PMF } & $002-001$ & & 001-030 & & 094-001 \\
\hline & 016-002 & & 005-001 & & 002-009 & & 094-002 \\
\hline & 028-006 & & 006-001 & \multirow[t]{9}{*}{ UST } & 009-004 & IMF & 019-001 \\
\hline & 030-004 & & 008-001 & & 015-007 & \multirow[t]{8}{*}{ MCT } & 008-001 \\
\hline \multirow[t]{7}{*}{ IMF } & 002-001 & & 018-001 & & 015-011 & & 008-006 \\
\hline & 003-001 & & 023-001 & & & & 008-008 \\
\hline & 004-001 & & 024-001 & & & & 008-013 \\
\hline & 005-001 & & $025-001$ & & & & 008-017 \\
\hline & 006-001 & PST & 001-006 & & & & 008-018 \\
\hline & 007-001 & & 011-006 & & & & 008-023 \\
\hline & 009-001 & & 020-007 & & & & \\
\hline
\end{tabular}

*Not confirmed by direct perturbation.

Except for the UCT system, the SDFs generated with ENDF/B-VII.1 from SCALE 6.1 or 6.2.2, were validated with direct perturbations and were deemed suitable for use in sensitivity analyses. Although the SDFs for the ${ }^{233} \mathrm{U}$ systems were not formally added to VALID, they help provide additional data for library comparisons. The comparisons between the two libraries are performed with TSUNAMI-IP to gauge the similarity or lack thereof. As noted previously, these comparisons are made by using the integral parameters $c_{k}$ and $E$.

\subsubsection{Comparison of Sensitivities}

The results of the $c_{k}$ and $E$ calculations from TSUNAMI-IP are provided in Table 17 and Table 18 using the ENDF/B-VIII.0 and -VII.1 56-group covariance data. For the ENDF/B-VIII.0 56-group covariance data, all $c_{k}$ values are in excess of 0.97, except for PMF-006-001 which had a $c_{k}$ of 0.9795 and is explained in more detail below; all $E$ values are in excess of 0.99 . The ENDF/B-VII. $1 c_{k}$ and $E$ values are provided as a reference. These results indicate excellent agreement between the two libraries for the same application systems. The higher values for $E$ over $c_{k}$ likely indicate that any differences between the 
SDFs occur in the isotopes and reactions with large uncertainties. The larger uncertainty reactions are given higher weight in calculating $c_{k}$; however, these reactions also generally have low sensitivities.

Table 17. Integral parameters comparing ENDF/B-VIII.0 and ENDF/B-VII.1 TSUNAMI-3D, KENO V.a

\begin{tabular}{|c|c|c|c|c|c|c|c|c|c|c|c|}
\hline \multirow[t]{2}{*}{ System } & \multirow[t]{2}{*}{ Case } & \multicolumn{2}{|c|}{$\begin{array}{c}\text { ENDF/B-VIII.0 } \\
\text { 56-group } \\
\text { covariance } \\
\end{array}$} & \multicolumn{2}{|c|}{$\begin{array}{l}\text { ENDF/B-VII.1 56- } \\
\text { group covariance }\end{array}$} & \multirow[t]{2}{*}{ System } & \multirow[t]{2}{*}{ Case } & \multicolumn{2}{|c|}{$\begin{array}{c}\text { ENDF/B-VIII.0 } \\
\text { 56-group } \\
\text { covariance } \\
\end{array}$} & \multicolumn{2}{|c|}{$\begin{array}{l}\text { ENDF/B-VII.1 56- } \\
\text { group covariance }\end{array}$} \\
\hline & & $c_{k}$ & $E$ & $c_{k}$ & $E$ & & & $c_{k}$ & $E$ & $c_{k}$ & $E$ \\
\hline \multirow[t]{11}{*}{$\mathrm{HMF}$} & $015-001$ & 0.9998 & 0.9997 & 0.9992 & 0.9997 & \multirow[t]{2}{*}{ MST } & $002-001$ & 1.0000 & 0.9999 & 1.0000 & 0.9999 \\
\hline & 016-001 & 0.9999 & 0.9998 & 0.9996 & 0.9998 & & 007-007 & 1.0000 & 0.9999 & 1.0000 & 0.9999 \\
\hline & 016-002 & 0.9999 & 0.9998 & 0.9996 & 0.9998 & \multirow[t]{8}{*}{ PMF } & $002-001$ & 0.9998 & 1.0000 & 0.9994 & 1.0000 \\
\hline & 017-001 & 0.9999 & 0.9998 & 0.9998 & 0.9998 & & 005-001 & 0.9999 & 1.0000 & 0.9993 & 1.0000 \\
\hline & 019-001 & 0.9974 & 0.9877 & 0.9974 & 0.9877 & & 006-001* & 0.9996 & 0.9998 & 0.9919 & 0.9998 \\
\hline & 020-001 & 0.9996 & 0.9988 & 0.9993 & 0.9988 & & 008-001 & 0.9996 & 0.9999 & 0.9988 & 0.9999 \\
\hline & $021-001$ & 0.9996 & 0.9997 & 0.9992 & 0.9997 & & 018-001 & 0.9999 & 1.0000 & 0.9996 & 1.0000 \\
\hline & $025-001$ & 0.9998 & 0.9997 & 0.9994 & 0.9997 & & 023-001 & 0.9982 & 0.9912 & 0.9881 & 0.9912 \\
\hline & $030-001$ & 0.9999 & 0.9998 & 0.9998 & 0.9998 & & 024-001 & 0.9997 & 0.9989 & 0.9987 & 0.9989 \\
\hline & 038-002 & 0.9997 & 0.9990 & 0.9995 & 0.9990 & & $025-001$ & 0.9998 & 0.9999 & 0.9992 & 0.9999 \\
\hline & $065-001$ & 0.9998 & 0.9997 & 0.9993 & 0.9997 & \multirow[t]{3}{*}{ PST } & 001-006 & 1.0000 & 0.9997 & 1.0000 & 0.9997 \\
\hline \multirow[t]{6}{*}{ HST } & 001-009 & 1.0000 & 1.0000 & 1.0000 & 1.0000 & & 011-006 & 1.0000 & 0.9996 & 1.0000 & 0.9996 \\
\hline & 013-001 & 1.0000 & 1.0000 & 1.0000 & 1.0000 & & 020-007 & 1.0000 & 0.9997 & 1.0000 & 0.9997 \\
\hline & 013-004 & 1.0000 & 1.0000 & 1.0000 & 1.0000 & UCT & 001-002 & 0.9998 & 0.9999 & 0.9999 & 0.9999 \\
\hline & 016-002 & 1.0000 & 1.0000 & 1.0000 & 1.0000 & \multirow[t]{5}{*}{ UMF } & $001-001$ & 0.9987 & 0.9996 & 0.9994 & 0.9996 \\
\hline & $028-006$ & 1.0000 & 1.0000 & 1.0000 & 1.0000 & & $002-001$ & 0.9987 & 0.9996 & 0.9991 & 0.9996 \\
\hline & 030-004 & 1.0000 & 1.0000 & 1.0000 & 1.0000 & & 003-001 & 0.9987 & 0.9996 & 0.9988 & 0.9996 \\
\hline \multirow[t]{7}{*}{ IMF } & $002-001$ & 0.9998 & 0.9994 & 0.9995 & 0.9994 & & 004-001 & 0.9990 & 0.9996 & 0.9994 & 0.9996 \\
\hline & 003-001 & 0.9999 & 0.9998 & 0.9989 & 0.9998 & & 005-002 & 0.9987 & 0.9996 & 0.9992 & 0.9996 \\
\hline & 004-001 & 0.9987 & 0.9927 & 0.9986 & 0.9927 & \multirow[t]{6}{*}{ USI } & $001-003$ & 0.9998 & 0.9999 & 0.9998 & 0.9999 \\
\hline & $005-001$ & 0.9996 & 0.9998 & 0.9996 & 0.9998 & & $001-006$ & 0.9993 & 0.9963 & 0.9992 & 0.9963 \\
\hline & 006-001 & 0.9999 & 0.9998 & 0.9995 & 0.9998 & & 001-010 & 0.9998 & 0.9999 & 0.9998 & 0.9999 \\
\hline & 007-001 & 0.9987 & 0.9969 & 0.9963 & 0.9969 & & 001-019 & 0.9998 & 0.9999 & 0.9999 & 0.9999 \\
\hline & 009-001 & 0.9990 & 0.9942 & 0.9988 & 0.9942 & & 001-024 & 0.9999 & 0.9999 & 0.9999 & 0.9999 \\
\hline \multirow[t]{4}{*}{ LCT } & $008-010$ & 0.9999 & 0.9999 & 0.9994 & 0.9999 & & 001-033 & 0.9997 & 0.9987 & 0.9997 & 0.9987 \\
\hline & 017-018 & 0.9995 & 0.9999 & 0.9968 & 0.9999 & \multirow[t]{3}{*}{ USM } & 001-014 & 0.9993 & 0.9967 & 0.9993 & 0.9967 \\
\hline & $050-008$ & 0.9999 & 0.9999 & 0.9997 & 0.9999 & & $001-030$ & 0.9993 & 0.9961 & 0.9993 & 0.9961 \\
\hline & 080-007 & 0.9999 & 0.9999 & 0.9999 & 0.9999 & & 002-009 & 0.9999 & 0.9999 & 0.9999 & 0.9999 \\
\hline \multirow[t]{2}{*}{ LST } & $002-001$ & 0.9999 & 0.9999 & 0.9999 & 0.9999 & \multirow[t]{7}{*}{ UST } & 009-004 & 1.0000 & 1.0000 & 1.0000 & 1.0000 \\
\hline & 003-009 & 0.9999 & 0.9999 & 0.9999 & 0.9999 & & 015-007 & 0.9993 & 0.9959 & 0.9992 & 0.9959 \\
\hline \multirow[t]{2}{*}{$\mathrm{MCF}$} & $005-001$ & 0.9987 & 0.9974 & 0.9979 & 0.9974 & & \multirow[t]{5}{*}{ 015-011 } & \multirow[t]{5}{*}{0.9999} & \multirow[t]{5}{*}{0.9999} & \multirow[t]{5}{*}{0.9999} & 0.9999 \\
\hline & 006-001 & 0.9972 & 0.9980 & 0.9864 & 0.9980 & & & & & & \\
\hline MCT & $001-001$ & 0.9999 & 0.9995 & 0.9999 & 0.9995 & & & & & & \\
\hline & $002-001 \mathrm{~S}$ & 0.9999 & 0.9999 & 0.9999 & 0.9999 & & & & & & \\
\hline & 004-011 & 1.0000 & 0.9999 & 1.0000 & 0.9999 & & & & & & \\
\hline
\end{tabular}

*SDFs generated with SCALE 6.3.b12.

Originally, PMF-006-001 had $c_{k}$ and $E$ values of 0.9795 and 0.9947 with the ENDF/B-VIII.0 covariance data and -0.0054 and 0.9947 with the ENDF/B-VII. 1 covariance data. This uncorrelated difference was further examined to investigated given the extreme values in $c_{k}$. PMF-006-001 is a plutonium sphere reflected by natural uranium, and so the lowest individual $c_{k}$ value contributing to the highest overall $c_{k}$ contribution in the covariance matrix was found to be the inelastic (n, n') scattering reaction of ${ }^{238} \mathrm{U}$. Figure 24 compares the sensitivity profile for the ${ }^{238} \mathrm{U}$ inelastic scattering reaction calculated using the ENDF/B-VIII.0 and the SCALE 6.2.2-generated profile. As noted in the Figure 24, there is a large discrepancy between the two sensitivity profiles in the higher energy regions. 
Table 18. Integral parameters comparing ENDF/B-VIII.0 and ENDF/B-VII.1 TSUNAMI-3D, KENO-VI

\begin{tabular}{|c|c|c|c|c|c|c|c|c|c|c|c|}
\hline \multirow[t]{2}{*}{ System } & \multirow[t]{2}{*}{ Case } & \multicolumn{2}{|c|}{$\begin{array}{c}\text { ENDF/B-VIII.0 } \\
\text { 56-group } \\
\text { covariance } \\
\end{array}$} & \multicolumn{2}{|c|}{$\begin{array}{l}\text { ENDF/B-VII.1 56- } \\
\text { group covariance }\end{array}$} & \multirow[t]{2}{*}{ System } & \multirow[t]{2}{*}{ Case } & \multicolumn{2}{|c|}{$\begin{array}{c}\text { ENDF/B-VIII.0 } \\
\text { 56-group } \\
\text { covariance }\end{array}$} & \multicolumn{2}{|c|}{$\begin{array}{l}\text { ENDF/B-VII.1 } 56 \\
\text { group covariance }\end{array}$} \\
\hline & & $c_{k}$ & $E$ & $c_{k}$ & $E$ & & & $c_{k}$ & $\mathbf{E}$ & $c_{k}$ & $\mathbf{E}$ \\
\hline \multirow[t]{15}{*}{ HMF } & $005-001$ & 0.9999 & 0.9998 & 0.9998 & 0.9998 & IMF & 019-001 & 0.9999 & 0.9998 & 0.9991 & 0.9998 \\
\hline & 005-002 & 0.9999 & 0.9998 & 0.9998 & 0.9998 & \multirow[t]{14}{*}{ MCT } & 008-001 & 0.9999 & 0.9999 & 0.9999 & 0.9999 \\
\hline & 008-001 & 0.9998 & 0.9997 & 0.9993 & 0.9997 & & 008-006 & 1.0000 & 0.9999 & 1.0000 & 0.9999 \\
\hline & 009-001 & 0.9998 & 0.9998 & 0.9996 & 0.9998 & & 008-008 & 1.0000 & 0.9999 & 0.9999 & 0.9999 \\
\hline & 009-002 & 0.9998 & 0.9998 & 0.9996 & 0.9998 & & $008-013$ & 1.0000 & 0.9999 & 0.9999 & 0.9999 \\
\hline & 010-001 & 0.9998 & 0.9997 & 0.9996 & 0.9997 & & $008-017$ & 1.0000 & 0.9999 & 0.9999 & 0.9999 \\
\hline & 010-002 & 0.9999 & 0.9997 & 0.9996 & 0.9997 & & $008-018$ & 1.0000 & 0.9999 & 0.9999 & 0.9999 \\
\hline & 011-001 & 0.9988 & 0.9946 & 0.9988 & 0.9946 & & 008-023 & 1.0000 & 0.9999 & 0.9999 & 0.9999 \\
\hline & 013-001 & 0.9998 & 0.9997 & 0.9993 & 0.9997 & & & & & & \\
\hline & 024-001 & 0.9993 & 0.9971 & 0.9992 & 0.9971 & & & & & & \\
\hline & 086-005 & 0.9998 & 0.9997 & 0.9993 & 0.9997 & & & & & & \\
\hline & 092-002 & 0.9999 & 0.9997 & 0.9995 & 0.9997 & & & & & & \\
\hline & 093-001 & 0.9999 & 0.9998 & 0.9997 & 0.9998 & & & & & & \\
\hline & 094-001 & 0.9991 & 0.9982 & 0.9941 & 0.9982 & & & & & & \\
\hline & 094-002 & 0.9985 & 0.9975 & 0.9929 & 0.9975 & & & & & & \\
\hline
\end{tabular}

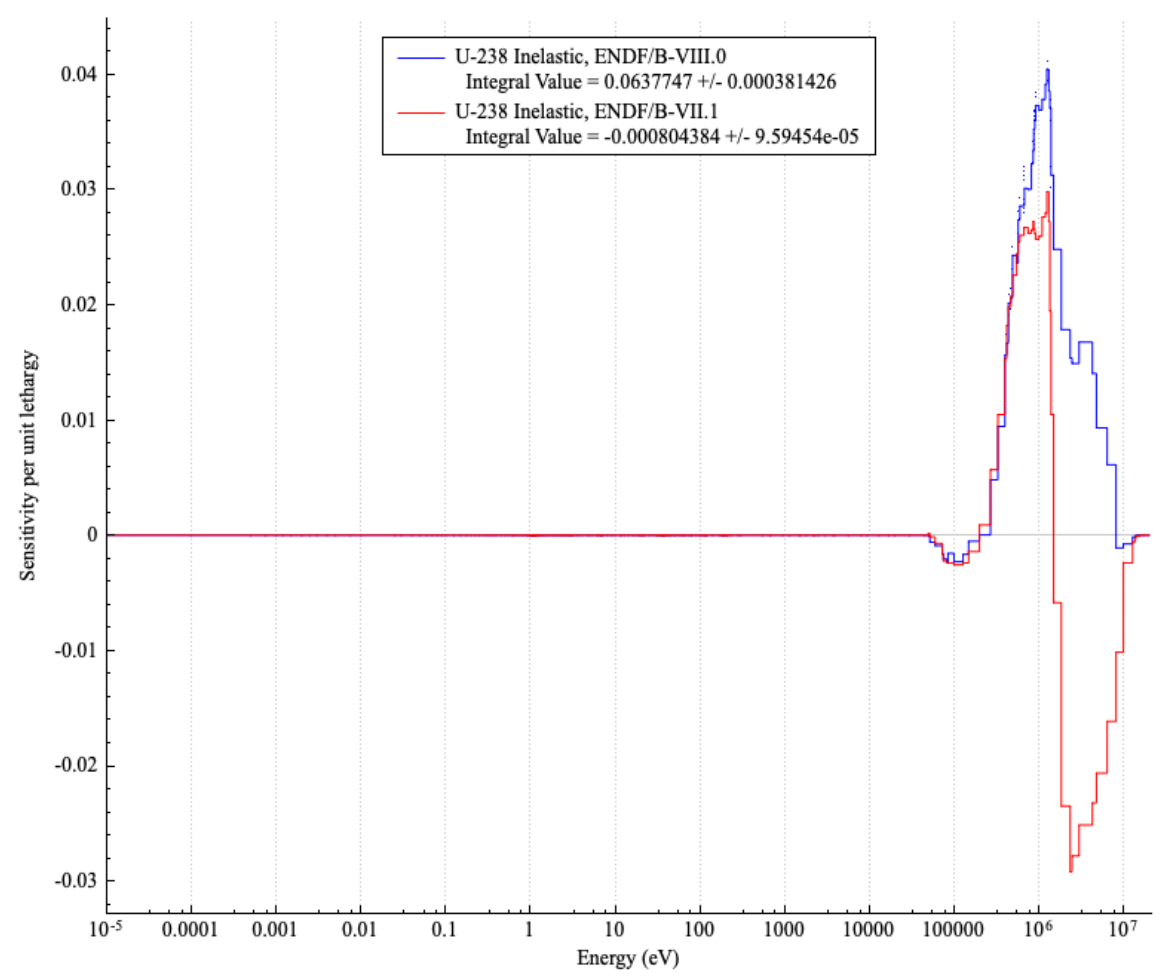

Figure 24. ${ }^{238} \mathrm{U}$ inelastic scattering profiles from the ENDF/B-VIII.0 and ENDF/B-VII.1 libraries with TSUNAMI-3D. 
The SDF for the ENDF/B-VII.1 library was generated by using SCALE 6.2.2 and the SDF for the ENDF/B-VIII.0 library was generated by using SCALE 6.3.b12. For the unresolved resonance region, SCALE 6.2.2 does not recalculate the total cross section after sampling the flux for inelastic scattering from this region. However, SCALE 6.3.b12 does recalculate the total cross section and thus results in a different sensitivity profile for inelastic scattering. A second SDF was then generated with SCALE 6.3.b12 and ENDF/B-VII.1 and compared with the one from the ENDF/B-VIII.0 library, as shown in Figure 25. The overall integral values are much more in line with each other, and the $c_{k}$ and $E$ values increase to 0.9996 and 0.9998 , respectively with the ENDF/B-VIII.0 56-group covariance library. These values are thus reported in Table 17 along with the $c_{k}$ and $E$ values for the ENDF/B-VII.1 56-group covariance library results with SDFs generated with SCALE 6.3.b12.

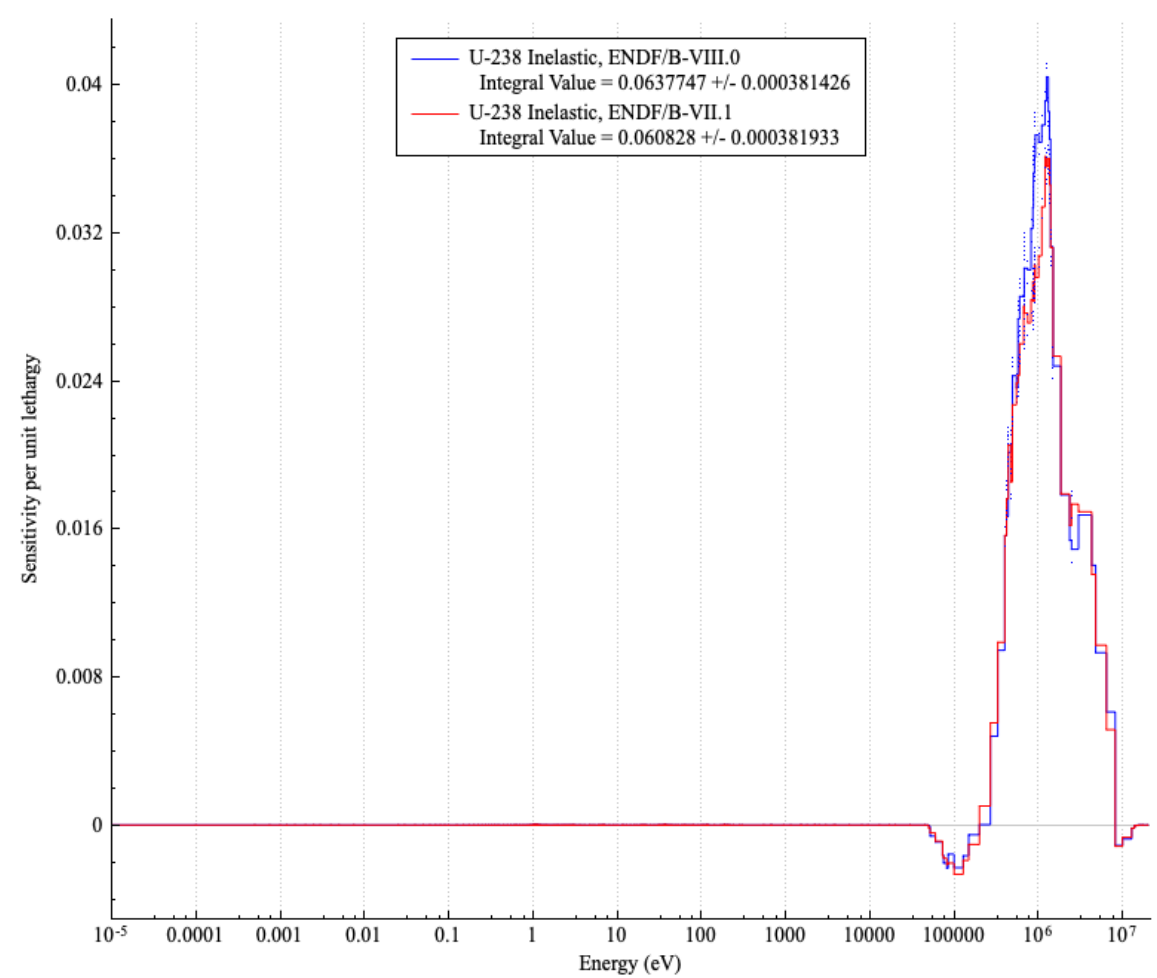

Figure 25. 238U inelastic scattering profiles from the ENDF/B-VIII.0 and ENDF/B-VII.1 libraries with TSUNAMI-3D and SCALE 6.3.b12. 


\section{SUMMARY AND CONCLUSIONS}

The results presented in this report provide the foundation for several conclusions regarding the comparison of the ENDF/B-VIII.0 and ENDF/B-VII.1 libraries via VALID. The average C/E values presented in Tables 4, 5, 13, and 14 indicate that the bias differences between the two libraries for all VALID cases are relatively small (less than $0.53 \% \Delta k$ ). The largest comparison bias difference between ENDF/B-VIII.0 and -VII. 1 for the 252-group library and KENO V.a was $-0.45 \% \Delta k$ for MST. For the CE libraries and KENO V.a, the largest bias difference was with PST at $-0.53 \% \Delta k$. The largest bias differences between the MG and CE libraries for KENO-VI were found in IMF at -0.25 and $0.18 \% \Delta k$, respectively. However, if the two IMF cases are removed, then the largest difference for the MG and CE libraries is found in MCT at $0.06 \% \Delta k$ and $\mathrm{HMF}$ at $0.06 \% \Delta k$, respectively.

The most noticeable differences between the two libraries are the treatment of mixed, plutonium, and ${ }^{233} \mathrm{U}$ systems. As noted previously, ${ }^{239} \mathrm{Pu}$ and ${ }^{233} \mathrm{U}$ cross sections have undergone adjustments that resulted in new evaluated data for both isotopes. For the mixed and plutonium solution systems, the overprediction of ${ }^{239} \mathrm{Pu}$ cross sections from the ENDF/B-VII.1 library was corrected, resulting in lower C/E values for these systems; however, this has resulted in a significant underprediction or negative bias of other thermal systems. ${ }^{233} \mathrm{U}$ cross sections were also adjusted to improve performance in the ICSBEP fast benchmarks, which have impacted all C/E values for ${ }^{233} \mathrm{U}$ systems. The MG and CE ENDF/B-VIII.0 libraries generally result in noticeably lower $\mathrm{C} / \mathrm{E}$ values compared with ENDF/B-VII.1. This same trend was observed by Brown et al. in the summary of $\mathrm{C} / \mathrm{E}$ values with the same ICSBEP benchmarks and ENDF/B-VIII.0 and MCNP6 [1].

The selected $c_{k}$ and E comparison results between the SDFs generated by TSUNAMI-3D indicate a high level of agreement between the two libraries with all values exceeding 0.99 after regenerating the sensitivity data for PMF-006-001 to account for a change in the physics treatment in TSUNAMI-3D. This demonstrates that systems analyzed with ENDF/B-VIII.0 libraries would be similarly affected by any nuclear data errors (i.e., cross section uncertainties) as the results generated with ENDF/B-VII.1 libraries.

Overall, although there are noticeable differences in C/E values between ENDF/B-VIII.0 and -VII.1 libraries, the magnitude of those differences is generally small when comparing both libraries across a range of systems commonly encountered in nuclear criticality safety applications. The thermal systems fueled with plutonium or a mixture of plutonium and uranium manifest a larger difference as a result of deliberate evaluation changes to lower the reactivity of plutonium solution systems. The results of the selected sensitivity comparisons also indicate a high degree of similarity between the same application system with different libraries as indicated by the high $\mathrm{c}_{\mathrm{k}}$ and $\mathrm{E}$ values. The data presented here are valuable because the results are based on models that are contained within VALID and have undergone extensive quality checks for validity, as described by Marshall and Reed [10]. 



\section{RECOMMENDATIONS FOR FUTURE WORK}

Recommendations for future work are summarized here, in no particular order.

- All VALID cases should be run with TSUNAMI-3D and the ENDF/B-VIII.0 library to acquire a complete picture of the sensitivity comparisons between ENDF/B-VIII.0 and -VII.1.

- The nuclear data uncertainty bands should be generated with the appropriate covariance data to examine the uncertainty in $k_{\text {eff }}$ associated with each experimental model due to cross section uncertainty.

- $\quad c_{k}$ and $E$ values below 0.99 should be further examined to identify whether other cases are affected by the calculational differences between SCALE 6.2.2 and 6.3.b12 when dealing with the unresolved resonance range of specific cross sections.

- As noted in the SCALE 6.2.2 validation report, additional cases should be added for KENO V.a and KENO-VI in VALID, as well as adding additional moderating materials, such as heavy water and graphite for advanced reactor concepts. 



\section{REFERENCES}

1. Brown, D.A., et al., ENDF/B-VIII. 0: the 8th major release of the nuclear reaction data library with CIELO-project cross sections, new standards and thermal scattering data. Nuclear Data Sheets, 2018. 148: p. 1-142.

2. SCALE Code System, M.A.J. B.T Rearden, Editor. 2017, Oak Ridge National Laboratory: Oak Ridge, Tennessee. p. 2747.

3. MCNP6 User's Manual D.B. Pelowitz, Editor. 2013, Los Alamos National Laboratory Los Alamos National Laboratory.

4. Wiarda, D.a.W., Mark L and Celik, Cihangir and Dunn, Michael E, AMPX: A Modern Cross Section Processing System for Generating Nuclear Data Libraries, in ICNC 2015. 2015: Charlotte, NC, USA.

5. W. J. Marshall, D.A.R., SCALE Procedure for Verified, Archived Library of Input and Data (VALID), in SCALE-CMP-012, Revision 2. 2013, Oak Ridge National Laboratory: Oak Ridge, TN.

6. International Handbook of Evaluated Criticality Safety Benchmark Experiments, ed. NEA/NSC/DOC. 2016, Paris, France: Nuclear Energy Agency/Organisation for Economic Cooperation and Development.

7. Chadwick, M.B., et al., ENDF/B-VII.1 Nuclear Data for Science and Technology: Cross Sections, Covariances, Fission Product Yields and Decay Data. Nuclear Data Sheets, 2011. 112(12): p. 2887-2996.

8. E. M. Saylor, W.J.M., J. B. Clarity, Z. J. Clifton, B. T. Reardon Criticality Safety Validation of SCALE 6.2.2. 2018, Oak Ridge National Laboratory.

9. W.J. Marshall, B.T.R., Criticality Safety Validation of SCALE 6.1. 2013, Oak Ridge National Laboratory: Oak Ridge, TN.

10. W. J. Marshall and D. A. Reed, "SCALE Procedure for Verified, Archived Library of Input and Data (VALID)," SCALE-CMP-012, Revision 2, Oak Ridge National Laboratory, Oak Ridge, TN (2013).

11. R. E. MacFarlane, D. W. Muir, and R. M. Boicourt, The NJOY Nuclear Data Processing System, Volume I: User's Manual, Los Alamos National Laboratory report LA-9303-M, Vol. I (ENDF324) (May 1982).

12. K. Shibata, O. Iwamoto, T. Nakagawa et al., "JENDL-4.0: A new library for nuclear science and engineering,” J. Nucl. Sci. Technol. 48, 1 (2011).

13. W. J. Marshall, "Bias between ENDF/B-VIII.0 and ENDF/B-VII.1 for LEU Pin Array Systems," ANS Winter Meeting, November 2019, Washington, DC.

14. A. Trkov, "CSEWG Validation - Contribution from the IAEA (Validation of codes for ACE libraries, LCT Benchmark analysis," CSEWG Meeting, November 2019, BNL 
APPENDIX A. DETAILED RESULTS FOR KENO V.A 



\section{APPENDIX A. DETAILED RESULTS FOR KENO V.A}

All uncertainties reported in this appendix are at the $1 \sigma$ level. The Monte Carlo experimental uncertainty values are absolute uncertainties and are reported in $\Delta k_{\text {eff }}$ units. The cross section uncertainty values are relative uncertainties and are reported in $\Delta k_{\text {eff }} / k_{\text {eff }}$ units.

Table A-1. Detailed ENDF/B-VIII.0 252-group results for KENO V.a HMF systems

\begin{tabular}{lcccccc}
\hline \multicolumn{1}{c}{ Case } & $\begin{array}{c}\text { Expected } \\
\boldsymbol{k}_{\text {eff }}\end{array}$ & $\begin{array}{c}\text { Experimental } \\
\text { uncertainty }\end{array}$ & $\boldsymbol{k}_{\text {eff }}$ & Uncertainty & C/E & $\begin{array}{c}\text { C/E } \\
\text { uncertainty }\end{array}$ \\
\hline $015-001$ & 0.9996 & 0.0017 & 0.99411 & 0.00010 & 0.99451 & 0.00169 \\
$016-001$ & 0.9996 & 0.0018 & 1.00041 & 0.00010 & 1.00081 & 0.00180 \\
$016-002$ & 0.9996 & 0.0018 & 0.99992 & 0.00010 & 1.00032 & 0.00180 \\
$017-001$ & 0.9993 & 0.0014 & 0.99956 & 0.00010 & 1.00026 & 0.00140 \\
$018-001$ & 1.0000 & 0.0014 & 1.00027 & 0.00010 & 1.00027 & 0.00140 \\
$018-001 \mathrm{~S}$ & 1.0000 & 0.0016 & 0.99941 & 0.00010 & 0.99941 & 0.00160 \\
$019-001$ & 1.0000 & 0.0028 & 1.00596 & 0.00010 & 1.00596 & 0.00282 \\
$019-001 \mathrm{~S}$ & 1.0000 & 0.0030 & 1.00604 & 0.00010 & 1.00604 & 0.00302 \\
$020-001$ & 1.0000 & 0.0028 & 1.00068 & 0.00010 & 1.00068 & 0.00280 \\
$020-001 \mathrm{~S}$ & 1.0000 & 0.0030 & 1.00040 & 0.00010 & 1.00040 & 0.00300 \\
$021-001$ & 1.0000 & 0.0024 & 1.00918 & 0.00010 & 1.00918 & 0.00242 \\
$021-001 \mathrm{~S}$ & 1.0000 & 0.0026 & 1.00908 & 0.00010 & 1.00908 & 0.00263 \\
$025-001$ & 0.9987 & 0.0014 & 0.99846 & 0.00010 & 0.99976 & 0.00140 \\
$025-002$ & 0.9990 & 0.0016 & 1.00051 & 0.00010 & 1.00151 & 0.00161 \\
$025-003$ & 0.9991 & 0.0016 & 1.00347 & 0.00010 & 1.00437 & 0.00161 \\
$025-004$ & 0.9995 & 0.0016 & 1.00436 & 0.00010 & 1.00486 & 0.00161 \\
$025-005$ & 0.9991 & 0.0016 & 1.00491 & 0.00010 & 1.00582 & 0.00161 \\
$030-001$ & 1.0000 & 0.0009 & 1.00254 & 0.00009 & 1.00254 & 0.00091 \\
$038-001$ & 0.9999 & 0.0007 & 1.00313 & 0.00009 & 1.00323 & 0.00071 \\
$038-002$ & 0.9999 & 0.0009 & 1.00355 & 0.00009 & 1.00365 & 0.00091 \\
$040-001$ & 0.9991 & 0.0011 & 1.00811 & 0.00010 & 1.00902 & 0.00112 \\
$052-001$ & 0.9993 & 0.0011 & 1.00673 & 0.00010 & 1.00744 & 0.00111 \\
$065-001$ & 0.9995 & 0.0013 & 0.99835 & 0.00010 & 0.99885 & 0.00130 \\
\hline
\end{tabular}

Table A-2. Detailed ENDF/B-VII.1 252-group results for KENO V.a HMF systems

\begin{tabular}{lcccccc}
\hline \multicolumn{1}{c}{ Case } & $\begin{array}{c}\text { Expected } \\
\boldsymbol{k}_{\text {eff }}\end{array}$ & $\begin{array}{c}\text { Experimental } \\
\text { uncertainty }\end{array}$ & $\boldsymbol{k}_{\text {eff }}$ & Uncertainty & C/E & $\begin{array}{c}\text { C/E } \\
\text { uncertainty }\end{array}$ \\
\hline $015-001$ & 0.9996 & 0.0017 & 0.99369 & 0.00010 & 0.99408 & 0.00169 \\
$016-001$ & 0.9996 & 0.0018 & 1.00132 & 0.00010 & 1.00172 & 0.00181 \\
$016-002$ & 0.9996 & 0.0018 & 1.00076 & 0.00010 & 1.00116 & 0.00181 \\
$017-001$ & 0.9993 & 0.0014 & 1.00087 & 0.00010 & 1.00157 & 0.00141 \\
$018-001$ & 1.0000 & 0.0014 & 1.00029 & 0.00010 & 1.00029 & 0.00140 \\
$018-001 \mathrm{~S}$ & 1.0000 & 0.0016 & 0.99964 & 0.00010 & 0.99964 & 0.00160 \\
$019-001$ & 1.0000 & 0.0028 & 1.00729 & 0.00010 & 1.00729 & 0.00282 \\
$019-001 \mathrm{~S}$ & 1.0000 & 0.0030 & 1.00696 & 0.00010 & 1.00696 & 0.00302 \\
$020-001$ & 1.0000 & 0.0028 & 1.00084 & 0.00010 & 1.00084 & 0.00280 \\
$020-001 \mathrm{~S}$ & 1.0000 & 0.0030 & 1.00067 & 0.00010 & 1.00067 & 0.00300 \\
$021-001$ & 1.0000 & 0.0024 & 1.00683 & 0.00010 & 1.00683 & 0.00242 \\
$021-001 \mathrm{~S}$ & 1.0000 & 0.0026 & 1.00709 & 0.00010 & 1.00709 & 0.00262 \\
$025-001$ & 0.9987 & 0.0014 & 0.99826 & 0.00010 & 0.99956 & 0.00140 \\
$025-002$ & 0.9990 & 0.0016 & 1.00050 & 0.00010 & 1.00151 & 0.00161 \\
$025-003$ & 0.9991 & 0.0016 & 1.00319 & 0.00010 & 1.00410 & 0.00161 \\
$025-004$ & 0.9995 & 0.0016 & 1.00443 & 0.00010 & 1.00493 & 0.00161 \\
$025-005$ & 0.9991 & 0.0016 & 1.00494 & 0.00010 & 1.00584 & 0.00161 \\
$030-001$ & 1.0000 & 0.0009 & 1.00325 & 0.00009 & 1.00325 & 0.00091 \\
$038-001$ & 0.9999 & 0.0007 & 1.00459 & 0.00009 & 1.00469 & 0.00071 \\
$038-002$ & 0.9999 & 0.0009 & 1.00349 & 0.00009 & 1.00359 & 0.00091 \\
$040-001$ & 0.9991 & 0.0011 & 1.00800 & 0.00010 & 1.00890 & 0.00112 \\
$052-001$ & 0.9993 & 0.0011 & 1.00756 & 0.00010 & 1.00827 & 0.00111 \\
$065-001$ & 0.9995 & 0.0013 & 0.99795 & 0.00010 & 0.99845 & 0.00130 \\
\hline
\end{tabular}


Table A-3. Detailed ENDF/B-VIII.0 CE results for KENO V.a HMF systems

\begin{tabular}{lcccccc}
\hline \multicolumn{1}{c}{ Case } & $\begin{array}{c}\text { Expected } \\
\boldsymbol{k}_{\text {eff }}\end{array}$ & $\begin{array}{c}\text { Experimental } \\
\text { uncertainty }\end{array}$ & $\boldsymbol{k}_{\text {eff }}$ & Uncertainty & $\mathbf{C} / \mathbf{E}$ & $\begin{array}{c}\text { C/E } \\
\text { uncertainty }\end{array}$ \\
\hline $015-001$ & 0.9996 & 0.0017 & 0.99481 & 0.00010 & 0.99521 & 0.00170 \\
$016-001$ & 0.9996 & 0.0018 & 1.00021 & 0.00010 & 1.00061 & 0.00180 \\
$016-002$ & 0.9996 & 0.0018 & 1.00129 & 0.00010 & 1.00169 & 0.00181 \\
$017-001$ & 0.9993 & 0.0014 & 0.99887 & 0.00010 & 0.99957 & 0.00140 \\
$018-001$ & 1.0000 & 0.0014 & 1.00031 & 0.00010 & 1.00031 & 0.00140 \\
$018-001 \mathrm{~S}$ & 1.0000 & 0.0016 & 0.99961 & 0.00010 & 0.99961 & 0.00160 \\
$019-001$ & 1.0000 & 0.0028 & 1.00578 & 0.00010 & 1.00578 & 0.00282 \\
$019-001 \mathrm{~S}$ & 1.0000 & 0.0030 & 1.00587 & 0.00010 & 1.00587 & 0.00302 \\
$020-001$ & 1.0000 & 0.0028 & 1.00016 & 0.00010 & 1.00016 & 0.00280 \\
$020-001 \mathrm{~S}$ & 1.0000 & 0.0030 & 1.00010 & 0.00010 & 1.00010 & 0.00300 \\
$021-001$ & 1.0000 & 0.0024 & 0.99971 & 0.00010 & 0.99971 & 0.00240 \\
$021-001 \mathrm{~S}$ & 1.0000 & 0.0026 & 0.99997 & 0.00010 & 0.99997 & 0.00260 \\
$025-001$ & 0.9987 & 0.0014 & 0.99888 & 0.00010 & 1.00018 & 0.00141 \\
$025-002$ & 0.9990 & 0.0016 & 1.00126 & 0.00010 & 1.00226 & 0.00161 \\
$025-003$ & 0.9991 & 0.0016 & 1.00396 & 0.00010 & 1.00487 & 0.00161 \\
$025-004$ & 0.9995 & 0.0016 & 1.00528 & 0.00010 & 1.00578 & 0.00161 \\
$025-005$ & 0.9991 & 0.0016 & 1.00577 & 0.00010 & 1.00668 & 0.00162 \\
$030-001$ & 1.0000 & 0.0009 & 1.00099 & 0.00008 & 1.00099 & 0.00090 \\
$038-001$ & 0.9999 & 0.0007 & 1.00138 & 0.00009 & 1.00148 & 0.00071 \\
$038-002$ & 0.9999 & 0.0009 & 1.00154 & 0.00009 & 1.00164 & 0.00091 \\
$040-001$ & 0.9991 & 0.0011 & 1.00469 & 0.00010 & 1.00559 & 0.00111 \\
$052-001$ & 0.9993 & 0.0011 & 1.00359 & 0.00010 & 1.00429 & 0.00111 \\
$065-001$ & 0.9995 & 0.0013 & 0.99834 & 0.00010 & 0.99884 & 0.00130 \\
\hline
\end{tabular}

Table A-4. Detailed ENDF/B-VII.1 CE results for KENO V.a HMF systems

\begin{tabular}{lcccccc}
\hline Case & $\begin{array}{c}\text { Expected } \\
\boldsymbol{k}_{\text {eff }}\end{array}$ & $\begin{array}{c}\text { Experimental } \\
\text { uncertainty }\end{array}$ & $\boldsymbol{k}_{\text {eff }}$ & Uncertainty & C/E & $\begin{array}{c}\text { C/E } \\
\text { uncertainty }\end{array}$ \\
\hline $015-001$ & 0.9996 & 0.0017 & 0.99459 & 0.00010 & 0.99499 & 0.00170 \\
$016-001$ & 0.9996 & 0.0018 & 1.00137 & 0.00010 & 1.00177 & 0.00181 \\
$016-002$ & 0.9996 & 0.0018 & 1.00223 & 0.00010 & 1.00263 & 0.00181 \\
$017-001$ & 0.9993 & 0.0014 & 1.00046 & 0.00010 & 1.00116 & 0.00141 \\
$018-001$ & 1.0000 & 0.0014 & 1.00014 & 0.00010 & 1.00014 & 0.00140 \\
$018-001 \mathrm{~S}$ & 1.0000 & 0.0016 & 0.99971 & 0.00010 & 0.99971 & 0.00160 \\
$019-001$ & 1.0000 & 0.0028 & 1.00721 & 0.00010 & 1.00721 & 0.00282 \\
$019-001 \mathrm{~S}$ & 1.0000 & 0.0030 & 1.00717 & 0.00010 & 1.00717 & 0.00302 \\
$020-001$ & 1.0000 & 0.0028 & 1.00088 & 0.00010 & 1.00088 & 0.00280 \\
$020-001 \mathrm{~S}$ & 1.0000 & 0.0030 & 1.00055 & 0.00010 & 1.00055 & 0.00300 \\
$021-001$ & 1.0000 & 0.0024 & 0.99611 & 0.00010 & 0.99611 & 0.00239 \\
$021-001 \mathrm{~S}$ & 1.0000 & 0.0026 & 0.99642 & 0.00010 & 0.99642 & 0.00259 \\
$025-001$ & 0.9987 & 0.0014 & 0.99889 & 0.00010 & 1.00019 & 0.00141 \\
$025-002$ & 0.9990 & 0.0016 & 1.00112 & 0.00010 & 1.00212 & 0.00161 \\
$025-003$ & 0.9991 & 0.0016 & 1.00381 & 0.00010 & 1.00472 & 0.00161 \\
$025-004$ & 0.9995 & 0.0016 & 1.00545 & 0.00010 & 1.00596 & 0.00161 \\
$025-005$ & 0.9991 & 0.0016 & 1.00568 & 0.00010 & 1.00658 & 0.00162 \\
$030-001$ & 1.0000 & 0.0009 & 1.00207 & 0.00009 & 1.00207 & 0.00091 \\
$038-001$ & 0.9999 & 0.0007 & 1.00314 & 0.00009 & 1.00324 & 0.00071 \\
$038-002$ & 0.9999 & 0.0009 & 1.00202 & 0.00008 & 1.00212 & 0.00091 \\
$040-001$ & 0.9991 & 0.0011 & 1.00457 & 0.00010 & 1.00547 & 0.00111 \\
$052-001$ & 0.9993 & 0.0011 & 1.00516 & 0.00010 & 1.00587 & 0.00111 \\
$065-001$ & 0.9995 & 0.0013 & 0.99801 & 0.00010 & 0.99851 & 0.00130 \\
\hline
\end{tabular}


Table A-5. Detailed ENDF/B-VIII.0 252-group results for KENO V.a HST systems

\begin{tabular}{|c|c|c|c|c|c|c|}
\hline Case & $\begin{array}{c}\text { Expected } \\
\boldsymbol{k}_{\text {eff }}\end{array}$ & $\begin{array}{c}\text { Experimental } \\
\text { uncertainty }\end{array}$ & $\boldsymbol{k}_{\text {eff }}$ & Uncertainty & $\mathbf{C} / \mathbf{E}$ & $\begin{array}{c}\mathbf{C} / \mathbf{E} \\
\text { uncertainty }\end{array}$ \\
\hline $001-001$ & 1.0004 & 0.0060 & 0.99869 & 0.00010 & 0.99829 & 0.00599 \\
\hline 001-002 & 1.0021 & 0.0072 & 0.99577 & 0.00010 & 0.99368 & 0.00714 \\
\hline $001-003$ & 1.0003 & 0.0035 & 1.00182 & 0.00010 & 1.00152 & 0.00351 \\
\hline 001-004 & 1.0008 & 0.0053 & 0.99796 & 0.00010 & 0.99716 & 0.00528 \\
\hline $001-005$ & 1.0001 & 0.0049 & 0.99805 & 0.00010 & 0.99795 & 0.00489 \\
\hline $001-006$ & 1.0002 & 0.0046 & 1.00152 & 0.00010 & 1.00132 & 0.00461 \\
\hline 001-007 & 1.0008 & 0.0040 & 0.99787 & 0.00010 & 0.99707 & 0.00399 \\
\hline 001-008 & 0.9998 & 0.0038 & 0.99818 & 0.00010 & 0.99838 & 0.00380 \\
\hline 001-009 & 1.0008 & 0.0054 & 0.99386 & 0.00010 & 0.99306 & 0.00536 \\
\hline 001-010 & 0.9993 & 0.0054 & 0.99197 & 0.00010 & 0.99266 & 0.00537 \\
\hline 013-001 & 1.0012 & 0.0026 & 0.99813 & 0.00010 & 0.99694 & 0.00259 \\
\hline 013-002 & 1.0007 & 0.0036 & 0.99760 & 0.00010 & 0.99690 & 0.00359 \\
\hline 013-003 & 1.0009 & 0.0036 & 0.99422 & 0.00010 & 0.99332 & 0.00357 \\
\hline 013-004 & 1.0003 & 0.0036 & 0.99580 & 0.00010 & 0.99550 & 0.00358 \\
\hline 014-001 & 1.0000 & 0.0028 & 0.99498 & 0.00010 & 0.99498 & 0.00279 \\
\hline 014-002 & 1.0000 & 0.0052 & 1.01170 & 0.00019 & 1.01170 & 0.00526 \\
\hline 014-003 & 1.0000 & 0.0087 & 1.02077 & 0.00019 & 1.02077 & 0.00888 \\
\hline 016-001 & 1.0000 & 0.0036 & 0.99144 & 0.00019 & 0.99144 & 0.00357 \\
\hline 016-002 & 1.0000 & 0.0069 & 1.00743 & 0.00019 & 1.00743 & 0.00695 \\
\hline 016-003 & 1.0000 & 0.0079 & 1.02613 & 0.00019 & 1.02613 & 0.00811 \\
\hline 028-001 & 1.0000 & 0.0023 & 0.99721 & 0.00010 & 0.99721 & 0.00230 \\
\hline 028-002 & 1.0000 & 0.0034 & 0.99747 & 0.00009 & 0.99747 & 0.00339 \\
\hline $028-003$ & 1.0000 & 0.0026 & 0.99902 & 0.00010 & 0.99902 & 0.00260 \\
\hline 028-004 & 1.0000 & 0.0028 & 0.99903 & 0.00009 & 0.99903 & 0.00280 \\
\hline $028-005$ & 1.0000 & 0.0031 & 0.99453 & 0.00010 & 0.99453 & 0.00308 \\
\hline $028-006$ & 1.0000 & 0.0023 & 0.99769 & 0.00010 & 0.99769 & 0.00230 \\
\hline 028-007 & 1.0000 & 0.0038 & 0.99836 & 0.00010 & 0.99836 & 0.00380 \\
\hline 028-008 & 1.0000 & 0.0027 & 0.99800 & 0.00010 & 0.99800 & 0.00270 \\
\hline 028-009 & 1.0000 & 0.0049 & 0.99731 & 0.00010 & 0.99731 & 0.00489 \\
\hline 028-010 & 1.0000 & 0.0053 & 0.99527 & 0.00010 & 0.99527 & 0.00528 \\
\hline 028-011 & 1.0000 & 0.0051 & 0.99876 & 0.00010 & 0.99876 & 0.00509 \\
\hline 028-012 & 1.0000 & 0.0046 & 0.99573 & 0.00010 & 0.99573 & 0.00458 \\
\hline 028-013 & 1.0000 & 0.0058 & 0.99761 & 0.00010 & 0.99761 & 0.00579 \\
\hline 028-014 & 1.0000 & 0.0046 & 0.99734 & 0.00010 & 0.99734 & 0.00459 \\
\hline $028-015$ & 1.0000 & 0.0064 & 1.00561 & 0.00010 & 1.00561 & 0.00644 \\
\hline 028-016 & 1.0000 & 0.0052 & 1.00152 & 0.00010 & 1.00152 & 0.00521 \\
\hline 028-017 & 1.0000 & 0.0066 & 0.99682 & 0.00010 & 0.99682 & 0.00658 \\
\hline 028-018 & 1.0000 & 0.0060 & 0.99755 & 0.00010 & 0.99755 & 0.00599 \\
\hline 029-001 & 1.0000 & 0.0066 & 0.99897 & 0.00010 & 0.99897 & 0.00659 \\
\hline 029-002 & 1.0000 & 0.0058 & 1.00213 & 0.00010 & 1.00213 & 0.00581 \\
\hline $029-003$ & 1.0000 & 0.0068 & 0.99445 & 0.00010 & 0.99445 & 0.00676 \\
\hline 029-004 & 1.0000 & 0.0074 & 0.99277 & 0.00010 & 0.99277 & 0.00735 \\
\hline 029-005 & 1.0000 & 0.0067 & 0.99770 & 0.00010 & 0.99770 & 0.00669 \\
\hline 029-006 & 1.0000 & 0.0065 & 0.99825 & 0.00010 & 0.99825 & 0.00649 \\
\hline $029-007$ & 1.0000 & 0.0063 & 0.99910 & 0.00010 & 0.99910 & 0.00630 \\
\hline 030-001 & 1.0000 & 0.0039 & 0.99728 & 0.00010 & 0.99728 & 0.00389 \\
\hline 030-002 & 1.0000 & 0.0032 & 0.99728 & 0.00010 & 0.99728 & 0.00319 \\
\hline 030-003 & 1.0000 & 0.0031 & 0.99563 & 0.00009 & 0.99563 & 0.00309 \\
\hline 030-004 & 1.0000 & 0.0064 & 1.00113 & 0.00010 & 1.00113 & 0.00641 \\
\hline $030-005$ & 1.0000 & 0.0058 & 0.99703 & 0.00010 & 0.99703 & 0.00578 \\
\hline $030-006$ & 1.0000 & 0.0059 & 0.99875 & 0.00010 & 0.99875 & 0.00589 \\
\hline $030-007$ & 1.0000 & 0.0064 & 0.99762 & 0.00010 & 0.99762 & 0.00639 \\
\hline
\end{tabular}


Table A-6. Detailed ENDF/B-VII.1 252-group results for KENO V.a HST systems

\begin{tabular}{|c|c|c|c|c|c|c|}
\hline Case & $\begin{array}{c}\text { Expected } \\
\boldsymbol{k}_{\text {eff }}\end{array}$ & $\begin{array}{c}\text { Experimental } \\
\text { uncertainty }\end{array}$ & $\boldsymbol{k}_{\text {eff }}$ & Uncertainty & $\mathbf{C} / \mathbf{E}$ & $\begin{array}{c}\mathbf{C} / \mathbf{E} \\
\text { uncertainty }\end{array}$ \\
\hline $001-001$ & 1.0004 & 0.0060 & 0.99548 & 0.00010 & 0.99508 & 0.00597 \\
\hline 001-002 & 1.0021 & 0.0072 & 0.99363 & 0.00010 & 0.99155 & 0.00712 \\
\hline $001-003$ & 1.0003 & 0.0035 & 0.99892 & 0.00010 & 0.99862 & 0.00350 \\
\hline 001-004 & 1.0008 & 0.0053 & 0.99593 & 0.00010 & 0.99513 & 0.00527 \\
\hline $001-005$ & 1.0001 & 0.0049 & 0.99536 & 0.00010 & 0.99526 & 0.00488 \\
\hline 001-006 & 1.0002 & 0.0046 & 0.99871 & 0.00010 & 0.99851 & 0.00459 \\
\hline 001-007 & 1.0008 & 0.0040 & 0.99517 & 0.00010 & 0.99438 & 0.00398 \\
\hline 001-008 & 0.9998 & 0.0038 & 0.99527 & 0.00010 & 0.99547 & 0.00378 \\
\hline 001-009 & 1.0008 & 0.0054 & 0.99174 & 0.00010 & 0.99095 & 0.00535 \\
\hline 001-010 & 0.9993 & 0.0054 & 0.98941 & 0.00010 & 0.99010 & 0.00535 \\
\hline 013-001 & 1.0012 & 0.0026 & 0.99748 & 0.00009 & 0.99628 & 0.00259 \\
\hline 013-002 & 1.0007 & 0.0036 & 0.99675 & 0.00010 & 0.99605 & 0.00358 \\
\hline 013-003 & 1.0009 & 0.0036 & 0.99335 & 0.00010 & 0.99245 & 0.00357 \\
\hline 013-004 & 1.0003 & 0.0036 & 0.99466 & 0.00010 & 0.99436 & 0.00358 \\
\hline 014-001 & 1.0000 & 0.0028 & 0.99219 & 0.00010 & 0.99219 & 0.00278 \\
\hline 014-002 & 1.0000 & 0.0052 & 1.00917 & 0.00019 & 1.00917 & 0.00525 \\
\hline 014-003 & 1.0000 & 0.0087 & 1.01795 & 0.00019 & 1.01795 & 0.00886 \\
\hline 016-001 & 1.0000 & 0.0036 & 0.98848 & 0.00019 & 0.98848 & 0.00356 \\
\hline 016-002 & 1.0000 & 0.0069 & 1.00418 & 0.00019 & 1.00418 & 0.00693 \\
\hline 016-003 & 1.0000 & 0.0079 & 1.02351 & 0.00019 & 1.02351 & 0.00809 \\
\hline 028-001 & 1.0000 & 0.0023 & 0.99429 & 0.00010 & 0.99429 & 0.00229 \\
\hline 028-002 & 1.0000 & 0.0034 & 0.99521 & 0.00009 & 0.99521 & 0.00338 \\
\hline $028-003$ & 1.0000 & 0.0026 & 0.99592 & 0.00010 & 0.99592 & 0.00259 \\
\hline 028-004 & 1.0000 & 0.0028 & 0.99678 & 0.00010 & 0.99678 & 0.00279 \\
\hline 028-005 & 1.0000 & 0.0031 & 0.99139 & 0.00010 & 0.99139 & 0.00307 \\
\hline 028-006 & 1.0000 & 0.0023 & 0.99509 & 0.00009 & 0.99509 & 0.00229 \\
\hline 028-007 & 1.0000 & 0.0038 & 0.99538 & 0.00010 & 0.99538 & 0.00378 \\
\hline 028-008 & 1.0000 & 0.0027 & 0.99547 & 0.00009 & 0.99547 & 0.00269 \\
\hline 028-009 & 1.0000 & 0.0049 & 0.99429 & 0.00010 & 0.99429 & 0.00487 \\
\hline 028-010 & 1.0000 & 0.0053 & 0.99334 & 0.00010 & 0.99334 & 0.00527 \\
\hline $028-011$ & 1.0000 & 0.0051 & 0.99594 & 0.00010 & 0.99594 & 0.00508 \\
\hline 028-012 & 1.0000 & 0.0046 & 0.99359 & 0.00010 & 0.99359 & 0.00457 \\
\hline $028-013$ & 1.0000 & 0.0058 & 0.99493 & 0.00010 & 0.99493 & 0.00577 \\
\hline 028-014 & 1.0000 & 0.0046 & 0.99503 & 0.00010 & 0.99503 & 0.00458 \\
\hline $028-015$ & 1.0000 & 0.0064 & 1.00312 & 0.00010 & 1.00312 & 0.00642 \\
\hline $028-016$ & 1.0000 & 0.0052 & 0.99921 & 0.00010 & 0.99921 & 0.00520 \\
\hline 028-017 & 1.0000 & 0.0066 & 0.99446 & 0.00010 & 0.99446 & 0.00656 \\
\hline 028-018 & 1.0000 & 0.0060 & 0.99529 & 0.00010 & 0.99529 & 0.00597 \\
\hline 029-001 & 1.0000 & 0.0066 & 0.99620 & 0.00010 & 0.99620 & 0.00658 \\
\hline 029-002 & 1.0000 & 0.0058 & 1.00022 & 0.00010 & 1.00022 & 0.00580 \\
\hline $029-003$ & 1.0000 & 0.0068 & 0.99262 & 0.00010 & 0.99262 & 0.00675 \\
\hline 029-004 & 1.0000 & 0.0074 & 0.99160 & 0.00010 & 0.99160 & 0.00734 \\
\hline $029-005$ & 1.0000 & 0.0067 & 0.99670 & 0.00010 & 0.99670 & 0.00668 \\
\hline 029-006 & 1.0000 & 0.0065 & 0.99659 & 0.00010 & 0.99659 & 0.00648 \\
\hline $029-007$ & 1.0000 & 0.0063 & 0.99715 & 0.00010 & 0.99715 & 0.00628 \\
\hline 030-001 & 1.0000 & 0.0039 & 0.99411 & 0.00010 & 0.99411 & 0.00388 \\
\hline 030-002 & 1.0000 & 0.0032 & 0.99518 & 0.00010 & 0.99518 & 0.00319 \\
\hline $030-003$ & 1.0000 & 0.0031 & 0.99368 & 0.00009 & 0.99368 & 0.00308 \\
\hline 030-004 & 1.0000 & 0.0064 & 0.99837 & 0.00010 & 0.99837 & 0.00639 \\
\hline $030-005$ & 1.0000 & 0.0058 & 0.99471 & 0.00010 & 0.99471 & 0.00577 \\
\hline $030-006$ & 1.0000 & 0.0059 & 0.99691 & 0.00010 & 0.99691 & 0.00588 \\
\hline $030-007$ & 1.0000 & 0.0064 & 0.99606 & 0.00010 & 0.99606 & 0.00638 \\
\hline
\end{tabular}


Table A-7. Detailed ENDF/B-VIII.0 CE results for KENO V.a HST systems

\begin{tabular}{|c|c|c|c|c|c|c|}
\hline Case & $\begin{array}{c}\text { Expected } \\
\boldsymbol{k}_{\text {eff }}\end{array}$ & $\begin{array}{c}\text { Experimental } \\
\text { uncertainty }\end{array}$ & $\boldsymbol{k}_{\text {eff }}$ & Uncertainty & $\mathbf{C} / \mathbf{E}$ & $\begin{array}{c}\mathbf{C} / \mathbf{E} \\
\text { uncertainty }\end{array}$ \\
\hline $001-001$ & 1.0004 & 0.0060 & 0.99784 & 0.00010 & 0.99744 & 0.00598 \\
\hline 001-002 & 1.0021 & 0.0072 & 0.99450 & 0.00010 & 0.99242 & 0.00713 \\
\hline $001-003$ & 1.0003 & 0.0035 & 1.00092 & 0.00010 & 1.00062 & 0.00350 \\
\hline 001-004 & 1.0008 & 0.0053 & 0.99673 & 0.00010 & 0.99594 & 0.00528 \\
\hline $001-005$ & 1.0001 & 0.0049 & 0.99799 & 0.00010 & 0.99789 & 0.00489 \\
\hline 001-006 & 1.0002 & 0.0046 & 1.00105 & 0.00010 & 1.00085 & 0.00460 \\
\hline 001-007 & 1.0008 & 0.0040 & 0.99726 & 0.00010 & 0.99646 & 0.00398 \\
\hline 001-008 & 0.9998 & 0.0038 & 0.99740 & 0.00010 & 0.99760 & 0.00379 \\
\hline 001-009 & 1.0008 & 0.0054 & 0.99273 & 0.00010 & 0.99193 & 0.00535 \\
\hline 001-010 & 0.9993 & 0.0054 & 0.99176 & 0.00010 & 0.99245 & 0.00536 \\
\hline 013-001 & 1.0012 & 0.0026 & 0.99836 & 0.00010 & 0.99717 & 0.00259 \\
\hline 013-002 & 1.0007 & 0.0036 & 0.99757 & 0.00010 & 0.99687 & 0.00359 \\
\hline 013-003 & 1.0009 & 0.0036 & 0.99443 & 0.00010 & 0.99354 & 0.00357 \\
\hline 013-004 & 1.0003 & 0.0036 & 0.99590 & 0.00010 & 0.99560 & 0.00358 \\
\hline 014-001 & 1.0000 & 0.0028 & 0.99457 & 0.00009 & 0.99457 & 0.00279 \\
\hline 014-002 & 1.0000 & 0.0052 & 1.01146 & 0.00019 & 1.01146 & 0.00526 \\
\hline 014-003 & 1.0000 & 0.0087 & 1.01996 & 0.00019 & 1.01996 & 0.00888 \\
\hline 016-001 & 1.0000 & 0.0036 & 0.99053 & 0.00019 & 0.99053 & 0.00357 \\
\hline 016-002 & 1.0000 & 0.0069 & 1.00716 & 0.00019 & 1.00716 & 0.00695 \\
\hline 016-003 & 1.0000 & 0.0079 & 1.02590 & 0.00019 & 1.02590 & 0.00811 \\
\hline 028-001 & 1.0000 & 0.0023 & 0.99685 & 0.00009 & 0.99685 & 0.00229 \\
\hline 028-002 & 1.0000 & 0.0034 & 0.99699 & 0.00009 & 0.99699 & 0.00339 \\
\hline $028-003$ & 1.0000 & 0.0026 & 0.99855 & 0.00009 & 0.99855 & 0.00260 \\
\hline 028-004 & 1.0000 & 0.0028 & 0.99875 & 0.00009 & 0.99875 & 0.00280 \\
\hline 028-005 & 1.0000 & 0.0031 & 0.99400 & 0.00010 & 0.99400 & 0.00308 \\
\hline 028-006 & 1.0000 & 0.0023 & 0.99713 & 0.00009 & 0.99713 & 0.00230 \\
\hline 028-007 & 1.0000 & 0.0038 & 0.99791 & 0.00009 & 0.99791 & 0.00379 \\
\hline 028-008 & 1.0000 & 0.0027 & 0.99763 & 0.00009 & 0.99763 & 0.00270 \\
\hline 028-009 & 1.0000 & 0.0049 & 0.99628 & 0.00010 & 0.99628 & 0.00488 \\
\hline 028-010 & 1.0000 & 0.0053 & 0.99440 & 0.00009 & 0.99440 & 0.00527 \\
\hline $028-011$ & 1.0000 & 0.0051 & 0.99770 & 0.00010 & 0.99770 & 0.00509 \\
\hline 028-012 & 1.0000 & 0.0046 & 0.99480 & 0.00010 & 0.99480 & 0.00458 \\
\hline $028-013$ & 1.0000 & 0.0058 & 0.99651 & 0.00010 & 0.99651 & 0.00578 \\
\hline 028-014 & 1.0000 & 0.0046 & 0.99638 & 0.00010 & 0.99638 & 0.00458 \\
\hline $028-015$ & 1.0000 & 0.0064 & 1.00442 & 0.00010 & 1.00442 & 0.00643 \\
\hline $028-016$ & 1.0000 & 0.0052 & 1.00036 & 0.00010 & 1.00036 & 0.00520 \\
\hline 028-017 & 1.0000 & 0.0066 & 0.99595 & 0.00010 & 0.99595 & 0.00657 \\
\hline 028-018 & 1.0000 & 0.0060 & 0.99660 & 0.00010 & 0.99660 & 0.00598 \\
\hline 029-001 & 1.0000 & 0.0066 & 0.99778 & 0.00010 & 0.99778 & 0.00659 \\
\hline 029-002 & 1.0000 & 0.0058 & 1.00140 & 0.00010 & 1.00140 & 0.00581 \\
\hline $029-003$ & 1.0000 & 0.0068 & 0.99362 & 0.00010 & 0.99362 & 0.00676 \\
\hline 029-004 & 1.0000 & 0.0074 & 0.99206 & 0.00010 & 0.99206 & 0.00734 \\
\hline $029-005$ & 1.0000 & 0.0067 & 0.99690 & 0.00010 & 0.99690 & 0.00668 \\
\hline $029-006$ & 1.0000 & 0.0065 & 0.99725 & 0.00010 & 0.99725 & 0.00648 \\
\hline $029-007$ & 1.0000 & 0.0063 & 0.99821 & 0.00010 & 0.99821 & 0.00629 \\
\hline 030-001 & 1.0000 & 0.0039 & 0.99668 & 0.00010 & 0.99668 & 0.00389 \\
\hline 030-002 & 1.0000 & 0.0032 & 0.99719 & 0.00009 & 0.99719 & 0.00319 \\
\hline $030-003$ & 1.0000 & 0.0031 & 0.99510 & 0.00009 & 0.99510 & 0.00309 \\
\hline 030-004 & 1.0000 & 0.0064 & 0.99997 & 0.00010 & 0.99997 & 0.00640 \\
\hline $030-005$ & 1.0000 & 0.0058 & 0.99591 & 0.00010 & 0.99591 & 0.00578 \\
\hline $030-006$ & 1.0000 & 0.0059 & 0.99793 & 0.00010 & 0.99793 & 0.00589 \\
\hline $030-007$ & 1.0000 & 0.0064 & 0.99661 & 0.00009 & 0.99661 & 0.00638 \\
\hline
\end{tabular}


Table A-8. Detailed ENDF/B-VII.1 CE results for KENO V.a HST systems

\begin{tabular}{|c|c|c|c|c|c|c|}
\hline Case & $\begin{array}{c}\text { Expected } \\
k_{\text {eff }}\end{array}$ & $\begin{array}{c}\text { Experimental } \\
\text { uncertainty }\end{array}$ & $\boldsymbol{k}_{\text {eff }}$ & Uncertainty & $\mathbf{C} / \mathbf{E}$ & $\begin{array}{c}\mathrm{C} / \mathrm{E} \\
\text { uncertainty }\end{array}$ \\
\hline $001-001$ & 1.0004 & 0.0060 & 0.99690 & 0.00010 & 0.99650 & 0.00598 \\
\hline 001-002 & 1.0021 & 0.0072 & 0.99490 & 0.00010 & 0.99282 & 0.00713 \\
\hline $001-003$ & 1.0003 & 0.0035 & 1.00060 & 0.00010 & 1.00030 & 0.00350 \\
\hline 001-004 & 1.0008 & 0.0053 & 0.99724 & 0.00010 & 0.99644 & 0.00528 \\
\hline $001-005$ & 1.0001 & 0.0049 & 0.99719 & 0.00010 & 0.99709 & 0.00489 \\
\hline 001-006 & 1.0002 & 0.0046 & 1.00041 & 0.00010 & 1.00021 & 0.00460 \\
\hline 001-007 & 1.0008 & 0.0040 & 0.99662 & 0.00010 & 0.99582 & 0.00398 \\
\hline 001-008 & 0.9998 & 0.0038 & 0.99687 & 0.00010 & 0.99707 & 0.00379 \\
\hline 001-009 & 1.0008 & 0.0054 & 0.99319 & 0.00010 & 0.99239 & 0.00536 \\
\hline 001-010 & 0.9993 & 0.0054 & 0.99090 & 0.00010 & 0.99160 & 0.00536 \\
\hline 013-001 & 1.0012 & 0.0026 & 0.99844 & 0.00010 & 0.99725 & 0.00259 \\
\hline 013-002 & 1.0007 & 0.0036 & 0.99753 & 0.00009 & 0.99683 & 0.00359 \\
\hline 013-003 & 1.0009 & 0.0036 & 0.99406 & 0.00010 & 0.99316 & 0.00357 \\
\hline 013-004 & 1.0003 & 0.0036 & 0.99559 & 0.00010 & 0.99529 & 0.00358 \\
\hline 014-001 & 1.0000 & 0.0028 & 0.99356 & 0.00009 & 0.99356 & 0.00278 \\
\hline 014-002 & 1.0000 & 0.0052 & 1.01032 & 0.00019 & 1.01032 & 0.00526 \\
\hline 014-003 & 1.0000 & 0.0087 & 1.01878 & 0.00019 & 1.01878 & 0.00887 \\
\hline 016-001 & 1.0000 & 0.0036 & 0.99006 & 0.00019 & 0.99006 & 0.00357 \\
\hline 016-002 & 1.0000 & 0.0069 & 1.00526 & 0.00019 & 1.00526 & 0.00694 \\
\hline 016-003 & 1.0000 & 0.0079 & 1.02441 & 0.00019 & 1.02441 & 0.00810 \\
\hline 028-001 & 1.0000 & 0.0023 & 0.99563 & 0.00009 & 0.99563 & 0.00229 \\
\hline 028-002 & 1.0000 & 0.0034 & 0.99647 & 0.00009 & 0.99647 & 0.00339 \\
\hline $028-003$ & 1.0000 & 0.0026 & 0.99733 & 0.00010 & 0.99733 & 0.00259 \\
\hline 028-004 & 1.0000 & 0.0028 & 0.99794 & 0.00009 & 0.99794 & 0.00280 \\
\hline 028-005 & 1.0000 & 0.0031 & 0.99269 & 0.00009 & 0.99269 & 0.00308 \\
\hline 028-006 & 1.0000 & 0.0023 & 0.99653 & 0.00009 & 0.99653 & 0.00229 \\
\hline 028-007 & 1.0000 & 0.0038 & 0.99689 & 0.00010 & 0.99689 & 0.00379 \\
\hline 028-008 & 1.0000 & 0.0027 & 0.99688 & 0.00009 & 0.99688 & 0.00269 \\
\hline 028-009 & 1.0000 & 0.0049 & 0.99563 & 0.00010 & 0.99563 & 0.00488 \\
\hline 028-010 & 1.0000 & 0.0053 & 0.99434 & 0.00010 & 0.99434 & 0.00527 \\
\hline $028-011$ & 1.0000 & 0.0051 & 0.99718 & 0.00010 & 0.99718 & 0.00509 \\
\hline 028-012 & 1.0000 & 0.0046 & 0.99456 & 0.00010 & 0.99456 & 0.00458 \\
\hline $028-013$ & 1.0000 & 0.0058 & 0.99607 & 0.00010 & 0.99607 & 0.00578 \\
\hline 028-014 & 1.0000 & 0.0046 & 0.99619 & 0.00010 & 0.99619 & 0.00458 \\
\hline $028-015$ & 1.0000 & 0.0064 & 1.00394 & 0.00010 & 1.00394 & 0.00643 \\
\hline $028-016$ & 1.0000 & 0.0052 & 1.00025 & 0.00010 & 1.00025 & 0.00520 \\
\hline 028-017 & 1.0000 & 0.0066 & 0.99552 & 0.00010 & 0.99552 & 0.00657 \\
\hline 028-018 & 1.0000 & 0.0060 & 0.99657 & 0.00010 & 0.99657 & 0.00598 \\
\hline 029-001 & 1.0000 & 0.0066 & 0.99762 & 0.00010 & 0.99762 & 0.00659 \\
\hline 029-002 & 1.0000 & 0.0058 & 1.00168 & 0.00010 & 1.00168 & 0.00581 \\
\hline $029-003$ & 1.0000 & 0.0068 & 0.99373 & 0.00010 & 0.99373 & 0.00676 \\
\hline 029-004 & 1.0000 & 0.0074 & 0.99260 & 0.00010 & 0.99260 & 0.00735 \\
\hline $029-005$ & 1.0000 & 0.0067 & 0.99744 & 0.00010 & 0.99744 & 0.00668 \\
\hline 029-006 & 1.0000 & 0.0065 & 0.99762 & 0.00010 & 0.99762 & 0.00649 \\
\hline $029-007$ & 1.0000 & 0.0063 & 0.99841 & 0.00010 & 0.99841 & 0.00629 \\
\hline 030-001 & 1.0000 & 0.0039 & 0.99564 & 0.00010 & 0.99564 & 0.00388 \\
\hline 030-002 & 1.0000 & 0.0032 & 0.99659 & 0.00009 & 0.99659 & 0.00319 \\
\hline $030-003$ & 1.0000 & 0.0031 & 0.99487 & 0.00009 & 0.99487 & 0.00309 \\
\hline 030-004 & 1.0000 & 0.0064 & 0.99961 & 0.00010 & 0.99961 & 0.00640 \\
\hline $030-005$ & 1.0000 & 0.0058 & 0.99571 & 0.00010 & 0.99571 & 0.00578 \\
\hline $030-006$ & 1.0000 & 0.0059 & 0.99797 & 0.00010 & 0.99797 & 0.00589 \\
\hline $030-007$ & 1.0000 & 0.0064 & 0.99703 & 0.00010 & 0.99703 & 0.00638 \\
\hline
\end{tabular}


Table A-9. Detailed ENDF/B-VIII.0 252-group results for KENO V.a IMF systems

\begin{tabular}{lcccrcc}
\hline \multicolumn{1}{c}{ Case } & $\begin{array}{c}\text { Expected } \\
\boldsymbol{k}_{\text {eff }}\end{array}$ & $\begin{array}{c}\text { Experimental } \\
\text { uncertainty }\end{array}$ & \multicolumn{1}{c}{$\boldsymbol{k}_{\text {eff }}$} & Uncertainty & C/E & $\begin{array}{c}\text { C/E } \\
\text { uncertainty }\end{array}$ \\
\hline $002-001$ & 1.0000 & 0.0030 & 0.99595 & 0.00010 & 0.99595 & 0.00299 \\
$003-001$ & 1.0000 & 0.0017 & 0.99983 & 0.00010 & 0.99983 & 0.00170 \\
$003-001 \mathrm{~S}$ & 1.0000 & 0.0019 & 0.99967 & 0.00010 & 0.99967 & 0.00190 \\
$004-001$ & 1.0000 & 0.0030 & 1.00473 & 0.00010 & 1.00473 & 0.00302 \\
$004-001 \mathrm{~S}$ & 1.0000 & 0.0032 & 1.00494 & 0.00010 & 1.00494 & 0.00322 \\
$005-001$ & 1.0000 & 0.0021 & 1.01044 & 0.00010 & 1.01044 & 0.00212 \\
$005-001 \mathrm{~S}$ & 1.0000 & 0.0023 & 1.01064 & 0.00010 & 1.01064 & 0.00233 \\
$006-001$ & 1.0000 & 0.0023 & 0.99908 & 0.00010 & 0.99908 & 0.00230 \\
$007-001$ & 1.0045 & 0.0007 & 1.00283 & 0.00010 & 0.99834 & 0.00070 \\
$008-001$ & 1.0000 & 0.0018 & 1.00283 & 0.00010 & 1.00283 & 0.00181 \\
$009-001$ & 1.0000 & 0.0053 & 1.00278 & 0.00010 & 1.00278 & 0.00532 \\
\hline
\end{tabular}

Table A-10. Detailed ENDF/B-VII.1 252-group results for KENO V.a IMF systems

\begin{tabular}{lcccrcc}
\hline \multicolumn{1}{c}{ Case } & $\begin{array}{c}\text { Expected } \\
\boldsymbol{k}_{\text {eff }}\end{array}$ & $\begin{array}{c}\text { Experimental } \\
\text { uncertainty }\end{array}$ & $\boldsymbol{k}_{\text {eff }}$ & Uncertainty & C/E & $\begin{array}{c}\mathbf{C} / \mathbf{E} \\
\text { uncertainty }\end{array}$ \\
\hline $002-001$ & 1.0000 & 0.0030 & 1.00027 & 0.00010 & 1.00027 & 0.00300 \\
$003-001$ & 1.0000 & 0.0017 & 1.00321 & 0.00010 & 1.00321 & 0.00171 \\
$003-001 \mathrm{~S}$ & 1.0000 & 0.0019 & 1.00328 & 0.00010 & 1.00328 & 0.00191 \\
$004-001$ & 1.0000 & 0.0030 & 1.00800 & 0.00010 & 1.00800 & 0.00303 \\
$004-001 \mathrm{~S}$ & 1.0000 & 0.0032 & 1.00793 & 0.00010 & 1.00793 & 0.00323 \\
$005-001$ & 1.0000 & 0.0021 & 1.01233 & 0.00010 & 1.01233 & 0.00213 \\
$005-001 \mathrm{~S}$ & 1.0000 & 0.0023 & 1.01216 & 0.00010 & 1.01216 & 0.00233 \\
$006-001$ & 1.0000 & 0.0023 & 1.00139 & 0.00010 & 1.00139 & 0.00231 \\
$007-001$ & 1.0045 & 0.0007 & 1.00463 & 0.00010 & 1.00013 & 0.00070 \\
$008-001$ & 1.0000 & 0.0018 & 1.00677 & 0.00010 & 1.00677 & 0.00181 \\
$009-001$ & 1.0000 & 0.0053 & 1.00750 & 0.00010 & 1.00750 & 0.00534 \\
\hline
\end{tabular}

Table A-11. Detailed ENDF/B-VIII.0 CE results for KENO V.a IMF systems

\begin{tabular}{lcccrcc}
\hline \multicolumn{1}{c}{ Case } & $\begin{array}{c}\text { Expected } \\
\boldsymbol{k}_{\text {eff }}\end{array}$ & $\begin{array}{c}\text { Experimental } \\
\text { uncertainty }\end{array}$ & $\boldsymbol{k}_{\text {eff }}$ & Uncertainty & C/E & $\begin{array}{c}\mathbf{C} / \mathbf{E} \\
\text { uncertainty }\end{array}$ \\
\hline $002-001$ & 1.0000 & 0.0030 & 0.99635 & 0.00010 & 0.99635 & 0.00299 \\
$003-001$ & 1.0000 & 0.0017 & 0.99967 & 0.00010 & 0.99967 & 0.00170 \\
$003-001 \mathrm{~S}$ & 1.0000 & 0.0019 & 1.00009 & 0.00010 & 1.00009 & 0.00190 \\
$004-001$ & 1.0000 & 0.0030 & 1.00475 & 0.00010 & 1.00475 & 0.00302 \\
$004-001 \mathrm{~S}$ & 1.0000 & 0.0032 & 1.00495 & 0.00010 & 1.00495 & 0.00322 \\
$005-001$ & 1.0000 & 0.0021 & 1.00102 & 0.00010 & 1.00102 & 0.00210 \\
$005-001 \mathrm{~S}$ & 1.0000 & 0.0023 & 1.00097 & 0.00010 & 1.00097 & 0.00230 \\
$006-001$ & 1.0000 & 0.0023 & 0.99400 & 0.00010 & 0.99400 & 0.00229 \\
$007-001$ & 1.0045 & 0.0007 & 1.00462 & 0.00010 & 1.00012 & 0.00070 \\
$008-001$ & 1.0000 & 0.0018 & 1.00249 & 0.00010 & 1.00249 & 0.00181 \\
$009-001$ & 1.0000 & 0.0053 & 1.00225 & 0.00010 & 1.00225 & 0.00531 \\
\hline
\end{tabular}


Table A-12. Detailed ENDF/B-VII.1 CE results for KENO V.a IMF systems

\begin{tabular}{lcccrcc}
\hline \multicolumn{1}{c}{ Case } & $\begin{array}{c}\text { Expected } \\
\boldsymbol{k}_{\text {eff }}\end{array}$ & $\begin{array}{c}\text { Experimental } \\
\text { uncertainty }\end{array}$ & $\boldsymbol{k}_{\text {eff }}$ & Uncertainty & $\mathbf{C} / \mathbf{E}$ & $\begin{array}{c}\mathbf{C} / \mathbf{E} \\
\text { uncertainty }\end{array}$ \\
\hline $002-001$ & 1.0000 & 0.0030 & 0.99923 & 0.00010 & 0.99923 & 0.00300 \\
$003-001$ & 1.0000 & 0.0017 & 1.00259 & 0.00010 & 1.00259 & 0.00171 \\
$003-001 \mathrm{~S}$ & 1.0000 & 0.0019 & 1.00263 & 0.00010 & 1.00263 & 0.00191 \\
$004-001$ & 1.0000 & 0.0030 & 1.00760 & 0.00010 & 1.00760 & 0.00302 \\
$004-001 \mathrm{~S}$ & 1.0000 & 0.0032 & 1.00767 & 0.00010 & 1.00767 & 0.00323 \\
$005-001$ & 1.0000 & 0.0021 & 1.00132 & 0.00010 & 1.00132 & 0.00211 \\
$005-001 \mathrm{~S}$ & 1.0000 & 0.0023 & 1.00138 & 0.00010 & 1.00138 & 0.00231 \\
$006-001$ & 1.0000 & 0.0023 & 0.99624 & 0.00010 & 0.99624 & 0.00229 \\
$007-001$ & 1.0045 & 0.0007 & 1.00494 & 0.00010 & 1.00044 & 0.00070 \\
$008-001$ & 1.0000 & 0.0018 & 1.00598 & 0.00010 & 1.00598 & 0.00181 \\
$009-001$ & 1.0000 & 0.0053 & 1.00675 & 0.00010 & 1.00675 & 0.00534 \\
\hline
\end{tabular}

Table A-13. Detailed ENDF/B-VIII.0 252-group results for KENO V.a LCT systems

\begin{tabular}{|c|c|c|c|c|c|c|}
\hline Case & $\begin{array}{c}\text { Expected } \\
k_{\text {eff }}\end{array}$ & $\begin{array}{c}\text { Experimental } \\
\text { uncertainty }\end{array}$ & $\boldsymbol{k}_{\text {eff }}$ & Uncertainty & $\mathbf{C} / \mathbf{E}$ & $\begin{array}{c}\mathrm{C} / \mathrm{E} \\
\text { uncertainty }\end{array}$ \\
\hline $001-001$ & 0.9998 & 0.0031 & 1.00032 & 0.00048 & 1.00052 & 0.00314 \\
\hline 001-002 & 0.9998 & 0.0031 & 0.99943 & 0.00036 & 0.99963 & 0.00312 \\
\hline $001-003$ & 0.9998 & 0.0031 & 0.99944 & 0.00048 & 0.99964 & 0.00314 \\
\hline 001-004 & 0.9998 & 0.0031 & 0.99868 & 0.00044 & 0.99888 & 0.00313 \\
\hline 001-005 & 0.9998 & 0.0031 & 0.99728 & 0.00045 & 0.99748 & 0.00313 \\
\hline 001-006 & 0.9998 & 0.0031 & 0.99959 & 0.00039 & 0.99979 & 0.00312 \\
\hline 001-007 & 0.9998 & 0.0031 & 0.99875 & 0.00043 & 0.99895 & 0.00313 \\
\hline 001-008 & 0.9998 & 0.0031 & 0.99745 & 0.00047 & 0.99765 & 0.00313 \\
\hline $002-001$ & 0.9997 & 0.0020 & 0.99889 & 0.00011 & 0.99919 & 0.00200 \\
\hline $002-002$ & 0.9997 & 0.0020 & 1.00070 & 0.00010 & 1.00100 & 0.00201 \\
\hline $002-003$ & 0.9997 & 0.0020 & 0.99991 & 0.00012 & 1.00021 & 0.00200 \\
\hline $002-004$ & 0.9997 & 0.0020 & 0.99966 & 0.00011 & 0.99996 & 0.00200 \\
\hline $002-005$ & 0.9997 & 0.0020 & 0.99847 & 0.00011 & 0.99877 & 0.00200 \\
\hline 008-001 & 1.0007 & 0.0012 & 1.00015 & 0.00010 & 0.99945 & 0.00120 \\
\hline 008-002 & 1.0007 & 0.0012 & 1.00051 & 0.00010 & 0.99981 & 0.00120 \\
\hline 008-003 & 1.0007 & 0.0012 & 1.00103 & 0.00010 & 1.00033 & 0.00120 \\
\hline 008-004 & 1.0007 & 0.0012 & 1.00040 & 0.00010 & 0.99970 & 0.00120 \\
\hline 008-005 & 1.0007 & 0.0012 & 0.99993 & 0.00010 & 0.99923 & 0.00120 \\
\hline $008-006$ & 1.0007 & 0.0012 & 1.00032 & 0.00010 & 0.99962 & 0.00120 \\
\hline 008-007 & 1.0007 & 0.0012 & 0.99959 & 0.00010 & 0.99889 & 0.00120 \\
\hline 008-008 & 1.0007 & 0.0012 & 0.99910 & 0.00010 & 0.99841 & 0.00120 \\
\hline 008-009 & 1.0007 & 0.0012 & 0.99932 & 0.00010 & 0.99862 & 0.00120 \\
\hline 008-010 & 1.0007 & 0.0012 & 1.00003 & 0.00010 & 0.99933 & 0.00120 \\
\hline 008-011 & 1.0007 & 0.0012 & 1.00093 & 0.00010 & 1.00023 & 0.00120 \\
\hline 008-012 & 1.0007 & 0.0012 & 1.00048 & 0.00009 & 0.99978 & 0.00120 \\
\hline $008-013$ & 1.0007 & 0.0012 & 1.00071 & 0.00010 & 1.00001 & 0.00120 \\
\hline 008-014 & 1.0007 & 0.0012 & 1.00047 & 0.00010 & 0.99977 & 0.00120 \\
\hline 008-015 & 1.0007 & 0.0012 & 1.00038 & 0.00010 & 0.99968 & 0.00120 \\
\hline $008-016$ & 1.0007 & 0.0012 & 1.00042 & 0.00010 & 0.99972 & 0.00120 \\
\hline 008-017 & 1.0007 & 0.0012 & 0.99971 & 0.00010 & 0.99901 & 0.00120 \\
\hline 010-001 & 1.0000 & 0.0021 & 1.00543 & 0.00009 & 1.00543 & 0.00211 \\
\hline 010-002 & 1.0000 & 0.0021 & 1.00587 & 0.00009 & 1.00587 & 0.00211 \\
\hline 010-003 & 1.0000 & 0.0021 & 1.00475 & 0.00010 & 1.00475 & 0.00211 \\
\hline 010-004 & 1.0000 & 0.0021 & 0.99773 & 0.00009 & 0.99773 & 0.00210 \\
\hline $010-005$ & 1.0000 & 0.0021 & 1.00003 & 0.00009 & 1.00003 & 0.00210 \\
\hline 010-006 & 1.0000 & 0.0021 & 1.00068 & 0.00010 & 1.00068 & 0.00210 \\
\hline $010-007$ & 1.0000 & 0.0021 & 1.00212 & 0.00010 & 1.00212 & 0.00211 \\
\hline 010-008 & 1.0000 & 0.0021 & 0.99859 & 0.00010 & 0.99859 & 0.00210 \\
\hline 010-009 & 1.0000 & 0.0021 & 1.00212 & 0.00009 & 1.00212 & 0.00211 \\
\hline $010-010$ & 1.0000 & 0.0021 & 1.00195 & 0.00010 & 1.00195 & 0.00211 \\
\hline 010-011 & 1.0000 & 0.0021 & 1.00189 & 0.00010 & 1.00189 & 0.00211 \\
\hline $010-012$ & 1.0000 & 0.0021 & 1.00081 & 0.00009 & 1.00081 & 0.00210 \\
\hline
\end{tabular}


Table A-13. Detailed ENDF/B-VIII.0 252-group results for KENO V.a LCT systems

\begin{tabular}{|c|c|c|c|c|c|c|}
\hline Case & $\begin{array}{c}\text { Expected } \\
k_{\text {eff }}\end{array}$ & $\begin{array}{c}\text { Experimental } \\
\text { uncertainty }\end{array}$ & $\boldsymbol{k}_{\text {eff }}$ & Uncertainty & $\mathbf{C} / \mathbf{E}$ & $\begin{array}{c}\mathrm{C} / \mathrm{E} \\
\text { uncertainty }\end{array}$ \\
\hline $010-013$ & 1.0000 & 0.0021 & 0.99864 & 0.00010 & 0.99864 & 0.00210 \\
\hline $010-014$ & 1.0000 & 0.0028 & 1.00221 & 0.00010 & 1.00221 & 0.00281 \\
\hline $010-015$ & 1.0000 & 0.0028 & 1.00255 & 0.00010 & 1.00255 & 0.00281 \\
\hline $010-016$ & 1.0000 & 0.0028 & 1.00301 & 0.00010 & 1.00301 & 0.00281 \\
\hline $010-017$ & 1.0000 & 0.0028 & 1.00234 & 0.00010 & 1.00234 & 0.00281 \\
\hline 010-018 & 1.0000 & 0.0028 & 1.00209 & 0.00010 & 1.00209 & 0.00281 \\
\hline 010-019 & 1.0000 & 0.0028 & 1.00180 & 0.00009 & 1.00180 & 0.00281 \\
\hline $010-020$ & 1.0000 & 0.0028 & 1.00345 & 0.00010 & 1.00345 & 0.00281 \\
\hline $010-021$ & 1.0000 & 0.0028 & 1.00369 & 0.00010 & 1.00369 & 0.00281 \\
\hline $010-022$ & 1.0000 & 0.0028 & 1.00305 & 0.00009 & 1.00305 & 0.00281 \\
\hline $010-023$ & 1.0000 & 0.0028 & 1.00162 & 0.00007 & 1.00162 & 0.00281 \\
\hline $010-024$ & 1.0000 & 0.0028 & 0.99986 & 0.00010 & 0.99986 & 0.00280 \\
\hline $010-025$ & 1.0000 & 0.0028 & 1.00122 & 0.00009 & 1.00122 & 0.00280 \\
\hline $010-026$ & 1.0000 & 0.0028 & 1.00138 & 0.00010 & 1.00138 & 0.00281 \\
\hline $010-027$ & 1.0000 & 0.0028 & 1.00170 & 0.00010 & 1.00170 & 0.00281 \\
\hline $010-028$ & 1.0000 & 0.0028 & 1.00200 & 0.00010 & 1.00200 & 0.00281 \\
\hline $010-029$ & 1.0000 & 0.0028 & 1.00217 & 0.00007 & 1.00217 & 0.00281 \\
\hline 010-030 & 1.0000 & 0.0028 & 1.00049 & 0.00009 & 1.00049 & 0.00280 \\
\hline 017-001 & 1.0000 & 0.0031 & 1.00169 & 0.00010 & 1.00169 & 0.00311 \\
\hline 017-002 & 1.0000 & 0.0031 & 1.00126 & 0.00010 & 1.00126 & 0.00311 \\
\hline 017-003 & 1.0000 & 0.0031 & 1.00017 & 0.00010 & 1.00017 & 0.00310 \\
\hline 017-004 & 1.0000 & 0.0031 & 0.99834 & 0.00010 & 0.99834 & 0.00310 \\
\hline 017-005 & 1.0000 & 0.0031 & 1.00010 & 0.00009 & 1.00010 & 0.00310 \\
\hline 017-006 & 1.0000 & 0.0031 & 1.00021 & 0.00010 & 1.00021 & 0.00310 \\
\hline $017-007$ & 1.0000 & 0.0031 & 1.00017 & 0.00010 & 1.00017 & 0.00310 \\
\hline 017-008 & 1.0000 & 0.0031 & 0.99876 & 0.00007 & 0.99876 & 0.00310 \\
\hline 017-009 & 1.0000 & 0.0031 & 0.99831 & 0.00008 & 0.99831 & 0.00310 \\
\hline 017-010 & 1.0000 & 0.0031 & 0.99917 & 0.00007 & 0.99917 & 0.00310 \\
\hline 017-011 & 1.0000 & 0.0031 & 0.99931 & 0.00009 & 0.99931 & 0.00310 \\
\hline 017-012 & 1.0000 & 0.0031 & 0.99897 & 0.00010 & 0.99897 & 0.00310 \\
\hline 017-013 & 1.0000 & 0.0031 & 0.99928 & 0.00009 & 0.99928 & 0.00310 \\
\hline $017-014$ & 1.0000 & 0.0031 & 0.99952 & 0.00010 & 0.99952 & 0.00310 \\
\hline 017-015 & 1.0000 & 0.0028 & 0.99850 & 0.00008 & 0.99850 & 0.00280 \\
\hline $017-016$ & 1.0000 & 0.0028 & 0.99930 & 0.00008 & 0.99930 & 0.00280 \\
\hline 017-017 & 1.0000 & 0.0028 & 1.00039 & 0.00006 & 1.00039 & 0.00280 \\
\hline $017-018$ & 1.0000 & 0.0028 & 0.99904 & 0.00008 & 0.99904 & 0.00280 \\
\hline 017-019 & 1.0000 & 0.0028 & 0.99935 & 0.00007 & 0.99935 & 0.00280 \\
\hline 017-020 & 1.0000 & 0.0028 & 0.99811 & 0.00007 & 0.99811 & 0.00280 \\
\hline $017-021$ & 1.0000 & 0.0028 & 0.99837 & 0.00006 & 0.99837 & 0.00280 \\
\hline 017-022 & 1.0000 & 0.0028 & 0.99755 & 0.00008 & 0.99755 & 0.00279 \\
\hline $017-023$ & 1.0000 & 0.0028 & 0.99956 & 0.00009 & 0.99956 & 0.00280 \\
\hline $017-024$ & 1.0000 & 0.0028 & 1.00052 & 0.00009 & 1.00052 & 0.00280 \\
\hline $017-025$ & 1.0000 & 0.0028 & 0.99859 & 0.00008 & 0.99859 & 0.00280 \\
\hline $017-026$ & 1.0000 & 0.0028 & 0.99623 & 0.00009 & 0.99623 & 0.00279 \\
\hline 017-027 & 1.0000 & 0.0028 & 0.99828 & 0.00008 & 0.99828 & 0.00280 \\
\hline $017-028$ & 1.0000 & 0.0028 & 0.99903 & 0.00007 & 0.99903 & 0.00280 \\
\hline $017-029$ & 1.0000 & 0.0028 & 0.99945 & 0.00007 & 0.99945 & 0.00280 \\
\hline 042-001 & 1.0000 & 0.0016 & 0.99872 & 0.00008 & 0.99872 & 0.00160 \\
\hline $042-002$ & 1.0000 & 0.0016 & 0.99813 & 0.00010 & 0.99813 & 0.00160 \\
\hline $042-003$ & 1.0000 & 0.0016 & 0.99874 & 0.00009 & 0.99874 & 0.00160 \\
\hline 042-004 & 1.0000 & 0.0017 & 0.99950 & 0.00010 & 0.99950 & 0.00170 \\
\hline $042-005$ & 1.0000 & 0.0033 & 0.99940 & 0.00010 & 0.99940 & 0.00330 \\
\hline $042-006$ & 1.0000 & 0.0016 & 0.99981 & 0.00009 & 0.99981 & 0.00160 \\
\hline $042-007$ & 1.0000 & 0.0018 & 0.99776 & 0.00010 & 0.99776 & 0.00180 \\
\hline 050-001 & 1.0004 & 0.0010 & 0.99934 & 0.00010 & 0.99894 & 0.00100 \\
\hline $050-002$ & 1.0004 & 0.0010 & 0.99914 & 0.00010 & 0.99874 & 0.00100 \\
\hline $050-003$ & 1.0004 & 0.0010 & 0.99963 & 0.00010 & 0.99923 & 0.00100 \\
\hline $050-004$ & 1.0004 & 0.0010 & 0.99917 & 0.00010 & 0.99877 & 0.00100 \\
\hline $050-005$ & 1.0004 & 0.0010 & 1.00015 & 0.00010 & 0.99975 & 0.00100 \\
\hline
\end{tabular}


Table A-13. Detailed ENDF/B-VIII.0 252-group results for KENO V.a LCT systems

\begin{tabular}{|c|c|c|c|c|c|c|}
\hline Case & $\begin{array}{c}\text { Expected } \\
k_{\text {eff }}\end{array}$ & $\begin{array}{c}\text { Experimental } \\
\text { uncertainty }\end{array}$ & $\boldsymbol{k}_{\text {eff }}$ & Uncertainty & $\mathrm{C} / \mathrm{E}$ & $\begin{array}{c}\mathrm{C} / \mathrm{E} \\
\text { uncertainty }\end{array}$ \\
\hline $050-006$ & 1.0004 & 0.0010 & 0.99998 & 0.00010 & 0.99958 & 0.00100 \\
\hline $050-007$ & 1.0004 & 0.0010 & 1.00038 & 0.00010 & 0.99998 & 0.00100 \\
\hline $050-008$ & 1.0004 & 0.0010 & 0.99754 & 0.00010 & 0.99714 & 0.00100 \\
\hline 050-009 & 1.0004 & 0.0010 & 0.99837 & 0.00010 & 0.99797 & 0.00100 \\
\hline $050-010$ & 1.0004 & 0.0010 & 0.99797 & 0.00010 & 0.99757 & 0.00100 \\
\hline $050-011$ & 1.0004 & 0.0010 & 0.99843 & 0.00010 & 0.99803 & 0.00100 \\
\hline $050-012$ & 1.0004 & 0.0010 & 0.99946 & 0.00010 & 0.99906 & 0.00100 \\
\hline $050-013$ & 1.0004 & 0.0010 & 0.99964 & 0.00010 & 0.99924 & 0.00100 \\
\hline 050-014 & 1.0004 & 0.0010 & 0.99897 & 0.00010 & 0.99857 & 0.00100 \\
\hline $050-015$ & 1.0004 & 0.0010 & 0.99975 & 0.00010 & 0.99935 & 0.00100 \\
\hline 050-016 & 1.0004 & 0.0010 & 1.00070 & 0.00010 & 1.00030 & 0.00100 \\
\hline $050-017$ & 1.0004 & 0.0010 & 1.00054 & 0.00010 & 1.00014 & 0.00100 \\
\hline $050-018$ & 1.0004 & 0.0010 & 1.00051 & 0.00010 & 1.00011 & 0.00100 \\
\hline 078-001 & 0.9995 & 0.0010 & 0.99705 & 0.00010 & 0.99755 & 0.00100 \\
\hline 078-002 & 0.9999 & 0.0010 & 0.99762 & 0.00010 & 0.99772 & 0.00100 \\
\hline 078-003 & 0.9990 & 0.0010 & 0.99656 & 0.00010 & 0.99756 & 0.00100 \\
\hline 078-004 & 0.9986 & 0.0010 & 0.99633 & 0.00010 & 0.99773 & 0.00100 \\
\hline $078-005$ & 0.9980 & 0.0010 & 0.99588 & 0.00010 & 0.99787 & 0.00100 \\
\hline 078-006 & 0.9974 & 0.0010 & 0.99556 & 0.00010 & 0.99815 & 0.00101 \\
\hline $078-007$ & 0.9994 & 0.0010 & 0.99719 & 0.00010 & 0.99778 & 0.00100 \\
\hline 078-008 & 0.9987 & 0.0010 & 0.99652 & 0.00009 & 0.99781 & 0.00100 \\
\hline 078-009 & 0.9978 & 0.0010 & 0.99540 & 0.00010 & 0.99760 & 0.00100 \\
\hline $078-010$ & 0.9969 & 0.0010 & 0.99441 & 0.00010 & 0.99751 & 0.00101 \\
\hline 078-011 & 0.9994 & 0.0010 & 0.99701 & 0.00010 & 0.99761 & 0.00100 \\
\hline $078-012$ & 0.9993 & 0.0010 & 0.99704 & 0.00010 & 0.99774 & 0.00100 \\
\hline $078-013$ & 0.9993 & 0.0010 & 0.99693 & 0.00010 & 0.99763 & 0.00100 \\
\hline $078-014$ & 0.9991 & 0.0010 & 0.99667 & 0.00010 & 0.99757 & 0.00100 \\
\hline $078-015$ & 0.9996 & 0.0010 & 0.99843 & 0.00010 & 0.99883 & 0.00100 \\
\hline 080-001 & 0.9976 & 0.0010 & 0.99477 & 0.00010 & 0.99717 & 0.00100 \\
\hline 080-002 & 0.9982 & 0.0010 & 0.99542 & 0.00010 & 0.99721 & 0.00100 \\
\hline $080-003$ & 0.9984 & 0.0010 & 0.99573 & 0.00010 & 0.99733 & 0.00100 \\
\hline 080-004 & 0.9981 & 0.0010 & 0.99526 & 0.00010 & 0.99715 & 0.00100 \\
\hline $080-005$ & 0.9979 & 0.0010 & 0.99496 & 0.00010 & 0.99705 & 0.00100 \\
\hline 080-006 & 0.9975 & 0.0010 & 0.99460 & 0.00010 & 0.99709 & 0.00100 \\
\hline 080-007 & 0.9993 & 0.0010 & 0.99650 & 0.00010 & 0.99720 & 0.00100 \\
\hline 080-008 & 0.9987 & 0.0010 & 0.99627 & 0.00010 & 0.99757 & 0.00100 \\
\hline 080-009 & 0.9982 & 0.0010 & 0.99545 & 0.00010 & 0.99724 & 0.00100 \\
\hline $080-010$ & 0.9972 & 0.0010 & 0.99460 & 0.00010 & 0.99739 & 0.00101 \\
\hline 080-011 & 0.9984 & 0.0010 & 0.99737 & 0.00010 & 0.99897 & 0.00101 \\
\hline
\end{tabular}


Table A-14. Detailed ENDF/B-VII.1 252-group results for KENO V.a LCT systems

\begin{tabular}{|c|c|c|c|c|c|c|}
\hline Case & $\begin{array}{c}\text { Expected } \\
\boldsymbol{k}_{\text {eff }}\end{array}$ & $\begin{array}{c}\text { Experimental } \\
\text { uncertainty }\end{array}$ & $\boldsymbol{k}_{\text {eff }}$ & Uncertainty & $\mathrm{C} / \mathrm{E}$ & $\begin{array}{c}\mathbf{C} / \mathbf{E} \\
\text { uncertainty }\end{array}$ \\
\hline $001-001$ & 0.9998 & 0.0031 & 0.99863 & 0.00049 & 0.99883 & 0.00314 \\
\hline 001-002 & 0.9998 & 0.0031 & 0.99815 & 0.00039 & 0.99835 & 0.00312 \\
\hline $001-003$ & 0.9998 & 0.0031 & 0.99800 & 0.00047 & 0.99820 & 0.00313 \\
\hline 001-004 & 0.9998 & 0.0031 & 0.99895 & 0.00045 & 0.99915 & 0.00313 \\
\hline $001-005$ & 0.9998 & 0.0031 & 0.99652 & 0.00038 & 0.99672 & 0.00311 \\
\hline 001-006 & 0.9998 & 0.0031 & 0.99805 & 0.00049 & 0.99825 & 0.00313 \\
\hline 001-007 & 0.9998 & 0.0031 & 0.99744 & 0.00049 & 0.99764 & 0.00313 \\
\hline 001-008 & 0.9998 & 0.0031 & 0.99605 & 0.00047 & 0.99625 & 0.00312 \\
\hline $002-001$ & 0.9997 & 0.0020 & 0.99759 & 0.00012 & 0.99789 & 0.00200 \\
\hline 002-002 & 0.9997 & 0.0020 & 0.99906 & 0.00010 & 0.99936 & 0.00200 \\
\hline $002-003$ & 0.9997 & 0.0020 & 0.99846 & 0.00011 & 0.99876 & 0.00200 \\
\hline 002-004 & 0.9997 & 0.0020 & 0.99832 & 0.00010 & 0.99862 & 0.00200 \\
\hline $002-005$ & 0.9997 & 0.0020 & 0.99696 & 0.00011 & 0.99726 & 0.00200 \\
\hline 008-001 & 1.0007 & 0.0012 & 0.99953 & 0.00010 & 0.99883 & 0.00120 \\
\hline 008-002 & 1.0007 & 0.0012 & 1.00013 & 0.00010 & 0.99943 & 0.00120 \\
\hline 008-003 & 1.0007 & 0.0012 & 1.00089 & 0.00010 & 1.00019 & 0.00120 \\
\hline 008-004 & 1.0007 & 0.0012 & 1.00007 & 0.00010 & 0.99937 & 0.00120 \\
\hline 008-005 & 1.0007 & 0.0012 & 0.99978 & 0.00010 & 0.99908 & 0.00120 \\
\hline 008-006 & 1.0007 & 0.0012 & 1.00016 & 0.00010 & 0.99946 & 0.00120 \\
\hline 008-007 & 1.0007 & 0.0012 & 0.99941 & 0.00010 & 0.99871 & 0.00120 \\
\hline 008-008 & 1.0007 & 0.0012 & 0.99885 & 0.00010 & 0.99815 & 0.00120 \\
\hline 008-009 & 1.0007 & 0.0012 & 0.99932 & 0.00010 & 0.99862 & 0.00120 \\
\hline 008-010 & 1.0007 & 0.0012 & 0.99988 & 0.00010 & 0.99918 & 0.00120 \\
\hline 008-011 & 1.0007 & 0.0012 & 1.00071 & 0.00010 & 1.00001 & 0.00120 \\
\hline 008-012 & 1.0007 & 0.0012 & 1.00045 & 0.00010 & 0.99975 & 0.00120 \\
\hline $008-013$ & 1.0007 & 0.0012 & 1.00022 & 0.00010 & 0.99952 & 0.00120 \\
\hline 008-014 & 1.0007 & 0.0012 & 1.00010 & 0.00010 & 0.99940 & 0.00120 \\
\hline 008-015 & 1.0007 & 0.0012 & 0.99987 & 0.00010 & 0.99917 & 0.00120 \\
\hline 008-016 & 1.0007 & 0.0012 & 1.00002 & 0.00010 & 0.99932 & 0.00120 \\
\hline $008-017$ & 1.0007 & 0.0012 & 0.99932 & 0.00010 & 0.99862 & 0.00120 \\
\hline 010-001 & 1.0000 & 0.0021 & 1.00437 & 0.00009 & 1.00437 & 0.00211 \\
\hline 010-002 & 1.0000 & 0.0021 & 1.00460 & 0.00010 & 1.00460 & 0.00211 \\
\hline 010-003 & 1.0000 & 0.0021 & 1.00373 & 0.00009 & 1.00373 & 0.00211 \\
\hline 010-004 & 1.0000 & 0.0021 & 0.99646 & 0.00009 & 0.99646 & 0.00209 \\
\hline $010-005$ & 1.0000 & 0.0021 & 0.99978 & 0.00010 & 0.99978 & 0.00210 \\
\hline 010-006 & 1.0000 & 0.0021 & 1.00003 & 0.00010 & 1.00003 & 0.00210 \\
\hline 010-007 & 1.0000 & 0.0021 & 1.00074 & 0.00010 & 1.00074 & 0.00210 \\
\hline 010-008 & 1.0000 & 0.0021 & 0.99767 & 0.00009 & 0.99767 & 0.00210 \\
\hline 010-009 & 1.0000 & 0.0021 & 1.00084 & 0.00009 & 1.00084 & 0.00210 \\
\hline $010-010$ & 1.0000 & 0.0021 & 1.00088 & 0.00010 & 1.00088 & 0.00210 \\
\hline 010-011 & 1.0000 & 0.0021 & 1.00084 & 0.00010 & 1.00084 & 0.00210 \\
\hline $010-012$ & 1.0000 & 0.0021 & 0.99969 & 0.00010 & 0.99969 & 0.00210 \\
\hline 010-013 & 1.0000 & 0.0021 & 0.99759 & 0.00009 & 0.99759 & 0.00210 \\
\hline 010-014 & 1.0000 & 0.0028 & 1.00193 & 0.00010 & 1.00193 & 0.00281 \\
\hline $010-015$ & 1.0000 & 0.0028 & 1.00231 & 0.00010 & 1.00231 & 0.00281 \\
\hline 010-016 & 1.0000 & 0.0028 & 1.00282 & 0.00010 & 1.00282 & 0.00281 \\
\hline $010-017$ & 1.0000 & 0.0028 & 1.00243 & 0.00010 & 1.00243 & 0.00281 \\
\hline 010-018 & 1.0000 & 0.0028 & 1.00194 & 0.00010 & 1.00194 & 0.00281 \\
\hline 010-019 & 1.0000 & 0.0028 & 1.00191 & 0.00010 & 1.00191 & 0.00281 \\
\hline $010-020$ & 1.0000 & 0.0028 & 1.00335 & 0.00010 & 1.00335 & 0.00281 \\
\hline 010-021 & 1.0000 & 0.0028 & 1.00356 & 0.00010 & 1.00356 & 0.00281 \\
\hline $010-022$ & 1.0000 & 0.0028 & 1.00284 & 0.00009 & 1.00284 & 0.00281 \\
\hline 010-023 & 1.0000 & 0.0028 & 1.00127 & 0.00007 & 1.00127 & 0.00280 \\
\hline 010-024 & 1.0000 & 0.0028 & 0.99984 & 0.00009 & 0.99984 & 0.00280 \\
\hline $010-025$ & 1.0000 & 0.0028 & 1.00116 & 0.00010 & 1.00116 & 0.00280 \\
\hline $010-026$ & 1.0000 & 0.0028 & 1.00144 & 0.00010 & 1.00144 & 0.00281 \\
\hline $010-027$ & 1.0000 & 0.0028 & 1.00187 & 0.00010 & 1.00187 & 0.00281 \\
\hline
\end{tabular}


Table A-14. Detailed ENDF/B-VII.1 252-group results for KENO V.a LCT systems (continued)

\begin{tabular}{|c|c|c|c|c|c|c|}
\hline Case & $\begin{array}{c}\text { Expected } \\
k_{\text {eff }}\end{array}$ & $\begin{array}{c}\text { Experimental } \\
\text { uncertainty }\end{array}$ & $\boldsymbol{k}_{\text {eff }}$ & Uncertainty & $\mathbf{C} / \mathbf{E}$ & $\begin{array}{c}\mathrm{C} / \mathrm{E} \\
\text { uncertainty }\end{array}$ \\
\hline $010-028$ & 1.0000 & 0.0028 & 1.00208 & 0.00010 & 1.00208 & 0.00281 \\
\hline 010-029 & 1.0000 & 0.0028 & 1.00193 & 0.00007 & 1.00193 & 0.00281 \\
\hline $010-030$ & 1.0000 & 0.0028 & 1.00016 & 0.00010 & 1.00016 & 0.00280 \\
\hline 017-001 & 1.0000 & 0.0031 & 1.00048 & 0.00010 & 1.00048 & 0.00310 \\
\hline 017-002 & 1.0000 & 0.0031 & 1.00017 & 0.00009 & 1.00017 & 0.00310 \\
\hline 017-003 & 1.0000 & 0.0031 & 0.99907 & 0.00009 & 0.99907 & 0.00310 \\
\hline 017-004 & 1.0000 & 0.0031 & 0.99753 & 0.00009 & 0.99753 & 0.00309 \\
\hline $017-005$ & 1.0000 & 0.0031 & 0.99923 & 0.00010 & 0.99923 & 0.00310 \\
\hline 017-006 & 1.0000 & 0.0031 & 0.99932 & 0.00009 & 0.99932 & 0.00310 \\
\hline 017-007 & 1.0000 & 0.0031 & 0.99914 & 0.00009 & 0.99914 & 0.00310 \\
\hline 017-008 & 1.0000 & 0.0031 & 0.99762 & 0.00007 & 0.99762 & 0.00309 \\
\hline 017-009 & 1.0000 & 0.0031 & 0.99705 & 0.00010 & 0.99705 & 0.00309 \\
\hline 017-010 & 1.0000 & 0.0031 & 0.99814 & 0.00007 & 0.99814 & 0.00310 \\
\hline 017-011 & 1.0000 & 0.0031 & 0.99815 & 0.00010 & 0.99815 & 0.00310 \\
\hline 017-012 & 1.0000 & 0.0031 & 0.99822 & 0.00009 & 0.99822 & 0.00310 \\
\hline 017-013 & 1.0000 & 0.0031 & 0.99817 & 0.00010 & 0.99817 & 0.00310 \\
\hline 017-014 & 1.0000 & 0.0031 & 0.99842 & 0.00009 & 0.99842 & 0.00310 \\
\hline 017-015 & 1.0000 & 0.0028 & 0.99752 & 0.00008 & 0.99752 & 0.00279 \\
\hline 017-016 & 1.0000 & 0.0028 & 0.99861 & 0.00008 & 0.99861 & 0.00280 \\
\hline 017-017 & 1.0000 & 0.0028 & 0.99967 & 0.00008 & 0.99967 & 0.00280 \\
\hline 017-018 & 1.0000 & 0.0028 & 0.99840 & 0.00008 & 0.99840 & 0.00280 \\
\hline 017-019 & 1.0000 & 0.0028 & 0.99882 & 0.00007 & 0.99882 & 0.00280 \\
\hline $017-020$ & 1.0000 & 0.0028 & 0.99773 & 0.00007 & 0.99773 & 0.00279 \\
\hline $017-021$ & 1.0000 & 0.0028 & 0.99760 & 0.00006 & 0.99760 & 0.00279 \\
\hline 017-022 & 1.0000 & 0.0028 & 0.99677 & 0.00008 & 0.99677 & 0.00279 \\
\hline $017-023$ & 1.0000 & 0.0028 & 0.99902 & 0.00009 & 0.99902 & 0.00280 \\
\hline $017-024$ & 1.0000 & 0.0028 & 0.99984 & 0.00008 & 0.99984 & 0.00280 \\
\hline $017-025$ & 1.0000 & 0.0028 & 0.99801 & 0.00009 & 0.99801 & 0.00280 \\
\hline $017-026$ & 1.0000 & 0.0028 & 0.99574 & 0.00009 & 0.99574 & 0.00279 \\
\hline $017-027$ & 1.0000 & 0.0028 & 0.99782 & 0.00008 & 0.99782 & 0.00280 \\
\hline 017-028 & 1.0000 & 0.0028 & 0.99854 & 0.00006 & 0.99854 & 0.00280 \\
\hline 017-029 & 1.0000 & 0.0028 & 0.99856 & 0.00007 & 0.99856 & 0.00280 \\
\hline $042-001$ & 1.0000 & 0.0016 & 0.99805 & 0.00008 & 0.99805 & 0.00160 \\
\hline $042-002$ & 1.0000 & 0.0016 & 0.99758 & 0.00010 & 0.99758 & 0.00160 \\
\hline $042-003$ & 1.0000 & 0.0016 & 0.99845 & 0.00010 & 0.99845 & 0.00160 \\
\hline 042-004 & 1.0000 & 0.0017 & 0.99916 & 0.00010 & 0.99916 & 0.00170 \\
\hline $042-005$ & 1.0000 & 0.0033 & 0.99940 & 0.00010 & 0.99940 & 0.00330 \\
\hline 042-006 & 1.0000 & 0.0016 & 0.99920 & 0.00009 & 0.99920 & 0.00160 \\
\hline 042-007 & 1.0000 & 0.0018 & 0.99749 & 0.00009 & 0.99749 & 0.00180 \\
\hline $050-001$ & 1.0004 & 0.0010 & 0.99825 & 0.00010 & 0.99785 & 0.00100 \\
\hline $050-002$ & 1.0004 & 0.0010 & 0.99792 & 0.00010 & 0.99752 & 0.00100 \\
\hline $050-003$ & 1.0004 & 0.0010 & 0.99860 & 0.00010 & 0.99820 & 0.00100 \\
\hline $050-004$ & 1.0004 & 0.0010 & 0.99828 & 0.00010 & 0.99788 & 0.00100 \\
\hline $050-005$ & 1.0004 & 0.0010 & 0.99947 & 0.00010 & 0.99907 & 0.00100 \\
\hline $050-006$ & 1.0004 & 0.0010 & 0.99951 & 0.00010 & 0.99911 & 0.00100 \\
\hline $050-007$ & 1.0004 & 0.0010 & 0.99953 & 0.00010 & 0.99913 & 0.00100 \\
\hline $050-008$ & 1.0004 & 0.0010 & 0.99652 & 0.00010 & 0.99612 & 0.00100 \\
\hline 050-009 & 1.0004 & 0.0010 & 0.99676 & 0.00010 & 0.99636 & 0.00100 \\
\hline $050-010$ & 1.0004 & 0.0010 & 0.99669 & 0.00010 & 0.99629 & 0.00100 \\
\hline $050-011$ & 1.0004 & 0.0010 & 0.99732 & 0.00010 & 0.99692 & 0.00100 \\
\hline $050-012$ & 1.0004 & 0.0010 & 0.99836 & 0.00010 & 0.99796 & 0.00100 \\
\hline $050-013$ & 1.0004 & 0.0010 & 0.99863 & 0.00010 & 0.99823 & 0.00100 \\
\hline $050-014$ & 1.0004 & 0.0010 & 0.99796 & 0.00010 & 0.99756 & 0.00100 \\
\hline $050-015$ & 1.0004 & 0.0010 & 0.99877 & 0.00010 & 0.99837 & 0.00100 \\
\hline $050-016$ & 1.0004 & 0.0010 & 0.99962 & 0.00010 & 0.99922 & 0.00100 \\
\hline $050-017$ & 1.0004 & 0.0010 & 0.99975 & 0.00010 & 0.99935 & 0.00100 \\
\hline $050-018$ & 1.0004 & 0.0010 & 0.99948 & 0.00010 & 0.99908 & 0.00100 \\
\hline 078-001 & 0.9995 & 0.0010 & 0.99704 & 0.00010 & 0.99754 & 0.00100 \\
\hline
\end{tabular}


Table A-14. Detailed ENDF/B-VII.1 252-group results for KENO V.a LCT systems (continued)

\begin{tabular}{lcccccc}
\hline Case & $\begin{array}{c}\text { Expected } \\
\boldsymbol{k}_{\text {eff }}\end{array}$ & $\begin{array}{c}\text { Experimental } \\
\text { uncertainty }\end{array}$ & $\boldsymbol{k}_{\text {eff }}$ & Uncertainty & $\mathbf{C} / \mathbf{E}$ & $\begin{array}{c}\text { C/E } \\
\text { uncertainty }\end{array}$ \\
\hline $078-002$ & 0.9999 & 0.0010 & 0.99758 & 0.00010 & 0.99768 & 0.00100 \\
$078-003$ & 0.9990 & 0.0010 & 0.99649 & 0.00010 & 0.99748 & 0.00100 \\
$078-004$ & 0.9986 & 0.0010 & 0.99594 & 0.00010 & 0.99733 & 0.00100 \\
$078-005$ & 0.9980 & 0.0010 & 0.99578 & 0.00010 & 0.99778 & 0.00100 \\
$078-006$ & 0.9974 & 0.0010 & 0.99517 & 0.00010 & 0.99777 & 0.00101 \\
$078-007$ & 0.9994 & 0.0010 & 0.99700 & 0.00010 & 0.99760 & 0.00100 \\
$078-008$ & 0.9987 & 0.0010 & 0.99637 & 0.00010 & 0.99767 & 0.00100 \\
$078-009$ & 0.9978 & 0.0010 & 0.99529 & 0.00010 & 0.99748 & 0.00100 \\
$078-010$ & 0.9969 & 0.0010 & 0.99415 & 0.00010 & 0.99724 & 0.00101 \\
$078-011$ & 0.9994 & 0.0010 & 0.99675 & 0.00010 & 0.99735 & 0.00100 \\
$078-012$ & 0.9993 & 0.0010 & 0.99680 & 0.00010 & 0.99750 & 0.00100 \\
$078-013$ & 0.9993 & 0.0010 & 0.99654 & 0.00010 & 0.99724 & 0.00100 \\
$078-014$ & 0.9991 & 0.0010 & 0.99671 & 0.00010 & 0.99760 & 0.00100 \\
$078-015$ & 0.9996 & 0.0010 & 0.99803 & 0.00010 & 0.99843 & 0.00100 \\
$080-001$ & 0.9976 & 0.0010 & 0.99534 & 0.00010 & 0.99774 & 0.00101 \\
$080-002$ & 0.9982 & 0.0010 & 0.99580 & 0.00010 & 0.99759 & 0.00100 \\
$080-003$ & 0.9984 & 0.0010 & 0.99583 & 0.00010 & 0.99742 & 0.00100 \\
$080-004$ & 0.9981 & 0.0010 & 0.99567 & 0.00010 & 0.99757 & 0.00100 \\
$080-005$ & 0.9979 & 0.0010 & 0.99532 & 0.00009 & 0.99741 & 0.00100 \\
$080-006$ & 0.9975 & 0.0010 & 0.99492 & 0.00010 & 0.99741 & 0.00100 \\
$080-007$ & 0.9993 & 0.0010 & 0.99692 & 0.00010 & 0.99761 & 0.00100 \\
$080-008$ & 0.9987 & 0.0010 & 0.99641 & 0.00010 & 0.99771 & 0.00100 \\
$080-009$ & 0.9982 & 0.0010 & 0.99566 & 0.00010 & 0.99746 & 0.00100 \\
$080-010$ & 0.9972 & 0.0010 & 0.99516 & 0.00010 & 0.99796 & 0.00101 \\
$080-011$ & 0.9984 & 0.0010 & 0.99734 & 0.00010 & 0.99894 & 0.00101 \\
\hline
\end{tabular}


Table A-15. Detailed ENDF/B-VIII.0 CE results for KENO V.a LCT systems

\begin{tabular}{|c|c|c|c|c|c|c|}
\hline Case & $\begin{array}{c}\text { Expected } \\
\boldsymbol{k}_{\text {eff }}\end{array}$ & $\begin{array}{c}\text { Experimental } \\
\text { uncertainty }\end{array}$ & $\boldsymbol{k}_{\text {eff }}$ & Uncertainty & $\mathrm{C} / \mathrm{E}$ & $\begin{array}{c}\mathbf{C} / \mathbf{E} \\
\text { uncertainty }\end{array}$ \\
\hline $001-001$ & 0.9998 & 0.0031 & 0.99979 & 0.00043 & 0.99999 & 0.00313 \\
\hline 001-002 & 0.9998 & 0.0031 & 0.99803 & 0.00049 & 0.99823 & 0.00313 \\
\hline $001-003$ & 0.9998 & 0.0031 & 0.99846 & 0.00048 & 0.99866 & 0.00313 \\
\hline 001-004 & 0.9998 & 0.0031 & 0.99900 & 0.00046 & 0.99920 & 0.00313 \\
\hline $001-005$ & 0.9998 & 0.0031 & 0.99765 & 0.00049 & 0.99785 & 0.00313 \\
\hline 001-006 & 0.9998 & 0.0031 & 0.99880 & 0.00046 & 0.99900 & 0.00313 \\
\hline 001-007 & 0.9998 & 0.0031 & 0.99839 & 0.00044 & 0.99859 & 0.00313 \\
\hline 001-008 & 0.9998 & 0.0031 & 0.99731 & 0.00041 & 0.99751 & 0.00312 \\
\hline $002-001$ & 0.9997 & 0.0020 & 0.99848 & 0.00012 & 0.99878 & 0.00200 \\
\hline 002-002 & 0.9997 & 0.0020 & 0.99946 & 0.00010 & 0.99976 & 0.00200 \\
\hline $002-003$ & 0.9997 & 0.0020 & 0.99922 & 0.00011 & 0.99952 & 0.00200 \\
\hline 002-004 & 0.9997 & 0.0020 & 0.99888 & 0.00011 & 0.99918 & 0.00200 \\
\hline $002-005$ & 0.9997 & 0.0020 & 0.99744 & 0.00012 & 0.99774 & 0.00200 \\
\hline 008-001 & 1.0007 & 0.0012 & 1.00101 & 0.00010 & 1.00031 & 0.00120 \\
\hline 008-002 & 1.0007 & 0.0012 & 1.00137 & 0.00010 & 1.00067 & 0.00120 \\
\hline 008-003 & 1.0007 & 0.0012 & 1.00168 & 0.00010 & 1.00097 & 0.00120 \\
\hline 008-004 & 1.0007 & 0.0012 & 1.00096 & 0.00010 & 1.00026 & 0.00120 \\
\hline 008-005 & 1.0007 & 0.0012 & 1.00060 & 0.00010 & 0.99990 & 0.00120 \\
\hline 008-006 & 1.0007 & 0.0012 & 1.00101 & 0.00010 & 1.00031 & 0.00120 \\
\hline 008-007 & 1.0007 & 0.0012 & 1.00005 & 0.00010 & 0.99935 & 0.00120 \\
\hline 008-008 & 1.0007 & 0.0012 & 0.99957 & 0.00010 & 0.99887 & 0.00120 \\
\hline 008-009 & 1.0007 & 0.0012 & 0.99979 & 0.00010 & 0.99909 & 0.00120 \\
\hline 008-010 & 1.0007 & 0.0012 & 1.00080 & 0.00010 & 1.00010 & 0.00120 \\
\hline 008-011 & 1.0007 & 0.0012 & 1.00159 & 0.00010 & 1.00089 & 0.00120 \\
\hline 008-012 & 1.0007 & 0.0012 & 1.00113 & 0.00010 & 1.00043 & 0.00120 \\
\hline $008-013$ & 1.0007 & 0.0012 & 1.00128 & 0.00010 & 1.00058 & 0.00120 \\
\hline 008-014 & 1.0007 & 0.0012 & 1.00094 & 0.00010 & 1.00024 & 0.00120 \\
\hline 008-015 & 1.0007 & 0.0012 & 1.00062 & 0.00010 & 0.99992 & 0.00120 \\
\hline 008-016 & 1.0007 & 0.0012 & 1.00100 & 0.00010 & 1.00030 & 0.00120 \\
\hline $008-017$ & 1.0007 & 0.0012 & 0.99982 & 0.00009 & 0.99912 & 0.00120 \\
\hline 010-001 & 1.0000 & 0.0021 & 1.00486 & 0.00009 & 1.00486 & 0.00211 \\
\hline 010-002 & 1.0000 & 0.0021 & 1.00502 & 0.00010 & 1.00502 & 0.00211 \\
\hline 010-003 & 1.0000 & 0.0021 & 1.00406 & 0.00010 & 1.00406 & 0.00211 \\
\hline 010-004 & 1.0000 & 0.0021 & 0.99677 & 0.00009 & 0.99677 & 0.00210 \\
\hline $010-005$ & 1.0000 & 0.0021 & 0.99900 & 0.00009 & 0.99900 & 0.00210 \\
\hline 010-006 & 1.0000 & 0.0021 & 0.99969 & 0.00010 & 0.99969 & 0.00210 \\
\hline 010-007 & 1.0000 & 0.0021 & 1.00123 & 0.00010 & 1.00123 & 0.00210 \\
\hline 010-008 & 1.0000 & 0.0021 & 0.99788 & 0.00010 & 0.99788 & 0.00210 \\
\hline 010-009 & 1.0000 & 0.0021 & 1.00012 & 0.00009 & 1.00012 & 0.00210 \\
\hline $010-010$ & 1.0000 & 0.0021 & 1.00014 & 0.00010 & 1.00014 & 0.00210 \\
\hline 010-011 & 1.0000 & 0.0021 & 1.00032 & 0.00010 & 1.00032 & 0.00210 \\
\hline $010-012$ & 1.0000 & 0.0021 & 0.99967 & 0.00010 & 0.99967 & 0.00210 \\
\hline 010-013 & 1.0000 & 0.0021 & 0.99729 & 0.00010 & 0.99729 & 0.00210 \\
\hline 010-014 & 1.0000 & 0.0028 & 1.00116 & 0.00008 & 1.00116 & 0.00280 \\
\hline $010-015$ & 1.0000 & 0.0028 & 1.00149 & 0.00010 & 1.00149 & 0.00281 \\
\hline 010-016 & 1.0000 & 0.0028 & 1.00204 & 0.00010 & 1.00204 & 0.00281 \\
\hline $010-017$ & 1.0000 & 0.0028 & 1.00132 & 0.00009 & 1.00132 & 0.00281 \\
\hline 010-018 & 1.0000 & 0.0028 & 1.00110 & 0.00010 & 1.00110 & 0.00280 \\
\hline 010-019 & 1.0000 & 0.0028 & 1.00117 & 0.00010 & 1.00117 & 0.00281 \\
\hline $010-020$ & 1.0000 & 0.0028 & 1.00288 & 0.00010 & 1.00288 & 0.00281 \\
\hline 010-021 & 1.0000 & 0.0028 & 1.00288 & 0.00009 & 1.00288 & 0.00281 \\
\hline $010-022$ & 1.0000 & 0.0028 & 1.00236 & 0.00009 & 1.00236 & 0.00281 \\
\hline 010-023 & 1.0000 & 0.0028 & 1.00091 & 0.00007 & 1.00091 & 0.00280 \\
\hline 010-024 & 1.0000 & 0.0028 & 0.99896 & 0.00010 & 0.99896 & 0.00280 \\
\hline $010-025$ & 1.0000 & 0.0028 & 1.00045 & 0.00009 & 1.00045 & 0.00280 \\
\hline $010-026$ & 1.0000 & 0.0028 & 1.00071 & 0.00010 & 1.00071 & 0.00280 \\
\hline $010-027$ & 1.0000 & 0.0028 & 1.00119 & 0.00010 & 1.00119 & 0.00280 \\
\hline
\end{tabular}


Table A-15. Detailed ENDF/B-VIII.0 CE results for KENO V.a LCT systems (continued)

\begin{tabular}{|c|c|c|c|c|c|c|}
\hline Case & $\begin{array}{c}\text { Expected } \\
k_{\text {eff }}\end{array}$ & $\begin{array}{c}\text { Experimental } \\
\text { uncertainty }\end{array}$ & $\boldsymbol{k}_{\text {eff }}$ & Uncertainty & $\mathbf{C} / \mathbf{E}$ & $\begin{array}{c}\mathrm{C} / \mathrm{E} \\
\text { uncertainty }\end{array}$ \\
\hline $010-028$ & 1.0000 & 0.0028 & 1.00149 & 0.00010 & 1.00149 & 0.00281 \\
\hline 010-029 & 1.0000 & 0.0028 & 1.00159 & 0.00007 & 1.00159 & 0.00281 \\
\hline $010-030$ & 1.0000 & 0.0028 & 0.99953 & 0.00010 & 0.99953 & 0.00280 \\
\hline 017-001 & 1.0000 & 0.0031 & 1.00153 & 0.00010 & 1.00153 & 0.00311 \\
\hline 017-002 & 1.0000 & 0.0031 & 1.00102 & 0.00010 & 1.00102 & 0.00310 \\
\hline $017-003$ & 1.0000 & 0.0031 & 0.99984 & 0.00010 & 0.99984 & 0.00310 \\
\hline 017-004 & 1.0000 & 0.0031 & 0.99798 & 0.00010 & 0.99798 & 0.00310 \\
\hline $017-005$ & 1.0000 & 0.0031 & 0.99979 & 0.00010 & 0.99979 & 0.00310 \\
\hline 017-006 & 1.0000 & 0.0031 & 0.99977 & 0.00010 & 0.99977 & 0.00310 \\
\hline 017-007 & 1.0000 & 0.0031 & 0.99999 & 0.00010 & 0.99999 & 0.00310 \\
\hline 017-008 & 1.0000 & 0.0031 & 0.99834 & 0.00007 & 0.99834 & 0.00310 \\
\hline 017-009 & 1.0000 & 0.0031 & 0.99782 & 0.00009 & 0.99782 & 0.00309 \\
\hline 017-010 & 1.0000 & 0.0031 & 0.99839 & 0.00007 & 0.99839 & 0.00310 \\
\hline 017-011 & 1.0000 & 0.0031 & 0.99837 & 0.00010 & 0.99837 & 0.00310 \\
\hline 017-012 & 1.0000 & 0.0031 & 0.99850 & 0.00010 & 0.99850 & 0.00310 \\
\hline 017-013 & 1.0000 & 0.0031 & 0.99892 & 0.00009 & 0.99892 & 0.00310 \\
\hline 017-014 & 1.0000 & 0.0031 & 0.99922 & 0.00009 & 0.99922 & 0.00310 \\
\hline 017-015 & 1.0000 & 0.0028 & 0.99753 & 0.00009 & 0.99753 & 0.00279 \\
\hline 017-016 & 1.0000 & 0.0028 & 0.99856 & 0.00006 & 0.99856 & 0.00280 \\
\hline 017-017 & 1.0000 & 0.0028 & 0.99974 & 0.00007 & 0.99974 & 0.00280 \\
\hline 017-018 & 1.0000 & 0.0028 & 0.99848 & 0.00007 & 0.99848 & 0.00280 \\
\hline 017-019 & 1.0000 & 0.0028 & 0.99894 & 0.00008 & 0.99894 & 0.00280 \\
\hline $017-020$ & 1.0000 & 0.0028 & 0.99803 & 0.00008 & 0.99803 & 0.00280 \\
\hline 017-021 & 1.0000 & 0.0028 & 0.99797 & 0.00005 & 0.99797 & 0.00279 \\
\hline 017-022 & 1.0000 & 0.0028 & 0.99733 & 0.00009 & 0.99733 & 0.00279 \\
\hline 017-023 & 1.0000 & 0.0028 & 0.99963 & 0.00009 & 0.99963 & 0.00280 \\
\hline $017-024$ & 1.0000 & 0.0028 & 1.00030 & 0.00009 & 1.00030 & 0.00280 \\
\hline $017-025$ & 1.0000 & 0.0028 & 0.99831 & 0.00009 & 0.99831 & 0.00280 \\
\hline $017-026$ & 1.0000 & 0.0028 & 0.99585 & 0.00010 & 0.99585 & 0.00279 \\
\hline 017-027 & 1.0000 & 0.0028 & 0.99803 & 0.00009 & 0.99803 & 0.00280 \\
\hline 017-028 & 1.0000 & 0.0028 & 0.99886 & 0.00008 & 0.99886 & 0.00280 \\
\hline 017-029 & 1.0000 & 0.0028 & 0.99912 & 0.00008 & 0.99912 & 0.00280 \\
\hline $042-001$ & 1.0000 & 0.0016 & 0.99800 & 0.00008 & 0.99800 & 0.00160 \\
\hline $042-002$ & 1.0000 & 0.0016 & 0.99761 & 0.00009 & 0.99761 & 0.00160 \\
\hline $042-003$ & 1.0000 & 0.0016 & 0.99820 & 0.00010 & 0.99820 & 0.00160 \\
\hline 042-004 & 1.0000 & 0.0017 & 0.99927 & 0.00009 & 0.99927 & 0.00170 \\
\hline $042-005$ & 1.0000 & 0.0033 & 0.99893 & 0.00009 & 0.99893 & 0.00330 \\
\hline 042-006 & 1.0000 & 0.0016 & 0.99904 & 0.00009 & 0.99904 & 0.00160 \\
\hline 042-007 & 1.0000 & 0.0018 & 0.99729 & 0.00009 & 0.99729 & 0.00180 \\
\hline $050-001$ & 1.0004 & 0.0010 & 0.99879 & 0.00010 & 0.99839 & 0.00100 \\
\hline $050-002$ & 1.0004 & 0.0010 & 0.99859 & 0.00010 & 0.99819 & 0.00100 \\
\hline $050-003$ & 1.0004 & 0.0010 & 0.99935 & 0.00010 & 0.99895 & 0.00100 \\
\hline $050-004$ & 1.0004 & 0.0010 & 0.99858 & 0.00010 & 0.99818 & 0.00100 \\
\hline $050-005$ & 1.0004 & 0.0010 & 0.99996 & 0.00010 & 0.99956 & 0.00100 \\
\hline $050-006$ & 1.0004 & 0.0010 & 0.99985 & 0.00010 & 0.99945 & 0.00100 \\
\hline $050-007$ & 1.0004 & 0.0010 & 0.99983 & 0.00010 & 0.99943 & 0.00100 \\
\hline $050-008$ & 1.0004 & 0.0010 & 0.99701 & 0.00010 & 0.99662 & 0.00100 \\
\hline 050-009 & 1.0004 & 0.0010 & 0.99779 & 0.00010 & 0.99739 & 0.00100 \\
\hline $050-010$ & 1.0004 & 0.0010 & 0.99734 & 0.00010 & 0.99694 & 0.00100 \\
\hline 050-011 & 1.0004 & 0.0010 & 0.99793 & 0.00010 & 0.99753 & 0.00100 \\
\hline $050-012$ & 1.0004 & 0.0010 & 0.99899 & 0.00010 & 0.99859 & 0.00100 \\
\hline $050-013$ & 1.0004 & 0.0010 & 0.99922 & 0.00010 & 0.99882 & 0.00100 \\
\hline $050-014$ & 1.0004 & 0.0010 & 0.99860 & 0.00010 & 0.99820 & 0.00100 \\
\hline $050-015$ & 1.0004 & 0.0010 & 0.99942 & 0.00010 & 0.99902 & 0.00100 \\
\hline $050-016$ & 1.0004 & 0.0010 & 1.00028 & 0.00010 & 0.99988 & 0.00100 \\
\hline $050-017$ & 1.0004 & 0.0010 & 1.00007 & 0.00010 & 0.99967 & 0.00100 \\
\hline $050-018$ & 1.0004 & 0.0010 & 1.00002 & 0.00010 & 0.99962 & 0.00100 \\
\hline 078-001 & 0.9995 & 0.0010 & 0.99733 & 0.00010 & 0.99783 & 0.00100 \\
\hline
\end{tabular}


Table A-15. Detailed ENDF/B-VIII.0 CE results for KENO V.a LCT systems (continued)

\begin{tabular}{lcccccc}
\hline Case & $\begin{array}{c}\text { Expected } \\
\boldsymbol{k}_{\text {eff }}\end{array}$ & $\begin{array}{c}\text { Experimental } \\
\text { uncertainty }\end{array}$ & $\boldsymbol{k}_{\text {eff }}$ & Uncertainty & C/E & $\begin{array}{c}\mathbf{C} / \mathbf{E} \\
\text { uncertainty }\end{array}$ \\
\hline $078-002$ & 0.9999 & 0.0010 & 0.99780 & 0.00010 & 0.99790 & 0.00100 \\
$078-003$ & 0.9990 & 0.0010 & 0.99704 & 0.00010 & 0.99804 & 0.00100 \\
$078-004$ & 0.9986 & 0.0010 & 0.99659 & 0.00010 & 0.99799 & 0.00100 \\
$078-005$ & 0.9980 & 0.0010 & 0.99604 & 0.00010 & 0.99804 & 0.00100 \\
$078-006$ & 0.9974 & 0.0010 & 0.99560 & 0.00010 & 0.99820 & 0.00101 \\
$078-007$ & 0.9994 & 0.0010 & 0.99735 & 0.00010 & 0.99795 & 0.00100 \\
$078-008$ & 0.9987 & 0.0010 & 0.99651 & 0.00010 & 0.99781 & 0.00100 \\
$078-009$ & 0.9978 & 0.0010 & 0.99573 & 0.00010 & 0.99792 & 0.00101 \\
$078-010$ & 0.9969 & 0.0010 & 0.99473 & 0.00010 & 0.99782 & 0.00101 \\
$078-011$ & 0.9994 & 0.0010 & 0.99748 & 0.00010 & 0.99807 & 0.00100 \\
$078-012$ & 0.9993 & 0.0010 & 0.99736 & 0.00010 & 0.99806 & 0.00100 \\
$078-013$ & 0.9993 & 0.0010 & 0.99720 & 0.00010 & 0.99790 & 0.00100 \\
$078-014$ & 0.9991 & 0.0010 & 0.99699 & 0.00010 & 0.99788 & 0.00100 \\
$078-015$ & 0.9996 & 0.0010 & 0.99792 & 0.00010 & 0.99832 & 0.00100 \\
$080-001$ & 0.9976 & 0.0010 & 0.99493 & 0.00010 & 0.99732 & 0.00100 \\
$080-002$ & 0.9982 & 0.0010 & 0.99542 & 0.00010 & 0.99721 & 0.00100 \\
$080-003$ & 0.9984 & 0.0010 & 0.99580 & 0.00010 & 0.99739 & 0.00100 \\
$080-004$ & 0.9981 & 0.0010 & 0.99528 & 0.00010 & 0.99717 & 0.00100 \\
$080-005$ & 0.9979 & 0.0010 & 0.99515 & 0.00010 & 0.99725 & 0.00100 \\
$080-006$ & 0.9975 & 0.0010 & 0.99451 & 0.00010 & 0.99700 & 0.00100 \\
$080-007$ & 0.9993 & 0.0010 & 0.99671 & 0.00010 & 0.99741 & 0.00100 \\
$080-008$ & 0.9987 & 0.0010 & 0.99616 & 0.00009 & 0.99745 & 0.00100 \\
$080-009$ & 0.9982 & 0.0010 & 0.99544 & 0.00009 & 0.99723 & 0.00100 \\
$080-010$ & 0.9972 & 0.0010 & 0.99475 & 0.00010 & 0.99754 & 0.00101 \\
$080-011$ & 0.9984 & 0.0010 & 0.99663 & 0.00010 & 0.99823 & 0.00100 \\
\hline
\end{tabular}


Table A-16. Detailed ENDF/B-VII.1 CE results for KENO V.a LCT systems

\begin{tabular}{|c|c|c|c|c|c|c|}
\hline Case & $\begin{array}{c}\text { Expected } \\
\boldsymbol{k}_{\text {eff }}\end{array}$ & $\begin{array}{c}\text { Experimental } \\
\text { uncertainty }\end{array}$ & $\boldsymbol{k}_{\text {eff }}$ & Uncertainty & $\mathrm{C} / \mathrm{E}$ & $\begin{array}{c}\mathbf{C} / \mathbf{E} \\
\text { uncertainty }\end{array}$ \\
\hline $001-001$ & 0.9998 & 0.0031 & 0.99930 & 0.00048 & 0.99950 & 0.00314 \\
\hline 001-002 & 0.9998 & 0.0031 & 0.99843 & 0.00046 & 0.99863 & 0.00313 \\
\hline $001-003$ & 0.9998 & 0.0031 & 0.99871 & 0.00048 & 0.99891 & 0.00313 \\
\hline 001-004 & 0.9998 & 0.0031 & 0.99960 & 0.00049 & 0.99980 & 0.00314 \\
\hline $001-005$ & 0.9998 & 0.0031 & 0.99633 & 0.00047 & 0.99653 & 0.00313 \\
\hline 001-006 & 0.9998 & 0.0031 & 0.99875 & 0.00049 & 0.99895 & 0.00314 \\
\hline 001-007 & 0.9998 & 0.0031 & 0.99755 & 0.00044 & 0.99775 & 0.00312 \\
\hline 001-008 & 0.9998 & 0.0031 & 0.99726 & 0.00043 & 0.99746 & 0.00312 \\
\hline $002-001$ & 0.9997 & 0.0020 & 0.99814 & 0.00011 & 0.99844 & 0.00200 \\
\hline 002-002 & 0.9997 & 0.0020 & 0.99952 & 0.00010 & 0.99982 & 0.00200 \\
\hline $002-003$ & 0.9997 & 0.0020 & 0.99909 & 0.00012 & 0.99939 & 0.00200 \\
\hline 002-004 & 0.9997 & 0.0020 & 0.99863 & 0.00010 & 0.99893 & 0.00200 \\
\hline $002-005$ & 0.9997 & 0.0020 & 0.99736 & 0.00011 & 0.99766 & 0.00200 \\
\hline 008-001 & 1.0007 & 0.0012 & 1.00072 & 0.00010 & 1.00002 & 0.00120 \\
\hline 008-002 & 1.0007 & 0.0012 & 1.00113 & 0.00010 & 1.00043 & 0.00120 \\
\hline 008-003 & 1.0007 & 0.0012 & 1.00152 & 0.00010 & 1.00082 & 0.00120 \\
\hline 008-004 & 1.0007 & 0.0012 & 1.00092 & 0.00010 & 1.00022 & 0.00120 \\
\hline 008-005 & 1.0007 & 0.0012 & 1.00060 & 0.00010 & 0.99990 & 0.00120 \\
\hline 008-006 & 1.0007 & 0.0012 & 1.00119 & 0.00010 & 1.00049 & 0.00120 \\
\hline 008-007 & 1.0007 & 0.0012 & 1.00049 & 0.00010 & 0.99979 & 0.00120 \\
\hline 008-008 & 1.0007 & 0.0012 & 1.00024 & 0.00010 & 0.99954 & 0.00120 \\
\hline 008-009 & 1.0007 & 0.0012 & 1.00016 & 0.00010 & 0.99946 & 0.00120 \\
\hline 008-010 & 1.0007 & 0.0012 & 1.00071 & 0.00010 & 1.00001 & 0.00120 \\
\hline 008-011 & 1.0007 & 0.0012 & 1.00150 & 0.00010 & 1.00080 & 0.00120 \\
\hline 008-012 & 1.0007 & 0.0012 & 1.00115 & 0.00010 & 1.00045 & 0.00120 \\
\hline $008-013$ & 1.0007 & 0.0012 & 1.00120 & 0.00010 & 1.00050 & 0.00120 \\
\hline 008-014 & 1.0007 & 0.0012 & 1.00108 & 0.00010 & 1.00038 & 0.00120 \\
\hline 008-015 & 1.0007 & 0.0012 & 1.00081 & 0.00010 & 1.00011 & 0.00120 \\
\hline 008-016 & 1.0007 & 0.0012 & 1.00063 & 0.00010 & 0.99993 & 0.00120 \\
\hline $008-017$ & 1.0007 & 0.0012 & 0.99975 & 0.00010 & 0.99905 & 0.00120 \\
\hline 010-001 & 1.0000 & 0.0021 & 1.00508 & 0.00009 & 1.00508 & 0.00211 \\
\hline 010-002 & 1.0000 & 0.0021 & 1.00521 & 0.00010 & 1.00521 & 0.00211 \\
\hline 010-003 & 1.0000 & 0.0021 & 1.00420 & 0.00010 & 1.00420 & 0.00211 \\
\hline 010-004 & 1.0000 & 0.0021 & 0.99683 & 0.00008 & 0.99683 & 0.00209 \\
\hline $010-005$ & 1.0000 & 0.0021 & 0.99964 & 0.00010 & 0.99964 & 0.00210 \\
\hline 010-006 & 1.0000 & 0.0021 & 1.00037 & 0.00009 & 1.00037 & 0.00210 \\
\hline 010-007 & 1.0000 & 0.0021 & 1.00117 & 0.00010 & 1.00117 & 0.00210 \\
\hline 010-008 & 1.0000 & 0.0021 & 0.99789 & 0.00010 & 0.99789 & 0.00210 \\
\hline 010-009 & 1.0000 & 0.0021 & 0.99997 & 0.00009 & 0.99997 & 0.00210 \\
\hline $010-010$ & 1.0000 & 0.0021 & 1.00018 & 0.00010 & 1.00018 & 0.00210 \\
\hline 010-011 & 1.0000 & 0.0021 & 1.00058 & 0.00010 & 1.00058 & 0.00210 \\
\hline $010-012$ & 1.0000 & 0.0021 & 0.99967 & 0.00010 & 0.99967 & 0.00210 \\
\hline 010-013 & 1.0000 & 0.0021 & 0.99767 & 0.00010 & 0.99767 & 0.00210 \\
\hline 010-014 & 1.0000 & 0.0028 & 1.00193 & 0.00010 & 1.00193 & 0.00281 \\
\hline $010-015$ & 1.0000 & 0.0028 & 1.00267 & 0.00010 & 1.00267 & 0.00281 \\
\hline 010-016 & 1.0000 & 0.0028 & 1.00328 & 0.00010 & 1.00328 & 0.00281 \\
\hline $010-017$ & 1.0000 & 0.0028 & 1.00267 & 0.00009 & 1.00267 & 0.00281 \\
\hline 010-018 & 1.0000 & 0.0028 & 1.00245 & 0.00009 & 1.00245 & 0.00281 \\
\hline 010-019 & 1.0000 & 0.0028 & 1.00217 & 0.00010 & 1.00217 & 0.00281 \\
\hline $010-020$ & 1.0000 & 0.0028 & 1.00406 & 0.00010 & 1.00406 & 0.00281 \\
\hline 010-021 & 1.0000 & 0.0028 & 1.00410 & 0.00010 & 1.00410 & 0.00281 \\
\hline $010-022$ & 1.0000 & 0.0028 & 1.00367 & 0.00009 & 1.00367 & 0.00281 \\
\hline 010-023 & 1.0000 & 0.0028 & 1.00198 & 0.00007 & 1.00198 & 0.00281 \\
\hline 010-024 & 1.0000 & 0.0028 & 1.00035 & 0.00010 & 1.00035 & 0.00280 \\
\hline $010-025$ & 1.0000 & 0.0028 & 1.00169 & 0.00010 & 1.00169 & 0.00281 \\
\hline $010-026$ & 1.0000 & 0.0028 & 1.00205 & 0.00010 & 1.00205 & 0.00281 \\
\hline $010-027$ & 1.0000 & 0.0028 & 1.00239 & 0.00010 & 1.00239 & 0.00281 \\
\hline
\end{tabular}


Table A-16. Detailed ENDF/B-VII.1 CE results for KENO V.a LCT systems (continued)

\begin{tabular}{|c|c|c|c|c|c|c|}
\hline Case & $\begin{array}{c}\text { Expected } \\
k_{\text {eff }}\end{array}$ & $\begin{array}{c}\text { Experimental } \\
\text { uncertainty }\end{array}$ & $\boldsymbol{k}_{\text {eff }}$ & Uncertainty & $\mathbf{C} / \mathbf{E}$ & $\begin{array}{c}\mathrm{C} / \mathbf{E} \\
\text { uncertainty }\end{array}$ \\
\hline $010-028$ & 1.0000 & 0.0028 & 1.00279 & 0.00010 & 1.00279 & 0.00281 \\
\hline 010-029 & 1.0000 & 0.0028 & 1.00264 & 0.00007 & 1.00264 & 0.00281 \\
\hline $010-030$ & 1.0000 & 0.0028 & 1.00061 & 0.00010 & 1.00061 & 0.00280 \\
\hline 017-001 & 1.0000 & 0.0031 & 1.00167 & 0.00010 & 1.00167 & 0.00311 \\
\hline 017-002 & 1.0000 & 0.0031 & 1.00118 & 0.00010 & 1.00118 & 0.00311 \\
\hline $017-003$ & 1.0000 & 0.0031 & 0.99960 & 0.00010 & 0.99960 & 0.00310 \\
\hline 017-004 & 1.0000 & 0.0031 & 0.99841 & 0.00009 & 0.99841 & 0.00310 \\
\hline $017-005$ & 1.0000 & 0.0031 & 1.00013 & 0.00010 & 1.00013 & 0.00310 \\
\hline 017-006 & 1.0000 & 0.0031 & 1.00001 & 0.00010 & 1.00001 & 0.00310 \\
\hline 017-007 & 1.0000 & 0.0031 & 1.00003 & 0.00010 & 1.00003 & 0.00310 \\
\hline 017-008 & 1.0000 & 0.0031 & 0.99837 & 0.00006 & 0.99837 & 0.00310 \\
\hline 017-009 & 1.0000 & 0.0031 & 0.99765 & 0.00010 & 0.99765 & 0.00309 \\
\hline 017-010 & 1.0000 & 0.0031 & 0.99830 & 0.00007 & 0.99830 & 0.00310 \\
\hline 017-011 & 1.0000 & 0.0031 & 0.99826 & 0.00010 & 0.99826 & 0.00310 \\
\hline 017-012 & 1.0000 & 0.0031 & 0.99841 & 0.00010 & 0.99841 & 0.00310 \\
\hline 017-013 & 1.0000 & 0.0031 & 0.99895 & 0.00009 & 0.99895 & 0.00310 \\
\hline $017-014$ & 1.0000 & 0.0031 & 0.99941 & 0.00010 & 0.99941 & 0.00310 \\
\hline 017-015 & 1.0000 & 0.0028 & 0.99743 & 0.00008 & 0.99743 & 0.00279 \\
\hline 017-016 & 1.0000 & 0.0028 & 0.99877 & 0.00008 & 0.99877 & 0.00280 \\
\hline 017-017 & 1.0000 & 0.0028 & 0.99993 & 0.00007 & 0.99993 & 0.00280 \\
\hline 017-018 & 1.0000 & 0.0028 & 0.99897 & 0.00006 & 0.99897 & 0.00280 \\
\hline 017-019 & 1.0000 & 0.0028 & 0.99935 & 0.00007 & 0.99935 & 0.00280 \\
\hline $017-020$ & 1.0000 & 0.0028 & 0.99823 & 0.00008 & 0.99823 & 0.00280 \\
\hline 017-021 & 1.0000 & 0.0028 & 0.99838 & 0.00006 & 0.99838 & 0.00280 \\
\hline $017-022$ & 1.0000 & 0.0028 & 0.99765 & 0.00007 & 0.99765 & 0.00279 \\
\hline 017-023 & 1.0000 & 0.0028 & 0.99991 & 0.00010 & 0.99991 & 0.00280 \\
\hline $017-024$ & 1.0000 & 0.0028 & 1.00066 & 0.00008 & 1.00066 & 0.00280 \\
\hline $017-025$ & 1.0000 & 0.0028 & 0.99860 & 0.00008 & 0.99860 & 0.00280 \\
\hline $017-026$ & 1.0000 & 0.0028 & 0.99652 & 0.00008 & 0.99652 & 0.00279 \\
\hline 017-027 & 1.0000 & 0.0028 & 0.99862 & 0.00008 & 0.99862 & 0.00280 \\
\hline 017-028 & 1.0000 & 0.0028 & 0.99944 & 0.00008 & 0.99944 & 0.00280 \\
\hline 017-029 & 1.0000 & 0.0028 & 0.99938 & 0.00009 & 0.99938 & 0.00280 \\
\hline $042-001$ & 1.0000 & 0.0016 & 0.99853 & 0.00008 & 0.99853 & 0.00160 \\
\hline $042-002$ & 1.0000 & 0.0016 & 0.99823 & 0.00010 & 0.99823 & 0.00160 \\
\hline $042-003$ & 1.0000 & 0.0016 & 0.99915 & 0.00010 & 0.99915 & 0.00160 \\
\hline 042-004 & 1.0000 & 0.0017 & 0.99986 & 0.00009 & 0.99986 & 0.00170 \\
\hline $042-005$ & 1.0000 & 0.0033 & 0.99971 & 0.00009 & 0.99971 & 0.00330 \\
\hline 042-006 & 1.0000 & 0.0016 & 0.99936 & 0.00008 & 0.99936 & 0.00160 \\
\hline 042-007 & 1.0000 & 0.0018 & 0.99779 & 0.00009 & 0.99779 & 0.00180 \\
\hline $050-001$ & 1.0004 & 0.0010 & 0.99906 & 0.00010 & 0.99866 & 0.00100 \\
\hline $050-002$ & 1.0004 & 0.0010 & 0.99886 & 0.00010 & 0.99846 & 0.00100 \\
\hline $050-003$ & 1.0004 & 0.0010 & 0.99966 & 0.00010 & 0.99926 & 0.00100 \\
\hline $050-004$ & 1.0004 & 0.0010 & 0.99912 & 0.00010 & 0.99872 & 0.00100 \\
\hline $050-005$ & 1.0004 & 0.0010 & 1.00071 & 0.00010 & 1.00031 & 0.00100 \\
\hline $050-006$ & 1.0004 & 0.0010 & 1.00058 & 0.00010 & 1.00018 & 0.00100 \\
\hline $050-007$ & 1.0004 & 0.0010 & 1.00045 & 0.00010 & 1.00005 & 0.00100 \\
\hline $050-008$ & 1.0004 & 0.0010 & 0.99754 & 0.00010 & 0.99714 & 0.00100 \\
\hline 050-009 & 1.0004 & 0.0010 & 0.99776 & 0.00010 & 0.99737 & 0.00100 \\
\hline $050-010$ & 1.0004 & 0.0010 & 0.99752 & 0.00010 & 0.99712 & 0.00100 \\
\hline 050-011 & 1.0004 & 0.0010 & 0.99827 & 0.00010 & 0.99787 & 0.00100 \\
\hline $050-012$ & 1.0004 & 0.0010 & 0.99938 & 0.00010 & 0.99898 & 0.00100 \\
\hline $050-013$ & 1.0004 & 0.0010 & 0.99951 & 0.00010 & 0.99911 & 0.00100 \\
\hline $050-014$ & 1.0004 & 0.0010 & 0.99912 & 0.00010 & 0.99872 & 0.00100 \\
\hline $050-015$ & 1.0004 & 0.0010 & 0.99990 & 0.00010 & 0.99950 & 0.00100 \\
\hline $050-016$ & 1.0004 & 0.0010 & 1.00079 & 0.00010 & 1.00039 & 0.00100 \\
\hline $050-017$ & 1.0004 & 0.0010 & 1.00063 & 0.00010 & 1.00023 & 0.00100 \\
\hline $050-018$ & 1.0004 & 0.0010 & 1.00060 & 0.00010 & 1.00020 & 0.00100 \\
\hline 078-001 & 0.9995 & 0.0010 & 0.99803 & 0.00010 & 0.99852 & 0.00100 \\
\hline
\end{tabular}


Table A-16. Detailed ENDF/B-VII.1 CE results for KENO V.a LCT systems (continued)

\begin{tabular}{lcccccc}
\hline Case & $\begin{array}{c}\text { Expected } \\
\boldsymbol{k}_{\text {eff }}\end{array}$ & $\begin{array}{c}\text { Experimental } \\
\text { uncertainty }\end{array}$ & $\boldsymbol{k}_{\text {eff }}$ & Uncertainty & C/E & $\begin{array}{c}\mathbf{C} / \mathbf{E} \\
\text { uncertainty }\end{array}$ \\
\hline $078-002$ & 0.9999 & 0.0010 & 0.99860 & 0.00010 & 0.99870 & 0.00100 \\
$078-003$ & 0.9990 & 0.0010 & 0.99758 & 0.00010 & 0.99858 & 0.00100 \\
$078-004$ & 0.9986 & 0.0010 & 0.99724 & 0.00010 & 0.99864 & 0.00100 \\
$078-005$ & 0.9980 & 0.0010 & 0.99677 & 0.00010 & 0.99877 & 0.00101 \\
$078-006$ & 0.9974 & 0.0010 & 0.99626 & 0.00010 & 0.99885 & 0.00101 \\
$078-007$ & 0.9994 & 0.0010 & 0.99801 & 0.00010 & 0.99861 & 0.00100 \\
$078-008$ & 0.9987 & 0.0010 & 0.99734 & 0.00010 & 0.99864 & 0.00100 \\
$078-009$ & 0.9978 & 0.0010 & 0.99628 & 0.00010 & 0.99848 & 0.00101 \\
$078-010$ & 0.9969 & 0.0010 & 0.99537 & 0.00010 & 0.99847 & 0.00101 \\
$078-011$ & 0.9994 & 0.0010 & 0.99800 & 0.00010 & 0.99860 & 0.00100 \\
$078-012$ & 0.9993 & 0.0010 & 0.99782 & 0.00010 & 0.99851 & 0.00100 \\
$078-013$ & 0.9993 & 0.0010 & 0.99779 & 0.00010 & 0.99848 & 0.00100 \\
$078-014$ & 0.9991 & 0.0010 & 0.99759 & 0.00010 & 0.99849 & 0.00100 \\
$078-015$ & 0.9996 & 0.0010 & 0.99875 & 0.00010 & 0.99915 & 0.00100 \\
$080-001$ & 0.9976 & 0.0010 & 0.99613 & 0.00010 & 0.99853 & 0.00101 \\
$080-002$ & 0.9982 & 0.0010 & 0.99666 & 0.00010 & 0.99846 & 0.00101 \\
$080-003$ & 0.9984 & 0.0010 & 0.99689 & 0.00010 & 0.99849 & 0.00100 \\
$080-004$ & 0.9981 & 0.0010 & 0.99654 & 0.00010 & 0.99844 & 0.00101 \\
$080-005$ & 0.9979 & 0.0010 & 0.99628 & 0.00010 & 0.99838 & 0.00101 \\
$080-006$ & 0.9975 & 0.0010 & 0.99595 & 0.00010 & 0.99845 & 0.00101 \\
$080-007$ & 0.9993 & 0.0010 & 0.99796 & 0.00010 & 0.99866 & 0.00100 \\
$080-008$ & 0.9987 & 0.0010 & 0.99710 & 0.00010 & 0.99840 & 0.00100 \\
$080-009$ & 0.9982 & 0.0010 & 0.99631 & 0.00010 & 0.99810 & 0.00100 \\
$080-010$ & 0.9972 & 0.0010 & 0.99566 & 0.00010 & 0.99846 & 0.00101 \\
$080-011$ & 0.9984 & 0.0010 & 0.99759 & 0.00010 & 0.99919 & 0.00101 \\
\hline
\end{tabular}

Table A-17. Detailed ENDF/B-VIII.0 252-group results for KENO V.a LST systems

\begin{tabular}{rcccccc}
\hline Case & $\begin{array}{c}\text { Expected } \\
\boldsymbol{k}_{\text {eff }}\end{array}$ & $\begin{array}{c}\text { Experimental } \\
\text { uncertainty }\end{array}$ & $\boldsymbol{k}_{\text {eff }}$ & Uncertainty & C/E & $\begin{array}{c}\mathbf{C} / \mathbf{E} \\
\text { uncertainty }\end{array}$ \\
\hline $002-001$ & 1.0038 & 0.0040 & 0.99918 & 0.00010 & 0.99539 & 0.00397 \\
$002-002$ & 1.0024 & 0.0037 & 0.99520 & 0.00010 & 0.99282 & 0.00367 \\
$002-003$ & 1.0024 & 0.0044 & 1.00034 & 0.00010 & 0.99794 & 0.00438 \\
$003-001$ & 0.9997 & 0.0039 & 0.99687 & 0.00010 & 0.99717 & 0.00389 \\
$003-002$ & 0.9993 & 0.0042 & 0.99566 & 0.00010 & 0.99636 & 0.00419 \\
$003-003$ & 0.9995 & 0.0042 & 1.00009 & 0.00010 & 1.00059 & 0.00421 \\
$003-004$ & 0.9995 & 0.0042 & 0.99354 & 0.00010 & 0.99404 & 0.00418 \\
$003-005$ & 0.9997 & 0.0048 & 0.99769 & 0.00010 & 0.99799 & 0.00479 \\
$003-006$ & 0.9999 & 0.0049 & 0.99810 & 0.00010 & 0.99820 & 0.00489 \\
$003-007$ & 0.9994 & 0.0049 & 0.99645 & 0.00010 & 0.99705 & 0.00489 \\
$003-008$ & 0.9993 & 0.0052 & 0.99972 & 0.00010 & 1.00042 & 0.00521 \\
$003-009$ & 0.9996 & 0.0052 & 0.99736 & 0.00010 & 0.99776 & 0.00519 \\
$004-001$ & 0.9994 & 0.0008 & 1.00056 & 0.00048 & 1.00116 & 0.00093 \\
$004-002$ & 0.9999 & 0.0009 & 1.00087 & 0.00048 & 1.00097 & 0.00102 \\
$004-003$ & 0.9999 & 0.0009 & 0.99888 & 0.00044 & 0.99898 & 0.00100 \\
$004-004$ & 0.9999 & 0.0010 & 1.00116 & 0.00044 & 1.00126 & 0.00109 \\
$004-005$ & 0.9999 & 0.0010 & 1.00075 & 0.00042 & 1.00085 & 0.00109 \\
$004-006$ & 0.9994 & 0.0011 & 1.00037 & 0.00040 & 1.00097 & 0.00117 \\
$004-007$ & 0.9996 & 0.0011 & 0.99997 & 0.00038 & 1.00037 & 0.00116 \\
\hline
\end{tabular}


Table A-18. Detailed ENDF/B-VII.1 252-group results for KENO V.a LST systems

\begin{tabular}{rcccccc}
\hline Case & $\begin{array}{c}\text { Expected } \\
\boldsymbol{k}_{\text {eff }}\end{array}$ & $\begin{array}{c}\text { Experimental } \\
\text { uncertainty }\end{array}$ & $\boldsymbol{k}_{\text {eff }}$ & Uncertainty & C/E & $\begin{array}{c}\text { C/E } \\
\text { uncertainty }\end{array}$ \\
\hline $002-001$ & 1.0038 & 0.0040 & 0.99852 & 0.00010 & 0.99474 & 0.00397 \\
$002-002$ & 1.0024 & 0.0037 & 0.99418 & 0.00010 & 0.99180 & 0.00366 \\
$002-003$ & 1.0024 & 0.0044 & 0.99935 & 0.00010 & 0.99696 & 0.00438 \\
$003-001$ & 0.9997 & 0.0039 & 0.99553 & 0.00010 & 0.99583 & 0.00389 \\
$003-002$ & 0.9993 & 0.0042 & 0.99468 & 0.00009 & 0.99538 & 0.00418 \\
$003-003$ & 0.9995 & 0.0042 & 0.99902 & 0.00010 & 0.99952 & 0.00420 \\
$003-004$ & 0.9995 & 0.0042 & 0.99255 & 0.00010 & 0.99305 & 0.00417 \\
$003-005$ & 0.9997 & 0.0048 & 0.99716 & 0.00010 & 0.99746 & 0.00479 \\
$003-006$ & 0.9999 & 0.0049 & 0.99785 & 0.00010 & 0.99795 & 0.00489 \\
$003-007$ & 0.9994 & 0.0049 & 0.99625 & 0.00010 & 0.99685 & 0.00489 \\
$003-008$ & 0.9993 & 0.0052 & 1.00006 & 0.00010 & 1.00076 & 0.00521 \\
$003-009$ & 0.9996 & 0.0052 & 0.99736 & 0.00010 & 0.99776 & 0.00519 \\
$004-001$ & 0.9994 & 0.0008 & 0.99805 & 0.00049 & 0.99865 & 0.00094 \\
$004-002$ & 0.9999 & 0.0009 & 1.00039 & 0.00042 & 1.00049 & 0.00099 \\
$004-003$ & 0.9999 & 0.0009 & 0.99822 & 0.00047 & 0.99832 & 0.00101 \\
$004-004$ & 0.9999 & 0.0010 & 1.00018 & 0.00039 & 1.00028 & 0.00107 \\
$004-005$ & 0.9999 & 0.0010 & 1.00039 & 0.00046 & 1.00049 & 0.00110 \\
$004-006$ & 0.9994 & 0.0011 & 0.99985 & 0.00043 & 1.00045 & 0.00118 \\
$004-007$ & 0.9996 & 0.0011 & 0.99992 & 0.00034 & 1.00032 & 0.00115 \\
\hline
\end{tabular}

Table A-19. Detailed ENDF/B-VIII.0 CE results for KENO V.a LST systems

\begin{tabular}{ccccccc}
\hline Case & $\begin{array}{c}\text { Expected } \\
\boldsymbol{k}_{\text {eff }}\end{array}$ & $\begin{array}{c}\text { Experimental } \\
\text { uncertainty }\end{array}$ & $\boldsymbol{k}_{\text {eff }}$ & Uncertainty & C/E & $\begin{array}{c}\mathbf{C} / \mathbf{E} \\
\text { uncertainty }\end{array}$ \\
\hline $002-001$ & 1.0038 & 0.0040 & 0.99904 & 0.00010 & 0.99526 & 0.00397 \\
$002-002$ & 1.0024 & 0.0037 & 0.99468 & 0.00010 & 0.99230 & 0.00366 \\
$002-003$ & 1.0024 & 0.0044 & 0.99985 & 0.00010 & 0.99746 & 0.00438 \\
$003-001$ & 0.9997 & 0.0039 & 0.99711 & 0.00010 & 0.99741 & 0.00389 \\
$003-002$ & 0.9993 & 0.0042 & 0.99594 & 0.00010 & 0.99663 & 0.00419 \\
$003-003$ & 0.9995 & 0.0042 & 1.00026 & 0.00010 & 1.00076 & 0.00421 \\
$003-004$ & 0.9995 & 0.0042 & 0.99375 & 0.00010 & 0.99424 & 0.00418 \\
$003-005$ & 0.9997 & 0.0048 & 0.99798 & 0.00010 & 0.99828 & 0.00479 \\
$003-006$ & 0.9999 & 0.0049 & 0.99841 & 0.00010 & 0.99851 & 0.00489 \\
$003-007$ & 0.9994 & 0.0049 & 0.99646 & 0.00010 & 0.99706 & 0.00489 \\
$003-008$ & 0.9993 & 0.0052 & 0.99987 & 0.00010 & 1.00057 & 0.00521 \\
$003-009$ & 0.9996 & 0.0052 & 0.99720 & 0.00010 & 0.99760 & 0.00519 \\
$004-001$ & 0.9994 & 0.0008 & 0.99906 & 0.00047 & 0.99966 & 0.00093 \\
$004-002$ & 0.9999 & 0.0009 & 1.00112 & 0.00046 & 1.00122 & 0.00101 \\
$004-003$ & 0.9999 & 0.0009 & 0.99869 & 0.00048 & 0.99879 & 0.00102 \\
$004-004$ & 0.9999 & 0.0010 & 1.00147 & 0.00045 & 1.00157 & 0.00110 \\
$004-005$ & 0.9999 & 0.0010 & 1.00131 & 0.00046 & 1.00141 & 0.00110 \\
$004-006$ & 0.9994 & 0.0011 & 1.00044 & 0.00048 & 1.00104 & 0.00120 \\
$004-007$ & 0.9996 & 0.0011 & 1.00035 & 0.00045 & 1.00075 & 0.00119 \\
\hline
\end{tabular}


Table A-20. Detailed ENDF/B-VII.1 CE results for KENO V.a LST systems

\begin{tabular}{ccccccc}
\hline Case & $\begin{array}{c}\text { Expected } \\
\boldsymbol{k}_{\text {eff }}\end{array}$ & $\begin{array}{c}\text { Experimental } \\
\text { uncertainty }\end{array}$ & $\boldsymbol{k}_{\text {eff }}$ & Uncertainty & $\mathbf{C} / \mathbf{E}$ & $\begin{array}{c}\text { C/E } \\
\text { uncertainty }\end{array}$ \\
\hline $002-001$ & 1.0038 & 0.0040 & 0.99872 & 0.00010 & 0.99494 & 0.00397 \\
$002-002$ & 1.0024 & 0.0037 & 0.99442 & 0.00010 & 0.99204 & 0.00366 \\
$002-003$ & 1.0024 & 0.0044 & 0.99966 & 0.00010 & 0.99726 & 0.00438 \\
$003-001$ & 0.9997 & 0.0039 & 0.99641 & 0.00010 & 0.99671 & 0.00389 \\
$003-002$ & 0.9993 & 0.0042 & 0.99539 & 0.00009 & 0.99609 & 0.00419 \\
$003-003$ & 0.9995 & 0.0042 & 0.99979 & 0.00010 & 1.00029 & 0.00420 \\
$003-004$ & 0.9995 & 0.0042 & 0.99333 & 0.00008 & 0.99382 & 0.00418 \\
$003-005$ & 0.9997 & 0.0048 & 0.99779 & 0.00010 & 0.99809 & 0.00479 \\
$003-006$ & 0.9999 & 0.0049 & 0.99821 & 0.00010 & 0.99831 & 0.00489 \\
$003-007$ & 0.9994 & 0.0049 & 0.99673 & 0.00010 & 0.99732 & 0.00489 \\
$003-008$ & 0.9993 & 0.0052 & 1.00028 & 0.00010 & 1.00098 & 0.00521 \\
$003-009$ & 0.9996 & 0.0052 & 0.99753 & 0.00010 & 0.99793 & 0.00519 \\
$004-001$ & 0.9994 & 0.0008 & 0.99883 & 0.00048 & 0.99943 & 0.00093 \\
$004-002$ & 0.9999 & 0.0009 & 1.00089 & 0.00037 & 1.00099 & 0.00097 \\
$004-003$ & 0.9999 & 0.0009 & 0.99873 & 0.00048 & 0.99883 & 0.00102 \\
$004-004$ & 0.9999 & 0.0010 & 1.00131 & 0.00046 & 1.00141 & 0.00110 \\
$004-005$ & 0.9999 & 0.0010 & 1.00059 & 0.00045 & 1.00069 & 0.00110 \\
$004-006$ & 0.9994 & 0.0011 & 0.99974 & 0.00047 & 1.00034 & 0.00120 \\
$004-007$ & 0.9996 & 0.0011 & 1.00040 & 0.00044 & 1.00080 & 0.00119 \\
\hline
\end{tabular}

Table A-21. Detailed ENDF/B-VIII.0 252-group results for KENO V.a MCF systems

\begin{tabular}{rcccccc}
\hline Case & $\begin{array}{c}\text { Expected } \\
\boldsymbol{k}_{\text {eff }}\end{array}$ & $\begin{array}{c}\text { Experimental } \\
\text { uncertainty }\end{array}$ & $\boldsymbol{k}_{\text {eff }}$ & Uncertainty & $\mathbf{C} / \mathbf{E}$ & $\begin{array}{c}\mathbf{C} / \mathbf{E} \\
\text { uncertainty }\end{array}$ \\
\hline $005-001$ & 0.9913 & 0.0023 & 0.98969 & 0.00010 & 0.99837 & 0.00232 \\
$006-001$ & 0.9889 & 0.0021 & 0.99287 & 0.00010 & 1.00402 & 0.00213 \\
\hline
\end{tabular}

Table A-22. Detailed ENDF/B-VII.1 252-group results for KENO V.a MCF systems

\begin{tabular}{ccccccc}
\hline Case & $\begin{array}{c}\text { Expected } \\
\boldsymbol{k}_{\text {eff }}\end{array}$ & $\begin{array}{c}\text { Experimental } \\
\text { uncertainty }\end{array}$ & $\boldsymbol{k}_{\text {eff }}$ & Uncertainty & $\mathbf{C} / \mathbf{E}$ & $\begin{array}{c}\mathbf{C} / \mathbf{E} \\
\text { uncertainty }\end{array}$ \\
\hline $005-001$ & 0.9913 & 0.0023 & 0.99057 & 0.00010 & 0.99927 & 0.00232 \\
$006-001$ & 0.9889 & 0.0021 & 0.99654 & 0.00010 & 1.00772 & 0.00214 \\
\hline
\end{tabular}

Table A-23. Detailed ENDF/B-VIII.0 CE results for KENO V.a MCF systems

\begin{tabular}{rcccccc}
\hline Case & $\begin{array}{c}\text { Expected } \\
\boldsymbol{k}_{\text {eff }}\end{array}$ & $\begin{array}{c}\text { Experimental } \\
\text { uncertainty }\end{array}$ & $\boldsymbol{k}_{\text {eff }}$ & Uncertainty & $\mathbf{C} / \mathbf{E}$ & $\begin{array}{c}\mathbf{C} / \mathbf{E} \\
\text { uncertainty }\end{array}$ \\
\hline $005-001$ & 0.9913 & 0.0023 & 0.98747 & 0.00010 & 0.99613 & 0.00231 \\
$006-001$ & 0.9889 & 0.0021 & 0.98871 & 0.00010 & 0.99981 & 0.00213 \\
\hline
\end{tabular}

Table A-24. Detailed ENDF/B-VII.1 CE results for KENO V.a MCF systems

\begin{tabular}{rcccccc}
\hline Case & $\begin{array}{c}\text { Expected } \\
\boldsymbol{k}_{\text {eff }}\end{array}$ & $\begin{array}{c}\text { Experimental } \\
\text { uncertainty }\end{array}$ & $\boldsymbol{k}_{\text {eff }}$ & Uncertainty & $\mathbf{C} / \mathbf{E}$ & $\begin{array}{c}\mathbf{C} / \mathbf{E} \\
\text { uncertainty }\end{array}$ \\
\hline $005-001$ & 0.9913 & 0.0023 & 0.98704 & 0.00010 & 0.99570 & 0.00231 \\
$006-001$ & 0.9889 & 0.0021 & 0.99098 & 0.00010 & 1.00210 & 0.00213 \\
\hline
\end{tabular}


Table A-25. Detailed ENDF/B-VIII.0 252-group results for KENO V.a MCT systems

\begin{tabular}{ccccccc}
\hline Case & $\begin{array}{c}\text { Expected } \\
\boldsymbol{k}_{\text {eff }}\end{array}$ & $\begin{array}{c}\text { Experimental } \\
\text { uncertainty }\end{array}$ & $\boldsymbol{k}_{\text {eff }}$ & Uncertainty & $\mathbf{C} / \mathbf{E}$ & $\begin{array}{c}\mathbf{C} / \mathbf{E} \\
\text { uncertainty }\end{array}$ \\
\hline $001-001$ & 1.0000 & 0.0025 & 1.00338 & 0.00010 & 1.00338 & 0.00251 \\
$001-002$ & 1.0000 & 0.0026 & 1.00072 & 0.00010 & 1.00072 & 0.00260 \\
$001-003$ & 1.0000 & 0.0032 & 0.99859 & 0.00010 & 0.99859 & 0.00320 \\
$001-004$ & 1.0000 & 0.0039 & 1.00034 & 0.00010 & 1.00034 & 0.00390 \\
$002-001 \mathrm{~S}$ & 1.0024 & 0.0060 & 1.00159 & 0.00010 & 0.99919 & 0.00598 \\
$002-002 \mathrm{~S}$ & 1.0009 & 0.0047 & 1.00230 & 0.00010 & 1.00139 & 0.00470 \\
$002-003 \mathrm{~S}$ & 1.0042 & 0.0031 & 1.00117 & 0.00010 & 0.99698 & 0.00308 \\
$002-004 \mathrm{~S}$ & 1.0024 & 0.0024 & 1.00531 & 0.00010 & 1.00291 & 0.00240 \\
$002-005 \mathrm{~S}$ & 1.0038 & 0.0025 & 1.00289 & 0.00010 & 0.99910 & 0.00249 \\
$002-006 \mathrm{~S}$ & 1.0029 & 0.0027 & 1.00523 & 0.00010 & 1.00232 & 0.00270 \\
$004-001$ & 1.0000 & 0.0046 & 0.99438 & 0.00010 & 0.99438 & 0.00458 \\
$004-002$ & 1.0000 & 0.0046 & 0.99521 & 0.00010 & 0.99521 & 0.00458 \\
$004-003$ & 1.0000 & 0.0046 & 0.99529 & 0.00010 & 0.99529 & 0.00458 \\
$004-004$ & 1.0000 & 0.0039 & 0.99464 & 0.00010 & 0.99464 & 0.00388 \\
$004-005$ & 1.0000 & 0.0039 & 0.99569 & 0.00010 & 0.99569 & 0.00388 \\
$004-006$ & 1.0000 & 0.0039 & 0.99546 & 0.00010 & 0.99546 & 0.00388 \\
$004-007$ & 1.0000 & 0.0040 & 0.99541 & 0.00010 & 0.99541 & 0.00398 \\
$004-008$ & 1.0000 & 0.0040 & 0.99600 & 0.00010 & 0.99600 & 0.00399 \\
$004-009$ & 1.0000 & 0.0040 & 0.99631 & 0.00010 & 0.99631 & 0.00399 \\
$004-010$ & 1.0000 & 0.0051 & 0.99613 & 0.00010 & 0.99613 & 0.00508 \\
$004-011$ & 1.0000 & 0.0051 & 0.99624 & 0.00010 & 0.99624 & 0.00508 \\
\hline
\end{tabular}

Table A-26. Detailed ENDF/B-VII.1 252-group results for KENO V.a MCT systems

\begin{tabular}{ccccccc}
\hline Case & $\begin{array}{c}\text { Expected } \\
\boldsymbol{k}_{\text {eff }}\end{array}$ & $\begin{array}{c}\text { Experimental } \\
\text { uncertainty }\end{array}$ & $\boldsymbol{k}_{\text {eff }}$ & Uncertainty & $\mathbf{C} / \mathbf{E}$ & $\begin{array}{c}\text { C/E } \\
\text { uncertainty }\end{array}$ \\
\hline $001-001$ & 1.0000 & 0.0025 & 0.99997 & 0.00010 & 0.99997 & 0.00250 \\
$001-002$ & 1.0000 & 0.0026 & 0.99860 & 0.00010 & 0.99860 & 0.00260 \\
$001-003$ & 1.0000 & 0.0032 & 0.99759 & 0.00010 & 0.99759 & 0.00319 \\
$001-004$ & 1.0000 & 0.0039 & 1.00013 & 0.00010 & 1.00013 & 0.00390 \\
$002-001 \mathrm{~S}$ & 1.0024 & 0.0060 & 1.00125 & 0.00010 & 0.99885 & 0.00598 \\
$002-002 \mathrm{~S}$ & 1.0009 & 0.0047 & 1.00219 & 0.00010 & 1.00129 & 0.00470 \\
$002-003 \mathrm{~S}$ & 1.0042 & 0.0031 & 1.00177 & 0.00010 & 0.99758 & 0.00308 \\
$002-004 \mathrm{~S}$ & 1.0024 & 0.0024 & 1.00626 & 0.00010 & 1.00385 & 0.00241 \\
$002-005 \mathrm{~S}$ & 1.0038 & 0.0025 & 1.00390 & 0.00010 & 1.00010 & 0.00249 \\
$002-006 \mathrm{~S}$ & 1.0029 & 0.0027 & 1.00630 & 0.00010 & 1.00339 & 0.00270 \\
$004-001$ & 1.0000 & 0.0046 & 0.99506 & 0.00010 & 0.99506 & 0.00458 \\
$004-002$ & 1.0000 & 0.0046 & 0.99574 & 0.00010 & 0.99574 & 0.00458 \\
$004-003$ & 1.0000 & 0.0046 & 0.99573 & 0.00010 & 0.99573 & 0.00458 \\
$004-004$ & 1.0000 & 0.0039 & 0.99551 & 0.00010 & 0.99551 & 0.00388 \\
$004-005$ & 1.0000 & 0.0039 & 0.99635 & 0.00010 & 0.99635 & 0.00389 \\
$004-006$ & 1.0000 & 0.0039 & 0.99627 & 0.00010 & 0.99627 & 0.00389 \\
$004-007$ & 1.0000 & 0.0040 & 0.99694 & 0.00010 & 0.99694 & 0.00399 \\
$004-008$ & 1.0000 & 0.0040 & 0.99716 & 0.00010 & 0.99716 & 0.00399 \\
$004-009$ & 1.0000 & 0.0040 & 0.99789 & 0.00010 & 0.99789 & 0.00399 \\
$004-010$ & 1.0000 & 0.0051 & 0.99796 & 0.00010 & 0.99796 & 0.00509 \\
$004-011$ & 1.0000 & 0.0051 & 0.99779 & 0.00010 & 0.99779 & 0.00509 \\
\hline
\end{tabular}


Table A-27. Detailed ENDF/B-VIII.0 CE results for KENO V.a MCT systems

\begin{tabular}{ccccccc}
\hline Case & $\begin{array}{c}\text { Expected } \\
\boldsymbol{k}_{\text {eff }}\end{array}$ & $\begin{array}{c}\text { Experimental } \\
\text { uncertainty }\end{array}$ & $\boldsymbol{k}_{\text {eff }}$ & Uncertainty & $\mathbf{C} / \mathbf{E}$ & $\begin{array}{c}\text { C/E } \\
\text { uncertainty }\end{array}$ \\
\hline $001-001$ & 1.0000 & 0.0025 & 1.00404 & 0.00010 & 1.00404 & 0.00251 \\
$001-002$ & 1.0000 & 0.0026 & 1.00090 & 0.00010 & 1.00090 & 0.00260 \\
$001-003$ & 1.0000 & 0.0032 & 0.99886 & 0.00010 & 0.99886 & 0.00320 \\
$001-004$ & 1.0000 & 0.0039 & 1.00048 & 0.00010 & 1.00048 & 0.00390 \\
$002-001 \mathrm{~S}$ & 1.0024 & 0.0060 & 1.00181 & 0.00010 & 0.99941 & 0.00598 \\
$002-002 \mathrm{~S}$ & 1.0009 & 0.0047 & 1.00278 & 0.00010 & 1.00188 & 0.00471 \\
$002-003 \mathrm{~S}$ & 1.0042 & 0.0031 & 1.00097 & 0.00010 & 0.99678 & 0.00308 \\
$002-004 \mathrm{~S}$ & 1.0024 & 0.0024 & 1.00529 & 0.00010 & 1.00289 & 0.00240 \\
$002-005 \mathrm{~S}$ & 1.0038 & 0.0025 & 1.00269 & 0.00010 & 0.99889 & 0.00249 \\
$002-006 \mathrm{~S}$ & 1.0029 & 0.0027 & 1.00499 & 0.00010 & 1.00208 & 0.00270 \\
$004-001$ & 1.0000 & 0.0046 & 0.99479 & 0.00010 & 0.99479 & 0.00458 \\
$004-002$ & 1.0000 & 0.0046 & 0.99569 & 0.00010 & 0.99569 & 0.00458 \\
$004-003$ & 1.0000 & 0.0046 & 0.99566 & 0.00010 & 0.99566 & 0.00458 \\
$004-004$ & 1.0000 & 0.0039 & 0.99512 & 0.00010 & 0.99512 & 0.00388 \\
$004-005$ & 1.0000 & 0.0039 & 0.99611 & 0.00010 & 0.99611 & 0.00389 \\
$004-006$ & 1.0000 & 0.0039 & 0.99606 & 0.00010 & 0.99606 & 0.00389 \\
$004-007$ & 1.0000 & 0.0040 & 0.99562 & 0.00010 & 0.99562 & 0.00398 \\
$004-008$ & 1.0000 & 0.0040 & 0.99622 & 0.00010 & 0.99622 & 0.00399 \\
$004-009$ & 1.0000 & 0.0040 & 0.99643 & 0.00010 & 0.99643 & 0.00399 \\
$004-010$ & 1.0000 & 0.0051 & 0.99616 & 0.00010 & 0.99616 & 0.00508 \\
$004-011$ & 1.0000 & 0.0051 & 0.99622 & 0.00010 & 0.99622 & 0.00508 \\
\hline
\end{tabular}

Table A-28. Detailed ENDF/B-VII.1 CE results for KENO V.a MCT systems

\begin{tabular}{|c|c|c|c|c|c|c|}
\hline Case & $\begin{array}{c}\text { Expected } \\
k_{\text {eff }} \\
\end{array}$ & $\begin{array}{c}\text { Experimental } \\
\text { uncertainty }\end{array}$ & $\boldsymbol{k}_{e f f}$ & Uncertainty & $\mathbf{C} / \mathbf{E}$ & $\begin{array}{c}\mathrm{C} / \mathbf{E} \\
\text { uncertainty }\end{array}$ \\
\hline 001-001 & 1.0000 & 0.0025 & 1.00104 & 0.00010 & 1.00104 & 0.00250 \\
\hline 001-002 & 1.0000 & 0.0026 & 1.00002 & 0.00010 & 1.00002 & 0.00260 \\
\hline 001-003 & 1.0000 & 0.0032 & 0.99864 & 0.00010 & 0.99864 & 0.00320 \\
\hline 001-004 & 1.0000 & 0.0039 & 1.00067 & 0.00010 & 1.00067 & 0.00390 \\
\hline $002-001 \mathrm{~S}$ & 1.0024 & 0.0060 & 1.00222 & 0.00010 & 0.99982 & 0.00599 \\
\hline $002-002 S$ & 1.0009 & 0.0047 & 1.00324 & 0.00010 & 1.00233 & 0.00471 \\
\hline 002-003S & 1.0042 & 0.0031 & 1.00260 & 0.00010 & 0.99841 & 0.00308 \\
\hline $002-004 \mathrm{~S}$ & 1.0024 & 0.0024 & 1.00663 & 0.00010 & 1.00421 & 0.00241 \\
\hline $002-005 \mathrm{~S}$ & 1.0038 & 0.0025 & 1.00429 & 0.00010 & 1.00048 & 0.00249 \\
\hline 002-006S & 1.0029 & 0.0027 & 1.00623 & 0.00010 & 1.00332 & 0.00270 \\
\hline 004-001 & 1.0000 & 0.0046 & 0.99623 & 0.00010 & 0.99623 & 0.00458 \\
\hline 004-002 & 1.0000 & 0.0046 & 0.99715 & 0.00010 & 0.99715 & 0.00459 \\
\hline 004-003 & 1.0000 & 0.0046 & 0.99692 & 0.00010 & 0.99692 & 0.00459 \\
\hline 004-004 & 1.0000 & 0.0039 & 0.99669 & 0.00010 & 0.99669 & 0.00389 \\
\hline 004-005 & 1.0000 & 0.0039 & 0.99755 & 0.00010 & 0.99755 & 0.00389 \\
\hline 004-006 & 1.0000 & 0.0039 & 0.99754 & 0.00010 & 0.99754 & 0.00389 \\
\hline 004-007 & 1.0000 & 0.0040 & 0.99779 & 0.00010 & 0.99779 & 0.00399 \\
\hline 004-008 & 1.0000 & 0.0040 & 0.99829 & 0.00010 & 0.99829 & 0.00399 \\
\hline 004-009 & 1.0000 & 0.0040 & 0.99864 & 0.00010 & 0.99864 & 0.00400 \\
\hline 004-010 & 1.0000 & 0.0051 & 0.99831 & 0.00010 & 0.99831 & 0.00509 \\
\hline 004-011 & 1.0000 & 0.0051 & 0.99829 & 0.00010 & 0.99829 & 0.00509 \\
\hline
\end{tabular}


Table A-29. Detailed ENDF/B-VIII.0 252-group results for KENO V.a MST systems

\begin{tabular}{rcccrrr}
\hline Case & $\begin{array}{c}\text { Expected } \\
\boldsymbol{k}_{\text {eff }}\end{array}$ & $\begin{array}{c}\text { Experimental } \\
\text { uncertainty }\end{array}$ & \multicolumn{1}{c}{$\boldsymbol{k}_{\text {eff }}$} & Uncertainty & \multicolumn{1}{c}{$\mathbf{C / E}$} & $\begin{array}{c}\mathbf{C} / \mathbf{E} \\
\text { uncertainty }\end{array}$ \\
\hline $002-001$ & 1.0000 & 0.0024 & 0.99561 & 0.00010 & 0.99561 & 0.00239 \\
$002-002$ & 1.0000 & 0.0024 & 0.99582 & 0.00010 & 0.99582 & 0.00239 \\
$002-003$ & 1.0000 & 0.0024 & 0.99557 & 0.00010 & 0.99557 & 0.00239 \\
$007-001$ & 1.0000 & 0.0043 & 0.99107 & 0.00010 & 0.99107 & 0.00426 \\
$007-002$ & 1.0000 & 0.0077 & 0.99216 & 0.00010 & 0.99216 & 0.00764 \\
$007-003$ & 1.0000 & 0.0046 & 0.99561 & 0.00010 & 0.99561 & 0.00458 \\
$007-004$ & 1.0000 & 0.0046 & 0.99445 & 0.00010 & 0.99445 & 0.00458 \\
$007-005$ & 1.0000 & 0.0091 & 0.99243 & 0.00010 & 0.99243 & 0.00903 \\
$007-006$ & 1.0000 & 0.0043 & 0.99185 & 0.00010 & 0.99185 & 0.00427 \\
$007-007$ & 1.0000 & 0.0034 & 0.98837 & 0.00010 & 0.98837 & 0.00336 \\
\hline
\end{tabular}

Table A-30. Detailed ENDF/B-VII.1 252-group results for KENO V.a MST systems

\begin{tabular}{rcccrrr}
\hline Case & $\begin{array}{c}\text { Expected } \\
\boldsymbol{k}_{\text {eff }}\end{array}$ & $\begin{array}{c}\text { Experimental } \\
\text { uncertainty }\end{array}$ & \multicolumn{1}{c}{$\boldsymbol{k}_{\text {eff }}$} & Uncertainty & \multicolumn{1}{c}{$\mathbf{C / E}$} & $\begin{array}{c}\text { C/E } \\
\text { uncertainty }\end{array}$ \\
\hline $002-001$ & 1.0000 & 0.0024 & 1.00140 & 0.00010 & 1.00140 & 0.00241 \\
$002-002$ & 1.0000 & 0.0024 & 1.00183 & 0.00010 & 1.00183 & 0.00241 \\
$002-003$ & 1.0000 & 0.0024 & 1.00130 & 0.00010 & 1.00130 & 0.00241 \\
$007-001$ & 1.0000 & 0.0043 & 0.99381 & 0.00010 & 0.99381 & 0.00427 \\
$007-002$ & 1.0000 & 0.0077 & 0.99546 & 0.00010 & 0.99546 & 0.00767 \\
$007-003$ & 1.0000 & 0.0046 & 0.99968 & 0.00010 & 0.99968 & 0.00460 \\
$007-004$ & 1.0000 & 0.0046 & 0.99866 & 0.00010 & 0.99866 & 0.00459 \\
$007-005$ & 1.0000 & 0.0091 & 0.99652 & 0.00010 & 0.99652 & 0.00907 \\
$007-006$ & 1.0000 & 0.0043 & 0.99641 & 0.00010 & 0.99641 & 0.00429 \\
$007-007$ & 1.0000 & 0.0034 & 0.99321 & 0.00010 & 0.99321 & 0.00338 \\
\hline
\end{tabular}

Table A-31. Detailed ENDF/B-VIII.0 CE results for KENO V.a MST systems

\begin{tabular}{rccrrrr}
\hline Case & $\begin{array}{c}\text { Expected } \\
\boldsymbol{k}_{\text {eff }}\end{array}$ & $\begin{array}{c}\text { Experimental } \\
\text { uncertainty }\end{array}$ & \multicolumn{1}{c}{$\boldsymbol{k}_{\text {eff }}$} & Uncertainty & \multicolumn{1}{c}{$\mathbf{C / E}$} & $\begin{array}{c}\text { C/E } \\
\text { uncertainty }\end{array}$ \\
\hline $002-001$ & 1.0000 & 0.0024 & 0.99535 & 0.00010 & 0.99535 & 0.00239 \\
$002-002$ & 1.0000 & 0.0024 & 0.99548 & 0.00010 & 0.99548 & 0.00239 \\
$002-003$ & 1.0000 & 0.0024 & 0.99529 & 0.00010 & 0.99529 & 0.00239 \\
$007-001$ & 1.0000 & 0.0043 & 0.99073 & 0.00010 & 0.99073 & 0.00426 \\
$007-002$ & 1.0000 & 0.0077 & 0.99215 & 0.00010 & 0.99215 & 0.00764 \\
$007-003$ & 1.0000 & 0.0046 & 0.99608 & 0.00010 & 0.99608 & 0.00458 \\
$007-004$ & 1.0000 & 0.0046 & 0.99503 & 0.00010 & 0.99503 & 0.00458 \\
$007-005$ & 1.0000 & 0.0091 & 0.99306 & 0.00010 & 0.99306 & 0.00904 \\
$007-006$ & 1.0000 & 0.0043 & 0.99290 & 0.00010 & 0.99290 & 0.00427 \\
$007-007$ & 1.0000 & 0.0034 & 0.98937 & 0.00010 & 0.98937 & 0.00337 \\
\hline
\end{tabular}

Table A-32. Detailed ENDF/B-VII.1 CE results for KENO V.a MST systems

\begin{tabular}{rcccrrr}
\hline Case & $\begin{array}{c}\text { Expected } \\
\boldsymbol{k}_{\text {eff }}\end{array}$ & $\begin{array}{c}\text { Experimental } \\
\text { uncertainty }\end{array}$ & \multicolumn{1}{c}{$\boldsymbol{k}_{\text {eff }}$} & Uncertainty & \multicolumn{1}{c}{$\mathbf{C / E}$} & $\begin{array}{c}\mathbf{C} / \mathbf{E} \\
\text { uncertainty }\end{array}$ \\
\hline $002-001$ & 1.0000 & 0.0024 & 1.00140 & 0.00010 & 1.00140 & 0.00241 \\
$002-002$ & 1.0000 & 0.0024 & 1.00156 & 0.00010 & 1.00156 & 0.00241 \\
$002-003$ & 1.0000 & 0.0024 & 1.00118 & 0.00010 & 1.00118 & 0.00240 \\
$007-001$ & 1.0000 & 0.0043 & 0.99481 & 0.00010 & 0.99481 & 0.00428 \\
$007-002$ & 1.0000 & 0.0077 & 0.99634 & 0.00010 & 0.99634 & 0.00767 \\
$007-003$ & 1.0000 & 0.0046 & 1.00023 & 0.00010 & 1.00023 & 0.00460 \\
$007-004$ & 1.0000 & 0.0046 & 0.99948 & 0.00010 & 0.99948 & 0.00460 \\
$007-005$ & 1.0000 & 0.0091 & 0.99751 & 0.00010 & 0.99751 & 0.00908 \\
$007-006$ & 1.0000 & 0.0043 & 0.99731 & 0.00010 & 0.99731 & 0.00429 \\
$007-007$ & 1.0000 & 0.0034 & 0.99405 & 0.00010 & 0.99405 & 0.00338 \\
\hline
\end{tabular}


Table A-33. Detailed ENDF/B-VIII.0 252-group results for KENO V.a PMF systems

\begin{tabular}{rcccccc}
\hline Case & $\begin{array}{c}\text { Expected } \\
\boldsymbol{k}_{\text {eff }}\end{array}$ & $\begin{array}{c}\text { Experimental } \\
\text { uncertainty }\end{array}$ & $\boldsymbol{k}_{\text {eff }}$ & Uncertainty & $\mathbf{C} / \mathbf{E}$ & $\begin{array}{c}\mathbf{C} / \mathbf{E} \\
\text { uncertainty }\end{array}$ \\
\hline $001-001$ & 1.0000 & 0.0020 & 0.99952 & 0.00010 & 0.99952 & 0.00200 \\
$002-001$ & 1.0000 & 0.0020 & 1.00103 & 0.00010 & 1.00103 & 0.00200 \\
$005-001$ & 1.0000 & 0.0013 & 0.99971 & 0.00010 & 0.99971 & 0.00130 \\
$006-001$ & 1.0000 & 0.0030 & 0.99881 & 0.00010 & 0.99881 & 0.00300 \\
$008-001$ & 1.0000 & 0.0006 & 0.99602 & 0.00010 & 0.99602 & 0.00061 \\
$010-001$ & 1.0000 & 0.0018 & 0.99751 & 0.00010 & 0.99751 & 0.00180 \\
$018-001$ & 1.0000 & 0.0030 & 0.99776 & 0.00010 & 0.99776 & 0.00299 \\
$022-001$ & 1.0000 & 0.0023 & 0.99775 & 0.00010 & 0.99775 & 0.00230 \\
$023-001$ & 1.0000 & 0.0022 & 0.99792 & 0.00010 & 0.99792 & 0.00220 \\
$024-001$ & 1.0000 & 0.0022 & 1.00103 & 0.00010 & 1.00103 & 0.00220 \\
$025-001$ & 1.0000 & 0.0020 & 0.99903 & 0.00010 & 0.99903 & 0.00200 \\
$026-001$ & 1.0000 & 0.0024 & 1.00792 & 0.00010 & 1.00792 & 0.00242 \\
\hline
\end{tabular}

Table A-34. Detailed ENDF/B-VII.1 252-group results for KENO V.a PMF systems

\begin{tabular}{rcccccc}
\hline Case & $\begin{array}{c}\text { Expected } \\
\boldsymbol{k}_{\text {eff }}\end{array}$ & $\begin{array}{c}\text { Experimental } \\
\text { uncertainty }\end{array}$ & $\boldsymbol{k}_{\text {eff }}$ & Uncertainty & C/E & $\begin{array}{c}\mathbf{C} / \mathbf{E} \\
\text { uncertainty }\end{array}$ \\
\hline $001-001$ & 1.0000 & 0.0020 & 0.99977 & 0.00010 & 0.99977 & 0.00200 \\
$002-001$ & 1.0000 & 0.0020 & 0.99984 & 0.00010 & 0.99984 & 0.00200 \\
$005-001$ & 1.0000 & 0.0013 & 1.00131 & 0.00010 & 1.00131 & 0.00131 \\
$006-001$ & 1.0000 & 0.0030 & 1.00062 & 0.00010 & 1.00062 & 0.00300 \\
$008-001$ & 1.0000 & 0.0006 & 0.99637 & 0.00010 & 0.99637 & 0.00061 \\
$010-001$ & 1.0000 & 0.0018 & 0.99969 & 0.00010 & 0.99969 & 0.00180 \\
$018-001$ & 1.0000 & 0.0030 & 0.99904 & 0.00010 & 0.99904 & 0.00300 \\
$022-001$ & 1.0000 & 0.0023 & 0.99849 & 0.00010 & 0.99849 & 0.00230 \\
$023-001$ & 1.0000 & 0.0022 & 0.99969 & 0.00010 & 0.99969 & 0.00220 \\
$024-001$ & 1.0000 & 0.0022 & 1.00205 & 0.00010 & 1.00205 & 0.00221 \\
$025-001$ & 1.0000 & 0.0020 & 0.99833 & 0.00010 & 0.99833 & 0.00200 \\
$026-001$ & 1.0000 & 0.0024 & 1.00514 & 0.00010 & 1.00514 & 0.00241 \\
\hline
\end{tabular}

Table A-35. Detailed ENDF/B-VIII.0 CE results for KENO V.a PMF systems

\begin{tabular}{rcccccc}
\hline Case & $\begin{array}{c}\text { Expected } \\
\boldsymbol{k}_{\text {eff }}\end{array}$ & $\begin{array}{c}\text { Experimental } \\
\text { uncertainty }\end{array}$ & $\boldsymbol{k}_{\text {eff }}$ & Uncertainty & $\begin{array}{c}\text { C/E } \\
\text { C/E } \\
\text { uncertainty }\end{array}$ \\
\hline $001-001$ & 1.0000 & 0.0020 & 0.99972 & 0.00010 & 0.99972 & 0.00200 \\
$002-001$ & 1.0000 & 0.0020 & 1.00158 & 0.00010 & 1.00158 & 0.00201 \\
$005-001$ & 1.0000 & 0.0013 & 0.99948 & 0.00010 & 0.99948 & 0.00130 \\
$006-001$ & 1.0000 & 0.0030 & 0.99986 & 0.00010 & 0.99986 & 0.00300 \\
$008-001$ & 1.0000 & 0.0006 & 0.99785 & 0.00010 & 0.99785 & 0.00061 \\
$010-001$ & 1.0000 & 0.0018 & 0.99810 & 0.00010 & 0.99810 & 0.00180 \\
$018-001$ & 1.0000 & 0.0030 & 0.99779 & 0.00010 & 0.99779 & 0.00300 \\
$022-001$ & 1.0000 & 0.0023 & 0.99810 & 0.00010 & 0.99810 & 0.00230 \\
$023-001$ & 1.0000 & 0.0022 & 0.99832 & 0.00010 & 0.99832 & 0.00220 \\
$024-001$ & 1.0000 & 0.0022 & 1.00088 & 0.00010 & 1.00088 & 0.00220 \\
$025-001$ & 1.0000 & 0.0020 & 0.99981 & 0.00010 & 0.99981 & 0.00200 \\
$026-001$ & 1.0000 & 0.0024 & 1.00152 & 0.00010 & 1.00152 & 0.00241 \\
\hline
\end{tabular}


Table A-36. Detailed ENDF/B-VII.1 CE results for KENO V.a PMF systems

\begin{tabular}{rcccccc}
\hline Case & $\begin{array}{c}\text { Expected } \\
\boldsymbol{k}_{\text {eff }}\end{array}$ & $\begin{array}{c}\text { Experimental } \\
\text { uncertainty }\end{array}$ & $\boldsymbol{k}_{\text {eff }}$ & Uncertainty & $\mathbf{C} / \mathbf{E}$ & $\begin{array}{c}\mathbf{C} / \mathbf{E} \\
\text { uncertainty }\end{array}$ \\
\hline $001-001$ & 1.0000 & 0.0020 & 0.99989 & 0.00010 & 0.99989 & 0.00200 \\
$002-001$ & 1.0000 & 0.0020 & 1.00007 & 0.00010 & 1.00007 & 0.00200 \\
$005-001$ & 1.0000 & 0.0013 & 1.00092 & 0.00010 & 1.00092 & 0.00131 \\
$006-001$ & 1.0000 & 0.0030 & 1.00149 & 0.00010 & 1.00149 & 0.00301 \\
$008-001$ & 1.0000 & 0.0006 & 0.99791 & 0.00010 & 0.99791 & 0.00061 \\
$010-001$ & 1.0000 & 0.0018 & 1.00002 & 0.00010 & 1.00002 & 0.00180 \\
$018-001$ & 1.0000 & 0.0030 & 0.99893 & 0.00010 & 0.99893 & 0.00300 \\
$022-001$ & 1.0000 & 0.0023 & 0.99871 & 0.00010 & 0.99871 & 0.00230 \\
$023-001$ & 1.0000 & 0.0022 & 0.99972 & 0.00010 & 0.99972 & 0.00220 \\
$024-001$ & 1.0000 & 0.0022 & 1.00169 & 0.00010 & 1.00169 & 0.00221 \\
$025-001$ & 1.0000 & 0.0020 & 0.99812 & 0.00010 & 0.99812 & 0.00200 \\
$026-001$ & 1.0000 & 0.0024 & 0.99678 & 0.00010 & 0.99678 & 0.00239 \\
\hline
\end{tabular}

Table A-37. Detailed ENDF/B-VIII.0 252-group results for KENO V.a PST systems

\begin{tabular}{|c|c|c|c|c|c|c|}
\hline Case & $\begin{array}{c}\text { Expected } \\
k_{\text {eff }} \\
\end{array}$ & $\begin{array}{c}\text { Experimental } \\
\text { uncertainty }\end{array}$ & $\boldsymbol{k}_{\text {eff }}$ & Uncertainty & $\mathbf{C} / \mathbf{E}$ & $\begin{array}{c}\mathrm{C} / \mathrm{E} \\
\text { uncertainty }\end{array}$ \\
\hline $001-001$ & 1.0000 & 0.0050 & 0.99997 & 0.00010 & 0.99997 & 0.00500 \\
\hline 001-002 & 1.0000 & 0.0050 & 1.00287 & 0.00010 & 1.00287 & 0.00502 \\
\hline 001-003 & 1.0000 & 0.0050 & 1.00592 & 0.00010 & 1.00592 & 0.00503 \\
\hline 001-004 & 1.0000 & 0.0050 & 1.00059 & 0.00010 & 1.00059 & 0.00500 \\
\hline $001-005$ & 1.0000 & 0.0050 & 1.00472 & 0.00010 & 1.00472 & 0.00502 \\
\hline 001-006 & 1.0000 & 0.0050 & 1.00802 & 0.00010 & 1.00802 & 0.00504 \\
\hline $002-001$ & 1.0000 & 0.0047 & 0.99809 & 0.00010 & 0.99809 & 0.00469 \\
\hline $002-002$ & 1.0000 & 0.0047 & 0.99901 & 0.00010 & 0.99901 & 0.00470 \\
\hline $002-003$ & 1.0000 & 0.0047 & 0.99801 & 0.00009 & 0.99801 & 0.00469 \\
\hline $002-004$ & 1.0000 & 0.0047 & 1.00108 & 0.00010 & 1.00108 & 0.00471 \\
\hline $002-005$ & 1.0000 & 0.0047 & 1.00394 & 0.00010 & 1.00394 & 0.00472 \\
\hline $002-006$ & 1.0000 & 0.0047 & 1.00024 & 0.00010 & 1.00024 & 0.00470 \\
\hline $002-007$ & 1.0000 & 0.0047 & 1.00290 & 0.00010 & 1.00290 & 0.00471 \\
\hline 003-001 & 1.0000 & 0.0047 & 0.99622 & 0.00010 & 0.99622 & 0.00468 \\
\hline 003-002 & 1.0000 & 0.0047 & 0.99598 & 0.00010 & 0.99598 & 0.00468 \\
\hline 003-003 & 1.0000 & 0.0047 & 0.99864 & 0.00010 & 0.99864 & 0.00469 \\
\hline 003-004 & 1.0000 & 0.0047 & 0.99807 & 0.00010 & 0.99807 & 0.00469 \\
\hline 003-005 & 1.0000 & 0.0047 & 0.99936 & 0.00010 & 0.99936 & 0.00470 \\
\hline 003-006 & 1.0000 & 0.0047 & 0.99973 & 0.00010 & 0.99973 & 0.00470 \\
\hline 003-007 & 1.0000 & 0.0047 & 1.00048 & 0.00010 & 1.00048 & 0.00470 \\
\hline 003-008 & 1.0000 & 0.0047 & 0.99940 & 0.00010 & 0.99940 & 0.00470 \\
\hline 004-001 & 1.0000 & 0.0047 & 0.99692 & 0.00009 & 0.99692 & 0.00469 \\
\hline 004-002 & 1.0000 & 0.0047 & 0.99199 & 0.00010 & 0.99199 & 0.00466 \\
\hline 004-003 & 1.0000 & 0.0047 & 0.99416 & 0.00010 & 0.99416 & 0.00467 \\
\hline 004-004 & 1.0000 & 0.0047 & 0.99205 & 0.00010 & 0.99205 & 0.00466 \\
\hline 004-005 & 1.0000 & 0.0047 & 0.99297 & 0.00010 & 0.99297 & 0.00467 \\
\hline 004-006 & 1.0000 & 0.0047 & 0.99524 & 0.00010 & 0.99524 & 0.00468 \\
\hline 004-007 & 1.0000 & 0.0047 & 0.99899 & 0.00010 & 0.99899 & 0.00470 \\
\hline 004-008 & 1.0000 & 0.0047 & 0.99462 & 0.00010 & 0.99462 & 0.00468 \\
\hline 004-009 & 1.0000 & 0.0047 & 0.99408 & 0.00010 & 0.99408 & 0.00467 \\
\hline 004-010 & 1.0000 & 0.0047 & 0.99562 & 0.00010 & 0.99562 & 0.00468 \\
\hline 004-011 & 1.0000 & 0.0047 & 0.99435 & 0.00010 & 0.99435 & 0.00467 \\
\hline 004-012 & 1.0000 & 0.0047 & 0.99660 & 0.00010 & 0.99660 & 0.00469 \\
\hline 004-013 & 1.0000 & 0.0047 & 0.99378 & 0.00010 & 0.99378 & 0.00467 \\
\hline 005-001 & 1.0000 & 0.0047 & 0.99563 & 0.00010 & 0.99563 & 0.00468 \\
\hline $005-002$ & 1.0000 & 0.0047 & 0.99672 & 0.00010 & 0.99672 & 0.00469 \\
\hline $005-003$ & 1.0000 & 0.0047 & 0.99671 & 0.00010 & 0.99671 & 0.00469 \\
\hline $005-004$ & 1.0000 & 0.0047 & 0.99880 & 0.00010 & 0.99880 & 0.00470 \\
\hline $005-005$ & 1.0000 & 0.0047 & 1.00025 & 0.00010 & 1.00025 & 0.00470 \\
\hline 005-006 & 1.0000 & 0.0047 & 1.00018 & 0.00010 & 1.00018 & 0.00470 \\
\hline $005-007$ & 1.0000 & 0.0047 & 0.99802 & 0.00010 & 0.99802 & 0.00469 \\
\hline 005-008 & 1.0000 & 0.0047 & 0.99327 & 0.00010 & 0.99327 & 0.00467 \\
\hline
\end{tabular}


Table A-37. Detailed ENDF/B-VIII.0 252-group results for KENO V.a PST systems

\begin{tabular}{|c|c|c|c|c|c|c|}
\hline Case & $\begin{array}{c}\text { Expected } \\
k_{\text {eff }}\end{array}$ & $\begin{array}{c}\text { Experimental } \\
\text { uncertainty }\end{array}$ & $\boldsymbol{k}_{\text {eff }}$ & Uncertainty & $\mathbf{C} / \mathbf{E}$ & $\begin{array}{c}\mathrm{C} / \mathrm{E} \\
\text { uncertainty }\end{array}$ \\
\hline 005-009 & 1.0000 & 0.0047 & 0.99572 & 0.00010 & 0.99572 & 0.00468 \\
\hline 006-001 & 1.0000 & 0.0035 & 0.99423 & 0.00010 & 0.99423 & 0.00348 \\
\hline 006-002 & 1.0000 & 0.0035 & 0.99514 & 0.00010 & 0.99514 & 0.00348 \\
\hline 006-003 & 1.0000 & 0.0035 & 0.99486 & 0.00010 & 0.99486 & 0.00348 \\
\hline 007-001 & 1.0000 & 0.0047 & 1.00729 & 0.00010 & 1.00729 & 0.00474 \\
\hline 007-002 & 1.0000 & 0.0047 & 1.00279 & 0.00010 & 1.00279 & 0.00471 \\
\hline 007-003 & 1.0000 & 0.0047 & 1.00519 & 0.00010 & 1.00519 & 0.00473 \\
\hline 007-004 & 1.0000 & 0.0047 & 0.99888 & 0.00010 & 0.99888 & 0.00470 \\
\hline $007-005$ & 1.0000 & 0.0047 & 1.00104 & 0.00010 & 1.00104 & 0.00471 \\
\hline 007-006 & 1.0000 & 0.0047 & 0.99411 & 0.00010 & 0.99411 & 0.00467 \\
\hline 007-007 & 1.0000 & 0.0047 & 0.99279 & 0.00010 & 0.99279 & 0.00467 \\
\hline 007-008 & 1.0000 & 0.0047 & 0.99429 & 0.00010 & 0.99429 & 0.00467 \\
\hline 011-001 & 1.0000 & 0.0052 & 1.00223 & 0.00010 & 1.00223 & 0.00521 \\
\hline 011-002 & 1.0000 & 0.0052 & 1.00767 & 0.00010 & 1.00767 & 0.00524 \\
\hline 011-003 & 1.0000 & 0.0052 & 1.00967 & 0.00010 & 1.00967 & 0.00525 \\
\hline 011-004 & 1.0000 & 0.0052 & 1.00329 & 0.00010 & 1.00329 & 0.00522 \\
\hline $011-005$ & 1.0000 & 0.0052 & 1.00069 & 0.00010 & 1.00069 & 0.00520 \\
\hline 011-006 & 1.0000 & 0.0052 & 0.98752 & 0.00010 & 0.98752 & 0.00514 \\
\hline 011-007 & 1.0000 & 0.0052 & 0.99445 & 0.00010 & 0.99445 & 0.00517 \\
\hline 011-008 & 1.0000 & 0.0052 & 0.99038 & 0.00010 & 0.99038 & 0.00515 \\
\hline 011-009 & 1.0000 & 0.0052 & 0.98642 & 0.00010 & 0.98642 & 0.00513 \\
\hline 011-010 & 1.0000 & 0.0052 & 0.99824 & 0.00010 & 0.99824 & 0.00519 \\
\hline 011-011 & 1.0000 & 0.0052 & 0.99371 & 0.00010 & 0.99371 & 0.00517 \\
\hline 011-012 & 1.0000 & 0.0052 & 0.99217 & 0.00010 & 0.99217 & 0.00516 \\
\hline 020-001 & 1.0000 & 0.0059 & 0.99790 & 0.00010 & 0.99790 & 0.00589 \\
\hline 020-002 & 1.0000 & 0.0059 & 0.99963 & 0.00010 & 0.99963 & 0.00590 \\
\hline 020-003 & 1.0000 & 0.0059 & 0.99469 & 0.00010 & 0.99469 & 0.00587 \\
\hline 020-004 & 1.0000 & 0.0059 & 0.99904 & 0.00010 & 0.99904 & 0.00590 \\
\hline 020-005 & 1.0000 & 0.0059 & 0.99885 & 0.00010 & 0.99885 & 0.00589 \\
\hline 020-006 & 1.0000 & 0.0059 & 0.99154 & 0.00010 & 0.99154 & 0.00585 \\
\hline 020-007 & 1.0000 & 0.0059 & 0.99909 & 0.00010 & 0.99909 & 0.00590 \\
\hline 020-008 & 1.0000 & 0.0059 & 0.98881 & 0.00010 & 0.98881 & 0.00583 \\
\hline 020-009 & 1.0000 & 0.0059 & 0.99798 & 0.00010 & 0.99798 & 0.00589 \\
\hline 020-010 & 1.0000 & 0.0059 & 0.99529 & 0.00010 & 0.99529 & 0.00587 \\
\hline 020-011 & 1.0000 & 0.0059 & 0.99676 & 0.00010 & 0.99676 & 0.00588 \\
\hline $020-012$ & 1.0000 & 0.0059 & 0.99796 & 0.00010 & 0.99796 & 0.00589 \\
\hline 020-013 & 1.0000 & 0.0059 & 0.98661 & 0.00010 & 0.98661 & 0.00582 \\
\hline $020-014$ & 1.0000 & 0.0059 & 0.99016 & 0.00010 & 0.99016 & 0.00584 \\
\hline $020-015$ & 1.0000 & 0.0059 & 0.99802 & 0.00010 & 0.99802 & 0.00589 \\
\hline
\end{tabular}


Table A-38. Detailed ENDF/B-VII.1 252-group results for KENO V.a PST systems

\begin{tabular}{|c|c|c|c|c|c|c|}
\hline Case & $\begin{array}{c}\text { Expected } \\
k_{\text {eff }}\end{array}$ & $\begin{array}{c}\text { Experimental } \\
\text { uncertainty }\end{array}$ & $\boldsymbol{k}_{\text {eff }}$ & Uncertainty & $\mathbf{C} / \mathbf{E}$ & $\begin{array}{c}\mathrm{C} / \mathbf{E} \\
\text { uncertainty }\end{array}$ \\
\hline 001-001 & 1.0000 & 0.0050 & 1.00340 & 0.00010 & 1.00340 & 0.00502 \\
\hline 001-002 & 1.0000 & 0.0050 & 1.00576 & 0.00010 & 1.00576 & 0.00503 \\
\hline 001-003 & 1.0000 & 0.0050 & 1.00831 & 0.00010 & 1.00831 & 0.00504 \\
\hline 001-004 & 1.0000 & 0.0050 & 1.00279 & 0.00010 & 1.00279 & 0.00501 \\
\hline $001-005$ & 1.0000 & 0.0050 & 1.00677 & 0.00010 & 1.00677 & 0.00503 \\
\hline 001-006 & 1.0000 & 0.0050 & 1.00819 & 0.00010 & 1.00819 & 0.00504 \\
\hline $002-001$ & 1.0000 & 0.0047 & 1.00246 & 0.00010 & 1.00246 & 0.00471 \\
\hline $002-002$ & 1.0000 & 0.0047 & 1.00319 & 0.00010 & 1.00319 & 0.00472 \\
\hline $002-003$ & 1.0000 & 0.0047 & 1.00219 & 0.00010 & 1.00219 & 0.00471 \\
\hline $002-004$ & 1.0000 & 0.0047 & 1.00508 & 0.00010 & 1.00508 & 0.00472 \\
\hline $002-005$ & 1.0000 & 0.0047 & 1.00801 & 0.00010 & 1.00801 & 0.00474 \\
\hline $002-006$ & 1.0000 & 0.0047 & 1.00387 & 0.00010 & 1.00387 & 0.00472 \\
\hline $002-007$ & 1.0000 & 0.0047 & 1.00626 & 0.00010 & 1.00626 & 0.00473 \\
\hline 003-001 & 1.0000 & 0.0047 & 1.00124 & 0.00010 & 1.00124 & 0.00471 \\
\hline 003-002 & 1.0000 & 0.0047 & 1.00077 & 0.00010 & 1.00077 & 0.00470 \\
\hline 003-003 & 1.0000 & 0.0047 & 1.00336 & 0.00010 & 1.00336 & 0.00472 \\
\hline 003-004 & 1.0000 & 0.0047 & 1.00279 & 0.00010 & 1.00279 & 0.00471 \\
\hline $003-005$ & 1.0000 & 0.0047 & 1.00381 & 0.00010 & 1.00381 & 0.00472 \\
\hline 003-006 & 1.0000 & 0.0047 & 1.00436 & 0.00010 & 1.00436 & 0.00472 \\
\hline 003-007 & 1.0000 & 0.0047 & 1.00528 & 0.00010 & 1.00528 & 0.00473 \\
\hline 003-008 & 1.0000 & 0.0047 & 1.00416 & 0.00010 & 1.00416 & 0.00472 \\
\hline 004-001 & 1.0000 & 0.0047 & 1.00228 & 0.00010 & 1.00228 & 0.00471 \\
\hline 004-002 & 1.0000 & 0.0047 & 0.99729 & 0.00010 & 0.99729 & 0.00469 \\
\hline 004-003 & 1.0000 & 0.0047 & 0.99942 & 0.00010 & 0.99942 & 0.00470 \\
\hline 004-004 & 1.0000 & 0.0047 & 0.99722 & 0.00010 & 0.99722 & 0.00469 \\
\hline 004-005 & 1.0000 & 0.0047 & 0.99837 & 0.00010 & 0.99837 & 0.00469 \\
\hline 004-006 & 1.0000 & 0.0047 & 1.00020 & 0.00010 & 1.00020 & 0.00470 \\
\hline 004-007 & 1.0000 & 0.0047 & 1.00418 & 0.00010 & 1.00418 & 0.00472 \\
\hline 004-008 & 1.0000 & 0.0047 & 0.99974 & 0.00010 & 0.99974 & 0.00470 \\
\hline 004-009 & 1.0000 & 0.0047 & 0.99926 & 0.00010 & 0.99926 & 0.00470 \\
\hline 004-010 & 1.0000 & 0.0047 & 1.00091 & 0.00010 & 1.00091 & 0.00471 \\
\hline 004-011 & 1.0000 & 0.0047 & 0.99918 & 0.00010 & 0.99918 & 0.00470 \\
\hline 004-012 & 1.0000 & 0.0047 & 1.00139 & 0.00010 & 1.00139 & 0.00471 \\
\hline 004-013 & 1.0000 & 0.0047 & 0.99888 & 0.00010 & 0.99888 & 0.00470 \\
\hline $005-001$ & 1.0000 & 0.0047 & 1.00132 & 0.00010 & 1.00132 & 0.00471 \\
\hline 005-002 & 1.0000 & 0.0047 & 1.00129 & 0.00010 & 1.00129 & 0.00471 \\
\hline $005-003$ & 1.0000 & 0.0047 & 1.00257 & 0.00010 & 1.00257 & 0.00471 \\
\hline 005-004 & 1.0000 & 0.0047 & 1.00373 & 0.00010 & 1.00373 & 0.00472 \\
\hline $005-005$ & 1.0000 & 0.0047 & 1.00488 & 0.00010 & 1.00488 & 0.00472 \\
\hline 005-006 & 1.0000 & 0.0047 & 1.00475 & 0.00010 & 1.00475 & 0.00472 \\
\hline $005-007$ & 1.0000 & 0.0047 & 1.00297 & 0.00010 & 1.00297 & 0.00471 \\
\hline 005-008 & 1.0000 & 0.0047 & 0.99800 & 0.00010 & 0.99800 & 0.00469 \\
\hline 005-009 & 1.0000 & 0.0047 & 1.00073 & 0.00010 & 1.00073 & 0.00470 \\
\hline 006-001 & 1.0000 & 0.0035 & 1.00013 & 0.00010 & 1.00013 & 0.00350 \\
\hline 006-002 & 1.0000 & 0.0035 & 1.00119 & 0.00010 & 1.00119 & 0.00351 \\
\hline 006-003 & 1.0000 & 0.0035 & 1.00038 & 0.00010 & 1.00038 & 0.00350 \\
\hline 007-001 & 1.0000 & 0.0047 & 1.00868 & 0.00010 & 1.00868 & 0.00474 \\
\hline $007-002$ & 1.0000 & 0.0047 & 1.00368 & 0.00010 & 1.00368 & 0.00472 \\
\hline 007-003 & 1.0000 & 0.0047 & 1.00772 & 0.00010 & 1.00772 & 0.00474 \\
\hline 007-004 & 1.0000 & 0.0047 & 1.00173 & 0.00010 & 1.00173 & 0.00471 \\
\hline $007-005$ & 1.0000 & 0.0047 & 1.00408 & 0.00010 & 1.00408 & 0.00472 \\
\hline $007-006$ & 1.0000 & 0.0047 & 0.99721 & 0.00010 & 0.99721 & 0.00469 \\
\hline $007-007$ & 1.0000 & 0.0047 & 0.99627 & 0.00010 & 0.99627 & 0.00468 \\
\hline 007-008 & 1.0000 & 0.0047 & 0.99964 & 0.00010 & 0.99964 & 0.00470 \\
\hline 011-001 & 1.0000 & 0.0052 & 1.00832 & 0.00010 & 1.00832 & 0.00524 \\
\hline 011-002 & 1.0000 & 0.0052 & 1.01287 & 0.00010 & 1.01287 & 0.00527 \\
\hline 011-003 & 1.0000 & 0.0052 & 1.01512 & 0.00010 & 1.01512 & 0.00528 \\
\hline 011-004 & 1.0000 & 0.0052 & 1.00725 & 0.00010 & 1.00725 & 0.00524 \\
\hline 011-005 & 1.0000 & 0.0052 & 1.00447 & 0.00010 & 1.00447 & 0.00522 \\
\hline
\end{tabular}


Table A-38. Detailed ENDF/B-VII.1 252-group results for KENO V.a PST systems

\begin{tabular}{rcccccc}
\hline Case & $\begin{array}{c}\text { Expected } \\
\boldsymbol{k}_{\text {eff }}\end{array}$ & $\begin{array}{c}\text { Experimental } \\
\text { uncertainty }\end{array}$ & $\boldsymbol{k}_{\text {eff }}$ & Uncertainty & C/E & $\begin{array}{c}\text { C/E } \\
\text { uncertainty }\end{array}$ \\
\hline $011-006$ & 1.0000 & 0.0052 & 0.99261 & 0.00010 & 0.99261 & 0.00516 \\
$011-007$ & 1.0000 & 0.0052 & 0.99879 & 0.00010 & 0.99879 & 0.00519 \\
$011-008$ & 1.0000 & 0.0052 & 0.99546 & 0.00010 & 0.99546 & 0.00518 \\
$011-009$ & 1.0000 & 0.0052 & 0.99219 & 0.00010 & 0.99219 & 0.00516 \\
$011-010$ & 1.0000 & 0.0052 & 1.00218 & 0.00010 & 1.00218 & 0.00521 \\
$011-011$ & 1.0000 & 0.0052 & 0.99879 & 0.00010 & 0.99879 & 0.00519 \\
$011-012$ & 1.0000 & 0.0052 & 0.99847 & 0.00010 & 0.99847 & 0.00519 \\
$020-001$ & 1.0000 & 0.0059 & 1.00264 & 0.00010 & 1.00264 & 0.00592 \\
$020-002$ & 1.0000 & 0.0059 & 1.00514 & 0.00010 & 1.00514 & 0.00593 \\
$020-003$ & 1.0000 & 0.0059 & 0.99967 & 0.00010 & 0.99967 & 0.00590 \\
$020-004$ & 1.0000 & 0.0059 & 1.00294 & 0.00010 & 1.00294 & 0.00592 \\
$020-005$ & 1.0000 & 0.0059 & 1.00394 & 0.00010 & 1.00394 & 0.00592 \\
$020-006$ & 1.0000 & 0.0059 & 0.99691 & 0.00010 & 0.99691 & 0.00588 \\
$020-007$ & 1.0000 & 0.0059 & 1.00169 & 0.00010 & 1.00169 & 0.00591 \\
$020-008$ & 1.0000 & 0.0059 & 0.99375 & 0.00010 & 0.99375 & 0.00586 \\
$020-009$ & 1.0000 & 0.0059 & 1.00341 & 0.00010 & 1.00341 & 0.00592 \\
$020-010$ & 1.0000 & 0.0059 & 1.00006 & 0.00010 & 1.00006 & 0.00590 \\
$020-011$ & 1.0000 & 0.0059 & 1.00150 & 0.00010 & 1.00150 & 0.00591 \\
$020-012$ & 1.0000 & 0.0059 & 1.00301 & 0.00010 & 1.00301 & 0.00592 \\
$020-013$ & 1.0000 & 0.0059 & 0.99157 & 0.00010 & 0.99157 & 0.00585 \\
$020-014$ & 1.0000 & 0.0059 & 0.99459 & 0.00010 & 0.99459 & 0.00587 \\
$020-015$ & 1.0000 & 0.0059 & 1.00262 & 0.00010 & 1.00262 & 0.00592 \\
\hline
\end{tabular}


Table A-39. Detailed ENDF/B-VIII.0 CE results for KENO V.a PST systems

\begin{tabular}{|c|c|c|c|c|c|c|}
\hline Case & $\begin{array}{c}\text { Expected } \\
\boldsymbol{k}_{\text {eff }}\end{array}$ & $\begin{array}{c}\text { Experimental } \\
\text { uncertainty }\end{array}$ & $\boldsymbol{k}_{\text {eff }}$ & Uncertainty & $\mathrm{C} / \mathrm{E}$ & $\begin{array}{c}\mathbf{C} / \mathbf{E} \\
\text { uncertainty }\end{array}$ \\
\hline $001-001$ & 1.0000 & 0.0050 & 1.00043 & 0.00010 & 1.00043 & 0.00500 \\
\hline 001-002 & 1.0000 & 0.0050 & 1.00281 & 0.00010 & 1.00281 & 0.00502 \\
\hline $001-003$ & 1.0000 & 0.0050 & 1.00571 & 0.00010 & 1.00571 & 0.00503 \\
\hline 001-004 & 1.0000 & 0.0050 & 1.00051 & 0.00010 & 1.00051 & 0.00500 \\
\hline $001-005$ & 1.0000 & 0.0050 & 1.00465 & 0.00010 & 1.00465 & 0.00502 \\
\hline 001-006 & 1.0000 & 0.0050 & 1.00775 & 0.00010 & 1.00775 & 0.00504 \\
\hline $002-001$ & 1.0000 & 0.0047 & 0.99846 & 0.00010 & 0.99846 & 0.00469 \\
\hline $002-002$ & 1.0000 & 0.0047 & 0.99918 & 0.00010 & 0.99918 & 0.00470 \\
\hline $002-003$ & 1.0000 & 0.0047 & 0.99827 & 0.00010 & 0.99827 & 0.00469 \\
\hline 002-004 & 1.0000 & 0.0047 & 1.00109 & 0.00010 & 1.00109 & 0.00471 \\
\hline $002-005$ & 1.0000 & 0.0047 & 1.00420 & 0.00010 & 1.00420 & 0.00472 \\
\hline $002-006$ & 1.0000 & 0.0047 & 1.00036 & 0.00010 & 1.00036 & 0.00470 \\
\hline $002-007$ & 1.0000 & 0.0047 & 1.00279 & 0.00010 & 1.00279 & 0.00471 \\
\hline 003-001 & 1.0000 & 0.0047 & 0.99640 & 0.00010 & 0.99640 & 0.00468 \\
\hline 003-002 & 1.0000 & 0.0047 & 0.99617 & 0.00010 & 0.99617 & 0.00468 \\
\hline 003-003 & 1.0000 & 0.0047 & 0.99884 & 0.00010 & 0.99884 & 0.00470 \\
\hline 003-004 & 1.0000 & 0.0047 & 0.99826 & 0.00010 & 0.99826 & 0.00469 \\
\hline 003-005 & 1.0000 & 0.0047 & 0.99967 & 0.00010 & 0.99967 & 0.00470 \\
\hline 003-006 & 1.0000 & 0.0047 & 1.00007 & 0.00010 & 1.00007 & 0.00470 \\
\hline 003-007 & 1.0000 & 0.0047 & 1.00074 & 0.00010 & 1.00074 & 0.00470 \\
\hline 003-008 & 1.0000 & 0.0047 & 0.99959 & 0.00010 & 0.99959 & 0.00470 \\
\hline 004-001 & 1.0000 & 0.0047 & 0.99747 & 0.00010 & 0.99747 & 0.00469 \\
\hline 004-002 & 1.0000 & 0.0047 & 0.99246 & 0.00010 & 0.99246 & 0.00467 \\
\hline 004-003 & 1.0000 & 0.0047 & 0.99461 & 0.00010 & 0.99461 & 0.00468 \\
\hline 004-004 & 1.0000 & 0.0047 & 0.99243 & 0.00010 & 0.99243 & 0.00467 \\
\hline 004-005 & 1.0000 & 0.0047 & 0.99354 & 0.00010 & 0.99354 & 0.00467 \\
\hline 004-006 & 1.0000 & 0.0047 & 0.99537 & 0.00010 & 0.99537 & 0.00468 \\
\hline 004-007 & 1.0000 & 0.0047 & 0.99955 & 0.00010 & 0.99955 & 0.00470 \\
\hline 004-008 & 1.0000 & 0.0047 & 0.99507 & 0.00010 & 0.99507 & 0.00468 \\
\hline 004-009 & 1.0000 & 0.0047 & 0.99455 & 0.00010 & 0.99455 & 0.00468 \\
\hline 004-010 & 1.0000 & 0.0047 & 0.99617 & 0.00010 & 0.99617 & 0.00468 \\
\hline 004-011 & 1.0000 & 0.0047 & 0.99481 & 0.00010 & 0.99481 & 0.00468 \\
\hline 004-012 & 1.0000 & 0.0047 & 0.99683 & 0.00010 & 0.99683 & 0.00469 \\
\hline 004-013 & 1.0000 & 0.0047 & 0.99416 & 0.00010 & 0.99416 & 0.00467 \\
\hline 005-001 & 1.0000 & 0.0047 & 0.99618 & 0.00010 & 0.99618 & 0.00468 \\
\hline 005-002 & 1.0000 & 0.0047 & 0.99684 & 0.00010 & 0.99684 & 0.00469 \\
\hline 005-003 & 1.0000 & 0.0047 & 0.99737 & 0.00010 & 0.99737 & 0.00469 \\
\hline 005-004 & 1.0000 & 0.0047 & 0.99911 & 0.00010 & 0.99911 & 0.00470 \\
\hline 005-005 & 1.0000 & 0.0047 & 1.00041 & 0.00010 & 1.00041 & 0.00470 \\
\hline $005-006$ & 1.0000 & 0.0047 & 0.99999 & 0.00010 & 0.99999 & 0.00470 \\
\hline 005-007 & 1.0000 & 0.0047 & 0.99849 & 0.00010 & 0.99849 & 0.00469 \\
\hline 005-008 & 1.0000 & 0.0047 & 0.99347 & 0.00010 & 0.99347 & 0.00467 \\
\hline 005-009 & 1.0000 & 0.0047 & 0.99613 & 0.00010 & 0.99613 & 0.00468 \\
\hline 006-001 & 1.0000 & 0.0035 & 0.99444 & 0.00010 & 0.99444 & 0.00348 \\
\hline 006-002 & 1.0000 & 0.0035 & 0.99575 & 0.00010 & 0.99575 & 0.00349 \\
\hline 006-003 & 1.0000 & 0.0035 & 0.99544 & 0.00010 & 0.99544 & 0.00349 \\
\hline $007-001$ & 1.0000 & 0.0047 & 1.00747 & 0.00010 & 1.00747 & 0.00474 \\
\hline 007-002 & 1.0000 & 0.0047 & 1.00175 & 0.00010 & 1.00175 & 0.00471 \\
\hline $007-003$ & 1.0000 & 0.0047 & 1.00514 & 0.00010 & 1.00514 & 0.00473 \\
\hline 007-004 & 1.0000 & 0.0047 & 0.99934 & 0.00010 & 0.99934 & 0.00470 \\
\hline 007-005 & 1.0000 & 0.0047 & 1.00109 & 0.00010 & 1.00109 & 0.00471 \\
\hline $007-006$ & 1.0000 & 0.0047 & 0.99476 & 0.00010 & 0.99476 & 0.00468 \\
\hline 007-007 & 1.0000 & 0.0047 & 0.99320 & 0.00010 & 0.99320 & 0.00467 \\
\hline 007-008 & 1.0000 & 0.0047 & 0.99669 & 0.00010 & 0.99669 & 0.00469 \\
\hline 011-001 & 1.0000 & 0.0052 & 1.00305 & 0.00010 & 1.00305 & 0.00522 \\
\hline 011-002 & 1.0000 & 0.0052 & 1.00752 & 0.00010 & 1.00752 & 0.00524 \\
\hline 011-003 & 1.0000 & 0.0052 & 1.00957 & 0.00010 & 1.00957 & 0.00525 \\
\hline
\end{tabular}


Table A-39. Detailed ENDF/B-VIII.0 CE results for KENO V.a PST systems (continued)

\begin{tabular}{lcccccc}
\hline Case & $\begin{array}{c}\text { Expected } \\
\boldsymbol{k}_{\text {eff }}\end{array}$ & $\begin{array}{c}\text { Experimental } \\
\text { uncertainty }\end{array}$ & $\boldsymbol{k}_{\text {eff }}$ & Uncertainty & $\mathbf{C} / \mathbf{E}$ & $\begin{array}{c}\mathbf{C} / \mathbf{E} \\
\text { uncertainty }\end{array}$ \\
\hline $011-004$ & 1.0000 & 0.0052 & 1.00283 & 0.00010 & 1.00283 & 0.00522 \\
$011-005$ & 1.0000 & 0.0052 & 0.99987 & 0.00010 & 0.99987 & 0.00520 \\
$011-006$ & 1.0000 & 0.0052 & 0.98748 & 0.00010 & 0.98748 & 0.00514 \\
$011-007$ & 1.0000 & 0.0052 & 0.99348 & 0.00010 & 0.99348 & 0.00517 \\
$011-008$ & 1.0000 & 0.0052 & 0.99012 & 0.00010 & 0.99012 & 0.00515 \\
$011-009$ & 1.0000 & 0.0052 & 0.98677 & 0.00010 & 0.98677 & 0.00513 \\
$011-010$ & 1.0000 & 0.0052 & 0.99686 & 0.00010 & 0.99686 & 0.00518 \\
$011-011$ & 1.0000 & 0.0052 & 0.99349 & 0.00010 & 0.99349 & 0.00517 \\
$011-012$ & 1.0000 & 0.0052 & 0.99260 & 0.00010 & 0.99260 & 0.00516 \\
$020-001$ & 1.0000 & 0.0059 & 0.99811 & 0.00010 & 0.99811 & 0.00589 \\
$020-002$ & 1.0000 & 0.0059 & 1.00053 & 0.00010 & 1.00053 & 0.00590 \\
$020-003$ & 1.0000 & 0.0059 & 0.99478 & 0.00010 & 0.99478 & 0.00587 \\
$020-004$ & 1.0000 & 0.0059 & 0.99882 & 0.00010 & 0.99882 & 0.00589 \\
$020-005$ & 1.0000 & 0.0059 & 0.99926 & 0.00010 & 0.99926 & 0.00590 \\
$020-006$ & 1.0000 & 0.0059 & 0.99253 & 0.00010 & 0.99253 & 0.00586 \\
$020-007$ & 1.0000 & 0.0059 & 0.99776 & 0.00010 & 0.99776 & 0.00589 \\
$020-008$ & 1.0000 & 0.0059 & 0.98880 & 0.00010 & 0.98880 & 0.00583 \\
$020-009$ & 1.0000 & 0.0059 & 0.99871 & 0.00010 & 0.99871 & 0.00589 \\
$020-010$ & 1.0000 & 0.0059 & 0.99538 & 0.00010 & 0.99538 & 0.00587 \\
$020-011$ & 1.0000 & 0.0059 & 0.99731 & 0.00010 & 0.99731 & 0.00588 \\
$020-012$ & 1.0000 & 0.0059 & 0.99842 & 0.00010 & 0.99842 & 0.00589 \\
$020-013$ & 1.0000 & 0.0059 & 0.98665 & 0.00010 & 0.98665 & 0.00582 \\
$020-014$ & 1.0000 & 0.0059 & 0.99092 & 0.00010 & 0.99092 & 0.00585 \\
$020-015$ & 1.0000 & 0.0059 & 0.99803 & 0.00010 & 0.99803 & 0.00589 \\
\hline
\end{tabular}

Table A-40. Detailed ENDF/B-VII.1 CE results for KENO V.a PST systems

\begin{tabular}{rcccccc}
\hline Case & $\begin{array}{c}\text { Expected } \\
\boldsymbol{k}_{\text {eff }}\end{array}$ & $\begin{array}{c}\text { Experimental } \\
\text { uncertainty }\end{array}$ & $\boldsymbol{k}_{\text {eff }}$ & Uncertainty & C/E & $\begin{array}{c}\mathbf{C} / \mathbf{E} \\
\text { uncertainty }\end{array}$ \\
\hline $001-001$ & 1.0000 & 0.0050 & 1.00479 & 0.00010 & 1.00479 & 0.00502 \\
$001-002$ & 1.0000 & 0.0050 & 1.00691 & 0.00010 & 1.00691 & 0.00504 \\
$001-003$ & 1.0000 & 0.0050 & 1.00949 & 0.00010 & 1.00949 & 0.00505 \\
$001-004$ & 1.0000 & 0.0050 & 1.00399 & 0.00010 & 1.00399 & 0.00502 \\
$001-005$ & 1.0000 & 0.0050 & 1.00776 & 0.00010 & 1.00776 & 0.00504 \\
$001-006$ & 1.0000 & 0.0050 & 1.00927 & 0.00010 & 1.00927 & 0.00505 \\
$002-001$ & 1.0000 & 0.0047 & 1.00363 & 0.00010 & 1.00363 & 0.00472 \\
$002-002$ & 1.0000 & 0.0047 & 1.00455 & 0.00010 & 1.00455 & 0.00472 \\
$002-003$ & 1.0000 & 0.0047 & 1.00346 & 0.00010 & 1.00346 & 0.00472 \\
$002-004$ & 1.0000 & 0.0047 & 1.00637 & 0.00010 & 1.00637 & 0.00473 \\
$002-005$ & 1.0000 & 0.0047 & 1.00905 & 0.00009 & 1.00905 & 0.00474 \\
$002-006$ & 1.0000 & 0.0047 & 1.00510 & 0.00010 & 1.00510 & 0.00473 \\
$002-007$ & 1.0000 & 0.0047 & 1.00736 & 0.00010 & 1.00736 & 0.00474 \\
$003-001$ & 1.0000 & 0.0047 & 1.00246 & 0.00010 & 1.00246 & 0.00471 \\
$003-002$ & 1.0000 & 0.0047 & 1.00211 & 0.00010 & 1.00211 & 0.00471 \\
$003-003$ & 1.0000 & 0.0047 & 1.00455 & 0.00010 & 1.00455 & 0.00472 \\
$003-004$ & 1.0000 & 0.0047 & 1.00393 & 0.00010 & 1.00393 & 0.00472 \\
$003-005$ & 1.0000 & 0.0047 & 1.00522 & 0.00010 & 1.00522 & 0.00473 \\
$003-006$ & 1.0000 & 0.0047 & 1.00556 & 0.00010 & 1.00556 & 0.00473 \\
$003-007$ & 1.0000 & 0.0047 & 1.00642 & 0.00010 & 1.00642 & 0.00473 \\
$003-008$ & 1.0000 & 0.0047 & 1.00522 & 0.00010 & 1.00522 & 0.00473 \\
$004-001$ & 1.0000 & 0.0047 & 1.00327 & 0.00010 & 1.00327 & 0.00472 \\
$004-002$ & 1.0000 & 0.0047 & 0.99830 & 0.00010 & 0.99830 & 0.00469 \\
$004-003$ & 1.0000 & 0.0047 & 1.00057 & 0.00010 & 1.00057 & 0.00470 \\
$004-004$ & 1.0000 & 0.0047 & 0.99846 & 0.00010 & 0.99846 & 0.00469 \\
$004-005$ & 1.0000 & 0.0047 & 0.99952 & 0.00010 & 0.99952 & 0.00470 \\
$004-006$ & 1.0000 & 0.0047 & 1.00122 & 0.00010 & 1.00122 & 0.00471 \\
\hline & & & & & \\
\hline
\end{tabular}


Table A-40. Detailed ENDF/B-VII.1 CE results for KENO V.a PST systems (continued)

\begin{tabular}{|c|c|c|c|c|c|c|}
\hline Case & $\begin{array}{c}\text { Expected } \\
k_{\text {eff }} \\
\end{array}$ & $\begin{array}{c}\text { Experimental } \\
\text { uncertainty }\end{array}$ & $\boldsymbol{k}_{e f f}$ & Uncertainty & $\mathbf{C} / \mathbf{E}$ & $\begin{array}{c}\mathrm{C} / \mathrm{E} \\
\text { uncertainty }\end{array}$ \\
\hline 004-007 & 1.0000 & 0.0047 & 1.00500 & 0.00010 & 1.00500 & 0.00472 \\
\hline 004-008 & 1.0000 & 0.0047 & 1.00080 & 0.00010 & 1.00080 & 0.00470 \\
\hline 004-009 & 1.0000 & 0.0047 & 1.00031 & 0.00009 & 1.00031 & 0.00470 \\
\hline 004-010 & 1.0000 & 0.0047 & 1.00177 & 0.00010 & 1.00177 & 0.00471 \\
\hline 004-011 & 1.0000 & 0.0047 & 1.00019 & 0.00010 & 1.00019 & 0.00470 \\
\hline 004-012 & 1.0000 & 0.0047 & 1.00264 & 0.00010 & 1.00264 & 0.00471 \\
\hline 004-013 & 1.0000 & 0.0047 & 0.99993 & 0.00010 & 0.99993 & 0.00470 \\
\hline 005-001 & 1.0000 & 0.0047 & 1.00180 & 0.00010 & 1.00180 & 0.00471 \\
\hline $005-002$ & 1.0000 & 0.0047 & 1.00242 & 0.00010 & 1.00242 & 0.00471 \\
\hline $005-003$ & 1.0000 & 0.0047 & 1.00317 & 0.00010 & 1.00317 & 0.00472 \\
\hline 005-004 & 1.0000 & 0.0047 & 1.00478 & 0.00010 & 1.00478 & 0.00472 \\
\hline $005-005$ & 1.0000 & 0.0047 & 1.00595 & 0.00010 & 1.00595 & 0.00473 \\
\hline 005-006 & 1.0000 & 0.0047 & 1.00533 & 0.00010 & 1.00533 & 0.00473 \\
\hline 005-007 & 1.0000 & 0.0047 & 1.00410 & 0.00010 & 1.00410 & 0.00472 \\
\hline 005-008 & 1.0000 & 0.0047 & 0.99899 & 0.00010 & 0.99899 & 0.00470 \\
\hline 005-009 & 1.0000 & 0.0047 & 1.00190 & 0.00010 & 1.00190 & 0.00471 \\
\hline 006-001 & 1.0000 & 0.0035 & 1.00021 & 0.00010 & 1.00021 & 0.00350 \\
\hline 006-002 & 1.0000 & 0.0035 & 1.00153 & 0.00010 & 1.00153 & 0.00351 \\
\hline 006-003 & 1.0000 & 0.0035 & 1.00131 & 0.00010 & 1.00131 & 0.00351 \\
\hline 007-001 & 1.0000 & 0.0047 & 1.00972 & 0.00010 & 1.00972 & 0.00475 \\
\hline 007-002 & 1.0000 & 0.0047 & 1.00376 & 0.00010 & 1.00376 & 0.00472 \\
\hline $007-003$ & 1.0000 & 0.0047 & 1.00906 & 0.00010 & 1.00906 & 0.00474 \\
\hline 007-004 & 1.0000 & 0.0047 & 1.00307 & 0.00010 & 1.00307 & 0.00472 \\
\hline 007-005 & 1.0000 & 0.0047 & 1.00504 & 0.00010 & 1.00504 & 0.00472 \\
\hline 007-006 & 1.0000 & 0.0047 & 0.99861 & 0.00010 & 0.99861 & 0.00469 \\
\hline 007-007 & 1.0000 & 0.0047 & 0.99708 & 0.00010 & 0.99708 & 0.00469 \\
\hline 007-008 & 1.0000 & 0.0047 & 1.00060 & 0.00010 & 1.00060 & 0.00470 \\
\hline 011-001 & 1.0000 & 0.0052 & 1.00937 & 0.00010 & 1.00937 & 0.00525 \\
\hline 011-002 & 1.0000 & 0.0052 & 1.01430 & 0.00010 & 1.01430 & 0.00528 \\
\hline 011-003 & 1.0000 & 0.0052 & 1.01595 & 0.00010 & 1.01595 & 0.00528 \\
\hline 011-004 & 1.0000 & 0.0052 & 1.00866 & 0.00010 & 1.00866 & 0.00525 \\
\hline $011-005$ & 1.0000 & 0.0052 & 1.00584 & 0.00010 & 1.00584 & 0.00523 \\
\hline 011-006 & 1.0000 & 0.0052 & 0.99381 & 0.00010 & 0.99381 & 0.00517 \\
\hline $011-007$ & 1.0000 & 0.0052 & 0.99997 & 0.00010 & 0.99997 & 0.00520 \\
\hline 011-008 & 1.0000 & 0.0052 & 0.99633 & 0.00010 & 0.99633 & 0.00518 \\
\hline 011-009 & 1.0000 & 0.0052 & 0.99291 & 0.00010 & 0.99291 & 0.00516 \\
\hline 011-010 & 1.0000 & 0.0052 & 1.00304 & 0.00010 & 1.00304 & 0.00522 \\
\hline 011-011 & 1.0000 & 0.0052 & 0.99968 & 0.00010 & 0.99968 & 0.00520 \\
\hline $011-012$ & 1.0000 & 0.0052 & 0.99923 & 0.00010 & 0.99923 & 0.00520 \\
\hline $020-001$ & 1.0000 & 0.0059 & 1.00345 & 0.00010 & 1.00345 & 0.00592 \\
\hline $020-002$ & 1.0000 & 0.0059 & 1.00582 & 0.00010 & 1.00582 & 0.00594 \\
\hline $020-003$ & 1.0000 & 0.0059 & 1.00034 & 0.00010 & 1.00034 & 0.00590 \\
\hline $020-004$ & 1.0000 & 0.0059 & 1.00395 & 0.00010 & 1.00395 & 0.00592 \\
\hline $020-005$ & 1.0000 & 0.0059 & 1.00444 & 0.00010 & 1.00444 & 0.00593 \\
\hline 020-006 & 1.0000 & 0.0059 & 0.99809 & 0.00010 & 0.99809 & 0.00589 \\
\hline 020-007 & 1.0000 & 0.0059 & 1.00297 & 0.00010 & 1.00297 & 0.00592 \\
\hline 020-008 & 1.0000 & 0.0059 & 0.99433 & 0.00010 & 0.99433 & 0.00587 \\
\hline 020-009 & 1.0000 & 0.0059 & 1.00401 & 0.00010 & 1.00401 & 0.00592 \\
\hline $020-010$ & 1.0000 & 0.0059 & 1.00088 & 0.00010 & 1.00088 & 0.00591 \\
\hline $020-011$ & 1.0000 & 0.0059 & 1.00264 & 0.00010 & 1.00264 & 0.00592 \\
\hline $020-012$ & 1.0000 & 0.0059 & 1.00358 & 0.00010 & 1.00358 & 0.00592 \\
\hline $020-013$ & 1.0000 & 0.0059 & 0.99267 & 0.00010 & 0.99267 & 0.00586 \\
\hline $020-014$ & 1.0000 & 0.0059 & 0.99605 & 0.00010 & 0.99605 & 0.00588 \\
\hline $020-015$ & 1.0000 & 0.0059 & 1.00357 & 0.00010 & 1.00357 & 0.00592 \\
\hline
\end{tabular}


Table A-41. Detailed ENDF/B-VIII.0 252-group results for KENO V.a UCT systems

\begin{tabular}{ccccccc}
\hline Case & $\begin{array}{c}\text { Expected } \\
\boldsymbol{k}_{\text {eff }}\end{array}$ & $\begin{array}{c}\text { Experimental } \\
\text { uncertainty }\end{array}$ & $\boldsymbol{k}_{\text {eff }}$ & Uncertainty & $\mathbf{C} / \mathbf{E}$ & $\begin{array}{c}\mathbf{C} / \mathbf{E} \\
\text { uncertainty }\end{array}$ \\
\hline $001-002$ & 1.0015 & 0.0025 & 0.99934 & 0.00010 & 0.99785 & 0.00249 \\
$001-003$ & 1.0000 & 0.0024 & 1.00027 & 0.00010 & 1.00027 & 0.00240 \\
$001-004$ & 1.0015 & 0.0024 & 0.99800 & 0.00010 & 0.99651 & 0.00239 \\
\hline
\end{tabular}

Table A-42. Detailed ENDF/B-VII.1 252-group results for KENO V.a UCT systems

\begin{tabular}{ccccccc}
\hline Case & $\begin{array}{c}\text { Expected } \\
\boldsymbol{k}_{\text {eff }}\end{array}$ & $\begin{array}{c}\text { Experimental } \\
\text { uncertainty }\end{array}$ & $\boldsymbol{k}_{\text {eff }}$ & Uncertainty & $\mathbf{C} / \mathbf{E}$ & $\begin{array}{c}\mathbf{C} / \mathbf{E} \\
\text { uncertainty }\end{array}$ \\
\hline $001-002$ & 1.0015 & 0.0025 & 1.00220 & 0.00010 & 1.00069 & 0.00250 \\
$001-003$ & 1.0000 & 0.0024 & 1.00203 & 0.00010 & 1.00203 & 0.00241 \\
$001-004$ & 1.0015 & 0.0024 & 1.00076 & 0.00010 & 0.99926 & 0.00240 \\
\hline
\end{tabular}

Table A-43. Detailed ENDF/B-VIII.0 252-group results for KENO V.a UCT systems

\begin{tabular}{rcccccc}
\hline Case & $\begin{array}{c}\text { Expected } \\
\boldsymbol{k}_{\text {eff }}\end{array}$ & $\begin{array}{c}\text { Experimental } \\
\text { uncertainty }\end{array}$ & $\boldsymbol{k}_{\text {eff }}$ & Uncertainty & $\mathbf{C} / \mathbf{E}$ & $\begin{array}{c}\mathbf{C} / \mathbf{E} \\
\text { uncertainty }\end{array}$ \\
\hline $001-002$ & 1.0015 & 0.0025 & 0.99900 & 0.00010 & 0.99750 & 0.00249 \\
$001-003$ & 1.0000 & 0.0024 & 1.00002 & 0.00010 & 1.00002 & 0.00240 \\
$001-004$ & 1.0015 & 0.0024 & 0.99851 & 0.00010 & 0.99701 & 0.00239 \\
\hline
\end{tabular}

Table A-44. Detailed ENDF/B-VII.1 252-group results for KENO V.a UCT systems

\begin{tabular}{ccccrrc}
\hline Case & $\begin{array}{c}\text { Expected } \\
\boldsymbol{k}_{\text {eff }}\end{array}$ & $\begin{array}{c}\text { Experimental } \\
\text { uncertainty }\end{array}$ & $\boldsymbol{k}_{\text {eff }}$ & Uncertainty & C/E & $\begin{array}{c}\mathbf{C} / \mathbf{E} \\
\text { uncertainty }\end{array}$ \\
\hline $001-002$ & 1.0015 & 0.0025 & 1.00230 & 0.00010 & 1.00080 & 0.00250 \\
$001-003$ & 1.0000 & 0.0024 & 1.00196 & 0.00010 & 1.00196 & 0.00241 \\
$001-004$ & 1.0015 & 0.0024 & 1.00113 & 0.00010 & 0.99963 & 0.00240 \\
\hline
\end{tabular}

Table A-45. Detailed ENDF/B-VIII.0 252-group results for KENO V.a UMF systems

\begin{tabular}{rcccccc}
\hline Case & $\begin{array}{c}\text { Expected } \\
\boldsymbol{k}_{\text {eff }}\end{array}$ & $\begin{array}{c}\text { Experimental } \\
\text { uncertainty }\end{array}$ & $\boldsymbol{k}_{\text {eff }}$ & Uncertainty & $\mathbf{C} / \mathbf{E}$ & $\begin{array}{c}\mathbf{C} / \mathbf{E} \\
\text { uncertainty }\end{array}$ \\
\hline $001-001$ & 1.0000 & 0.0010 & 0.99999 & 0.00010 & 0.99999 & 0.00100 \\
$002-001$ & 1.0000 & 0.0010 & 0.99977 & 0.00010 & 0.99977 & 0.00100 \\
$002-002$ & 1.0000 & 0.0011 & 1.00117 & 0.00010 & 1.00117 & 0.00111 \\
$003-001$ & 1.0000 & 0.0010 & 0.99917 & 0.00010 & 0.99917 & 0.00100 \\
$003-002$ & 1.0000 & 0.0010 & 0.99943 & 0.00010 & 0.99943 & 0.00100 \\
$004-001$ & 1.0000 & 0.0007 & 0.99944 & 0.00010 & 0.99944 & 0.00071 \\
$004-002$ & 1.0000 & 0.0008 & 0.99638 & 0.00010 & 0.99638 & 0.00080 \\
$005-001$ & 1.0000 & 0.0030 & 0.99699 & 0.00010 & 0.99699 & 0.00299 \\
$005-002$ & 1.0000 & 0.0030 & 0.99653 & 0.00010 & 0.99653 & 0.00299 \\
$006-001$ & 1.0000 & 0.0014 & 0.99858 & 0.00010 & 0.99858 & 0.00140 \\
\hline
\end{tabular}

Table A-46. Detailed ENDF/B-VII.1 252-group results for KENO V.a UMF systems

\begin{tabular}{ccccccc}
\hline Case & $\begin{array}{c}\text { Expected } \\
\boldsymbol{k}_{\text {eff }}\end{array}$ & $\begin{array}{c}\text { Experimental } \\
\text { uncertainty }\end{array}$ & $\boldsymbol{k}_{\text {eff }}$ & Uncertainty & C/E & $\begin{array}{c}\mathbf{C} / \mathbf{E} \\
\text { uncertainty }\end{array}$ \\
\hline $001-001$ & 1.0000 & 0.0010 & 1.00024 & 0.00010 & 1.00024 & 0.00101 \\
$002-001$ & 1.0000 & 0.0010 & 0.99932 & 0.00010 & 0.99932 & 0.00100 \\
$002-002$ & 1.0000 & 0.0011 & 1.00071 & 0.00010 & 1.00071 & 0.00111 \\
$003-001$ & 1.0000 & 0.0010 & 0.99984 & 0.00010 & 0.99984 & 0.00100 \\
$003-002$ & 1.0000 & 0.0010 & 1.00042 & 0.00010 & 1.00042 & 0.00101 \\
$004-001$ & 1.0000 & 0.0007 & 0.99910 & 0.00010 & 0.99910 & 0.00071 \\
$004-002$ & 1.0000 & 0.0008 & 0.99613 & 0.00010 & 0.99613 & 0.00080 \\
$005-001$ & 1.0000 & 0.0030 & 0.99625 & 0.00010 & 0.99625 & 0.00299 \\
$005-002$ & 1.0000 & 0.0030 & 0.99539 & 0.00010 & 0.99539 & 0.00299 \\
$006-001$ & 1.0000 & 0.0014 & 0.99936 & 0.00010 & 0.99936 & 0.00140 \\
\hline
\end{tabular}


Table A-47. Detailed ENDF/B-VIII.0 CE results for KENO V.a UMF systems

\begin{tabular}{ccccccc}
\hline Case & $\begin{array}{c}\text { Expected } \\
\boldsymbol{k}_{\text {eff }}\end{array}$ & $\begin{array}{c}\text { Experimental } \\
\text { uncertainty }\end{array}$ & $\boldsymbol{k}_{\text {eff }}$ & Uncertainty & $\mathbf{C / E}$ & $\begin{array}{c}\mathbf{C} / \mathbf{E} \\
\text { uncertainty }\end{array}$ \\
\hline $001-001$ & 1.0000 & 0.0010 & 0.99991 & 0.00010 & 0.99991 & 0.00100 \\
$002-001$ & 1.0000 & 0.0010 & 0.99950 & 0.00010 & 0.99950 & 0.00100 \\
$002-002$ & 1.0000 & 0.0011 & 1.00105 & 0.00010 & 1.00105 & 0.00111 \\
$003-001$ & 1.0000 & 0.0010 & 0.99901 & 0.00010 & 0.99901 & 0.00100 \\
$003-002$ & 1.0000 & 0.0010 & 0.99951 & 0.00010 & 0.99951 & 0.00100 \\
$004-001$ & 1.0000 & 0.0007 & 0.99885 & 0.00010 & 0.99885 & 0.00071 \\
$004-002$ & 1.0000 & 0.0008 & 0.99580 & 0.00010 & 0.99580 & 0.00080 \\
$005-001$ & 1.0000 & 0.0030 & 0.99675 & 0.00010 & 0.99675 & 0.00299 \\
$005-002$ & 1.0000 & 0.0030 & 0.99655 & 0.00010 & 0.99655 & 0.00299 \\
$006-001$ & 1.0000 & 0.0014 & 0.99905 & 0.00010 & 0.99905 & 0.00140 \\
\hline
\end{tabular}

Table A-48. Detailed ENDF/B-VII.1 CE results for KENO V.a UMF systems

\begin{tabular}{|c|c|c|c|c|c|c|}
\hline Case & $\begin{array}{c}\text { Expected } \\
\boldsymbol{k}_{\text {eff }} \\
\end{array}$ & $\begin{array}{c}\text { Experimental } \\
\text { uncertainty }\end{array}$ & $\boldsymbol{k}_{e f f}$ & Uncertainty & $\mathbf{C} / \mathbf{E}$ & $\begin{array}{c}\mathrm{C} / \mathbf{E} \\
\text { uncertainty }\end{array}$ \\
\hline 001-001 & 1.0000 & 0.0010 & 1.00012 & 0.00010 & 1.00012 & 0.00101 \\
\hline 002-001 & 1.0000 & 0.0010 & 0.99900 & 0.00010 & 0.99900 & 0.00100 \\
\hline 002-002 & 1.0000 & 0.0011 & 1.00053 & 0.00010 & 1.00053 & 0.00111 \\
\hline 003-001 & 1.0000 & 0.0010 & 0.99966 & 0.00010 & 0.99966 & 0.00100 \\
\hline 003-002 & 1.0000 & 0.0010 & 1.00014 & 0.00010 & 1.00014 & 0.00101 \\
\hline 004-001 & 1.0000 & 0.0007 & 0.99882 & 0.00010 & 0.99882 & 0.00071 \\
\hline 004-002 & 1.0000 & 0.0008 & 0.99571 & 0.00010 & 0.99571 & 0.00080 \\
\hline 005-001 & 1.0000 & 0.0030 & 0.99610 & 0.00010 & 0.99610 & 0.00299 \\
\hline 005-002 & 1.0000 & 0.0030 & 0.99510 & 0.00010 & 0.99510 & 0.00299 \\
\hline 006-001 & 1.0000 & 0.0014 & 0.99936 & 0.00010 & 0.99936 & 0.00140 \\
\hline
\end{tabular}

Table A-49. Detailed ENDF/B-VIII.0 252-group results for KENO V.a USI systems

\begin{tabular}{|c|c|c|c|c|c|c|}
\hline Case & $\begin{array}{c}\text { Expected } \\
\boldsymbol{k}_{\text {eff }} \\
\end{array}$ & $\begin{array}{c}\text { Experimental } \\
\text { uncertainty }\end{array}$ & $\boldsymbol{k}_{\text {eff }}$ & Uncertainty & $\mathbf{C} / \mathbf{E}$ & $\begin{array}{c}\mathrm{C} / \mathrm{E} \\
\text { uncertainty }\end{array}$ \\
\hline 001-001 & 1.0000 & 0.0083 & 0.97991 & 0.00010 & 0.97991 & 0.00813 \\
\hline 001-002 & 1.0000 & 0.0085 & 0.97595 & 0.00010 & 0.97595 & 0.00830 \\
\hline $001-003$ & 1.0000 & 0.0066 & 0.97716 & 0.00010 & 0.97716 & 0.00645 \\
\hline 001-004 & 1.0000 & 0.0061 & 0.98993 & 0.00010 & 0.98993 & 0.00604 \\
\hline 001-005 & 1.0000 & 0.0082 & 0.98094 & 0.00011 & 0.98094 & 0.00804 \\
\hline 001-006 & 1.0000 & 0.0061 & 0.98359 & 0.00011 & 0.98359 & 0.00600 \\
\hline 001-007 & 1.0000 & 0.0059 & 0.97829 & 0.00010 & 0.97829 & 0.00577 \\
\hline 001-008 & 1.0000 & 0.0056 & 0.97879 & 0.00011 & 0.97879 & 0.00548 \\
\hline 001-009 & 1.0000 & 0.0068 & 0.97770 & 0.00011 & 0.97770 & 0.00665 \\
\hline $001-010$ & 1.0000 & 0.0053 & 0.97559 & 0.00012 & 0.97559 & 0.00517 \\
\hline 001-011 & 1.0000 & 0.0057 & 0.97822 & 0.00012 & 0.97822 & 0.00558 \\
\hline 001-012 & 1.0000 & 0.0091 & 0.97610 & 0.00011 & 0.97610 & 0.00888 \\
\hline $001-013$ & 1.0000 & 0.0071 & 0.97725 & 0.00011 & 0.97725 & 0.00694 \\
\hline $001-015$ & 1.0000 & 0.0075 & 0.97554 & 0.00011 & 0.97554 & 0.00732 \\
\hline $001-017$ & 1.0000 & 0.0055 & 0.98599 & 0.00010 & 0.98599 & 0.00542 \\
\hline $001-018$ & 1.0000 & 0.0057 & 0.97432 & 0.00011 & 0.97432 & 0.00555 \\
\hline 001-019 & 1.0000 & 0.0083 & 0.97151 & 0.00011 & 0.97151 & 0.00806 \\
\hline $001-020$ & 1.0000 & 0.0056 & 0.97756 & 0.00011 & 0.97756 & 0.00548 \\
\hline 001-021 & 1.0000 & 0.0050 & 0.96946 & 0.00011 & 0.96946 & 0.00485 \\
\hline 001-022 & 1.0000 & 0.0049 & 0.97496 & 0.00012 & 0.97496 & 0.00478 \\
\hline $001-023$ & 1.0000 & 0.0047 & 0.98798 & 0.00011 & 0.98798 & 0.00464 \\
\hline $001-024$ & 1.0000 & 0.0081 & 0.98678 & 0.00011 & 0.98678 & 0.00799 \\
\hline $001-025$ & 1.0000 & 0.0081 & 0.98016 & 0.00011 & 0.98016 & 0.00794 \\
\hline $001-026$ & 1.0000 & 0.0065 & 0.98415 & 0.00011 & 0.98415 & 0.00640 \\
\hline $001-028$ & 1.0000 & 0.0061 & 0.97884 & 0.00011 & 0.97884 & 0.00597 \\
\hline 001-029 & 1.0000 & 0.0098 & 0.97303 & 0.00011 & 0.97303 & 0.00954 \\
\hline 001-031 & 1.0000 & 0.0071 & 0.98704 & 0.00011 & 0.98704 & 0.00701 \\
\hline 001-032 & 1.0000 & 0.0053 & 0.97202 & 0.00011 & 0.97202 & 0.00515 \\
\hline 001-033 & 1.0000 & 0.0046 & 0.99130 & 0.00011 & 0.99130 & 0.00456 \\
\hline
\end{tabular}


Table A-50. Detailed ENDF/B-VII.1 252-group results for KENO V.a USI systems

\begin{tabular}{ccccccc}
\hline Case & $\begin{array}{c}\text { Expected } \\
\boldsymbol{k}_{\text {eff }}\end{array}$ & $\begin{array}{c}\text { Experimental } \\
\text { uncertainty }\end{array}$ & $\boldsymbol{k}_{\text {eff }}$ & Uncertainty & C/E & $\begin{array}{c}\text { C/E } \\
\text { uncertainty }\end{array}$ \\
\hline $001-001$ & 1.0000 & 0.0083 & 0.98505 & 0.00010 & 0.98505 & 0.00818 \\
$001-002$ & 1.0000 & 0.0085 & 0.98003 & 0.00010 & 0.98003 & 0.00833 \\
$001-003$ & 1.0000 & 0.0066 & 0.98064 & 0.00011 & 0.98064 & 0.00647 \\
$001-004$ & 1.0000 & 0.0061 & 0.99142 & 0.00010 & 0.99142 & 0.00605 \\
$001-005$ & 1.0000 & 0.0082 & 0.98376 & 0.00011 & 0.98376 & 0.00807 \\
$001-006$ & 1.0000 & 0.0061 & 0.98465 & 0.00011 & 0.98465 & 0.00601 \\
$001-007$ & 1.0000 & 0.0059 & 0.98103 & 0.00010 & 0.98103 & 0.00579 \\
$001-008$ & 1.0000 & 0.0056 & 0.97966 & 0.00011 & 0.97966 & 0.00549 \\
$001-009$ & 1.0000 & 0.0068 & 0.97875 & 0.00011 & 0.97875 & 0.00666 \\
$001-010$ & 1.0000 & 0.0053 & 0.97746 & 0.00011 & 0.97746 & 0.00518 \\
$001-011$ & 1.0000 & 0.0057 & 0.97922 & 0.00011 & 0.97922 & 0.00558 \\
$001-012$ & 1.0000 & 0.0091 & 0.98130 & 0.00011 & 0.98130 & 0.00893 \\
$001-013$ & 1.0000 & 0.0071 & 0.98174 & 0.00011 & 0.98174 & 0.00697 \\
$001-015$ & 1.0000 & 0.0075 & 0.97950 & 0.00011 & 0.97950 & 0.00735 \\
$001-017$ & 1.0000 & 0.0055 & 0.98801 & 0.00011 & 0.98801 & 0.00544 \\
$001-018$ & 1.0000 & 0.0057 & 0.97762 & 0.00011 & 0.97762 & 0.00557 \\
$001-019$ & 1.0000 & 0.0083 & 0.97422 & 0.00011 & 0.97422 & 0.00809 \\
$001-020$ & 1.0000 & 0.0056 & 0.97897 & 0.00011 & 0.97897 & 0.00548 \\
$001-021$ & 1.0000 & 0.0050 & 0.97188 & 0.00011 & 0.97188 & 0.00486 \\
$001-022$ & 1.0000 & 0.0049 & 0.97692 & 0.00012 & 0.97692 & 0.00479 \\
$001-023$ & 1.0000 & 0.0047 & 0.98881 & 0.00012 & 0.98881 & 0.00465 \\
$001-024$ & 1.0000 & 0.0081 & 0.99229 & 0.00011 & 0.99229 & 0.00804 \\
$001-025$ & 1.0000 & 0.0081 & 0.98480 & 0.00011 & 0.98480 & 0.00798 \\
$001-026$ & 1.0000 & 0.0065 & 0.98845 & 0.00011 & 0.98845 & 0.00643 \\
$001-028$ & 1.0000 & 0.0061 & 0.98264 & 0.00011 & 0.98264 & 0.00600 \\
$001-029$ & 1.0000 & 0.0098 & 0.97654 & 0.00011 & 0.97654 & 0.00957 \\
$001-031$ & 1.0000 & 0.0071 & 0.98971 & 0.00011 & 0.98971 & 0.00703 \\
$001-032$ & 1.0000 & 0.0053 & 0.97455 & 0.00011 & 0.97455 & 0.00517 \\
$001-033$ & 1.0000 & 0.0046 & 0.99243 & 0.00011 & 0.99243 & 0.00457 \\
\hline & & & & & \\
\hline
\end{tabular}


Table A-51. Detailed ENDF/B-VIII.0 CE results for KENO V.a USI systems

\begin{tabular}{rcccccc}
\hline Case & $\begin{array}{c}\text { Expected } \\
\boldsymbol{k}_{\text {eff }}\end{array}$ & $\begin{array}{c}\text { Experimental } \\
\text { uncertainty }\end{array}$ & $\boldsymbol{k}_{\text {eff }}$ & Uncertainty & $\mathbf{C} / \mathbf{E}$ & $\begin{array}{c}\text { C/E } \\
\text { uncertainty }\end{array}$ \\
\hline $001-001$ & 1.0000 & 0.0083 & 0.97996 & 0.00010 & 0.97996 & 0.00813 \\
$001-002$ & 1.0000 & 0.0085 & 0.97584 & 0.00010 & 0.97584 & 0.00830 \\
$001-003$ & 1.0000 & 0.0066 & 0.97716 & 0.00010 & 0.97716 & 0.00645 \\
$001-004$ & 1.0000 & 0.0061 & 0.98984 & 0.00010 & 0.98984 & 0.00604 \\
$001-005$ & 1.0000 & 0.0082 & 0.98104 & 0.00010 & 0.98104 & 0.00805 \\
$001-006$ & 1.0000 & 0.0061 & 0.98367 & 0.00011 & 0.98367 & 0.00600 \\
$001-007$ & 1.0000 & 0.0059 & 0.97858 & 0.00010 & 0.97858 & 0.00577 \\
$001-008$ & 1.0000 & 0.0056 & 0.97890 & 0.00011 & 0.97890 & 0.00548 \\
$001-009$ & 1.0000 & 0.0068 & 0.97780 & 0.00011 & 0.97780 & 0.00665 \\
$001-010$ & 1.0000 & 0.0053 & 0.97569 & 0.00011 & 0.97569 & 0.00517 \\
$001-011$ & 1.0000 & 0.0057 & 0.97847 & 0.00011 & 0.97847 & 0.00558 \\
$001-012$ & 1.0000 & 0.0091 & 0.97602 & 0.00011 & 0.97602 & 0.00888 \\
$001-013$ & 1.0000 & 0.0071 & 0.97747 & 0.00010 & 0.97747 & 0.00694 \\
$001-015$ & 1.0000 & 0.0075 & 0.97570 & 0.00010 & 0.97570 & 0.00732 \\
$001-017$ & 1.0000 & 0.0055 & 0.98615 & 0.00010 & 0.98615 & 0.00542 \\
$001-018$ & 1.0000 & 0.0057 & 0.97443 & 0.00010 & 0.97443 & 0.00556 \\
$001-019$ & 1.0000 & 0.0083 & 0.97166 & 0.00011 & 0.97166 & 0.00807 \\
$001-020$ & 1.0000 & 0.0056 & 0.97795 & 0.00011 & 0.97795 & 0.00548 \\
$001-021$ & 1.0000 & 0.0050 & 0.96967 & 0.00011 & 0.96967 & 0.00485 \\
$001-022$ & 1.0000 & 0.0049 & 0.97513 & 0.00011 & 0.97513 & 0.00478 \\
$001-023$ & 1.0000 & 0.0047 & 0.98804 & 0.00011 & 0.98804 & 0.00465 \\
$001-024$ & 1.0000 & 0.0081 & 0.98687 & 0.00010 & 0.98687 & 0.00799 \\
$001-025$ & 1.0000 & 0.0081 & 0.98029 & 0.00010 & 0.98029 & 0.00794 \\
$001-026$ & 1.0000 & 0.0065 & 0.98429 & 0.00011 & 0.98429 & 0.00640 \\
$001-028$ & 1.0000 & 0.0061 & 0.97907 & 0.00011 & 0.97907 & 0.00597 \\
$001-029$ & 1.0000 & 0.0098 & 0.97342 & 0.00011 & 0.97342 & 0.00954 \\
$001-031$ & 1.0000 & 0.0071 & 0.98719 & 0.00011 & 0.98719 & 0.00701 \\
$001-032$ & 1.0000 & 0.0053 & 0.97218 & 0.00011 & 0.97218 & 0.00515 \\
$001-033$ & 1.0000 & 0.0046 & 0.99164 & 0.00011 & 0.99164 & 0.00456 \\
\hline
\end{tabular}

Table A-52. Detailed ENDF/B-VII.1 CE results for KENO V.a USI systems

\begin{tabular}{rcccccc}
\hline Case & $\begin{array}{c}\text { Expected } \\
\boldsymbol{k}_{\text {eff }}\end{array}$ & $\begin{array}{c}\text { Experimental } \\
\text { uncertainty }\end{array}$ & $\boldsymbol{k}_{\text {eff }}$ & Uncertainty & $\mathbf{C} / \mathbf{E}$ & $\begin{array}{c}\mathbf{C} / \mathbf{E} \\
\text { uncertainty }\end{array}$ \\
\hline $001-001$ & 1.0000 & 0.0083 & 0.98489 & 0.00010 & 0.98489 & 0.00818 \\
$001-002$ & 1.0000 & 0.0085 & 0.98025 & 0.00010 & 0.98025 & 0.00833 \\
$001-003$ & 1.0000 & 0.0066 & 0.98124 & 0.00010 & 0.98124 & 0.00648 \\
$001-004$ & 1.0000 & 0.0061 & 0.99202 & 0.00010 & 0.99202 & 0.00605 \\
$001-005$ & 1.0000 & 0.0082 & 0.98421 & 0.00011 & 0.98421 & 0.00807 \\
$001-006$ & 1.0000 & 0.0061 & 0.98538 & 0.00010 & 0.98538 & 0.00601 \\
$001-007$ & 1.0000 & 0.0059 & 0.98182 & 0.00010 & 0.98182 & 0.00579 \\
$001-008$ & 1.0000 & 0.0056 & 0.98027 & 0.00010 & 0.98027 & 0.00549 \\
$001-009$ & 1.0000 & 0.0068 & 0.97950 & 0.00011 & 0.97950 & 0.00666 \\
$001-010$ & 1.0000 & 0.0053 & 0.97841 & 0.00011 & 0.97841 & 0.00519 \\
$001-011$ & 1.0000 & 0.0057 & 0.98015 & 0.00011 & 0.98015 & 0.00559 \\
$001-012$ & 1.0000 & 0.0091 & 0.98115 & 0.00011 & 0.98115 & 0.00893 \\
$001-013$ & 1.0000 & 0.0071 & 0.98196 & 0.00011 & 0.98196 & 0.00697 \\
$001-015$ & 1.0000 & 0.0075 & 0.97990 & 0.00011 & 0.97990 & 0.00735 \\
$001-017$ & 1.0000 & 0.0055 & 0.98865 & 0.00010 & 0.98865 & 0.00544 \\
$001-018$ & 1.0000 & 0.0057 & 0.97849 & 0.00010 & 0.97849 & 0.00558 \\
$001-019$ & 1.0000 & 0.0083 & 0.97506 & 0.00011 & 0.97506 & 0.00809 \\
$001-020$ & 1.0000 & 0.0056 & 0.97947 & 0.00011 & 0.97947 & 0.00549 \\
$001-021$ & 1.0000 & 0.0050 & 0.97268 & 0.00011 & 0.97268 & 0.00486 \\
$001-022$ & 1.0000 & 0.0049 & 0.97786 & 0.00011 & 0.97786 & 0.00479 \\
$001-023$ & 1.0000 & 0.0047 & 0.98977 & 0.00011 & 0.98977 & 0.00465 \\
$001-024$ & 1.0000 & 0.0081 & 0.99232 & 0.00011 & 0.99232 & 0.00804 \\
$001-025$ & 1.0000 & 0.0081 & 0.98525 & 0.00010 & 0.98525 & 0.00798 \\
$001-026$ & 1.0000 & 0.0065 & 0.98880 & 0.00011 & 0.98880 & 0.00643 \\
$001-028$ & 1.0000 & 0.0061 & 0.98327 & 0.00011 & 0.98327 & 0.00600 \\
\hline
\end{tabular}


Table A-52. Detailed ENDF/B-VII.1 CE results for KENO V.a USI systems

\begin{tabular}{rcccccc}
\hline Case & $\begin{array}{c}\text { Expected } \\
\boldsymbol{k}_{\text {eff }}\end{array}$ & $\begin{array}{c}\text { Experimental } \\
\text { uncertainty }\end{array}$ & $\boldsymbol{k}_{\text {eff }}$ & Uncertainty & C/E & $\begin{array}{c}\mathbf{C} / \mathbf{E} \\
\text { uncertainty }\end{array}$ \\
\hline $001-029$ & 1.0000 & 0.0098 & 0.97715 & 0.00011 & 0.97715 & 0.00958 \\
$001-031$ & 1.0000 & 0.0071 & 0.99058 & 0.00011 & 0.99058 & 0.00703 \\
$001-032$ & 1.0000 & 0.0053 & 0.97554 & 0.00011 & 0.97554 & 0.00517 \\
$001-033$ & 1.0000 & 0.0046 & 0.99359 & 0.00011 & 0.99359 & 0.00457 \\
\hline
\end{tabular}

Table A-53. Detailed ENDF/B-VIII.0 252-group results for KENO V.a USM systems

\begin{tabular}{|c|c|c|c|c|c|c|}
\hline Case & $\begin{array}{c}\text { Expected } \\
\boldsymbol{k}_{\text {eff }} \\
\end{array}$ & $\begin{array}{c}\text { Experimental } \\
\text { uncertainty }\end{array}$ & $\boldsymbol{k}_{e f f}$ & Uncertainty & $\mathbf{C} / \mathbf{E}$ & $\begin{array}{c}\mathrm{C} / \mathrm{E} \\
\text { uncertainty }\end{array}$ \\
\hline $001-014$ & 1.0000 & 0.0052 & 0.98710 & 0.00011 & 0.98710 & 0.00513 \\
\hline 001-016 & 1.0000 & 0.0028 & 0.97081 & 0.00011 & 0.97081 & 0.00272 \\
\hline 001-030 & 1.0000 & 0.0053 & 0.97556 & 0.00011 & 0.97556 & 0.00517 \\
\hline $002-003$ & 1.0000 & 0.0068 & 0.98136 & 0.00011 & 0.98136 & 0.00667 \\
\hline $002-005$ & 1.0000 & 0.0055 & 0.98138 & 0.00011 & 0.98138 & 0.00540 \\
\hline $002-006$ & 1.0000 & 0.0099 & 0.97228 & 0.00011 & 0.97228 & 0.00963 \\
\hline $002-008$ & 1.0000 & 0.0067 & 0.96902 & 0.00011 & 0.96902 & 0.00649 \\
\hline 002-009 & 1.0000 & 0.0050 & 0.96474 & 0.00010 & 0.96474 & 0.00482 \\
\hline
\end{tabular}

Table 19. Detailed ENDF/B-VII.1 252-group results for KENO V.a USM systems

\begin{tabular}{rcccccc}
\hline Case & $\begin{array}{c}\text { Expected } \\
\boldsymbol{k}_{\text {eff }}\end{array}$ & $\begin{array}{c}\text { Experimental } \\
\text { uncertainty }\end{array}$ & $\boldsymbol{k}_{\text {eff }}$ & Uncertainty & $\mathbf{C} / \mathbf{E}$ & $\begin{array}{c}\mathbf{C} / \mathbf{E} \\
\text { uncertainty }\end{array}$ \\
\hline $001-014$ & 1.0000 & 0.0052 & 0.98927 & 0.00011 & 0.98927 & 0.00515 \\
$001-016$ & 1.0000 & 0.0028 & 0.97394 & 0.00010 & 0.97394 & 0.00273 \\
$001-030$ & 1.0000 & 0.0053 & 0.97663 & 0.00011 & 0.97663 & 0.00518 \\
$002-003$ & 1.0000 & 0.0068 & 0.98613 & 0.00011 & 0.98613 & 0.00671 \\
$002-005$ & 1.0000 & 0.0055 & 0.98547 & 0.00011 & 0.98547 & 0.00542 \\
$002-006$ & 1.0000 & 0.0099 & 0.97561 & 0.00011 & 0.97561 & 0.00966 \\
$002-008$ & 1.0000 & 0.0067 & 0.97197 & 0.00011 & 0.97197 & 0.00651 \\
$002-009$ & 1.0000 & 0.0050 & 0.96735 & 0.00010 & 0.96735 & 0.00484 \\
\hline
\end{tabular}

Table A-55. Detailed ENDF/B-VIII.0 CE results for KENO V.a USM systems

\begin{tabular}{rcccccc}
\hline Case & $\begin{array}{c}\text { Expected } \\
\boldsymbol{k}_{\text {eff }}\end{array}$ & $\begin{array}{c}\text { Experimental } \\
\text { uncertainty }\end{array}$ & $\boldsymbol{k}_{\text {eff }}$ & Uncertainty & C/E & $\begin{array}{c}\mathbf{C} / \mathbf{E} \\
\text { uncertainty }\end{array}$ \\
\hline $001-014$ & 1.0000 & 0.0052 & 0.98687 & 0.00010 & 0.98687 & 0.00513 \\
$001-016$ & 1.0000 & 0.0028 & 0.97058 & 0.00010 & 0.97058 & 0.00272 \\
$001-030$ & 1.0000 & 0.0053 & 0.97598 & 0.00011 & 0.97598 & 0.00517 \\
$002-003$ & 1.0000 & 0.0068 & 0.98155 & 0.00011 & 0.98155 & 0.00668 \\
$002-005$ & 1.0000 & 0.0055 & 0.98167 & 0.00011 & 0.98167 & 0.00540 \\
$002-006$ & 1.0000 & 0.0099 & 0.97230 & 0.00011 & 0.97230 & 0.00963 \\
$002-008$ & 1.0000 & 0.0067 & 0.96933 & 0.00011 & 0.96933 & 0.00650 \\
$002-009$ & 1.0000 & 0.0050 & 0.96540 & 0.00010 & 0.96540 & 0.00483 \\
\hline
\end{tabular}

Table A-56. Detailed ENDF/B-VII.1 CE results for KENO V.a USM systems

\begin{tabular}{rcccccc}
\hline Case & $\begin{array}{c}\text { Expected } \\
\boldsymbol{k}_{\text {eff }}\end{array}$ & $\begin{array}{c}\text { Experimental } \\
\text { uncertainty }\end{array}$ & $\boldsymbol{k}_{\text {eff }}$ & Uncertainty & $\mathbf{C} / \mathbf{E}$ & $\begin{array}{c}\mathbf{C} / \mathbf{E} \\
\text { uncertainty }\end{array}$ \\
\hline $001-014$ & 1.0000 & 0.0052 & 0.98966 & 0.00010 & 0.98966 & 0.00515 \\
$001-016$ & 1.0000 & 0.0028 & 0.97426 & 0.00010 & 0.97426 & 0.00273 \\
$001-030$ & 1.0000 & 0.0053 & 0.97769 & 0.00011 & 0.97769 & 0.00518 \\
$002-003$ & 1.0000 & 0.0068 & 0.98656 & 0.00011 & 0.98656 & 0.00671 \\
$002-005$ & 1.0000 & 0.0055 & 0.98605 & 0.00011 & 0.98605 & 0.00542 \\
$002-006$ & 1.0000 & 0.0099 & 0.97650 & 0.00011 & 0.97650 & 0.00967 \\
$002-008$ & 1.0000 & 0.0067 & 0.97289 & 0.00011 & 0.97289 & 0.00652 \\
$002-009$ & 1.0000 & 0.0050 & 0.96847 & 0.00010 & 0.96847 & 0.00484 \\
\hline
\end{tabular}


Table A-57. Detailed ENDF/B-VIII.0 252-group results for KENO V.a UST systems

\begin{tabular}{|c|c|c|c|c|c|c|}
\hline Case & $\begin{array}{c}\text { Expected } \\
\boldsymbol{k}_{\text {eff }}\end{array}$ & $\begin{array}{c}\text { Experimental } \\
\text { uncertainty }\end{array}$ & $\boldsymbol{k}_{\text {eff }}$ & Uncertainty & $\mathrm{C} / \mathrm{E}$ & $\begin{array}{c}\mathbf{C} / \mathbf{E} \\
\text { uncertainty }\end{array}$ \\
\hline $001-001$ & 1.0000 & 0.0031 & 0.99870 & 0.00010 & 0.99870 & 0.00310 \\
\hline 001-002 & 1.0005 & 0.0033 & 0.99879 & 0.00010 & 0.99829 & 0.00329 \\
\hline $001-003$ & 1.0006 & 0.0033 & 0.99820 & 0.00010 & 0.99760 & 0.00329 \\
\hline 001-004 & 0.9998 & 0.0033 & 0.99816 & 0.00010 & 0.99836 & 0.00330 \\
\hline $001-005$ & 0.9999 & 0.0033 & 0.99777 & 0.00010 & 0.99787 & 0.00329 \\
\hline $002-001$ & 1.0040 & 0.0087 & 1.00263 & 0.00011 & 0.99864 & 0.00865 \\
\hline 002-002 & 1.0040 & 0.0087 & 0.99090 & 0.00011 & 0.98695 & 0.00855 \\
\hline $002-003$ & 1.0040 & 0.0087 & 1.00697 & 0.00011 & 1.00296 & 0.00869 \\
\hline 002-004 & 1.0040 & 0.0087 & 1.00418 & 0.00011 & 1.00018 & 0.00867 \\
\hline $002-005$ & 1.0040 & 0.0087 & 1.00918 & 0.00010 & 1.00516 & 0.00871 \\
\hline $002-006$ & 1.0040 & 0.0087 & 0.99590 & 0.00010 & 0.99193 & 0.00860 \\
\hline $002-007$ & 1.0040 & 0.0087 & 0.98572 & 0.00010 & 0.98179 & 0.00851 \\
\hline $002-008$ & 1.0040 & 0.0087 & 0.99963 & 0.00010 & 0.99565 & 0.00863 \\
\hline 002-009 & 1.0040 & 0.0087 & 0.98836 & 0.00010 & 0.98443 & 0.00853 \\
\hline $002-010$ & 1.0040 & 0.0087 & 1.00145 & 0.00010 & 0.99746 & 0.00864 \\
\hline $002-011$ & 1.0040 & 0.0087 & 1.01003 & 0.00010 & 1.00600 & 0.00872 \\
\hline 002-012 & 1.0040 & 0.0087 & 0.98885 & 0.00011 & 0.98491 & 0.00854 \\
\hline $002-013$ & 1.0040 & 0.0087 & 0.98845 & 0.00011 & 0.98451 & 0.00853 \\
\hline $002-014$ & 1.0040 & 0.0087 & 0.99838 & 0.00010 & 0.99440 & 0.00862 \\
\hline $002-015$ & 1.0040 & 0.0087 & 1.00572 & 0.00010 & 1.00171 & 0.00868 \\
\hline $002-017$ & 1.0040 & 0.00870 & 1.00841 & 0.00010 & 1.00439 & 0.00870 \\
\hline 003-001 & 0.9995 & 0.00871 & 0.99799 & 0.00011 & 0.99849 & 0.00870 \\
\hline 003-002 & 0.9991 & 0.01513 & 1.01390 & 0.00011 & 1.01481 & 0.01537 \\
\hline 003-003 & 1.0007 & 0.00871 & 0.99559 & 0.00011 & 0.99489 & 0.00866 \\
\hline 003-004 & 1.0015 & 0.01258 & 1.00022 & 0.00011 & 0.99872 & 0.01255 \\
\hline 003-005 & 1.0006 & 0.01222 & 1.00686 & 0.00011 & 1.00626 & 0.01229 \\
\hline 003-006 & 1.0012 & 0.00871 & 1.01947 & 0.00011 & 1.01825 & 0.00886 \\
\hline 003-007 & 1.0016 & 0.00871 & 1.01319 & 0.00010 & 1.01157 & 0.00880 \\
\hline 003-008 & 1.0016 & 0.00871 & 1.00949 & 0.00010 & 1.00788 & 0.00877 \\
\hline 003-009 & 1.0018 & 0.00871 & 1.00956 & 0.00010 & 1.00775 & 0.00876 \\
\hline 003-010 & 1.0008 & 0.00871 & 1.00645 & 0.00010 & 1.00564 & 0.00875 \\
\hline 004-001 & 1.0039 & 0.0088 & 0.99960 & 0.00010 & 0.99572 & 0.00873 \\
\hline 004-002 & 1.0034 & 0.0086 & 1.00282 & 0.00011 & 0.99942 & 0.00857 \\
\hline 004-003 & 1.0041 & 0.0089 & 0.99186 & 0.00011 & 0.98781 & 0.00876 \\
\hline 004-004 & 1.0051 & 0.0089 & 0.98264 & 0.00011 & 0.97765 & 0.00866 \\
\hline 004-005 & 1.0037 & 0.0090 & 0.98832 & 0.00011 & 0.98468 & 0.00883 \\
\hline 004-006 & 1.0020 & 0.0105 & 0.99941 & 0.00011 & 0.99742 & 0.01045 \\
\hline 004-007 & 1.0020 & 0.0104 & 0.99639 & 0.00011 & 0.99440 & 0.01032 \\
\hline 004-008 & 1.0020 & 0.0102 & 1.00382 & 0.00011 & 1.00182 & 0.01020 \\
\hline $005-001$ & 1.0000 & 0.0040 & 0.99842 & 0.00011 & 0.99842 & 0.00400 \\
\hline 005-002 & 1.0000 & 0.0049 & 1.00165 & 0.00010 & 1.00165 & 0.00491 \\
\hline 008-001 & 1.0006 & 0.0029 & 0.99926 & 0.00010 & 0.99866 & 0.00290 \\
\hline 009-001 & 0.9966 & 0.0044 & 0.99367 & 0.00010 & 0.99706 & 0.00440 \\
\hline 009-002 & 0.9981 & 0.0040 & 0.99697 & 0.00010 & 0.99887 & 0.00400 \\
\hline $009-003$ & 0.9989 & 0.0038 & 0.99843 & 0.00010 & 0.99953 & 0.00380 \\
\hline 009-004 & 0.9998 & 0.0038 & 0.99733 & 0.00010 & 0.99753 & 0.00379 \\
\hline $011-027$ & 1.0000 & 0.0051 & 0.98773 & 0.00011 & 0.98773 & 0.00504 \\
\hline 012-001 & 0.9990 & 0.0028 & 0.99655 & 0.00010 & 0.99755 & 0.00280 \\
\hline 012-002 & 0.9993 & 0.0025 & 0.99656 & 0.00010 & 0.99726 & 0.00250 \\
\hline $012-003$ & 0.9994 & 0.0023 & 1.00640 & 0.00010 & 1.00700 & 0.00232 \\
\hline 012-004 & 1.0000 & 0.0015 & 0.99936 & 0.00010 & 0.99936 & 0.00150 \\
\hline $012-005$ & 1.0000 & 0.0071 & 1.00122 & 0.00010 & 1.00122 & 0.00711 \\
\hline $012-006$ & 0.9987 & 0.0011 & 1.00092 & 0.00010 & 1.00222 & 0.00111 \\
\hline $012-007$ & 1.0000 & 0.0038 & 0.99813 & 0.00010 & 0.99813 & 0.00379 \\
\hline $012-008$ & 1.0000 & 0.0048 & 0.99515 & 0.00010 & 0.99515 & 0.00478 \\
\hline 013-001 & 0.9992 & 0.0073 & 1.00015 & 0.00012 & 1.00095 & 0.00731 \\
\hline 013-002 & 0.9992 & 0.0070 & 1.00002 & 0.00012 & 1.00082 & 0.00701 \\
\hline
\end{tabular}


Table A-57. Detailed ENDF/B-VIII.0 252-group results for KENO V.a UST systems (continued)

\begin{tabular}{|c|c|c|c|c|c|c|}
\hline Case & $\begin{array}{c}\text { Expected } \\
k_{\text {eff }} \\
\end{array}$ & $\begin{array}{c}\text { Experimental } \\
\text { uncertainty }\end{array}$ & $\boldsymbol{k}_{\text {eff }}$ & Uncertainty & $\mathbf{C} / \mathbf{E}$ & $\begin{array}{c}\mathbf{C} / \mathbf{E} \\
\text { uncertainty }\end{array}$ \\
\hline $013-003$ & 0.9992 & 0.0069 & 1.00052 & 0.00012 & 1.00132 & 0.00692 \\
\hline 013-004 & 0.9992 & 0.0073 & 1.00069 & 0.00012 & 1.00149 & 0.00732 \\
\hline 013-005 & 0.9992 & 0.0067 & 1.00157 & 0.00012 & 1.00237 & 0.00672 \\
\hline 013-006 & 0.9992 & 0.0050 & 1.00124 & 0.00011 & 1.00204 & 0.00502 \\
\hline 013-007 & 0.9992 & 0.0054 & 1.00093 & 0.00011 & 1.00173 & 0.00541 \\
\hline 013-008 & 0.9992 & 0.0050 & 1.00180 & 0.00011 & 1.00260 & 0.00502 \\
\hline 013-009 & 0.9992 & 0.0045 & 1.00206 & 0.00012 & 1.00286 & 0.00452 \\
\hline 013-010 & 0.9992 & 0.0046 & 1.00217 & 0.00010 & 1.00297 & 0.00462 \\
\hline 013-011 & 0.9992 & 0.0054 & 1.00011 & 0.00010 & 1.00091 & 0.00541 \\
\hline 013-012 & 0.9992 & 0.0050 & 1.00081 & 0.00012 & 1.00161 & 0.00501 \\
\hline 013-013 & 0.9992 & 0.0062 & 0.99842 & 0.00010 & 0.99922 & 0.00620 \\
\hline 013-014 & 0.9992 & 0.0051 & 1.00140 & 0.00012 & 1.00220 & 0.00512 \\
\hline 013-015 & 0.9992 & 0.0077 & 1.01648 & 0.00011 & 1.01729 & 0.00784 \\
\hline 013-016 & 0.9992 & 0.0069 & 0.98838 & 0.00011 & 0.98917 & 0.00683 \\
\hline 013-017 & 0.9992 & 0.0052 & 0.99125 & 0.00010 & 0.99204 & 0.00516 \\
\hline 013-018 & 0.9992 & 0.0020 & 0.99536 & 0.00010 & 0.99616 & 0.00200 \\
\hline 013-019 & 0.9992 & 0.0089 & 0.99138 & 0.00011 & 0.99217 & 0.00884 \\
\hline $013-020$ & 0.9992 & 0.0056 & 0.99386 & 0.00011 & 0.99466 & 0.00558 \\
\hline 013-021 & 0.9992 & 0.0034 & 0.99752 & 0.00010 & 0.99832 & 0.00340 \\
\hline $015-001$ & 1.0000 & 0.0075 & 0.98445 & 0.00011 & 0.98445 & 0.00738 \\
\hline 015-002 & 1.0000 & 0.0070 & 0.98018 & 0.00011 & 0.98018 & 0.00686 \\
\hline $015-004$ & 1.0000 & 0.0041 & 0.98619 & 0.00010 & 0.98619 & 0.00404 \\
\hline 015-007 & 1.0000 & 0.0070 & 0.98437 & 0.00010 & 0.98437 & 0.00689 \\
\hline $015-010$ & 1.0000 & 0.0051 & 0.98745 & 0.00010 & 0.98745 & 0.00504 \\
\hline $015-011$ & 1.0000 & 0.0075 & 0.98760 & 0.00011 & 0.98760 & 0.00741 \\
\hline 015-012 & 1.0000 & 0.0069 & 0.98840 & 0.00011 & 0.98840 & 0.00682 \\
\hline $015-013$ & 1.0000 & 0.0069 & 0.98676 & 0.00011 & 0.98676 & 0.00681 \\
\hline 015-014 & 1.0000 & 0.0036 & 0.99334 & 0.00010 & 0.99334 & 0.00358 \\
\hline $015-015$ & 1.0000 & 0.0060 & 0.98467 & 0.00011 & 0.98467 & 0.00591 \\
\hline $015-016$ & 1.0000 & 0.0043 & 0.98391 & 0.00011 & 0.98391 & 0.00423 \\
\hline 015-017 & 1.0000 & 0.0029 & 0.99422 & 0.00010 & 0.99422 & 0.00288 \\
\hline $015-018$ & 1.0000 & 0.0056 & 0.97044 & 0.00012 & 0.97044 & 0.00544 \\
\hline 015-019 & 1.0000 & 0.0052 & 0.97074 & 0.00011 & 0.97074 & 0.00505 \\
\hline $015-020$ & 1.0000 & 0.0079 & 0.98980 & 0.00010 & 0.98980 & 0.00782 \\
\hline $015-021$ & 1.0000 & 0.0070 & 0.99288 & 0.00010 & 0.99288 & 0.00695 \\
\hline $015-022$ & 1.0000 & 0.0062 & 0.99107 & 0.00011 & 0.99107 & 0.00615 \\
\hline $015-023$ & 1.0000 & 0.0055 & 0.98933 & 0.00011 & 0.98933 & 0.00544 \\
\hline $015-024$ & 1.0000 & 0.0051 & 0.98597 & 0.00011 & 0.98597 & 0.00503 \\
\hline $015-025$ & 1.0000 & 0.0023 & 0.99328 & 0.00010 & 0.99328 & 0.00229 \\
\hline $015-026$ & 1.0000 & 0.0066 & 0.98953 & 0.00010 & 0.98953 & 0.00653 \\
\hline $015-027$ & 1.0000 & 0.0063 & 0.99437 & 0.00011 & 0.99437 & 0.00627 \\
\hline $015-028$ & 1.0000 & 0.0058 & 0.99231 & 0.00010 & 0.99231 & 0.00576 \\
\hline 015-029 & 1.0000 & 0.0051 & 0.99108 & 0.00010 & 0.99108 & 0.00506 \\
\hline $015-030$ & 1.0000 & 0.0048 & 0.99023 & 0.00010 & 0.99023 & 0.00475 \\
\hline $015-031$ & 1.0000 & 0.0055 & 0.98959 & 0.00011 & 0.98959 & 0.00544 \\
\hline 016-001 & 0.9987 & 0.0037 & 0.99889 & 0.00011 & 1.00019 & 0.00371 \\
\hline 016-002 & 0.9983 & 0.0044 & 1.00001 & 0.00010 & 1.00171 & 0.00442 \\
\hline 016-003 & 0.9992 & 0.0036 & 0.99952 & 0.00012 & 1.00032 & 0.00361 \\
\hline 016-004 & 0.9992 & 0.0035 & 1.00096 & 0.00012 & 1.00176 & 0.00351 \\
\hline 016-006 & 0.9993 & 0.0034 & 0.99105 & 0.00012 & 0.99174 & 0.00338 \\
\hline 016-007 & 1.0008 & 0.0034 & 0.99201 & 0.00012 & 0.99122 & 0.00337 \\
\hline 016-008 & 1.0011 & 0.0028 & 0.99147 & 0.00010 & 0.99038 & 0.00277 \\
\hline 016-009 & 1.0000 & 0.0027 & 0.99144 & 0.00012 & 0.99144 & 0.00268 \\
\hline 016-010 & 1.0000 & 0.0030 & 0.99953 & 0.00010 & 0.99953 & 0.00300 \\
\hline 016-011 & 0.9992 & 0.0041 & 0.99937 & 0.00012 & 1.00017 & 0.00411 \\
\hline 016-012 & 0.9992 & 0.0047 & 0.99948 & 0.00012 & 1.00028 & 0.00471 \\
\hline 016-013 & 0.9993 & 0.0036 & 0.99995 & 0.00012 & 1.00065 & 0.00361 \\
\hline 016-014 & 1.0000 & 0.0026 & 1.00062 & 0.00012 & 1.00062 & 0.00260 \\
\hline
\end{tabular}


Table A-57. Detailed ENDF/B-VIII.0 252-group results for KENO V.a UST systems (continued)

\begin{tabular}{lcccccc}
\hline Case & $\begin{array}{c}\text { Expected } \\
\boldsymbol{k}_{\text {eff }}\end{array}$ & $\begin{array}{c}\text { Experimental } \\
\text { uncertainty }\end{array}$ & $\boldsymbol{k}_{\text {eff }}$ & Uncertainty & $\mathbf{C} / \mathbf{E}$ & $\begin{array}{c}\text { C/E } \\
\text { uncertainty }\end{array}$ \\
\hline $016-015$ & 1.0000 & 0.0027 & 1.00158 & 0.00012 & 1.00158 & 0.00271 \\
$016-016$ & 0.9994 & 0.0031 & 1.00454 & 0.00012 & 1.00514 & 0.00312 \\
$016-017$ & 1.0000 & 0.0028 & 0.99038 & 0.00012 & 0.99038 & 0.00278 \\
$016-018$ & 0.9988 & 0.0036 & 0.99038 & 0.00012 & 0.99157 & 0.00358 \\
$016-019$ & 1.0000 & 0.0035 & 0.99027 & 0.00012 & 0.99027 & 0.00347 \\
$016-021$ & 1.0000 & 0.0028 & 1.00424 & 0.00012 & 1.00424 & 0.00281 \\
$016-022$ & 1.0000 & 0.0034 & 1.00431 & 0.00011 & 1.00431 & 0.00342 \\
$016-023$ & 1.0000 & 0.0031 & 1.00428 & 0.00012 & 1.00428 & 0.00312 \\
$016-024$ & 1.0012 & 0.0024 & 1.00484 & 0.00011 & 1.00364 & 0.00241 \\
$016-025$ & 0.9981 & 0.0040 & 0.99493 & 0.00010 & 0.99682 & 0.00400 \\
$016-026$ & 0.9980 & 0.0034 & 1.00034 & 0.00011 & 1.00234 & 0.00342 \\
$016-027$ & 0.9988 & 0.0037 & 0.99817 & 0.00011 & 0.99937 & 0.00370 \\
$016-028$ & 0.9986 & 0.0037 & 0.99332 & 0.00012 & 0.99471 & 0.00369 \\
$016-029$ & 0.9985 & 0.0031 & 0.99434 & 0.00011 & 0.99583 & 0.00309 \\
$016-030$ & 0.9993 & 0.0032 & 0.99382 & 0.00012 & 0.99452 & 0.00319 \\
$016-031$ & 0.9990 & 0.0034 & 1.00501 & 0.00010 & 1.00601 & 0.00343 \\
$016-032$ & 0.9985 & 0.0032 & 1.00706 & 0.00010 & 1.00857 & 0.00323 \\
$016-033$ & 0.9986 & 0.0039 & 1.00707 & 0.00010 & 1.00848 & 0.00394 \\
$017-001$ & 0.9997 & 0.0032 & 1.00151 & 0.00011 & 1.00181 & 0.00321 \\
$017-002$ & 1.0000 & 0.0025 & 0.99719 & 0.00011 & 0.99719 & 0.00250 \\
$017-003$ & 1.0001 & 0.0035 & 1.00217 & 0.00011 & 1.00207 & 0.00351 \\
$017-004$ & 0.9994 & 0.0040 & 1.00211 & 0.00011 & 1.00271 & 0.00401 \\
$017-005$ & 1.0000 & 0.0029 & 0.99917 & 0.00010 & 0.99917 & 0.00290 \\
$017-006$ & 1.0000 & 0.0029 & 0.99714 & 0.00010 & 0.99714 & 0.00289 \\
$017-007$ & 1.0000 & 0.0037 & 0.99654 & 0.00010 & 0.99654 & 0.00369 \\
\hline
\end{tabular}

Table A-58. Detailed ENDF/B-VII.1 252-group results for KENO V.a UST systems

\begin{tabular}{rcccccc}
\hline Case & $\begin{array}{c}\text { Expected } \\
\boldsymbol{k}_{\text {eff }}\end{array}$ & $\begin{array}{c}\text { Experimental } \\
\text { uncertainty }\end{array}$ & $\boldsymbol{k}_{\text {eff }}$ & Uncertainty & $\mathbf{C} / \mathbf{E}$ & $\begin{array}{c}\text { C/E } \\
\text { uncertainty }\end{array}$ \\
\hline $001-001$ & 1.0000 & 0.0031 & 1.00023 & 0.00010 & 1.00023 & 0.00310 \\
$001-002$ & 1.0005 & 0.0033 & 1.00035 & 0.00010 & 0.99985 & 0.00330 \\
$001-003$ & 1.0006 & 0.0033 & 0.99986 & 0.00010 & 0.99926 & 0.00330 \\
$001-004$ & 0.9998 & 0.0033 & 0.99964 & 0.00010 & 0.99984 & 0.00330 \\
$001-005$ & 0.9999 & 0.0033 & 0.99922 & 0.00010 & 0.99932 & 0.00330 \\
$002-001$ & 1.0040 & 0.0087 & 1.00474 & 0.00011 & 1.00074 & 0.00867 \\
$002-002$ & 1.0040 & 0.0087 & 0.99281 & 0.00011 & 0.98885 & 0.00857 \\
$002-003$ & 1.0040 & 0.0087 & 1.00832 & 0.00011 & 1.00430 & 0.00870 \\
$002-004$ & 1.0040 & 0.0087 & 1.00522 & 0.00011 & 1.00122 & 0.00868 \\
$002-005$ & 1.0040 & 0.0087 & 1.01012 & 0.00011 & 1.00610 & 0.00872 \\
$002-006$ & 1.0040 & 0.0087 & 0.99658 & 0.00010 & 0.99261 & 0.00860 \\
$002-007$ & 1.0040 & 0.0087 & 0.98624 & 0.00010 & 0.98231 & 0.00851 \\
$002-008$ & 1.0040 & 0.0087 & 1.00019 & 0.00010 & 0.99621 & 0.00863 \\
$002-009$ & 1.0040 & 0.0087 & 0.98877 & 0.00010 & 0.98483 & 0.00853 \\
$002-010$ & 1.0040 & 0.0087 & 1.00185 & 0.00010 & 0.99786 & 0.00865 \\
$002-011$ & 1.0040 & 0.0087 & 1.01066 & 0.00010 & 1.00663 & 0.00872 \\
$002-012$ & 1.0040 & 0.0087 & 0.99147 & 0.00011 & 0.98752 & 0.00856 \\
$002-013$ & 1.0040 & 0.0087 & 0.99159 & 0.00011 & 0.98764 & 0.00856 \\
$002-014$ & 1.0040 & 0.0087 & 1.00030 & 0.00011 & 0.99631 & 0.00863 \\
$002-015$ & 1.0040 & 0.0087 & 1.00695 & 0.00010 & 1.00294 & 0.00869 \\
$002-017$ & 1.0040 & 0.00870 & 1.00884 & 0.00010 & 1.00482 & 0.00871 \\
$003-001$ & 0.9995 & 0.00871 & 1.00100 & 0.00011 & 1.00150 & 0.00873 \\
$003-002$ & 0.9991 & 0.01513 & 1.01580 & 0.00011 & 1.01672 & 0.01540 \\
$003-003$ & 1.0007 & 0.00871 & 0.99835 & 0.00011 & 0.99765 & 0.00868 \\
$003-004$ & 1.0015 & 0.01258 & 1.00267 & 0.00011 & 1.00117 & 0.01258 \\
$003-005$ & 1.0006 & 0.01222 & 1.00909 & 0.00011 & 1.00848 & 0.01232 \\
$003-006$ & 1.0012 & 0.00871 & 1.02105 & 0.00011 & 1.01983 & 0.00887 \\
\hline & & & & & & \\
& & & & & & \\
& & & & & &
\end{tabular}


Table A-58. Detailed ENDF/B-VII.1 252-group results for KENO V.a UST systems (continued)

\begin{tabular}{|c|c|c|c|c|c|c|}
\hline Case & $\begin{array}{c}\text { Expected } \\
k_{\text {eff }}\end{array}$ & $\begin{array}{c}\text { Experimental } \\
\text { uncertainty }\end{array}$ & $\boldsymbol{k}_{\text {eff }}$ & Uncertainty & $\mathbf{C} / \mathbf{E}$ & $\begin{array}{c}\mathbf{C} / \mathbf{E} \\
\text { uncertainty }\end{array}$ \\
\hline $003-007$ & 1.0016 & 0.00871 & 1.01422 & 0.00010 & 1.01260 & 0.00881 \\
\hline 003-008 & 1.0016 & 0.00871 & 1.01020 & 0.00010 & 1.00859 & 0.00877 \\
\hline 003-009 & 1.0018 & 0.00871 & 1.01034 & 0.00010 & 1.00852 & 0.00877 \\
\hline 003-010 & 1.0008 & 0.00871 & 1.00682 & 0.00010 & 1.00602 & 0.00876 \\
\hline 004-001 & 1.0039 & 0.0088 & 1.00177 & 0.00010 & 0.99787 & 0.00875 \\
\hline 004-002 & 1.0034 & 0.0086 & 1.00476 & 0.00011 & 1.00136 & 0.00858 \\
\hline 004-003 & 1.0041 & 0.0089 & 0.99514 & 0.00011 & 0.99108 & 0.00879 \\
\hline 004-004 & 1.0051 & 0.0089 & 0.98592 & 0.00011 & 0.98092 & 0.00869 \\
\hline 004-005 & 1.0037 & 0.0090 & 0.99148 & 0.00012 & 0.98783 & 0.00886 \\
\hline 004-006 & 1.0020 & 0.0105 & 1.00243 & 0.00011 & 1.00043 & 0.01048 \\
\hline 004-007 & 1.0020 & 0.0104 & 0.99937 & 0.00011 & 0.99738 & 0.01035 \\
\hline 004-008 & 1.0020 & 0.0102 & 1.00563 & 0.00011 & 1.00362 & 0.01022 \\
\hline $005-001$ & 1.0000 & 0.0040 & 0.99989 & 0.00010 & 0.99989 & 0.00400 \\
\hline $005-002$ & 1.0000 & 0.0049 & 1.00295 & 0.00010 & 1.00295 & 0.00492 \\
\hline 008-001 & 1.0006 & 0.0029 & 1.00095 & 0.00010 & 1.00035 & 0.00290 \\
\hline $009-001$ & 0.9966 & 0.0044 & 0.99557 & 0.00010 & 0.99897 & 0.00441 \\
\hline 009-002 & 0.9981 & 0.0040 & 0.99850 & 0.00010 & 1.00040 & 0.00401 \\
\hline 009-003 & 0.9989 & 0.0038 & 1.00024 & 0.00010 & 1.00134 & 0.00381 \\
\hline 009-004 & 0.9998 & 0.0038 & 0.99907 & 0.00010 & 0.99927 & 0.00380 \\
\hline $011-027$ & 1.0000 & 0.0051 & 0.98960 & 0.00011 & 0.98960 & 0.00505 \\
\hline $012-001$ & 0.9990 & 0.0028 & 0.99771 & 0.00010 & 0.99871 & 0.00280 \\
\hline 012-002 & 0.9993 & 0.0025 & 0.99768 & 0.00010 & 0.99838 & 0.00250 \\
\hline $012-003$ & 0.9994 & 0.0023 & 1.00779 & 0.00010 & 1.00839 & 0.00232 \\
\hline $012-004$ & 1.0000 & 0.0015 & 1.00084 & 0.00010 & 1.00084 & 0.00150 \\
\hline $012-005$ & 1.0000 & 0.0071 & 1.00251 & 0.00010 & 1.00251 & 0.00712 \\
\hline $012-006$ & 0.9987 & 0.0011 & 1.00217 & 0.00010 & 1.00348 & 0.00111 \\
\hline 012-007 & 1.0000 & 0.0038 & 0.99971 & 0.00010 & 0.99971 & 0.00380 \\
\hline 012-008 & 1.0000 & 0.0048 & 0.99693 & 0.00010 & 0.99693 & 0.00479 \\
\hline 013-001 & 0.9992 & 0.0073 & 1.00220 & 0.00012 & 1.00300 & 0.00733 \\
\hline 013-002 & 0.9992 & 0.0070 & 1.00240 & 0.00012 & 1.00320 & 0.00703 \\
\hline 013-003 & 0.9992 & 0.0069 & 1.00275 & 0.00012 & 1.00355 & 0.00693 \\
\hline 013-004 & 0.9992 & 0.0073 & 1.00294 & 0.00012 & 1.00374 & 0.00733 \\
\hline 013-005 & 0.9992 & 0.0067 & 1.00347 & 0.00012 & 1.00427 & 0.00674 \\
\hline 013-006 & 0.9992 & 0.0050 & 1.00323 & 0.00012 & 1.00403 & 0.00503 \\
\hline 013-007 & 0.9992 & 0.0054 & 1.00321 & 0.00012 & 1.00401 & 0.00543 \\
\hline 013-008 & 0.9992 & 0.0050 & 1.00382 & 0.00012 & 1.00462 & 0.00503 \\
\hline 013-009 & 0.9992 & 0.0045 & 1.00418 & 0.00012 & 1.00498 & 0.00453 \\
\hline 013-010 & 0.9992 & 0.0046 & 1.00464 & 0.00010 & 1.00544 & 0.00463 \\
\hline 013-011 & 0.9992 & 0.0054 & 1.00211 & 0.00010 & 1.00291 & 0.00542 \\
\hline 013-012 & 0.9992 & 0.0050 & 1.00293 & 0.00012 & 1.00373 & 0.00502 \\
\hline 013-013 & 0.9992 & 0.0062 & 1.00068 & 0.00010 & 1.00148 & 0.00621 \\
\hline 013-014 & 0.9992 & 0.0051 & 1.00352 & 0.00012 & 1.00432 & 0.00513 \\
\hline 013-015 & 0.9992 & 0.0077 & 1.01846 & 0.00011 & 1.01928 & 0.00786 \\
\hline 013-016 & 0.9992 & 0.0069 & 0.99088 & 0.00011 & 0.99167 & 0.00685 \\
\hline 013-017 & 0.9992 & 0.0052 & 0.99326 & 0.00010 & 0.99405 & 0.00517 \\
\hline 013-018 & 0.9992 & 0.0020 & 0.99772 & 0.00010 & 0.99852 & 0.00200 \\
\hline 013-019 & 0.9992 & 0.0089 & 0.99359 & 0.00011 & 0.99439 & 0.00886 \\
\hline $013-020$ & 0.9992 & 0.0056 & 0.99588 & 0.00010 & 0.99668 & 0.00559 \\
\hline 013-021 & 0.9992 & 0.0034 & 0.99960 & 0.00010 & 1.00040 & 0.00341 \\
\hline $015-001$ & 1.0000 & 0.0075 & 0.99010 & 0.00011 & 0.99010 & 0.00743 \\
\hline 015-002 & 1.0000 & 0.0070 & 0.98526 & 0.00011 & 0.98526 & 0.00690 \\
\hline 015-004 & 1.0000 & 0.0041 & 0.98818 & 0.00010 & 0.98818 & 0.00405 \\
\hline $015-007$ & 1.0000 & 0.0070 & 0.98550 & 0.00010 & 0.98550 & 0.00690 \\
\hline 015-010 & 1.0000 & 0.0051 & 0.98846 & 0.00010 & 0.98846 & 0.00504 \\
\hline 015-011 & 1.0000 & 0.0075 & 0.99312 & 0.00011 & 0.99312 & 0.00745 \\
\hline 015-012 & 1.0000 & 0.0069 & 0.99356 & 0.00011 & 0.99356 & 0.00686 \\
\hline $015-013$ & 1.0000 & 0.0069 & 0.99114 & 0.00011 & 0.99114 & 0.00684 \\
\hline 015-014 & 1.0000 & 0.0036 & 0.99566 & 0.00010 & 0.99566 & 0.00359 \\
\hline
\end{tabular}


Table A-58. Detailed ENDF/B-VII.1 252-group results for KENO V.a UST systems (continued)

\begin{tabular}{|c|c|c|c|c|c|c|}
\hline Case & $\begin{array}{c}\text { Expected } \\
k_{\text {eff }}\end{array}$ & $\begin{array}{c}\text { Experimental } \\
\text { uncertainty }\end{array}$ & $\boldsymbol{k}_{\text {eff }}$ & Uncertainty & $\mathbf{C} / \mathbf{E}$ & $\begin{array}{c}\mathrm{C} / \mathrm{E} \\
\text { uncertainty }\end{array}$ \\
\hline $015-015$ & 1.0000 & 0.0060 & 0.98876 & 0.00011 & 0.98876 & 0.00593 \\
\hline $015-016$ & 1.0000 & 0.0043 & 0.98762 & 0.00011 & 0.98762 & 0.00425 \\
\hline $015-017$ & 1.0000 & 0.0029 & 0.99545 & 0.00010 & 0.99545 & 0.00289 \\
\hline $015-018$ & 1.0000 & 0.0056 & 0.97314 & 0.00011 & 0.97314 & 0.00545 \\
\hline 015-019 & 1.0000 & 0.0052 & 0.97323 & 0.00011 & 0.97323 & 0.00506 \\
\hline $015-020$ & 1.0000 & 0.0079 & 0.99523 & 0.00010 & 0.99523 & 0.00786 \\
\hline 015-021 & 1.0000 & 0.0070 & 0.99776 & 0.00011 & 0.99776 & 0.00699 \\
\hline $015-022$ & 1.0000 & 0.0062 & 0.99560 & 0.00011 & 0.99560 & 0.00617 \\
\hline $015-023$ & 1.0000 & 0.0055 & 0.99317 & 0.00011 & 0.99317 & 0.00546 \\
\hline $015-024$ & 1.0000 & 0.0051 & 0.98984 & 0.00011 & 0.98984 & 0.00505 \\
\hline $015-025$ & 1.0000 & 0.0023 & 0.99480 & 0.00010 & 0.99480 & 0.00229 \\
\hline $015-026$ & 1.0000 & 0.0066 & 0.99392 & 0.00010 & 0.99392 & 0.00656 \\
\hline $015-027$ & 1.0000 & 0.0063 & 0.99805 & 0.00010 & 0.99805 & 0.00629 \\
\hline $015-028$ & 1.0000 & 0.0058 & 0.99623 & 0.00010 & 0.99623 & 0.00578 \\
\hline 015-029 & 1.0000 & 0.0051 & 0.99445 & 0.00010 & 0.99445 & 0.00507 \\
\hline $015-030$ & 1.0000 & 0.0048 & 0.99330 & 0.00010 & 0.99330 & 0.00477 \\
\hline 015-031 & 1.0000 & 0.0055 & 0.99236 & 0.00011 & 0.99236 & 0.00546 \\
\hline 016-001 & 0.9987 & 0.0037 & 1.00099 & 0.00012 & 1.00229 & 0.00372 \\
\hline 016-002 & 0.9983 & 0.0044 & 1.00192 & 0.00010 & 1.00363 & 0.00442 \\
\hline 016-003 & 0.9992 & 0.0036 & 1.00149 & 0.00012 & 1.00229 & 0.00361 \\
\hline 016-004 & 0.9992 & 0.0035 & 1.00318 & 0.00012 & 1.00398 & 0.00352 \\
\hline 016-006 & 0.9993 & 0.0034 & 0.99321 & 0.00012 & 0.99391 & 0.00338 \\
\hline 016-007 & 1.0008 & 0.0034 & 0.99409 & 0.00012 & 0.99330 & 0.00338 \\
\hline 016-008 & 1.0011 & 0.0028 & 0.99344 & 0.00010 & 0.99235 & 0.00278 \\
\hline 016-009 & 1.0000 & 0.0027 & 0.99351 & 0.00012 & 0.99351 & 0.00269 \\
\hline 016-010 & 1.0000 & 0.0030 & 1.00153 & 0.00010 & 1.00153 & 0.00301 \\
\hline 016-011 & 0.9992 & 0.0041 & 1.00167 & 0.00012 & 1.00247 & 0.00412 \\
\hline 016-012 & 0.9992 & 0.0047 & 1.00164 & 0.00012 & 1.00244 & 0.00472 \\
\hline 016-013 & 0.9993 & 0.0036 & 1.00194 & 0.00012 & 1.00264 & 0.00361 \\
\hline 016-014 & 1.0000 & 0.0026 & 1.00260 & 0.00012 & 1.00260 & 0.00261 \\
\hline 016-015 & 1.0000 & 0.0027 & 1.00358 & 0.00012 & 1.00358 & 0.00271 \\
\hline 016-016 & 0.9994 & 0.0031 & 1.00647 & 0.00012 & 1.00707 & 0.00313 \\
\hline 016-017 & 1.0000 & 0.0028 & 0.99234 & 0.00012 & 0.99234 & 0.00278 \\
\hline $016-018$ & 0.9988 & 0.0036 & 0.99264 & 0.00012 & 0.99383 & 0.00358 \\
\hline 016-019 & 1.0000 & 0.0035 & 0.99237 & 0.00012 & 0.99237 & 0.00348 \\
\hline $016-021$ & 1.0000 & 0.0028 & 1.00634 & 0.00012 & 1.00634 & 0.00282 \\
\hline 016-022 & 1.0000 & 0.0034 & 1.00650 & 0.00012 & 1.00650 & 0.00342 \\
\hline 016-023 & 1.0000 & 0.0031 & 1.00664 & 0.00012 & 1.00664 & 0.00312 \\
\hline 016-024 & 1.0012 & 0.0024 & 1.00705 & 0.00012 & 1.00584 & 0.00241 \\
\hline 016-025 & 0.9981 & 0.0040 & 0.99704 & 0.00010 & 0.99894 & 0.00400 \\
\hline 016-026 & 0.9980 & 0.0034 & 1.00243 & 0.00011 & 1.00444 & 0.00342 \\
\hline 016-027 & 0.9988 & 0.0037 & 1.00006 & 0.00011 & 1.00126 & 0.00371 \\
\hline $016-028$ & 0.9986 & 0.0037 & 0.99578 & 0.00011 & 0.99718 & 0.00370 \\
\hline 016-029 & 0.9985 & 0.0031 & 0.99630 & 0.00011 & 0.99780 & 0.00310 \\
\hline 016-030 & 0.9993 & 0.0032 & 0.99602 & 0.00011 & 0.99672 & 0.00319 \\
\hline 016-031 & 0.9990 & 0.0034 & 1.00712 & 0.00010 & 1.00813 & 0.00343 \\
\hline 016-032 & 0.9985 & 0.0032 & 1.00902 & 0.00010 & 1.01054 & 0.00324 \\
\hline 016-033 & 0.9986 & 0.0039 & 1.00928 & 0.00010 & 1.01069 & 0.00395 \\
\hline 017-001 & 0.9997 & 0.0032 & 1.00271 & 0.00010 & 1.00301 & 0.00321 \\
\hline 017-002 & 1.0000 & 0.0025 & 0.99881 & 0.00011 & 0.99881 & 0.00250 \\
\hline 017-003 & 1.0001 & 0.0035 & 1.00341 & 0.00010 & 1.00331 & 0.00351 \\
\hline 017-004 & 0.9994 & 0.0040 & 1.00376 & 0.00011 & 1.00436 & 0.00402 \\
\hline 017-005 & 1.0000 & 0.0029 & 1.00059 & 0.00010 & 1.00059 & 0.00290 \\
\hline 017-006 & 1.0000 & 0.0029 & 0.99841 & 0.00010 & 0.99841 & 0.00290 \\
\hline $017-007$ & 1.0000 & 0.0037 & 0.99810 & 0.00010 & 0.99810 & 0.00369 \\
\hline
\end{tabular}


Table A-59. Detailed ENDF/B-VIII.0 CE results for KENO V.a UST systems

\begin{tabular}{|c|c|c|c|c|c|c|}
\hline Case & $\begin{array}{c}\text { Expected } \\
\boldsymbol{k}_{\text {eff }}\end{array}$ & $\begin{array}{c}\text { Experimental } \\
\text { uncertainty }\end{array}$ & $\boldsymbol{k}_{\text {eff }}$ & Uncertainty & $\mathrm{C} / \mathrm{E}$ & $\begin{array}{c}\mathbf{C} / \mathbf{E} \\
\text { uncertainty }\end{array}$ \\
\hline $001-001$ & 1.0000 & 0.0031 & 0.99942 & 0.00010 & 0.99942 & 0.00310 \\
\hline 001-002 & 1.0005 & 0.0033 & 0.99946 & 0.00010 & 0.99896 & 0.00330 \\
\hline $001-003$ & 1.0006 & 0.0033 & 0.99914 & 0.00010 & 0.99854 & 0.00329 \\
\hline 001-004 & 0.9998 & 0.0033 & 0.99900 & 0.00010 & 0.99920 & 0.00330 \\
\hline $001-005$ & 0.9999 & 0.0033 & 0.99850 & 0.00010 & 0.99859 & 0.00330 \\
\hline $002-001$ & 1.0040 & 0.0087 & 1.00276 & 0.00010 & 0.99876 & 0.00866 \\
\hline 002-002 & 1.0040 & 0.0087 & 0.99131 & 0.00010 & 0.98736 & 0.00856 \\
\hline $002-003$ & 1.0040 & 0.0087 & 1.00745 & 0.00010 & 1.00344 & 0.00870 \\
\hline 002-004 & 1.0040 & 0.0087 & 1.00471 & 0.00010 & 1.00071 & 0.00867 \\
\hline $002-005$ & 1.0040 & 0.0087 & 1.00980 & 0.00010 & 1.00578 & 0.00872 \\
\hline $002-006$ & 1.0040 & 0.0087 & 0.99658 & 0.00010 & 0.99261 & 0.00860 \\
\hline $002-007$ & 1.0040 & 0.0087 & 0.98645 & 0.00010 & 0.98252 & 0.00851 \\
\hline $002-008$ & 1.0040 & 0.0087 & 1.00049 & 0.00010 & 0.99650 & 0.00864 \\
\hline 002-009 & 1.0040 & 0.0087 & 0.98917 & 0.00010 & 0.98523 & 0.00854 \\
\hline $002-010$ & 1.0040 & 0.0087 & 1.00202 & 0.00010 & 0.99803 & 0.00865 \\
\hline $002-011$ & 1.0040 & 0.0087 & 1.01097 & 0.00010 & 1.00695 & 0.00873 \\
\hline 002-012 & 1.0040 & 0.0087 & 0.98916 & 0.00010 & 0.98522 & 0.00854 \\
\hline $002-013$ & 1.0040 & 0.0087 & 0.98857 & 0.00010 & 0.98463 & 0.00853 \\
\hline $002-014$ & 1.0040 & 0.0087 & 0.99887 & 0.00010 & 0.99489 & 0.00862 \\
\hline $002-015$ & 1.0040 & 0.0087 & 1.00602 & 0.00010 & 1.00201 & 0.00868 \\
\hline $002-017$ & 1.0040 & 0.00870 & 1.00896 & 0.00010 & 1.00494 & 0.00871 \\
\hline 003-001 & 0.9995 & 0.00871 & 0.99782 & 0.00010 & 0.99832 & 0.00870 \\
\hline 003-002 & 0.9991 & 0.01513 & 1.01369 & 0.00010 & 1.01460 & 0.01537 \\
\hline 003-003 & 1.0007 & 0.00871 & 0.99566 & 0.00010 & 0.99496 & 0.00866 \\
\hline 003-004 & 1.0015 & 0.01258 & 0.99995 & 0.00010 & 0.99845 & 0.01254 \\
\hline 003-005 & 1.0006 & 0.01222 & 1.00664 & 0.00011 & 1.00604 & 0.01229 \\
\hline 003-006 & 1.0012 & 0.00871 & 1.01989 & 0.00010 & 1.01867 & 0.00886 \\
\hline 003-007 & 1.0016 & 0.00871 & 1.01382 & 0.00010 & 1.01220 & 0.00880 \\
\hline 003-008 & 1.0016 & 0.00871 & 1.01011 & 0.00010 & 1.00850 & 0.00877 \\
\hline 003-009 & 1.0018 & 0.00871 & 1.01049 & 0.00010 & 1.00867 & 0.00877 \\
\hline 003-010 & 1.0008 & 0.00871 & 1.00768 & 0.00010 & 1.00687 & 0.00876 \\
\hline 004-001 & 1.0039 & 0.0088 & 0.99958 & 0.00010 & 0.99570 & 0.00873 \\
\hline 004-002 & 1.0034 & 0.0086 & 1.00287 & 0.00010 & 0.99947 & 0.00857 \\
\hline 004-003 & 1.0041 & 0.0089 & 0.99204 & 0.00010 & 0.98799 & 0.00876 \\
\hline 004-004 & 1.0051 & 0.0089 & 0.98238 & 0.00010 & 0.97740 & 0.00866 \\
\hline 004-005 & 1.0037 & 0.0090 & 0.98809 & 0.00010 & 0.98445 & 0.00883 \\
\hline 004-006 & 1.0020 & 0.0105 & 0.99939 & 0.00011 & 0.99740 & 0.01045 \\
\hline 004-007 & 1.0020 & 0.0104 & 0.99646 & 0.00010 & 0.99447 & 0.01032 \\
\hline 004-008 & 1.0020 & 0.0102 & 1.00398 & 0.00010 & 1.00198 & 0.01020 \\
\hline $005-001$ & 1.0000 & 0.0040 & 0.99956 & 0.00010 & 0.99956 & 0.00400 \\
\hline 005-002 & 1.0000 & 0.0049 & 1.00295 & 0.00010 & 1.00295 & 0.00492 \\
\hline 008-001 & 1.0006 & 0.0029 & 0.99952 & 0.00010 & 0.99892 & 0.00290 \\
\hline 009-001 & 0.9966 & 0.0044 & 0.99434 & 0.00010 & 0.99773 & 0.00441 \\
\hline 009-002 & 0.9981 & 0.0040 & 0.99758 & 0.00010 & 0.99948 & 0.00401 \\
\hline $009-003$ & 0.9989 & 0.0038 & 0.99871 & 0.00010 & 0.99981 & 0.00380 \\
\hline 009-004 & 0.9998 & 0.0038 & 0.99779 & 0.00010 & 0.99799 & 0.00379 \\
\hline $011-027$ & 1.0000 & 0.0051 & 0.98772 & 0.00010 & 0.98772 & 0.00504 \\
\hline 012-001 & 0.9990 & 0.0028 & 0.99727 & 0.00010 & 0.99826 & 0.00280 \\
\hline 012-002 & 0.9993 & 0.0025 & 0.99756 & 0.00010 & 0.99825 & 0.00250 \\
\hline $012-003$ & 0.9994 & 0.0023 & 1.00719 & 0.00010 & 1.00779 & 0.00232 \\
\hline 012-004 & 1.0000 & 0.0015 & 1.00051 & 0.00010 & 1.00051 & 0.00150 \\
\hline $012-005$ & 1.0000 & 0.0071 & 1.00256 & 0.00010 & 1.00256 & 0.00712 \\
\hline $012-006$ & 0.9987 & 0.0011 & 1.00220 & 0.00010 & 1.00351 & 0.00111 \\
\hline $012-007$ & 1.0000 & 0.0038 & 0.99936 & 0.00010 & 0.99936 & 0.00380 \\
\hline $012-008$ & 1.0000 & 0.0048 & 0.99661 & 0.00010 & 0.99661 & 0.00478 \\
\hline 013-001 & 0.9992 & 0.0073 & 1.00169 & 0.00011 & 1.00249 & 0.00732 \\
\hline 013-002 & 0.9992 & 0.0070 & 1.00136 & 0.00011 & 1.00216 & 0.00702 \\
\hline
\end{tabular}


Table A-59. Detailed ENDF/B-VIII.0 CE results for KENO V.a UST systems (continued)

\begin{tabular}{|c|c|c|c|c|c|c|}
\hline Case & $\begin{array}{c}\text { Expected } \\
k_{\text {eff }} \\
\end{array}$ & $\begin{array}{c}\text { Experimental } \\
\text { uncertainty }\end{array}$ & $\boldsymbol{k}_{\text {eff }}$ & Uncertainty & $\mathbf{C} / \mathbf{E}$ & $\begin{array}{c}\mathrm{C} / \mathrm{E} \\
\text { uncertainty }\end{array}$ \\
\hline $013-003$ & 0.9992 & 0.0069 & 1.00168 & 0.00011 & 1.00248 & 0.00692 \\
\hline 013-004 & 0.9992 & 0.0073 & 1.00233 & 0.00011 & 1.00313 & 0.00733 \\
\hline 013-005 & 0.9992 & 0.0067 & 1.00257 & 0.00011 & 1.00337 & 0.00673 \\
\hline 013-006 & 0.9992 & 0.0050 & 1.00221 & 0.00011 & 1.00301 & 0.00502 \\
\hline 013-007 & 0.9992 & 0.0054 & 1.00245 & 0.00011 & 1.00325 & 0.00542 \\
\hline 013-008 & 0.9992 & 0.0050 & 1.00307 & 0.00011 & 1.00387 & 0.00502 \\
\hline 013-009 & 0.9992 & 0.0045 & 1.00365 & 0.00011 & 1.00445 & 0.00452 \\
\hline 013-010 & 0.9992 & 0.0046 & 1.00382 & 0.00010 & 1.00462 & 0.00463 \\
\hline 013-011 & 0.9992 & 0.0054 & 1.00153 & 0.00010 & 1.00233 & 0.00542 \\
\hline 013-012 & 0.9992 & 0.0050 & 1.00220 & 0.00011 & 1.00300 & 0.00502 \\
\hline 013-013 & 0.9992 & 0.0062 & 0.99987 & 0.00010 & 1.00067 & 0.00621 \\
\hline 013-014 & 0.9992 & 0.0051 & 1.00292 & 0.00011 & 1.00372 & 0.00512 \\
\hline 013-015 & 0.9992 & 0.0077 & 1.01782 & 0.00011 & 1.01863 & 0.00785 \\
\hline 013-016 & 0.9992 & 0.0069 & 0.99013 & 0.00011 & 0.99092 & 0.00684 \\
\hline 013-017 & 0.9992 & 0.0052 & 0.99246 & 0.00010 & 0.99325 & 0.00517 \\
\hline 013-018 & 0.9992 & 0.0020 & 0.99688 & 0.00010 & 0.99768 & 0.00200 \\
\hline 013-019 & 0.9992 & 0.0089 & 0.99308 & 0.00010 & 0.99388 & 0.00885 \\
\hline 013-020 & 0.9992 & 0.0056 & 0.99570 & 0.00010 & 0.99650 & 0.00559 \\
\hline $013-021$ & 0.9992 & 0.0034 & 0.99924 & 0.00010 & 1.00004 & 0.00340 \\
\hline 015-001 & 1.0000 & 0.0075 & 0.98432 & 0.00010 & 0.98432 & 0.00738 \\
\hline 015-002 & 1.0000 & 0.0070 & 0.98035 & 0.00011 & 0.98035 & 0.00686 \\
\hline 015-004 & 1.0000 & 0.0041 & 0.98626 & 0.00010 & 0.98626 & 0.00404 \\
\hline 015-007 & 1.0000 & 0.0070 & 0.98459 & 0.00010 & 0.98459 & 0.00689 \\
\hline $015-010$ & 1.0000 & 0.0051 & 0.98789 & 0.00010 & 0.98789 & 0.00504 \\
\hline 015-011 & 1.0000 & 0.0075 & 0.98760 & 0.00011 & 0.98760 & 0.00741 \\
\hline 015-012 & 1.0000 & 0.0069 & 0.98866 & 0.00010 & 0.98866 & 0.00682 \\
\hline $015-013$ & 1.0000 & 0.0069 & 0.98703 & 0.00011 & 0.98703 & 0.00681 \\
\hline $015-014$ & 1.0000 & 0.0036 & 0.99328 & 0.00010 & 0.99328 & 0.00358 \\
\hline $015-015$ & 1.0000 & 0.0060 & 0.98505 & 0.00011 & 0.98505 & 0.00591 \\
\hline $015-016$ & 1.0000 & 0.0043 & 0.98420 & 0.00011 & 0.98420 & 0.00423 \\
\hline 015-017 & 1.0000 & 0.0029 & 0.99448 & 0.00010 & 0.99448 & 0.00289 \\
\hline 015-018 & 1.0000 & 0.0056 & 0.97064 & 0.00011 & 0.97064 & 0.00544 \\
\hline 015-019 & 1.0000 & 0.0052 & 0.97118 & 0.00011 & 0.97118 & 0.00505 \\
\hline $015-020$ & 1.0000 & 0.0079 & 0.98985 & 0.00010 & 0.98985 & 0.00782 \\
\hline 015-021 & 1.0000 & 0.0070 & 0.99287 & 0.00011 & 0.99287 & 0.00695 \\
\hline $015-022$ & 1.0000 & 0.0062 & 0.99127 & 0.00011 & 0.99127 & 0.00615 \\
\hline $015-023$ & 1.0000 & 0.0055 & 0.98952 & 0.00011 & 0.98952 & 0.00544 \\
\hline $015-024$ & 1.0000 & 0.0051 & 0.98619 & 0.00010 & 0.98619 & 0.00503 \\
\hline $015-025$ & 1.0000 & 0.0023 & 0.99360 & 0.00010 & 0.99360 & 0.00229 \\
\hline $015-026$ & 1.0000 & 0.0066 & 0.98960 & 0.00010 & 0.98960 & 0.00653 \\
\hline $015-027$ & 1.0000 & 0.0063 & 0.99435 & 0.00010 & 0.99435 & 0.00627 \\
\hline $015-028$ & 1.0000 & 0.0058 & 0.99272 & 0.00010 & 0.99272 & 0.00576 \\
\hline 015-029 & 1.0000 & 0.0051 & 0.99160 & 0.00010 & 0.99160 & 0.00506 \\
\hline $015-030$ & 1.0000 & 0.0048 & 0.99101 & 0.00010 & 0.99101 & 0.00476 \\
\hline 015-031 & 1.0000 & 0.0055 & 0.99050 & 0.00011 & 0.99050 & 0.00545 \\
\hline 016-001 & 0.9987 & 0.0037 & 0.99988 & 0.00011 & 1.00118 & 0.00371 \\
\hline 016-002 & 0.9983 & 0.0044 & 1.00128 & 0.00010 & 1.00299 & 0.00442 \\
\hline $016-003$ & 0.9992 & 0.0036 & 1.00043 & 0.00011 & 1.00123 & 0.00361 \\
\hline 016-004 & 0.9992 & 0.0035 & 1.00218 & 0.00011 & 1.00298 & 0.00351 \\
\hline 016-006 & 0.9993 & 0.0034 & 0.99226 & 0.00011 & 0.99296 & 0.00338 \\
\hline $016-007$ & 1.0008 & 0.0034 & 0.99294 & 0.00011 & 0.99215 & 0.00337 \\
\hline 016-008 & 1.0011 & 0.0028 & 0.99266 & 0.00010 & 0.99157 & 0.00278 \\
\hline 016-009 & 1.0000 & 0.0027 & 0.99248 & 0.00011 & 0.99248 & 0.00268 \\
\hline 016-010 & 1.0000 & 0.0030 & 1.00087 & 0.00010 & 1.00087 & 0.00300 \\
\hline 016-011 & 0.9992 & 0.0041 & 1.00056 & 0.00011 & 1.00136 & 0.00411 \\
\hline 016-012 & 0.9992 & 0.0047 & 1.00092 & 0.00011 & 1.00172 & 0.00471 \\
\hline $016-013$ & 0.9993 & 0.0036 & 1.00108 & 0.00011 & 1.00178 & 0.00361 \\
\hline $016-014$ & 1.0000 & 0.0026 & 1.00166 & 0.00011 & 1.00166 & 0.00261 \\
\hline
\end{tabular}


Table A-59. Detailed ENDF/B-VIII.0 CE results for KENO V.a UST systems (continued)

\begin{tabular}{lcccccc}
\hline Case & $\begin{array}{c}\text { Expected } \\
\boldsymbol{k}_{\text {eff }}\end{array}$ & $\begin{array}{c}\text { Experimental } \\
\text { uncertainty }\end{array}$ & $\boldsymbol{k}_{\text {eff }}$ & Uncertainty & C/E & $\begin{array}{c}\text { C/E } \\
\text { uncertainty }\end{array}$ \\
\hline $016-015$ & 1.0000 & 0.0027 & 1.00275 & 0.00011 & 1.00275 & 0.00271 \\
$016-016$ & 0.9994 & 0.0031 & 1.00575 & 0.00011 & 1.00635 & 0.00312 \\
$016-017$ & 1.0000 & 0.0028 & 0.99119 & 0.00011 & 0.99119 & 0.00278 \\
$016-018$ & 0.9988 & 0.0036 & 0.99184 & 0.00011 & 0.99303 & 0.00358 \\
$016-019$ & 1.0000 & 0.0035 & 0.99173 & 0.00011 & 0.99173 & 0.00347 \\
$016-021$ & 1.0000 & 0.0028 & 1.00558 & 0.00011 & 1.00558 & 0.00282 \\
$016-022$ & 1.0000 & 0.0034 & 1.00571 & 0.00011 & 1.00571 & 0.00342 \\
$016-023$ & 1.0000 & 0.0031 & 1.00584 & 0.00011 & 1.00584 & 0.00312 \\
$016-024$ & 1.0012 & 0.0024 & 1.00648 & 0.00011 & 1.00527 & 0.00241 \\
$016-025$ & 0.9981 & 0.0040 & 0.99632 & 0.00010 & 0.99822 & 0.00400 \\
$016-026$ & 0.9980 & 0.0034 & 1.00149 & 0.00010 & 1.00350 & 0.00342 \\
$016-027$ & 0.9988 & 0.0037 & 0.99964 & 0.00010 & 1.00084 & 0.00371 \\
$016-028$ & 0.9986 & 0.0037 & 0.99503 & 0.00011 & 0.99642 & 0.00369 \\
$016-029$ & 0.9985 & 0.0031 & 0.99567 & 0.00010 & 0.99717 & 0.00310 \\
$016-030$ & 0.9993 & 0.0032 & 0.99539 & 0.00011 & 0.99609 & 0.00319 \\
$016-031$ & 0.9990 & 0.0034 & 1.00670 & 0.00010 & 1.00770 & 0.00343 \\
$016-032$ & 0.9985 & 0.0032 & 1.00852 & 0.00010 & 1.01004 & 0.00324 \\
$016-033$ & 0.9986 & 0.0039 & 1.00858 & 0.00010 & 1.00999 & 0.00395 \\
$017-001$ & 0.9997 & 0.0032 & 1.00222 & 0.00010 & 1.00252 & 0.00321 \\
$017-002$ & 1.0000 & 0.0025 & 0.99825 & 0.00010 & 0.99825 & 0.00250 \\
$017-003$ & 1.0001 & 0.0035 & 1.00322 & 0.00010 & 1.00312 & 0.00351 \\
$017-004$ & 0.9994 & 0.0040 & 1.00311 & 0.00010 & 1.00371 & 0.00402 \\
$017-005$ & 1.0000 & 0.0029 & 1.00055 & 0.00010 & 1.00055 & 0.00290 \\
$017-006$ & 1.0000 & 0.0029 & 0.99827 & 0.00010 & 0.99827 & 0.00290 \\
$017-007$ & 1.0000 & 0.0037 & 0.99762 & 0.00010 & 0.99762 & 0.00369 \\
\hline
\end{tabular}

Table A-60. Detailed ENDF/B-VII.1 CE results for KENO V.a UST systems

\begin{tabular}{rcccccc}
\hline Case & $\begin{array}{c}\text { Expected } \\
\boldsymbol{k}_{\text {eff }}\end{array}$ & $\begin{array}{c}\text { Experimental } \\
\text { uncertainty }\end{array}$ & $\boldsymbol{k}_{\text {eff }}$ & Uncertainty & $\mathbf{C} / \mathbf{E}$ & $\begin{array}{c}\text { C/E } \\
\text { uncertainty }\end{array}$ \\
\hline $001-001$ & 1.0000 & 0.0031 & 1.00109 & 0.00010 & 1.00109 & 0.00310 \\
$001-002$ & 1.0005 & 0.0033 & 1.00123 & 0.00010 & 1.00072 & 0.00330 \\
$001-003$ & 1.0006 & 0.0033 & 1.00057 & 0.00010 & 0.99997 & 0.00330 \\
$001-004$ & 0.9998 & 0.0033 & 1.00078 & 0.00010 & 1.00098 & 0.00331 \\
$001-005$ & 0.9999 & 0.0033 & 1.00005 & 0.00010 & 1.00015 & 0.00330 \\
$002-001$ & 1.0040 & 0.0087 & 1.00562 & 0.00010 & 1.00161 & 0.00868 \\
$002-002$ & 1.0040 & 0.0087 & 0.99375 & 0.00010 & 0.98979 & 0.00858 \\
$002-003$ & 1.0040 & 0.0087 & 1.00962 & 0.00010 & 1.00560 & 0.00871 \\
$002-004$ & 1.0040 & 0.0087 & 1.00629 & 0.00010 & 1.00228 & 0.00869 \\
$002-005$ & 1.0040 & 0.0087 & 1.01130 & 0.00010 & 1.00727 & 0.00873 \\
$002-006$ & 1.0040 & 0.0087 & 0.99794 & 0.00010 & 0.99396 & 0.00861 \\
$002-007$ & 1.0040 & 0.0087 & 0.98774 & 0.00010 & 0.98380 & 0.00853 \\
$002-008$ & 1.0040 & 0.0087 & 1.00167 & 0.00010 & 0.99768 & 0.00865 \\
$002-009$ & 1.0040 & 0.0087 & 0.99023 & 0.00010 & 0.98628 & 0.00855 \\
$002-010$ & 1.0040 & 0.0087 & 1.00315 & 0.00010 & 0.99915 & 0.00866 \\
$002-011$ & 1.0040 & 0.0087 & 1.01184 & 0.00010 & 1.00781 & 0.00873 \\
$002-012$ & 1.0040 & 0.0087 & 0.99255 & 0.00010 & 0.98860 & 0.00857 \\
$002-013$ & 1.0040 & 0.0087 & 0.99207 & 0.00011 & 0.98812 & 0.00856 \\
$002-014$ & 1.0040 & 0.0087 & 1.00141 & 0.00010 & 0.99742 & 0.00864 \\
$002-015$ & 1.0040 & 0.0087 & 1.00811 & 0.00010 & 1.00409 & 0.00870 \\
$002-017$ & 1.0040 & 0.00870 & 1.01027 & 0.00010 & 1.00625 & 0.00872 \\
$003-001$ & 0.9995 & 0.00871 & 1.00156 & 0.00011 & 1.00206 & 0.00873 \\
$003-002$ & 0.9991 & 0.01513 & 1.01655 & 0.00010 & 1.01747 & 0.01541 \\
$003-003$ & 1.0007 & 0.00871 & 0.99918 & 0.00011 & 0.99848 & 0.00869 \\
$003-004$ & 1.0015 & 0.01258 & 1.00324 & 0.00010 & 1.00174 & 0.01258 \\
$003-005$ & 1.0006 & 0.01222 & 1.00954 & 0.00010 & 1.00893 & 0.01232 \\
$003-006$ & 1.0012 & 0.00871 & 1.02212 & 0.00010 & 1.02089 & 0.00888 \\
\hline & & & & & & \\
& & & & & & \\
\end{tabular}


Table A-60. Detailed ENDF/B-VII.1 CE results for KENO V.a UST systems (continued)

\begin{tabular}{|c|c|c|c|c|c|c|}
\hline Case & $\begin{array}{c}\text { Expected } \\
k_{\text {eff }} \\
\end{array}$ & $\begin{array}{c}\text { Experimental } \\
\text { uncertainty }\end{array}$ & $\boldsymbol{k}_{e f f}$ & Uncertainty & $\mathbf{C} / \mathbf{E}$ & $\begin{array}{c}\mathrm{C} / \mathrm{E} \\
\text { uncertainty }\end{array}$ \\
\hline 003-007 & 1.0016 & 0.00871 & 1.01555 & 0.00010 & 1.01393 & 0.00882 \\
\hline 003-008 & 1.0016 & 0.00871 & 1.01147 & 0.00010 & 1.00985 & 0.00878 \\
\hline 003-009 & 1.0018 & 0.00871 & 1.01181 & 0.00010 & 1.00999 & 0.00878 \\
\hline 003-010 & 1.0008 & 0.00871 & 1.00823 & 0.00010 & 1.00743 & 0.00877 \\
\hline 004-001 & 1.0039 & 0.0088 & 1.00264 & 0.00010 & 0.99874 & 0.00876 \\
\hline 004-002 & 1.0034 & 0.0086 & 1.00558 & 0.00010 & 1.00217 & 0.00859 \\
\hline 004-003 & 1.0041 & 0.0089 & 0.99567 & 0.00010 & 0.99160 & 0.00879 \\
\hline 004-004 & 1.0051 & 0.0089 & 0.98661 & 0.00010 & 0.98160 & 0.00869 \\
\hline 004-005 & 1.0037 & 0.0090 & 0.99204 & 0.00010 & 0.98838 & 0.00886 \\
\hline 004-006 & 1.0020 & 0.0105 & 1.00321 & 0.00011 & 1.00121 & 0.01049 \\
\hline 004-007 & 1.0020 & 0.0104 & 1.00004 & 0.00010 & 0.99804 & 0.01036 \\
\hline 004-008 & 1.0020 & 0.0102 & 1.00652 & 0.00010 & 1.00451 & 0.01023 \\
\hline $005-001$ & 1.0000 & 0.0040 & 1.00120 & 0.00010 & 1.00120 & 0.00401 \\
\hline 005-002 & 1.0000 & 0.0049 & 1.00456 & 0.00010 & 1.00456 & 0.00492 \\
\hline 008-001 & 1.0006 & 0.0029 & 1.00172 & 0.00010 & 1.00112 & 0.00290 \\
\hline 009-001 & 0.9966 & 0.0044 & 0.99596 & 0.00010 & 0.99936 & 0.00441 \\
\hline 009-002 & 0.9981 & 0.0040 & 0.99922 & 0.00010 & 1.00112 & 0.00401 \\
\hline 009-003 & 0.9989 & 0.0038 & 1.00054 & 0.00010 & 1.00164 & 0.00381 \\
\hline 009-004 & 0.9998 & 0.0038 & 0.99947 & 0.00010 & 0.99967 & 0.00380 \\
\hline 011-027 & 1.0000 & 0.0051 & 0.99008 & 0.00011 & 0.99008 & 0.00505 \\
\hline 012-001 & 0.9990 & 0.0028 & 0.99895 & 0.00010 & 0.99995 & 0.00280 \\
\hline 012-002 & 0.9993 & 0.0025 & 0.99890 & 0.00010 & 0.99960 & 0.00250 \\
\hline $012-003$ & 0.9994 & 0.0023 & 1.00944 & 0.00010 & 1.01004 & 0.00233 \\
\hline $012-004$ & 1.0000 & 0.0015 & 1.00219 & 0.00010 & 1.00219 & 0.00151 \\
\hline $012-005$ & 1.0000 & 0.0071 & 1.00388 & 0.00010 & 1.00388 & 0.00713 \\
\hline $012-006$ & 0.9987 & 0.0011 & 1.00370 & 0.00010 & 1.00501 & 0.00111 \\
\hline 012-007 & 1.0000 & 0.0038 & 1.00123 & 0.00010 & 1.00123 & 0.00381 \\
\hline 012-008 & 1.0000 & 0.0048 & 0.99808 & 0.00010 & 0.99808 & 0.00479 \\
\hline 013-001 & 0.9992 & 0.0073 & 1.00441 & 0.00011 & 1.00521 & 0.00734 \\
\hline 013-002 & 0.9992 & 0.0070 & 1.00461 & 0.00011 & 1.00541 & 0.00704 \\
\hline 013-003 & 0.9992 & 0.0069 & 1.00434 & 0.00011 & 1.00514 & 0.00694 \\
\hline 013-004 & 0.9992 & 0.0073 & 1.00493 & 0.00011 & 1.00573 & 0.00735 \\
\hline 013-005 & 0.9992 & 0.0067 & 1.00539 & 0.00011 & 1.00619 & 0.00675 \\
\hline 013-006 & 0.9992 & 0.0050 & 1.00537 & 0.00011 & 1.00617 & 0.00504 \\
\hline 013-007 & 0.9992 & 0.0054 & 1.00508 & 0.00011 & 1.00588 & 0.00544 \\
\hline 013-008 & 0.9992 & 0.0050 & 1.00555 & 0.00011 & 1.00636 & 0.00504 \\
\hline 013-009 & 0.9992 & 0.0045 & 1.00599 & 0.00011 & 1.00680 & 0.00454 \\
\hline 013-010 & 0.9992 & 0.0046 & 1.00635 & 0.00010 & 1.00716 & 0.00464 \\
\hline 013-011 & 0.9992 & 0.0054 & 1.00402 & 0.00010 & 1.00482 & 0.00543 \\
\hline 013-012 & 0.9992 & 0.0050 & 1.00487 & 0.00011 & 1.00567 & 0.00503 \\
\hline 013-013 & 0.9992 & 0.0062 & 1.00258 & 0.00010 & 1.00338 & 0.00623 \\
\hline 013-014 & 0.9992 & 0.0051 & 1.00525 & 0.00011 & 1.00605 & 0.00514 \\
\hline 013-015 & 0.9992 & 0.0077 & 1.02032 & 0.00010 & 1.02114 & 0.00787 \\
\hline 013-016 & 0.9992 & 0.0069 & 0.99285 & 0.00010 & 0.99364 & 0.00686 \\
\hline 013-017 & 0.9992 & 0.0052 & 0.99523 & 0.00010 & 0.99603 & 0.00518 \\
\hline 013-018 & 0.9992 & 0.0020 & 0.99954 & 0.00010 & 1.00034 & 0.00200 \\
\hline 013-019 & 0.9992 & 0.0089 & 0.99560 & 0.00010 & 0.99640 & 0.00888 \\
\hline 013-020 & 0.9992 & 0.0056 & 0.99758 & 0.00010 & 0.99838 & 0.00560 \\
\hline 013-021 & 0.9992 & 0.0034 & 1.00181 & 0.00010 & 1.00261 & 0.00341 \\
\hline 015-001 & 1.0000 & 0.0075 & 0.99016 & 0.00010 & 0.99016 & 0.00743 \\
\hline 015-002 & 1.0000 & 0.0070 & 0.98529 & 0.00011 & 0.98529 & 0.00690 \\
\hline 015-004 & 1.0000 & 0.0041 & 0.98908 & 0.00010 & 0.98908 & 0.00406 \\
\hline 015-007 & 1.0000 & 0.0070 & 0.98635 & 0.00010 & 0.98635 & 0.00691 \\
\hline 015-010 & 1.0000 & 0.0051 & 0.98975 & 0.00010 & 0.98975 & 0.00505 \\
\hline 015-011 & 1.0000 & 0.0075 & 0.99295 & 0.00010 & 0.99295 & 0.00745 \\
\hline 015-012 & 1.0000 & 0.0069 & 0.99378 & 0.00011 & 0.99378 & 0.00686 \\
\hline 015-013 & 1.0000 & 0.0069 & 0.99170 & 0.00011 & 0.99170 & 0.00684 \\
\hline 015-014 & 1.0000 & 0.0036 & 0.99643 & 0.00010 & 0.99643 & 0.00359 \\
\hline
\end{tabular}


Table A-60. Detailed ENDF/B-VII.1 CE results for KENO V.a UST systems (continued)

\begin{tabular}{|c|c|c|c|c|c|c|}
\hline Case & $\begin{array}{c}\text { Expected } \\
k_{\text {eff }} \\
\end{array}$ & $\begin{array}{c}\text { Experimental } \\
\text { uncertainty }\end{array}$ & $\boldsymbol{k}_{e f f}$ & Uncertainty & $\mathbf{C} / \mathbf{E}$ & $\begin{array}{c}\mathrm{C} / \mathrm{E} \\
\text { uncertainty }\end{array}$ \\
\hline $015-015$ & 1.0000 & 0.0060 & 0.98936 & 0.000011 & 0.98936 & 0.00594 \\
\hline 015-016 & 1.0000 & 0.0043 & 0.98838 & 0.00011 & 0.98838 & 0.00425 \\
\hline 015-017 & 1.0000 & 0.0029 & 0.99625 & 0.00010 & 0.99625 & 0.00289 \\
\hline 015-018 & 1.0000 & 0.0056 & 0.97424 & 0.00011 & 0.97424 & 0.00546 \\
\hline 015-019 & 1.0000 & 0.0052 & 0.97421 & 0.00011 & 0.97421 & 0.00507 \\
\hline 015-020 & 1.0000 & 0.0079 & 0.99466 & 0.00010 & 0.99466 & 0.00786 \\
\hline 015-021 & 1.0000 & 0.0070 & 0.99776 & 0.00011 & 0.99776 & 0.00699 \\
\hline 015-022 & 1.0000 & 0.0062 & 0.99586 & 0.00011 & 0.99586 & 0.00618 \\
\hline $015-023$ & 1.0000 & 0.0055 & 0.99394 & 0.00010 & 0.99394 & 0.00547 \\
\hline $015-024$ & 1.0000 & 0.0051 & 0.99043 & 0.00010 & 0.99043 & 0.00505 \\
\hline $015-025$ & 1.0000 & 0.0023 & 0.99570 & 0.00010 & 0.99570 & 0.00229 \\
\hline 015-026 & 1.0000 & 0.0066 & 0.99410 & 0.00010 & 0.99410 & 0.00656 \\
\hline 015-027 & 1.0000 & 0.0063 & 0.99852 & 0.00010 & 0.99852 & 0.00629 \\
\hline 015-028 & 1.0000 & 0.0058 & 0.99650 & 0.00010 & 0.99650 & 0.00578 \\
\hline 015-029 & 1.0000 & 0.0051 & 0.99510 & 0.00010 & 0.99510 & 0.00508 \\
\hline 015-030 & 1.0000 & 0.0048 & 0.99428 & 0.00010 & 0.99428 & 0.00477 \\
\hline 015-031 & 1.0000 & 0.0055 & 0.99373 & 0.00011 & 0.99373 & 0.00547 \\
\hline 016-001 & 0.9987 & 0.0037 & 1.00295 & 0.00011 & 1.00426 & 0.00372 \\
\hline 016-002 & 0.9983 & 0.0044 & 1.00393 & 0.00010 & 1.00564 & 0.00443 \\
\hline 016-003 & 0.9992 & 0.0036 & 1.00357 & 0.00011 & 1.00437 & 0.00362 \\
\hline 016-004 & 0.9992 & 0.0035 & 1.00483 & 0.00011 & 1.00563 & 0.00352 \\
\hline 016-006 & 0.9993 & 0.0034 & 0.99520 & 0.00011 & 0.99590 & 0.00339 \\
\hline 016-007 & 1.0008 & 0.0034 & 0.99587 & 0.00011 & 0.99507 & 0.00338 \\
\hline 016-008 & 1.0011 & 0.0028 & 0.99552 & 0.00010 & 0.99443 & 0.00278 \\
\hline 016-009 & 1.0000 & 0.0027 & 0.99553 & 0.00011 & 0.99553 & 0.00269 \\
\hline 016-010 & 1.0000 & 0.0030 & 1.00375 & 0.00010 & 1.00375 & 0.00301 \\
\hline 016-011 & 0.9992 & 0.0041 & 1.00373 & 0.00012 & 1.00453 & 0.00412 \\
\hline 016-012 & 0.9992 & 0.0047 & 1.00364 & 0.00011 & 1.00444 & 0.00473 \\
\hline 016-013 & 0.9993 & 0.0036 & 1.00396 & 0.00011 & 1.00466 & 0.00362 \\
\hline 016-014 & 1.0000 & 0.0026 & 1.00446 & 0.00011 & 1.00446 & 0.00261 \\
\hline 016-015 & 1.0000 & 0.0027 & 1.00550 & 0.00011 & 1.00550 & 0.00272 \\
\hline 016-016 & 0.9994 & 0.0031 & 1.00869 & 0.00011 & 1.00930 & 0.00313 \\
\hline 016-017 & 1.0000 & 0.0028 & 0.99404 & 0.00011 & 0.99404 & 0.00279 \\
\hline 016-018 & 0.9988 & 0.0036 & 0.99448 & 0.00011 & 0.99567 & 0.00359 \\
\hline 016-019 & 1.0000 & 0.0035 & 0.99463 & 0.00011 & 0.99463 & 0.00348 \\
\hline 016-021 & 1.0000 & 0.0028 & 1.00858 & 0.00011 & 1.00858 & 0.00283 \\
\hline 016-022 & 1.0000 & 0.0034 & 1.00856 & 0.00012 & 1.00856 & 0.00343 \\
\hline $016-023$ & 1.0000 & 0.0031 & 1.00877 & 0.00011 & 1.00877 & 0.00313 \\
\hline 016-024 & 1.0012 & 0.0024 & 1.00945 & 0.00011 & 1.00824 & 0.00242 \\
\hline 016-025 & 0.9981 & 0.0040 & 0.99890 & 0.00010 & 1.00080 & 0.00401 \\
\hline 016-026 & 0.9980 & 0.0034 & 1.00435 & 0.00011 & 1.00636 & 0.00343 \\
\hline 016-027 & 0.9988 & 0.0037 & 1.00230 & 0.00010 & 1.00350 & 0.00372 \\
\hline 016-028 & 0.9986 & 0.0037 & 0.99792 & 0.00010 & 0.99932 & 0.00370 \\
\hline 016-029 & 0.9985 & 0.0031 & 0.99846 & 0.00010 & 0.99996 & 0.00311 \\
\hline 016-030 & 0.9993 & 0.0032 & 0.99815 & 0.00010 & 0.99885 & 0.00320 \\
\hline 016-031 & 0.9990 & 0.0034 & 1.00917 & 0.00010 & 1.01018 & 0.00344 \\
\hline 016-032 & 0.9985 & 0.0032 & 1.01106 & 0.00010 & 1.01258 & 0.00325 \\
\hline 016-033 & 0.9986 & 0.0039 & 1.01122 & 0.00010 & 1.01264 & 0.00396 \\
\hline 017-001 & 0.9997 & 0.0032 & 1.00401 & 0.00010 & 1.00431 & 0.00322 \\
\hline 017-002 & 1.0000 & 0.0025 & 0.99992 & 0.00010 & 0.99992 & 0.00250 \\
\hline 017-003 & 1.0001 & 0.0035 & 1.00501 & 0.00010 & 1.00491 & 0.00352 \\
\hline 017-004 & 0.9994 & 0.0040 & 1.00489 & 0.00010 & 1.00549 & 0.00403 \\
\hline 017-005 & 1.0000 & 0.0029 & 1.00203 & 0.00010 & 1.00203 & 0.00291 \\
\hline 017-006 & 1.0000 & 0.0029 & 1.00009 & 0.00010 & 1.00009 & 0.00290 \\
\hline 017-007 & 1.0000 & 0.0037 & 0.99948 & 0.00010 & 0.99948 & 0.00370 \\
\hline
\end{tabular}



APPENDIX B. DETAILED RESULTS FOR KENO-VI 



\section{APPENDIX B. DETAILED RESULTS FOR KENO-VI}

All uncertainties reported in this appendix are at the $1 \sigma$ level. The Monte Carlo experimental uncertainty values are absolute uncertainties and are reported in $\Delta k_{\text {eff }}$ units. The cross section uncertainty values are relative uncertainties and are reported in $\Delta k_{\text {eff }} / k_{\text {eff }}$ units.

Table B-1. Detailed ENDF/B-VIII.0 252-group results for KENO-VI HMF systems

\begin{tabular}{rcccccc}
\hline Case & $\begin{array}{c}\text { Expected } \\
\boldsymbol{k}_{\text {eff }}\end{array}$ & $\begin{array}{c}\text { Experimental } \\
\text { uncertainty }\end{array}$ & $\boldsymbol{k}_{\text {eff }}$ & Uncertainty & C/E & $\begin{array}{c}\text { C/E } \\
\text { uncertainty }\end{array}$ \\
\hline $005-001$ & 1.0000 & 0.0036 & 0.99707 & 0.00010 & 0.99707 & 0.00359 \\
$005-002$ & 1.0007 & 0.0036 & 0.99897 & 0.00010 & 0.99827 & 0.00359 \\
$005-003$ & 0.9996 & 0.0036 & 1.00063 & 0.00010 & 1.00103 & 0.00361 \\
$005-004$ & 0.9989 & 0.0036 & 0.99363 & 0.00010 & 0.99473 & 0.00359 \\
$005-005$ & 0.9980 & 0.0036 & 0.99971 & 0.00010 & 1.00171 & 0.00361 \\
$005-006$ & 0.9987 & 0.0036 & 0.99790 & 0.00010 & 0.99920 & 0.00360 \\
$008-001$ & 0.9989 & 0.0016 & 0.99551 & 0.00010 & 0.99660 & 0.00160 \\
$009-001$ & 0.9992 & 0.0015 & 0.99581 & 0.00010 & 0.99660 & 0.00150 \\
$009-002$ & 0.9992 & 0.0015 & 0.99390 & 0.00010 & 0.99470 & 0.00150 \\
$010-001$ & 0.9992 & 0.0015 & 0.99719 & 0.00010 & 0.99799 & 0.00150 \\
$010-002$ & 0.9992 & 0.0015 & 0.99606 & 0.00010 & 0.99686 & 0.00150 \\
$011-001$ & 0.9989 & 0.0015 & 0.99247 & 0.00010 & 0.99356 & 0.00150 \\
$013-001$ & 0.9990 & 0.0015 & 0.99884 & 0.00010 & 0.99984 & 0.00150 \\
$024-001$ & 0.9990 & 0.0015 & 0.99639 & 0.00010 & 0.99738 & 0.00150 \\
$080-001$ & 1.0000 & 0.0012 & 1.00725 & 0.00010 & 1.00725 & 0.00121 \\
$086-001$ & 0.9986 & 0.0026 & 0.98682 & 0.00005 & 0.98821 & 0.00257 \\
$086-002$ & 0.9986 & 0.0026 & 0.98694 & 0.00005 & 0.98833 & 0.00257 \\
$086-003$ & 0.9986 & 0.0026 & 0.98770 & 0.00005 & 0.98908 & 0.00258 \\
$086-004$ & 0.9986 & 0.0026 & 0.98860 & 0.00005 & 0.98999 & 0.00258 \\
$086-005$ & 1.0056 & 0.0026 & 0.99347 & 0.00005 & 0.98793 & 0.00255 \\
$092-001$ & 0.9986 & 0.0011 & 1.00104 & 0.00010 & 1.00244 & 0.00111 \\
$092-002$ & 0.9989 & 0.0013 & 1.00284 & 0.00010 & 1.00394 & 0.00131 \\
$092-003$ & 0.9993 & 0.0012 & 1.00420 & 0.00010 & 1.00491 & 0.00121 \\
$092-004$ & 0.9993 & 0.0013 & 1.00365 & 0.00010 & 1.00436 & 0.00131 \\
$093-001$ & 0.9978 & 0.0012 & 1.00428 & 0.00010 & 1.00650 & 0.00121 \\
$094-001$ & 0.9994 & 0.0012 & 1.00458 & 0.00010 & 1.00519 & 0.00121 \\
$094-002$ & 0.9993 & 0.0010 & 1.00592 & 0.00010 & 1.00662 & 0.00101 \\
\hline
\end{tabular}

Table B-2. Detailed ENDF/B-VII.1 252-group results for KENO-VI HMF systems

\begin{tabular}{rcccccc}
\hline Case & $\begin{array}{c}\text { Expected } \\
\boldsymbol{k}_{\text {eff }}\end{array}$ & $\begin{array}{c}\text { Experimental } \\
\text { uncertainty }\end{array}$ & $\boldsymbol{k}_{\text {eff }}$ & Uncertainty & $\mathbf{C} / \mathbf{E}$ & $\begin{array}{c}\mathbf{C} / \mathbf{E} \\
\text { uncertainty }\end{array}$ \\
\hline $005-001$ & 1.0000 & 0.0036 & 0.99676 & 0.00010 & 0.99676 & 0.00359 \\
$005-002$ & 1.0007 & 0.0036 & 0.99949 & 0.00010 & 0.99879 & 0.00359 \\
$005-003$ & 0.9996 & 0.0036 & 1.00136 & 0.00010 & 1.00176 & 0.00361 \\
$005-004$ & 0.9989 & 0.0036 & 0.99528 & 0.00010 & 0.99638 & 0.00359 \\
$005-005$ & 0.9980 & 0.0036 & 1.00120 & 0.00010 & 1.00321 & 0.00362 \\
$005-006$ & 0.9987 & 0.0036 & 0.99952 & 0.00010 & 1.00082 & 0.00361 \\
$008-001$ & 0.9989 & 0.0016 & 0.99567 & 0.00010 & 0.99677 & 0.00160 \\
$009-001$ & 0.9992 & 0.0015 & 0.99693 & 0.00010 & 0.99773 & 0.00150 \\
$009-002$ & 0.9992 & 0.0015 & 0.99503 & 0.00010 & 0.99582 & 0.00150 \\
$010-001$ & 0.9992 & 0.0015 & 0.99793 & 0.00010 & 0.99873 & 0.00150 \\
$010-002$ & 0.9992 & 0.0015 & 0.99678 & 0.00010 & 0.99758 & 0.00150 \\
$011-001$ & 0.9989 & 0.0015 & 0.99497 & 0.00010 & 0.99607 & 0.00150 \\
$013-001$ & 0.9990 & 0.0015 & 0.99728 & 0.00010 & 0.99828 & 0.00150 \\
$024-001$ & 0.9990 & 0.0015 & 0.99713 & 0.00010 & 0.99812 & 0.00150 \\
$080-001$ & 1.0000 & 0.0012 & 1.00692 & 0.00010 & 1.00692 & 0.00121 \\
$086-001$ & 0.9986 & 0.0026 & 0.98660 & 0.00005 & 0.98798 & 0.00257 \\
$086-002$ & 0.9986 & 0.0026 & 0.98671 & $0.00005 \mathrm{z}$ & 0.98810 & 0.00257 \\
\hline
\end{tabular}


Table B-2. Detailed ENDF/B-VII.1 252-group results for KENO-VI HMF systems

\begin{tabular}{ccccccc}
\hline Case & $\begin{array}{c}\text { Expected } \\
\boldsymbol{k}_{\text {eff }}\end{array}$ & $\begin{array}{c}\text { Experimental } \\
\text { uncertainty }\end{array}$ & $\boldsymbol{k}_{\text {eff }}$ & Uncertainty & $\mathbf{C} / \mathbf{E}$ & $\begin{array}{c}\mathbf{C} / \mathbf{E} \\
\text { uncertainty }\end{array}$ \\
\hline $086-003$ & 0.9986 & 0.0026 & 0.98753 & 0.00005 & 0.98891 & 0.00258 \\
$086-004$ & 0.9986 & 0.0026 & 0.98830 & 0.00005 & 0.98969 & 0.00258 \\
$086-005$ & 1.0056 & 0.0026 & 0.99333 & 0.00005 & 0.98780 & 0.00255 \\
$092-001$ & 0.9986 & 0.0011 & 1.00089 & 0.00010 & 1.00229 & 0.00111 \\
$092-002$ & 0.9989 & 0.0013 & 1.00277 & 0.00010 & 1.00387 & 0.00131 \\
$092-003$ & 0.9993 & 0.0012 & 1.00385 & 0.00010 & 1.00456 & 0.00121 \\
$092-004$ & 0.9993 & 0.0013 & 1.00348 & 0.00010 & 1.00418 & 0.00131 \\
$093-001$ & 0.9978 & 0.0012 & 1.00341 & 0.00010 & 1.00562 & 0.00121 \\
$094-001$ & 0.9994 & 0.0012 & 1.00621 & 0.00010 & 1.00681 & 0.00121 \\
$094-002$ & 0.9993 & 0.0010 & 1.00649 & 0.00010 & 1.00720 & 0.00101 \\
\hline
\end{tabular}

Table B-3. Detailed ENDF/B-VIII.0 CE results for KENO-VI HMF systems

\begin{tabular}{rcccccc}
\hline Case & $\begin{array}{c}\text { Expected } \\
\boldsymbol{k}_{\text {eff }}\end{array}$ & $\begin{array}{c}\text { Experimental } \\
\text { uncertainty }\end{array}$ & $\boldsymbol{k}_{\text {eff }}$ & Uncertainty & C/E & $\begin{array}{c}\text { C/E } \\
\text { uncertainty }\end{array}$ \\
\hline $005-001$ & 1.0000 & 0.0036 & 0.99622 & 0.00010 & 0.99622 & 0.00359 \\
$005-002$ & 1.0007 & 0.0036 & 0.99812 & 0.00010 & 0.99742 & 0.00359 \\
$005-003$ & 0.9996 & 0.0036 & 0.99963 & 0.00010 & 1.00003 & 0.00360 \\
$005-004$ & 0.9989 & 0.0036 & 0.99270 & 0.00010 & 0.99379 & 0.00358 \\
$005-005$ & 0.9980 & 0.0036 & 0.99802 & 0.00010 & 1.00002 & 0.00361 \\
$005-006$ & 0.9987 & 0.0036 & 0.99719 & 0.00010 & 0.99849 & 0.00360 \\
$008-001$ & 0.9989 & 0.0016 & 0.99574 & 0.00010 & 0.99683 & 0.00160 \\
$009-001$ & 0.9992 & 0.0015 & 0.99606 & 0.00010 & 0.99685 & 0.00150 \\
$009-002$ & 0.9992 & 0.0015 & 0.99518 & 0.00010 & 0.99597 & 0.00150 \\
$010-001$ & 0.9992 & 0.0015 & 0.99772 & 0.00010 & 0.99852 & 0.00150 \\
$010-002$ & 0.9992 & 0.0015 & 0.99714 & 0.00010 & 0.99794 & 0.00150 \\
$011-001$ & 0.9989 & 0.0015 & 0.99228 & 0.00010 & 0.99337 & 0.00149 \\
$013-001$ & 0.9990 & 0.0015 & 0.99879 & 0.00010 & 0.99979 & 0.00150 \\
$024-001$ & 0.9990 & 0.0015 & 0.99589 & 0.00010 & 0.99689 & 0.00150 \\
$080-001$ & 1.0000 & 0.0012 & 1.01002 & 0.00010 & 1.01002 & 0.00122 \\
$086-001$ & 0.9986 & 0.0026 & 0.98682 & 0.00005 & 0.98821 & 0.00257 \\
$086-002$ & 0.9986 & 0.0026 & 0.98694 & 0.00005 & 0.98833 & 0.00257 \\
$086-003$ & 0.9986 & 0.0026 & 0.98770 & 0.00005 & 0.98908 & 0.00258 \\
$086-004$ & 0.9986 & 0.0026 & 0.98860 & 0.00005 & 0.98999 & 0.00258 \\
$086-005$ & 1.0056 & 0.0026 & 0.99347 & 0.00005 & 0.98793 & 0.00255 \\
$092-001$ & 0.9986 & 0.0011 & 1.00104 & 0.00010 & 1.00244 & 0.00111 \\
$092-002$ & 0.9989 & 0.0013 & 1.00284 & 0.00010 & 1.00394 & 0.00131 \\
$092-003$ & 0.9993 & 0.0012 & 1.00420 & 0.00010 & 1.00491 & 0.00121 \\
$092-004$ & 0.9993 & 0.0013 & 1.00365 & 0.00010 & 1.00436 & 0.00131 \\
$093-001$ & 0.9978 & 0.0012 & 1.00428 & 0.00010 & 1.00650 & 0.00121 \\
$094-001$ & 0.9994 & 0.0012 & 1.00458 & 0.00010 & 1.00519 & 0.00121 \\
$094-002$ & 0.9993 & 0.0010 & 1.00592 & 0.00010 & 1.00662 & 0.00101 \\
\hline & & & & & \\
\hline
\end{tabular}

Table B-4. Detailed ENDF/B-VII.1 CE results for KENO-VI HMF systems

\begin{tabular}{rcccccc}
\hline Case & $\begin{array}{c}\text { Expected } \\
\boldsymbol{k}_{\text {eff }}\end{array}$ & $\begin{array}{c}\text { Experimental } \\
\text { uncertainty }\end{array}$ & $\boldsymbol{k}_{\text {eff }}$ & Uncertainty & C/E & $\begin{array}{c}\text { C/E } \\
\text { uncertainty }\end{array}$ \\
\hline $005-001$ & 1.0000 & 0.0036 & 0.99631 & 0.00010 & 0.99631 & 0.00359 \\
$005-002$ & 1.0007 & 0.0036 & 0.99853 & 0.00010 & 0.99784 & 0.00359 \\
$005-003$ & 0.9996 & 0.0036 & 1.00060 & 0.00010 & 1.00100 & 0.00361 \\
$005-004$ & 0.9989 & 0.0036 & 0.99441 & 0.00010 & 0.99551 & 0.00359 \\
$005-005$ & 0.9980 & 0.0036 & 0.99917 & 0.00010 & 1.00118 & 0.00361 \\
$005-006$ & 0.9987 & 0.0036 & 0.99821 & 0.00010 & 0.99951 & 0.00360 \\
$008-001$ & 0.9989 & 0.0016 & 0.99569 & 0.00010 & 0.99679 & 0.00160 \\
$009-001$ & 0.9992 & 0.0015 & 0.99735 & 0.00010 & 0.99815 & 0.00150 \\
$009-002$ & 0.9992 & 0.0015 & 0.99633 & 0.00010 & 0.99712 & 0.00150 \\
$010-001$ & 0.9992 & 0.0015 & 0.99828 & 0.00010 & 0.99908 & 0.00150 \\
$010-002$ & 0.9992 & 0.0015 & 0.99773 & 0.00010 & 0.99852 & 0.00150 \\
$011-001$ & 0.9989 & 0.0015 & 0.99453 & 0.00010 & 0.99562 & 0.00150 \\
\hline
\end{tabular}


Table B-4. Detailed ENDF/B-VII.1 CE results for KENO-VI HMF systems

\begin{tabular}{lllllll}
\hline $013-001$ & 0.9990 & 0.0015 & 0.99663 & 0.00010 & 0.99762 & 0.00150 \\
$024-001$ & 0.9990 & 0.0015 & 0.99648 & 0.00010 & 0.99748 & 0.00150 \\
$080-001$ & 1.0000 & 0.0012 & 1.00949 & 0.00010 & 1.00949 & 0.00122 \\
$086-001$ & 0.9986 & 0.0026 & 0.98880 & 0.00005 & 0.99019 & 0.00258 \\
$086-002$ & 0.9986 & 0.0026 & 0.98886 & 0.00005 & 0.99025 & 0.00258 \\
$086-003$ & 0.9986 & 0.0026 & 0.98976 & 0.00005 & 0.99115 & 0.00258 \\
$086-004$ & 0.9986 & 0.0026 & 0.99051 & 0.00005 & 0.99190 & 0.00258 \\
$086-005$ & 1.0056 & 0.0026 & 0.99550 & 0.00005 & 0.98996 & 0.00256 \\
$092-001$ & 0.9986 & 0.0011 & 1.00133 & 0.00010 & 1.00273 & 0.00111 \\
$092-002$ & 0.9989 & 0.0013 & 1.00313 & 0.00010 & 1.00423 & 0.00131 \\
$092-003$ & 0.9993 & 0.0012 & 1.00422 & 0.00010 & 1.00492 & 0.00121 \\
$092-004$ & 0.9993 & 0.0013 & 1.00375 & 0.00010 & 1.00446 & 0.00131 \\
$093-001$ & 0.9978 & 0.0012 & 1.00364 & 0.00010 & 1.00586 & 0.00121 \\
$094-001$ & 0.9994 & 0.0012 & 1.00357 & 0.00010 & 1.00417 & 0.00121 \\
$094-002$ & 0.9993 & 0.0010 & 1.00360 & 0.00010 & 1.00430 & 0.00101 \\
\hline
\end{tabular}

Table B-5. Detailed ENDF/B-VIII.0 252-group results for KENO-VI IMF systems

\begin{tabular}{rcccccc}
\hline Case & $\begin{array}{c}\text { Expected } \\
\boldsymbol{k}_{\text {eff }}\end{array}$ & $\begin{array}{c}\text { Experimental } \\
\text { uncertainty }\end{array}$ & $\boldsymbol{k}_{\text {eff }}$ & Uncertainty & $\mathbf{C} / \mathbf{E}$ & $\begin{array}{c}\mathbf{C} / \mathbf{E} \\
\text { uncertainty }\end{array}$ \\
\hline $019-001$ & 1.0008 & 0.0035 & 1.00392 & 0.00010 & 1.00312 & 0.00351 \\
$019-002$ & 1.0007 & 0.0042 & 1.00358 & 0.00010 & 1.00288 & 0.00421 \\
\hline
\end{tabular}

Table B-6. Detailed ENDF/B-VII1.1 252-group results for KENO-VI IMF systems

\begin{tabular}{rcccccc}
\hline Case & $\begin{array}{c}\text { Expected } \\
\boldsymbol{k}_{\text {eff }}\end{array}$ & $\begin{array}{c}\text { Experimental } \\
\text { uncertainty }\end{array}$ & $\boldsymbol{k}_{\text {eff }}$ & Uncertainty & $\mathbf{C} / \mathbf{E}$ & $\begin{array}{c}\mathbf{C} / \mathbf{E} \\
\text { uncertainty }\end{array}$ \\
\hline $019-001$ & 1.0008 & 0.0035 & 1.00661 & 0.00010 & 1.00581 & 0.00352 \\
$019-002$ & 1.0007 & 0.0042 & 1.00593 & 0.00010 & 1.00522 & 0.00422 \\
\hline
\end{tabular}

Table B-7. Detailed ENDF/B-VIII.0 CE results for KENO-VI IMF systems

\begin{tabular}{rcccccc}
\hline Case & $\begin{array}{c}\text { Expected } \\
\boldsymbol{k}_{\text {eff }}\end{array}$ & $\begin{array}{c}\text { Experimental } \\
\text { uncertainty }\end{array}$ & $\boldsymbol{k}_{\text {eff }}$ & Uncertainty & $\mathbf{C} / \mathbf{E}$ & $\begin{array}{c}\mathbf{C} / \mathbf{E} \\
\text { uncertainty }\end{array}$ \\
\hline $019-001$ & 1.0008 & 0.0035 & 1.00484 & 0.00010 & 1.00403 & 0.00351 \\
$019-002$ & 1.0007 & 0.0042 & 1.00481 & 0.00010 & 1.00410 & 0.00422 \\
\hline
\end{tabular}

Table B-8. Detailed ENDF/B-VII.1 CE results for KENO-VI IMF systems

\begin{tabular}{rcccccc}
\hline Case & $\begin{array}{c}\text { Expected } \\
\boldsymbol{k}_{\text {eff }}\end{array}$ & $\begin{array}{c}\text { Experimental } \\
\text { uncertainty }\end{array}$ & $\boldsymbol{k}_{\text {eff }}$ & Uncertainty & C/E & $\begin{array}{c}\mathbf{C} / \mathbf{E} \\
\text { uncertainty }\end{array}$ \\
\hline $019-001$ & 1.0008 & 0.0035 & 1.00674 & 0.00010 & 1.00593 & 0.00352 \\
$019-002$ & 1.0007 & 0.0042 & 1.00656 & 0.00010 & 1.00585 & 0.00422 \\
\hline
\end{tabular}

Table B-9. Detailed ENDF/B-VIII.0 252-group results for KENO-VI MCT systems

\begin{tabular}{rcccrcc}
\hline Case & $\begin{array}{c}\text { Expected } \\
\boldsymbol{k}_{\text {eff }}\end{array}$ & $\begin{array}{c}\text { Experimental } \\
\text { uncertainty }\end{array}$ & $\boldsymbol{k}_{\text {eff }}$ & Uncertainty & C/E & $\begin{array}{c}\mathbf{C} / \mathbf{E} \\
\text { uncertainty }\end{array}$ \\
\hline $008-001$ & 0.9997 & 0.0032 & 0.99751 & 0.00007 & 0.99781 & 0.00319 \\
$008-002$ & 1.0008 & 0.0030 & 0.99766 & 0.00010 & 0.99686 & 0.00299 \\
$008-003$ & 1.0023 & 0.0038 & 0.99721 & 0.00010 & 0.99493 & 0.00377 \\
$008-004$ & 1.0015 & 0.0047 & 1.00035 & 0.00010 & 0.99885 & 0.00469 \\
$008-005$ & 1.0022 & 0.0056 & 1.00097 & 0.00010 & 0.99877 & 0.00558 \\
$008-006$ & 1.0028 & 0.0065 & 1.00103 & 0.00010 & 0.99823 & 0.00647 \\
$008-007$ & 1.0023 & 0.0039 & 0.99562 & 0.00010 & 0.99334 & 0.00387 \\
$008-008$ & 1.0023 & 0.0039 & 0.99574 & 0.00010 & 0.99345 & 0.00387 \\
$008-009$ & 1.0023 & 0.0039 & 0.99570 & 0.00010 & 0.99341 & 0.00387 \\
$008-010$ & 1.0023 & 0.0039 & 0.99493 & 0.00010 & 0.99264 & 0.00386 \\
$008-011$ & 1.0023 & 0.0039 & 0.99458 & 0.00009 & 0.99230 & 0.00386 \\
\hline
\end{tabular}


Table B-9. Detailed ENDF/B-VIII.0 252-group results for KENO-VI MCT systems

\begin{tabular}{lllllll}
\hline $008-012$ & 1.0023 & 0.0039 & 0.99397 & 0.00010 & 0.99169 & 0.00386 \\
$008-013$ & 1.0023 & 0.0039 & 0.99522 & 0.00009 & 0.99293 & 0.00386 \\
$008-014$ & 1.0023 & 0.0039 & 0.99497 & 0.00010 & 0.99269 & 0.00386 \\
$008-015$ & 1.0023 & 0.0039 & 0.99453 & 0.00010 & 0.99225 & 0.00386 \\
$008-016$ & 1.0023 & 0.0039 & 0.99367 & 0.00010 & 0.99139 & 0.00386 \\
$008-017$ & 1.0023 & 0.0041 & 0.99432 & 0.00010 & 0.99204 & 0.00406 \\
$008-018$ & 1.0023 & 0.0041 & 0.99376 & 0.00010 & 0.99148 & 0.00406 \\
$008-019$ & 1.0023 & 0.0041 & 0.99415 & 0.00010 & 0.99187 & 0.00406 \\
$008-020$ & 1.0023 & 0.0041 & 0.99404 & 0.00010 & 0.99175 & 0.00406 \\
$008-021$ & 1.0023 & 0.0041 & 0.99357 & 0.00010 & 0.99129 & 0.00406 \\
$008-022$ & 1.0023 & 0.0041 & 0.99406 & 0.00010 & 0.99178 & 0.00406 \\
$008-023$ & 1.0023 & 0.0041 & 0.99379 & 0.00009 & 0.99151 & 0.00406 \\
$008-024$ & 1.0023 & 0.0041 & 0.99419 & 0.00010 & 0.99191 & 0.00406 \\
$008-025$ & 1.0023 & 0.0041 & 0.99389 & 0.00009 & 0.99161 & 0.00406 \\
$008-026$ & 1.0023 & 0.0041 & 0.99355 & 0.00010 & 0.99127 & 0.00406 \\
$008-027$ & 1.0023 & 0.0040 & 0.99355 & 0.00010 & 0.99127 & 0.00396 \\
$008-028$ & 1.0023 & 0.0040 & 0.99393 & 0.00010 & 0.99165 & 0.00396 \\
\hline
\end{tabular}

Table B-10. Detailed ENDF/B-VII.1 252-group results for KENO-VI MCT systems

\begin{tabular}{rcccccc}
\hline Case & $\begin{array}{c}\text { Expected } \\
\boldsymbol{k}_{\text {eff }}\end{array}$ & $\begin{array}{c}\text { Experimental } \\
\text { uncertainty }\end{array}$ & $\boldsymbol{k}_{\text {eff }}$ & Uncertainty & $\mathbf{C} / \mathbf{E}$ & $\begin{array}{c}\text { C/E } \\
\text { uncertainty }\end{array}$ \\
\hline $008-001$ & 0.9997 & 0.0032 & 0.99685 & 0.00007 & 0.99715 & 0.00319 \\
$008-002$ & 1.0008 & 0.0030 & 0.99794 & 0.00010 & 0.99714 & 0.00299 \\
$008-003$ & 1.0023 & 0.0038 & 0.99809 & 0.00010 & 0.99580 & 0.00378 \\
$008-004$ & 1.0015 & 0.0047 & 1.00115 & 0.00010 & 0.99965 & 0.00469 \\
$008-005$ & 1.0022 & 0.0056 & 1.00229 & 0.00010 & 1.00009 & 0.00559 \\
$008-006$ & 1.0028 & 0.0065 & 1.00203 & 0.00010 & 0.99923 & 0.00648 \\
$008-007$ & 1.0023 & 0.0039 & 0.99636 & 0.00010 & 0.99407 & 0.00387 \\
$008-008$ & 1.0023 & 0.0039 & 0.99628 & 0.00010 & 0.99400 & 0.00387 \\
$008-009$ & 1.0023 & 0.0039 & 0.99657 & 0.00010 & 0.99428 & 0.00387 \\
$008-010$ & 1.0023 & 0.0039 & 0.99568 & 0.00010 & 0.99339 & 0.00387 \\
$008-011$ & 1.0023 & 0.0039 & 0.99511 & 0.00010 & 0.99283 & 0.00386 \\
$008-012$ & 1.0023 & 0.0039 & 0.99454 & 0.00009 & 0.99225 & 0.00386 \\
$008-013$ & 1.0023 & 0.0039 & 0.99561 & 0.00010 & 0.99333 & 0.00387 \\
$008-014$ & 1.0023 & 0.0039 & 0.99551 & 0.00010 & 0.99322 & 0.00387 \\
$008-015$ & 1.0023 & 0.0039 & 0.99539 & 0.00009 & 0.99310 & 0.00387 \\
$008-016$ & 1.0023 & 0.0039 & 0.99427 & 0.00010 & 0.99199 & 0.00386 \\
$008-017$ & 1.0023 & 0.0041 & 0.99493 & 0.00010 & 0.99264 & 0.00406 \\
$008-018$ & 1.0023 & 0.0041 & 0.99426 & 0.00008 & 0.99197 & 0.00406 \\
$008-019$ & 1.0023 & 0.0041 & 0.99484 & 0.00010 & 0.99256 & 0.00406 \\
$008-020$ & 1.0023 & 0.0041 & 0.99459 & 0.00010 & 0.99230 & 0.00406 \\
$008-021$ & 1.0023 & 0.0041 & 0.99427 & 0.00010 & 0.99199 & 0.00406 \\
$008-022$ & 1.0023 & 0.0041 & 0.99464 & 0.00010 & 0.99236 & 0.00406 \\
$008-023$ & 1.0023 & 0.0041 & 0.99422 & 0.00010 & 0.99194 & 0.00406 \\
$008-024$ & 1.0023 & 0.0041 & 0.99479 & 0.00009 & 0.99251 & 0.00406 \\
$008-025$ & 1.0023 & 0.0041 & 0.99441 & 0.00010 & 0.99213 & 0.00406 \\
$008-026$ & 1.0023 & 0.0041 & 0.99421 & 0.00010 & 0.99192 & 0.00406 \\
$008-027$ & 1.0023 & 0.0040 & 0.99435 & 0.00009 & 0.99207 & 0.00396 \\
$008-028$ & 1.0023 & 0.0040 & 0.99459 & 0.00009 & 0.99231 & 0.00396 \\
\hline
\end{tabular}


Table B-11. Detailed ENDF/B-VIII.0 CE results for KENO-VI MCT systems

\begin{tabular}{rcccccc}
\hline Case & $\begin{array}{c}\text { Expected } \\
\boldsymbol{k}_{\text {eff }}\end{array}$ & $\begin{array}{c}\text { Experimental } \\
\text { uncertainty }\end{array}$ & $\boldsymbol{k}_{\text {eff }}$ & Uncertainty & C/E & $\begin{array}{c}\text { C/E } \\
\text { uncertainty }\end{array}$ \\
\hline $008-001$ & 0.9997 & 0.0032 & 0.99832 & 0.00007 & 0.99862 & 0.00320 \\
$008-002$ & 1.0008 & 0.0030 & 0.99824 & 0.00010 & 0.99744 & 0.00299 \\
$008-003$ & 1.0023 & 0.0038 & 0.99779 & 0.00010 & 0.99550 & 0.00378 \\
$008-004$ & 1.0015 & 0.0047 & 1.00078 & 0.00010 & 0.99929 & 0.00469 \\
$008-005$ & 1.0022 & 0.0056 & 1.00142 & 0.00010 & 0.99922 & 0.00558 \\
$008-006$ & 1.0028 & 0.0065 & 1.00125 & 0.00010 & 0.99846 & 0.00647 \\
$008-007$ & 1.0023 & 0.0039 & 0.99592 & 0.00010 & 0.99364 & 0.00387 \\
$008-008$ & 1.0023 & 0.0039 & 0.99605 & 0.00010 & 0.99376 & 0.00387 \\
$008-009$ & 1.0023 & 0.0039 & 0.99604 & 0.00010 & 0.99376 & 0.00387 \\
$008-010$ & 1.0023 & 0.0039 & 0.99564 & 0.00010 & 0.99335 & 0.00387 \\
$008-011$ & 1.0023 & 0.0039 & 0.99471 & 0.00010 & 0.99243 & 0.00386 \\
$008-012$ & 1.0023 & 0.0039 & 0.99423 & 0.00010 & 0.99195 & 0.00386 \\
$008-013$ & 1.0023 & 0.0039 & 0.99564 & 0.00010 & 0.99335 & 0.00387 \\
$008-014$ & 1.0023 & 0.0039 & 0.99530 & 0.00010 & 0.99302 & 0.00387 \\
$008-015$ & 1.0023 & 0.0039 & 0.99513 & 0.00010 & 0.99284 & 0.00386 \\
$008-016$ & 1.0023 & 0.0039 & 0.99423 & 0.00010 & 0.99195 & 0.00386 \\
$008-017$ & 1.0023 & 0.0041 & 0.99454 & 0.00010 & 0.99226 & 0.00406 \\
$008-018$ & 1.0023 & 0.0041 & 0.99442 & 0.00010 & 0.99214 & 0.00406 \\
$008-019$ & 1.0023 & 0.0041 & 0.99438 & 0.00010 & 0.99210 & 0.00406 \\
$008-020$ & 1.0023 & 0.0041 & 0.99440 & 0.00009 & 0.99212 & 0.00406 \\
$008-021$ & 1.0023 & 0.0041 & 0.99390 & 0.00010 & 0.99162 & 0.00406 \\
$008-022$ & 1.0023 & 0.0041 & 0.99422 & 0.00010 & 0.99194 & 0.00406 \\
$008-023$ & 1.0023 & 0.0041 & 0.99385 & 0.00010 & 0.99156 & 0.00406 \\
$008-024$ & 1.0023 & 0.0041 & 0.99462 & 0.00010 & 0.99234 & 0.00406 \\
$008-025$ & 1.0023 & 0.0041 & 0.99408 & 0.00010 & 0.99180 & 0.00406 \\
$008-026$ & 1.0023 & 0.0041 & 0.99378 & 0.00010 & 0.99150 & 0.00406 \\
$008-027$ & 1.0023 & 0.0040 & 0.99388 & 0.00010 & 0.99160 & 0.00396 \\
$008-028$ & 1.0023 & 0.0040 & 0.99415 & 0.00010 & 0.99187 & 0.00396 \\
\hline
\end{tabular}


Table B-12. Detailed ENDF/B-VII.1 CE results for KENO-VI MCT systems

\begin{tabular}{rcccccc}
\hline Case & $\begin{array}{c}\text { Expected } \\
\boldsymbol{k}_{\text {eff }}\end{array}$ & $\begin{array}{c}\text { Experimental } \\
\text { uncertainty }\end{array}$ & $\boldsymbol{k}_{\text {eff }}$ & Uncertainty & $\mathbf{C} / \mathbf{E}$ & $\begin{array}{c}\text { C/E } \\
\text { uncertainty }\end{array}$ \\
\hline $008-001$ & 0.9997 & 0.0032 & 0.99814 & 0.00007 & 0.99844 & 0.00320 \\
$008-002$ & 1.0008 & 0.0030 & 0.99882 & 0.00010 & 0.99802 & 0.00299 \\
$008-003$ & 1.0023 & 0.0038 & 0.99845 & 0.00010 & 0.99616 & 0.00378 \\
$008-004$ & 1.0015 & 0.0047 & 1.00099 & 0.00010 & 0.99949 & 0.00469 \\
$008-005$ & 1.0022 & 0.0056 & 1.00162 & 0.00010 & 0.99942 & 0.00559 \\
$008-006$ & 1.0028 & 0.0065 & 1.00118 & 0.00010 & 0.99838 & 0.00647 \\
$008-007$ & 1.0023 & 0.0039 & 0.99666 & 0.00010 & 0.99437 & 0.00387 \\
$008-008$ & 1.0023 & 0.0039 & 0.99656 & 0.00010 & 0.99428 & 0.00387 \\
$008-009$ & 1.0023 & 0.0039 & 0.99676 & 0.00010 & 0.99447 & 0.00387 \\
$008-010$ & 1.0023 & 0.0039 & 0.99600 & 0.00010 & 0.99371 & 0.00387 \\
$008-011$ & 1.0023 & 0.0039 & 0.99542 & 0.00010 & 0.99313 & 0.00387 \\
$008-012$ & 1.0023 & 0.0039 & 0.99493 & 0.00010 & 0.99264 & 0.00386 \\
$008-013$ & 1.0023 & 0.0039 & 0.99612 & 0.00009 & 0.99384 & 0.00387 \\
$008-014$ & 1.0023 & 0.0039 & 0.99590 & 0.00010 & 0.99361 & 0.00387 \\
$008-015$ & 1.0023 & 0.0039 & 0.99589 & 0.00010 & 0.99360 & 0.00387 \\
$008-016$ & 1.0023 & 0.0039 & 0.99476 & 0.00010 & 0.99248 & 0.00386 \\
$008-017$ & 1.0023 & 0.0041 & 0.99525 & 0.00010 & 0.99297 & 0.00406 \\
$008-018$ & 1.0023 & 0.0041 & 0.99472 & 0.00010 & 0.99243 & 0.00406 \\
$008-019$ & 1.0023 & 0.0041 & 0.99512 & 0.00010 & 0.99283 & 0.00406 \\
$008-020$ & 1.0023 & 0.0041 & 0.99484 & 0.00010 & 0.99256 & 0.00406 \\
$008-021$ & 1.0023 & 0.0041 & 0.99440 & 0.00010 & 0.99212 & 0.00406 \\
$008-022$ & 1.0023 & 0.0041 & 0.99499 & 0.00010 & 0.99270 & 0.00406 \\
$008-023$ & 1.0023 & 0.0041 & 0.99465 & 0.00009 & 0.99236 & 0.00406 \\
$008-024$ & 1.0023 & 0.0041 & 0.99511 & 0.00010 & 0.99283 & 0.00406 \\
$008-025$ & 1.0023 & 0.0041 & 0.99485 & 0.00010 & 0.99257 & 0.00406 \\
$008-026$ & 1.0023 & 0.0041 & 0.99459 & 0.00009 & 0.99231 & 0.00406 \\
$008-027$ & 1.0023 & 0.0040 & 0.99467 & 0.00010 & 0.99239 & 0.00396 \\
$008-028$ & 1.0023 & 0.0040 & 0.99493 & 0.00010 & 0.99264 & 0.00396 \\
\hline
\end{tabular}

